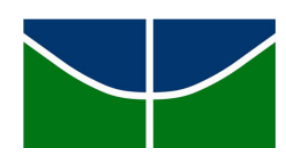

UNIVERSIDADE DE BRASÍLIA

FACULDADE DE SAÚDE

PROGRAMA DE PÓS-GRADUAÇÃO EM CIÊNCIAS FARMACÊUTICAS

SUS PARA TODOS? AVANÇOS E DESAFIOS NAS POLÍTICAS FARMACÊUTICAS PARA DOENÇAS DA POBREZA

RAFAEL SANTOS SANTANA

ORIENTADORA: Dra. Silvana Nair Leite

BRASÍLIA-DF, 2017 
UNIVERSIDADE DE BRASÍLIA

FACULDADE DE SAÚDE

PROGRAMA DE PÓS-GRADUAÇÃOEM CIÊNCIAS FARMACÊUTICAS

\section{SUS PARA TODOS? AVANÇOS E DESAFIOS NAS POLÍTICAS FARMACÊUTICAS PARA DOENÇAS DA POBREZA}

\section{RAFAEL SANTOS SANTANA}

Tese de doutorado submetida ao Programa de PósGraduação em Ciências Farmacêuticas da Faculdade de Saúde da Universidade de Brasília, como parte dos requisitos necessários para a obtenção do grau de doutor em ciências farmacêuticas. 
Autorizo a reprodução e divulgação total ou parcial deste trabalho, por qualquer meio impresso ou eletrônico, para fins de ensino, pesquisa e extensão desde que citada a fonte.

Catalogação da Publicação 


\section{RAFAEL SANTOS SANTANA}

\section{SUS PARA TODOS? AVANÇOS E DESAFIOS NAS POLÍTICAS FARMACÊUTICAS PARA DOENÇAS DA POBREZA}

Aprovada em 02 de fevereiro de 2017.

Banca Examinadora:

Presidente: Dra. Silvana Nair Leite - UnB

Membro: Dra. Janeth de Oliveira da Silva Naves - UnB

Membro: Dra. Noêmia Urruth Leão Tavares - UnB

Membro: Dra. Dayde Lane Mendonça da Silva - UnB

Membro: Dra. Fabiola Sulpino Vieira - IPEA

Suplente: Dr. Jorge Otávio Maia Barreto - Fiocruz 
EPIGRAFE

"Quando estou na favela tenho a impressão que sou um objeto fora de uso, digno de estar num quarto de despejo" (Carolina Maria de Jesus).

“Cidadão é o que ganha, come, sabe, mora, pode se curar" (Texto introdutório da Constituição Cidadã de 1988, escrito por Ulysses Guimarães)

"Sei que assim falando pensas Que esse desespero é moda em 76

E eu quero é que esse canto torto Feito faca, corte a carne de vocês"

(À Palo Seco, Belchior) 


\section{DEDICATÓRIA}

Dedico esta tese a todos aqueles que jamais poderão lê-la, não por desinteresse comum a nós letrados, mas por não terem tido a oportunidade de sequer conhecer as letras. 


\section{AGRADECIMENTOS}

Antes de mais nada, agradeço ao povo brasileiro que investiu em mim desde o tenro início escolar até aqui, em estudos de doutoramento na universidade de Darcy Ribeiro. Esse "povonação" como ele definiu, é resultado do processo civilizador lusitano com coloridos diversificadores indígenas e africanos que se destaca pela surpreendente unidade étnicocultural em contraste com uma vergonhosa estratificação social ${ }^{1}$.

Assim como os "primeiros brasileiros" filhos de homens portugueses e mulheres indígenas agradeço a minha "mãemeluca" Rosângela, lusitana de pai e índia de mãe, sem você jamais estaria aqui. Agradeço ainda aos meus irmãos Amanda, Kallyno e Victória pelo apoio e torcida em todos os momentos dessa caminhada.

Não teria adentrado na seara da farmácia social sem a influência do meu avô Antônio e também não teria vindo a Brasília sem o incentivo de Geovanna. Mesmo agora distantes do meu cotidiano, vocês foram marcantes e decisivos para esse projeto.

"A crise de educação no Brasil, não é uma crise é um projeto" também falou Ribeiro. Não poderia ter melhor orientadora que Silvana, com sua admirável e inspiradora consciência do papel da universidade na luta contra qualquer projeto de manutenção de opressões sociais e por uma sociedade mais justa. Em seu nome agradeço a todos os membros da banca de qualificação, da banca de defesa, aos queridos professores e colegas da UnB e UFS, especialmente Marcela, Marselle, Simony e Fernando.

Aos grandes amigos do Departamento de Assistência Farmacêutica, Luiz, Evandro, Alane, Fernando, Diana, Rodrigo, Nicole, Gustavo, Cristiano, Igor, Soraya, Isa, Deborah e Ricardo que contribuíram ora diretamente no projeto de pesquisa, ora no apoio nos momentos difíceis desses quatro anos de trabalho. Citando vocês, agradeço a todos os colegas do Ministério da Saúde que lutam por um SUS equitativo e sem doenças relacionadas à pobreza.

Assim como os amigos de todas as horas Lísia e Junior tão fundamentais na minha vida em Brasília que sequer acho palavras para agradece-los.

Por fim finalizo com outro ensinamento do idealizador dessa universidade, quando disse que "só há duas opções nessa vida: se resignar ou se indignar", como Darcy, torço para que não nos resignemos nunca com as aviltantes diferenças sociais e com o sofrimento dos mais pobres.

${ }^{1}$ Obra "O Povo Brasileiro" de Darcy Ribeiro 


\section{RESUMO}

\section{SUS PARA TODOS? AVANÇOS E DESAFIOS NAS POLÍTICAS FARMACÊUTICAS}

PARA DOENÇAS DA POBREZA. A superação das desigualdades sociais tem sido o grande desafio da humanidade. Na saúde as iniquidades também são evidentes e se expressam no que está se convencionado a chamar de doenças da pobreza. Este trabalho pretende analisar as políticas farmacêuticas brasileiras para estas doenças, tradicionalmente caraterizadas pela escassez da oferta de medicamentos. O estudo é composto de três fases: (i) uma análise exploratória do tema por meio de uma revisão da literatura cientifica do tipo "scopestudy", descrita no capítulo 1; (ii) análises de políticas pré-acesso a estes medicamentos por meio do levantamento dos registros de ensaios clínicos com medicamentos realizados no país (capítulo 2), o panorama das normas regulatórias e registros de medicamentos do Brasil, e as políticas de incorporação dessas tecnologias no SUS (capítulo 3); (iii) as políticas de financiamento e organização do acesso a esses medicamentos nos serviços de saúde, com análise das estratégias de financiamento e aquisições realizadas pelo Ministério da Saúde na última década - 2005 à 2014 (capítulo 4) e por último análise das diretrizes nacionais que regulam o tratamento dessas doenças e consequentemente o uso desses medicamentos no SUS (capítulo 5). No estudo exploratório, foi possível verificar que os últimos trabalhos publicados sobre o tema reforçam a tese da falta de interesse do mercado farmacêutico em pesquisas de medicamentos para doença da pobreza e indicam a necessidade de maior protagonismo dos entes públicos. Nas análises dos ensaios clínicos com medicamentos realizados no país durante o período de 2012 a 2015 foi observado uma prevalência na pesquisa de doenças globais não transmissíveis em $84,8 \%$ (734) dos casos e um baixo número para doenças da pobreza representando apenas $4 \%$ (38) das pesquisas realizadas no país. Verificou-se um total de 132 medicamentos elencados na Rename para atendimento específico das doenças da pobreza, sendo que mais de um terço (49) possuem apenas um produtor nacional e outros 24 não possuem registro no país. A falta de regulação diferenciada para medicamentos com pouco interesse comercial foi apontada como barreira para novos registros. Apesar disso, no período de 2006 a 2014, houve crescimento de $46 \%$ do número de medicamentos na Rename para tais doenças. Na análise das estratégias adotadas pelo governo brasileiro para garantir acesso a esses medicamentos nos últimos dez anos (2005 a 2014), observouse três grandes ações: (1) aquisição via organismos internacionais, responsável por $24 \%$ das aquisições durante o período; (2) centralização do financiamento/aquisição pelo governo federal de quase $80 \%$ dos medicamentos para essas doenças; (3) fortalecimento dos laboratórios oficiais, responsável por $62 \%$ das aquisições realizadas no período. Na análise das diretrizes de tratamento observou-se que a elaboração dos documentos para doenças da pobreza não segue o padrão definido pelo próprio Ministério da Saúde para outras doenças relacionadas a medicamentos de alto custo. Pela ferramenta AGREE II foi verificado um menor percentual de "rigor no desenvolvimento" (48\% e 7\%), de "envolvimento das partes interessadas" (43\% - 26\%) e de "independência editorial" (43\% e $1 \%$ ). Os achados desse trabalho demonstram que há pontos de êxito nas políticas farmacêuticas, principalmente quando observamos as estratégias para financiamento dos medicamentos já disponíveis, porém há necessidade de maior ação governamental para redefinir as prioridades de pesquisa com medicamentos, modernizar as normas regulatórias para registro e incorporação de medicamentos com menor apelo comercial e melhorar o padrão de qualidade das diretrizes de cuidado dessas doenças. Novos estudos que abordem questões de iniquidades em saúde nas políticas farmacêuticas são recomendados para que o acesso e uso racional de medicamentos não se torne um privilégio de poucos, mas sim um direito de todos.

Palavras-chaves: Doenças da Pobreza; Iniquidades em Saúde; Políticas Farmacêuticas. 


\section{RESUMEN}

¿SALUD PARA TODOS? AVANCES Y RETOS EN LAS POLÍTICAS FARMACÉUTICAS PARA ENFERMEDADES DE LA POBREZA. Los desafíos para la superación de la desigualdad social humana también presuponen el fin de las dichas enfermedades de la pobreza. La presente tesis objetiva analizar las políticas públicas farmacéuticas brasileñas de suministro de medicinas para dichas enfermedades. La tesis está dividida en tres partes: (i) Análisis exploratorio por medio de una revisión de las investigaciones sobre la temática, que se describe en el capítulo uno; (ii) Análisis de políticas pre-acceso, a estos medicamentos, por medio de la investigación de los ensayos clínicos con fármacos realizados en el país (Capítulo 2). Los requisitos reglamentarios y registros de medicamentos de Brasil, y las políticas de incorporación de tecnologías SUS (capítulo 3); (iii) Las políticas de financiación y organización del acceso de estos medicamentos en los servicios de sanidad, con el análisis de las estrategias de financiación y adquisiciones realizadas por el Ministerio de Sanidad en la última década - 2005-2014 (capítulo 4) y finalmente, el análisis de las directrices clínicas nacionales de tratamiento de estas enfermedades y uso de estos fármacos en el sistema de sanidad (capítulo 5). En el estudio exploratorio, se observó que los últimos trabajos publicados sobre el tema, refuerza la tesis de la falta de interés del mercado farmacéutico en la investigación de medicamentos para la enfermedad de la pobreza e indican la necesidad de un mayor papel de las entidades públicas. En el análisis de los ensayos clínicos de fármacos llevados a cabo en el país durante el período 2012-2015 se observó una prevalencia en el estudio de las enfermedades no transmisibles globales el 84,8\% (734) de los casos y un bajo número de enfermedades que acometen a los más pobres, que representa sólo el 4\% (38) de la investigación. Hubo un total de 132 medicamentos en el listado nacional para el cuidado específico de enfermedades de la pobreza, donde más de un tercio (49) tienen un único productor nacional y otros 24 no tienen productores en el país. La falta de regulación diferenciada para los medicamentos con poco interés comercial fue identificada como una barrera para nuevos registros. Aunque, en el período 2006-2014, el crecimiento fue del $46 \%$ en el número de medicamentos en el listado nacional para este tipo de enfermedades. En el análisis de las estrategias adoptadas por el gobierno brasileño para garantizar el acceso a estos fármacos en los últimos diez años (2005-2014), hay tres acciones principales: (1) La adquisición a través de organizaciones internacionales, responsables de $24 \%$ de las adquisiciones durante el periodo; (2) la centralización de los fondos / adquisición de casi el $80 \%$ de los medicamentos para estas enfermedades; (3) el fortalecimiento de los laboratorios oficiales responsables de $62 \%$ de las adquisiciones en el período. En el análisis de las directrices de tratamiento se observó que la preparación de documentos para las enfermedades de la pobreza no sigue el estándar establecido por el Ministerio de Salud para otras enfermedades relacionadas con medicamentos de alto costo. El método AGREE II se encontró un menor porcentaje de exactitud en el desarrollo (48\% e 7\%), la participación de las partes interesadas (43\% e $26 \%$ ) y la independencia editorial ( $43 \%$ e $1 \%)$. Los resultados de este estudio muestran que hay puntos de éxito en las políticas farmacéuticas, especialmente cuando nos fijamos en las estrategias para la financiación de los medicamentos que ya están disponibles, pero existe la necesidad de más acción gubernamental para redefinir las prioridades de investigación con las drogas, la modernización de las normas reguladoras para el registro y la incorporación de fármacos con menos atractivo comercial y mejorar el estándar de calidad de las guías de atención para estas enfermedades. Se recomiendan más estudios que aborden las inequidades en las políticas farmacéuticas para el acceso y el uso racional de los medicamentos no se convierte en un privilegio de unos, sino en derecho para todos.

Palabras clave: enfermedades de la pobreza; Las desigualdades en sanidad; Políticas farmacéuticas. 


\section{ABSTRACT}

HEALTH FOR EVERYONE? ADVANCES AND CHALLENGES IN PHARMACEUTICAL POLICIES FOR POVERTY DISEASES. The overcoming of social inequalities has been the great challenge of humanity. In health inequities are also evident and are expressed in what is agreed to be called diseases of poverty. The study is composed of three phases: (i) an exploratory analysis of the theme through a review of the scientific literature of the type "scope study" described in chapter 1; (ii) analyzes of pre-access policies for these drugs through the collection of clinical trials registries with medicines carried out in the country (chapter 2), the overview of Brazilian regulatory standards and drug registries, and the policies for incorporating these technologies in Brazilian health system (Chapter 3); (iii) policies for financing and organizing access to medicines in health services, with an analysis of the financing and procurement strategies carried out by the Ministry of Health in the last decade - 2005 to 2014 (chapter 4), and lastly, the analysis of the national guidelines Regulate the treatment of these diseases and consequently the use of these drugs in Brazilian health system (Chapter 5). In the exploratory study, it was possible to verify that the last published articles on the subject reinforce the thesis of the lack of interest of the pharmaceutical market in researches of medicines for disease of poverty and indicate the need of greater protagonist of the public entities. In the analyzes of the clinical trials with drugs carried out in the country during the period from 2012 to 2015 , a prevalence of global noncommunicable diseases was observed in $84.8 \%$ (734) of the cases and a low number for diseases of poverty representing only $4 \%$ (38) of the research carried out in the country. A total of 132 medicines listed in National List were verified for specific services of the diseases of the poverty, being more than a third (49) own only one national producer and 24 medicines not registered in the country. The lack of differentiated regulation for drugs with little commercial interest was pointed out as a barrier to new registrations. Nevertheless, in the period from 2006 to 2014, there was a $46 \%$ increase in the number of medicines in National List for such diseases. In the analysis of the strategies adopted by the Brazilian government to guarantee access to these drugs in the last ten years (2005 to 2014), there were three major actions: (1) acquisition through international organizations, responsible for $24 \%$ of acquisitions during the period; (2) centralization of financing / acquisition of almost $80 \%$ of medicines for these diseases; (3) strengthening of official laboratories, responsible for $62 \%$ of the acquisitions made in the period. In the analysis of the treatment guidelines, it was observed that the elaboration of the documents for diseases of poverty does not follow the standard defined by the Ministry of Health itself for other diseases related to high-cost drugs. The AGREE II method showed a lower percentage of development rigor (48\% e $7 \%)$, stakeholder involvement ( $43 \%-26 \%)$ and editorial independence (43\% e 1\%) when compared. The findings of this study demonstrate that there are success points in pharmaceutical policies, especially when we look at the strategies for financing the drugs already available, but there is a need for more government action to redefine drug research priorities, modernize regulatory standards for registration and incorporation of medicines with lower commercial appeal and to improve the quality standard of care guidelines for these diseases. New studies that address issues of health inequities in pharmaceutical policies are recommended so that access to and rational use of medicines does not become a privilege of few, but rather a right of all.

Keywords: Poverty Diseases; Inequities in Health; Pharmaceutical Policies. 


\section{SUMÁRIO}

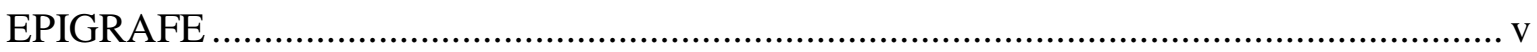

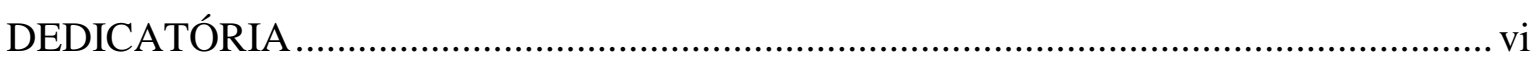

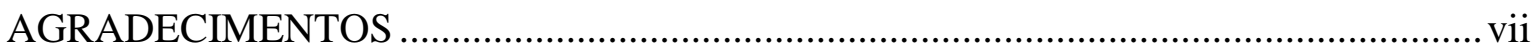

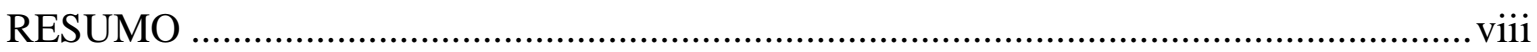

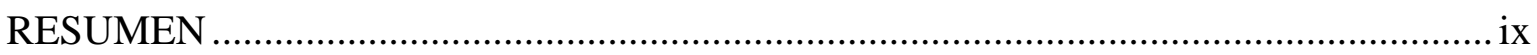

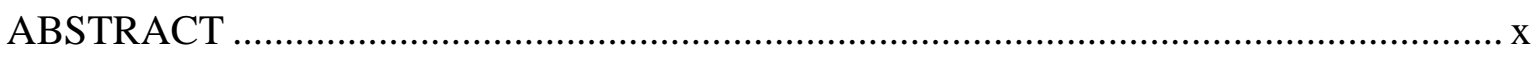

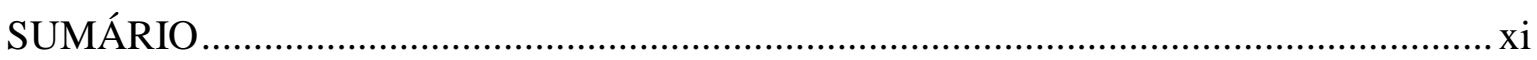

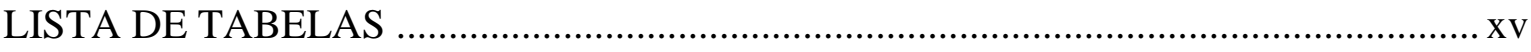

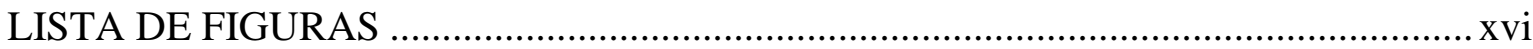

LISTA DE ABREVIATURAS E SIGLAS …..................................................................

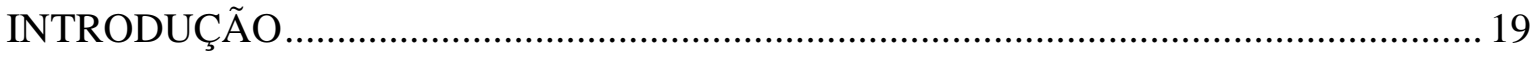

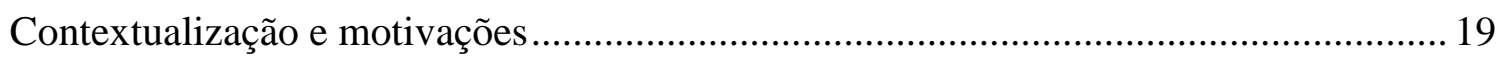

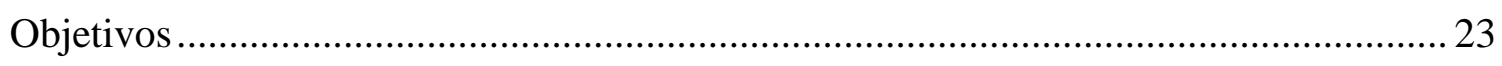

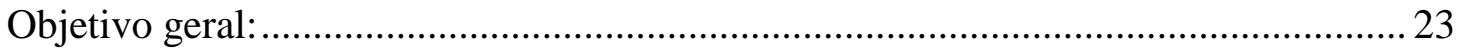

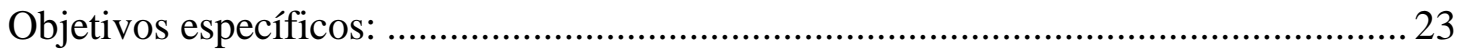

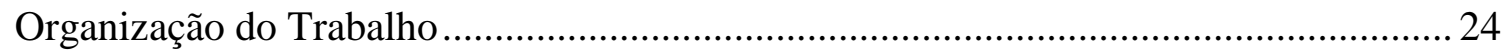

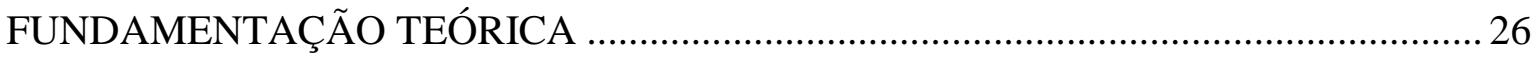

Superação da Pobreza: um problema global, o maior dos desafios brasileiros. .............. 26

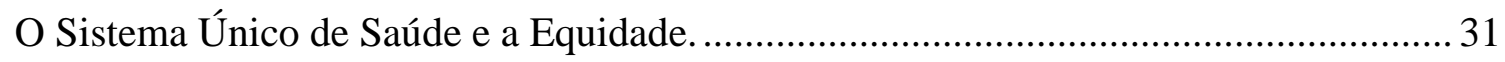

Doenças da pobreza: um conceito que alerta sobre a vulnerabilidade sanitária.............. 33

Doenças infeciosas imunopreveníveis e o êxito da cultura vacinal no Brasil. ................. 36

Doenças infeciosas não imunopreveníveis, alguns avanços e muitos desafios. ............... 38

Doenças e agravos relacionados à pobreza não infeciosos ........................................... 46

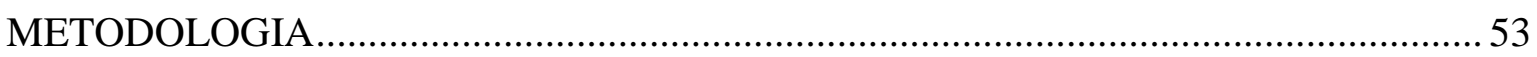

Fase I - Exploratória: Revisão da literatura das políticas farmacêutica para doenças relacionadas à pobreza no Brasil.

Fase II - Pré-Acesso: Análise das pesquisas clínicas com medicamentos com foco nas doenças da pobreza

Fase II - Pré-Acesso: Panorama da regulação do mercado e incorporação de medicamentos para doenças da pobreza no SUS. ........................................................ 56

Fase III - Acesso: Estratégias de Financiamento e Aquisição de medicamentos para Doenças da Pobreza..... 
Fase III - Acesso: Padrões de cuidado e assistência terapêutica para doenças da pobreza...

Coleta de dados e aspectos éticos: .58

CAPÍTULO I - DOENÇAS DA POBREZA NO BRASIL: UMA REVISÃO DAS POLÍTICAS FARMACÊUTICAS PARA POPULAÇÕES VULNERÁVEIS

Resumo: 61

Palavras-Chave: 61

Introdução: 61

Métodos: 62

Resultados: 64

Pesquisa, desenvolvimento e produção de fármacos: direito negado pelo mercado. ...... 65

Acessibilidade às terapias disponíveis: direito garantido? 69

Assistência farmacêutica integral: uma negligência? 74

Considerações Finais: .77

CAPITULO II - PRIORIDADES DE PESQUISA COM MEDICAMENTOS NO BRASIL E AS DOENÇAS DA POBREZA.

Resumo: .81

Palavras-Chave: .81

Introdução: 81

Métodos: .85

Resultados e Discussão: .87

Considerações Finais: .96

CAPÍTULO III - REGISTRO E INCORPORAÇÃO DE TECNOLOGIAS NO SUS: BARREIRAS DE ACESSO À MEDICAMENTOS PARA DOENÇAS DA POBREZA?

Resumo: .99

Palavras-chave: .99

Introdução: .99

Métodos 102

Resultados e Discussão 103

Considerações Finais

CAPÍTULO IV - ESTRATÉGIAS PARA GARANTIA DO ACESSO E O GASTO FEDERAL COM MEDICAMENTOS PARA DOENÇAS DA POBREZA ....

Resumo:

Palavras-chave: 120 
Introdução: 120

Resultados e Discussão:

Métodos:

Estratégia 01 - Aquisição de medicamentos via Organismo Internacional.................... 123

Estratégia 02 - Centralização do financiamento e aquisição ........................................ 126

Estratégia 03 - Fortalecimento e utilização dos laboratórios oficiais............................. 127

Contradições na divisão do orçamento: uma ameaça a sustentabilidade do

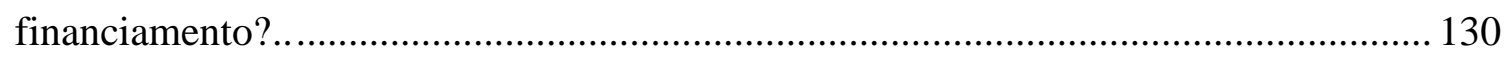

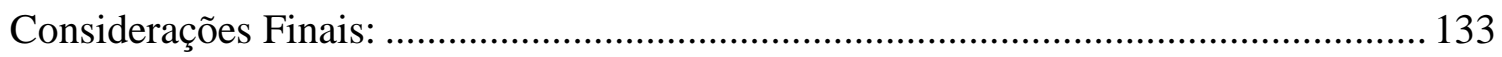

CAPÍTULO V - O DUPLO PADRÃO DE DIRETRIZES CLÍNICAS DO SUS: DOENÇAS DE ALTO CUSTO VERSUS DOENÇAS DA POBREZA .......................................... 136

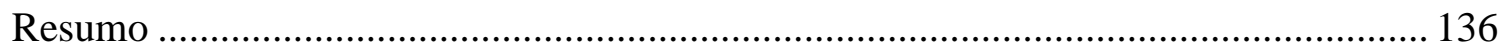

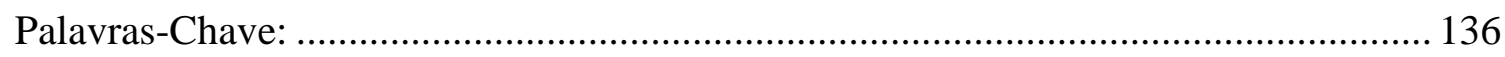

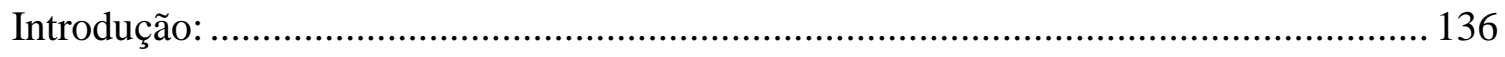

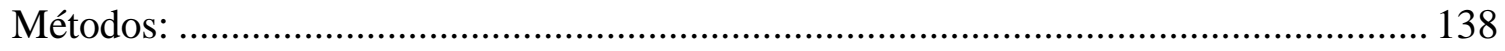

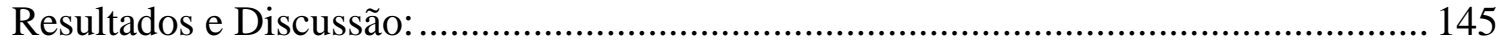

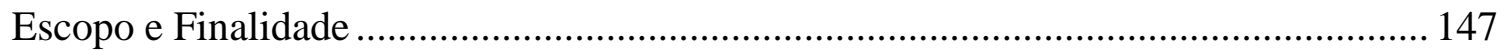

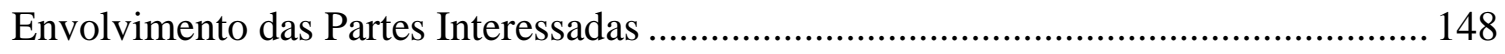

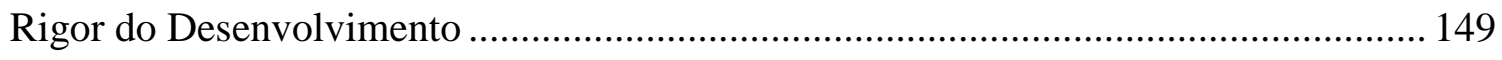

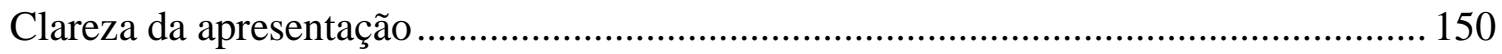

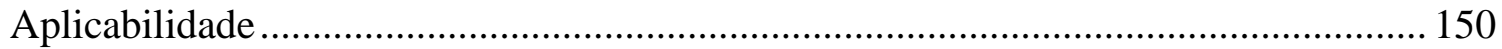

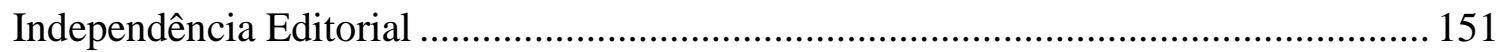

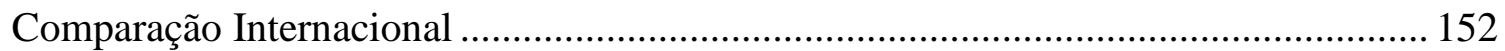

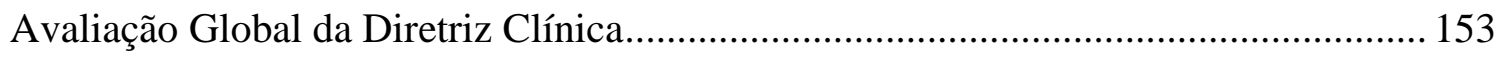

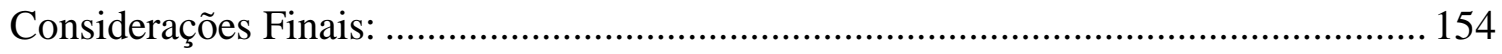

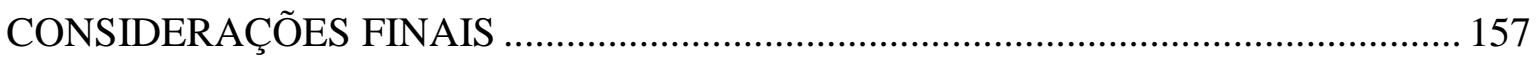

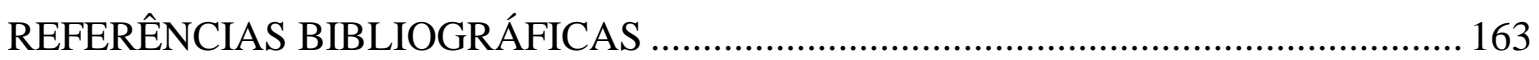

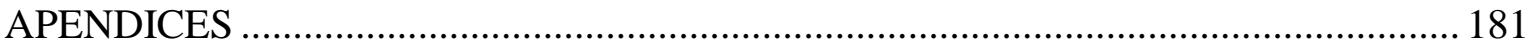

Apêndice I - Medicamentos utilizados em doenças e agravos relacionados à pobreza.... 181

Apêndice II - Resultados das Diretrizes Avaliadas segundo a ferramenta AGREE II ..... 193

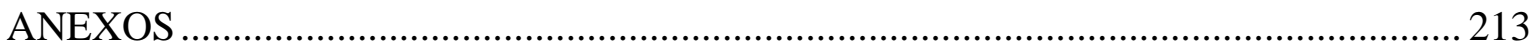

Anexo I - Artigo aceito para publicação na Revista Ciência \& Saúde Coletiva (2016) ... 213 Anexo II - Artigo aceito para publicação na Revista Pan-americana de Saúde Pública (2016).. 
Anexo III - Trabalho apresentado no V Congresso Brasileiro do Uso Racional de

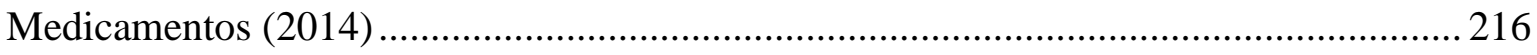

Anexo IV - Trabalho apresentado no 51 ${ }^{\circ}$ Congresso da Sociedade Brasileira de Medicina Tropical (Fortaleza - CE, 2015) .... 217 


\section{LISTA DE TABELAS}

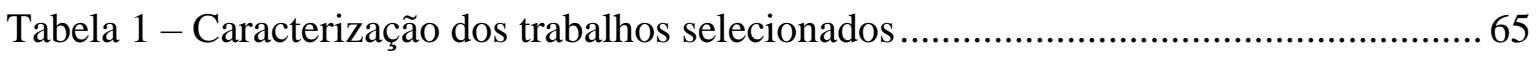

Tabela 2 - Doenças da pobreza nos ensaios clínicos brasileiros (2012-2015).................... 89

Tabela 3 - Comparação entre percentual de ensaios clínicos registrados no Brasil (2012-

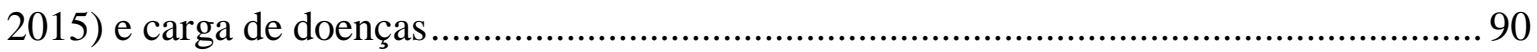

Tabela 4 - Proporção de ensaios registrados por tipo de doença ....................................... 92

Tabela 5 - Instituições responsáveis pela condução dos ensaios clínicos (2012-2015).... 94

Tabela 6 - Tipo de financiamento dos ensaios clínicos (2012-2015) ................................ 95

Tabela 7 - Comparação entre normas e incentivos regulatórios das agências Anvisa, FDA e

EMA. 104

Tabela 8 - Número de medicamentos para doenças da pobreza contemplados nas edições da Rename (2006-2014).

Tabela 9 - Relatórios de recomendação da Conitec relacionados às doenças da pobreza (2012-2015)

Tabela 10 - Medicamentos para doenças da pobreza e respectivo número de empresas com registro no Brasil em agosto de 2016

Tabela 11 - Diretrizes Clínicas do Ministério da Saúde para doenças e agravos relacionados com a Pobreza.

Tabela 12 - Diretrizes Clínicas do Ministério da Saúde selecionadas para o estudo 142

Tabela 13 - Coeficiente de Kappa segundo Landis \& Koch 145

Tabela 14 - Percentuais de adequação das diretrizes avaliadas segundo AGREE II ........ 146

Tabela 15 - Média das Pontuações de Diretrizes de Doenças da Pobreza versus Doenças Globais de Alto Custo segundo AGREE II 147 


\section{LISTA DE FIGURAS}

Figura 1 - Percentual de pobreza global baseado na renda e multidimensional ................. 28

Figura 2 - Cobertura de saúde da família versus plano de saúde por renda familiar ........... 32

Figura 3 - Fluxograma de tratamento dos estudos durante o processo de revisão............... 64

Figura 4 - Proporção de temas pesquisados por categoria de vulnerabilidade ................... 87

Figura 5 - Número de registros ativos de medicamentos na Anvisa para doenças da pobreza $(\mathrm{n}=132)$.

Figura 6 - Número de recomendações da Conitec quanto às tecnologias avaliadas no período de 2012 a 2015, classificadas por tipo de doença.

Figura 7 - Elenco de medicamentos para doenças da pobreza por tipo de aquisição

Figura 8 - Vias de fornecimento de medicamentos para Doenças da Pobreza na última década (2005 a 2014) por número de aquisições. 128

Figura 9 - Vias de fornecimento de medicamentos para Doenças da Pobreza na última década (2005 a 2014) por volume de recurso.

Figura 10 - Comparação da evolução dos gastos de medicamentos para doenças da pobreza, com orçamentos de HIV/AIDS, excepcionais e demanda judicial.

Figura 11 - Comparação entre população atendida (x), gastos com medicamentos (y) e valor per capta (tamanho da bola)..... 132

Figura 12 - Percentuais de adequação dos domínios do AGREE II comparados as diretrizes internacionais de Alonso-Colho et al. (2010). 


\section{LISTA DE ABREVIATURAS E SIGLAS}

AGREE Appraisal of Guidelines for Research and Evaluation”

Anvisa Agência Nacional de Vigilância Sanitária

ATS Avaliação de Tecnologias em Saúde

BM Banco Mundial

Conitec Comissão Nacional de Incorporação de Tecnologias no SUS

Cesaf Componente Estratégico da Assistência Farmacêutica

Ceaf Componente Especializado da Assistência Farmacêutica

CMED Câmara de Regulação do Mercado de Medicamentos

DALY Disability Adjusted Life of Years

DNDi Drugs for Neglected Diseases initiative

DRP Doenças Relacionadas à Pobreza

GAC Doenças Globais de Alto Custo

IBGE Instituto Brasileiro de Geografia e Estatística

Ipea Instituto de Pesquisa Econômica Aplicada

MHT Monitoramento do Horizonte Tecnológico”

ONU Organização das Nações Unidas

OMS Organização Mundial de Saúde

Opas Organização Pan-americana da Saúde

P\&D Pesquisa e Desenvolvimento

PNAUM Pesquisa Nacional sobre Acesso, Utilização e Promoção do Uso Racional de Medicamentos no Brasil

PNI Programa Nacional de Imunizações

PNUD Programa das Nações Unidas para o Desenvolvimento

ReBEC Registro Brasileiro de Ensaios Clínicos

Rename Relação Nacional de Medicamentos Essenciais

SUS Sistema Único de Saúde 


$$
T
$$




\section{INTRODUÇÃo}

\section{Contextualização e motivações}

O debate na área de assistência farmacêutica nos últimos anos parece estar centrado na crescente demanda por formas de custeio do acesso, nos impactos da incorporação de tecnologias de alto custo e no cenário de intensa judicialização da saúde.

A pauta das altas tecnologias e a preocupação com a sustentabilidade dos custos em saúde merece uma atenção cada vez maior da comunidade científica, no entanto, esse autor, que toma a liberdade de se comunicar em primeira pessoa neste momento, tem se preocupado com um possível esvaziamento do debate sobre as dificuldades de acesso a tratamentos para populações vulneráveis.

Entendo que nos últimos anos, apesar de alguns avanços, estamos de uma maneira geral deixando de evoluir na discussão sobre as lacunas de acesso a medicamentos para determinadas populações. E essa, é a primeira motivação dessa tese: reaquecer esse debate.

Rozenfeld (2008), define bem a atual lógica de iniquidades no campo da assistência farmacêutica, onde vivemos um paradoxo entre a "falta de acesso" a tratamentos para determinadas doenças e seguimentos populacionais e o "excesso de utilização" por outros.

Esse quadro faz parte de uma adequação mercadológica à chamada "transição epidemiológica" presente principalmente nos países desenvolvidos, caracterizada pelo acentuado declínio da mortalidade por doenças transmissíveis e predomínio das condições crônico degenerativas. A indústria farmacêutica direciona então seus investimentos de pesquisa e produção para atendimento de um determinado grupo consumidor de países e doenças. Sendo a maior parte dos gastos com pesquisas voltadas para problemas como calvície, enxaqueca, depressão, e para substâncias que, eventualmente, atuariam no adiamento do envelhecimento ou no controle da obesidade (MSF, 2001; OLIVEIRA et al, 2006). 
Na contramão dessa tendência, países em desenvolvimento que ainda necessitam combater doenças transmissíveis como Malária, Tuberculose, Doença de Chagas, Hanseníase e outras, sofrem com a falta de investimentos em inovação e consequente escassez de tratamentos medicamentosos (GOMES et al., 2012; HUNT; KHOSLA, 2008).

As dificuldades de acesso à medicamentos eficazes, seguros e fáceis de utilizar para essas doenças consideradas "negligenciadas" é justificado pela sua ocorrência majoritária em grupos populacionais vulneráveis e em países em desenvolvimento. Nesta tese, adotamos a postura de alguns pesquisadores e instituições de saúde que redirecionaram a terminologia para denunciar o componente social desta negligência e optamos por designalas de "doenças decorrentes e perpetuadoras da pobreza", "doenças relacionadas à pobreza" ou simplesmente "doenças da pobreza" dada sua associação com estigmas culturais, preconceitos, marginalização e baixa visibilidade social, que ao longo do trabalho será melhor explorado.

Entendo também que o termo "doença negligenciada" direcionou ao longo dos anos o debate para a falta de interesse do mercado farmacêutico, o que foi importante, mas é necessário destacar que nesta tese pretendemos ampliar a discussão, analisando também a responsabilidade dos governos de garantir acesso as terapias disponíveis, promover uma assistência farmacêutica integral e fomentar o desenvolvimento de tecnologias para essas doenças.

Encarar esse quadro como um simples resultado imutável da falta de interesse industrial no desenvolvimento de produtos que atingem doenças da pobreza é relegar populações vulneráveis à própria sorte (GARCIA, 2011; TROUILLER et al., 2001).

Fazendo parte de uma estrutura governamental definidora de políticas públicas nacionais, pude perceber que nem sempre as prioridades de saúde coincidem com as prioridades da gestão e respectivos orçamentos, mesmo para a área de saúde, onde 
influencias políticas e econômicas não deveriam se sobrepor as necessidades dos indivíduos, das famílias e do povo. O incomodo com esse quadro foi minha segunda motivação para este tema.

Entendo que a capacidade das políticas governamentais de mudar esse quadro, reorientando as prioridades de desenvolvimento científico e tecnológico aliada ao planejamento de políticas farmacêuticas que ampliem o acesso a medicamentos e sua utilização adequada é determinante para o sucesso na superação das doenças da pobreza.

A preocupação com um olhar diferenciado para essas doenças não possui apenas motivações altruístas e éticas, tampouco está embasada em ideais paternalistas à setores populacionais que ao meu ver não tiveram as mesmas oportunidades para sair do ciclo de incapacidades sociais. A necessidade de maior atenção para estas doenças regionais é dada também pelo seu potencial impacto global.

Mesmo atingindo seguimentos populacionais limitados ou restrito a países pobres essas doenças podem cobrar um preço caro pelo tempo de negligência. Exemplo disso, foi a última grande epidemia de ebola em 2015 que matou quase 5 mil pessoas no continente africano, demonstrou seu potencial de se espalhar por outros continentes e ganhou visibilidade por atingir alguns pacientes de países desenvolvidos. O que mobilizou o rápido investimento em novos testes diagnósticos e vacinais para um vírus que já havia sido descoberto em 1976 (COHEN, 2014; LEVER; WHITTY, 2016).

A emergência sanitária global decretada em 2016 pela OMS devido a disseminação do vírus zika, transmitido pelo mesmo vetor (Aedes aegypti) da dengue e chikungunya, é outro exemplo marcante do potencial de globalização das doenças da pobreza. Além da propagação atualmente facilitada pelos fluxos migratórios e pela maior mobilidade entre os países, observa-se que algumas doenças começam a apresentar padrões de danos aumentados, como se observou com os casos de microcefalia pela infecção do Zika em 
mulheres grávidas ou a relação desse vírus com o aumento dos casos de síndrome de Guillain Barré (FARIA et al., 2016; HAMEL et al., 2016).

Em ambos os exemplos, além de intensificar medidas de controle da transmissão, prover assistência farmacêutica integral são deveres legais do Estado. Sendo necessário destacar que o acesso adequado ao medicamento somente se concretiza, de fato, com sua utilização racional (SANT'ANA et al., 2011) que apesar de ser um direito assegurado legalmente, ainda possui um componente de iniquidade relevante.

Dados sobre acesso global de medicamentos no Brasil, obtidos por meio da Pesquisa Nacional sobre Acesso, Utilização e Promoção do Uso Racional de Medicamentos (PNAUM) demonstram diferenças relacionadas ao status socioeconômico da população. Com diferença de prevalência de 51,9\% de uso para as classes "A/B" e de 43,5\% para a classe "E", independentemente do tipo de medicamento (BERTOLDI et al., 2016). Ainda com dados dessa pesquisa, outro estudo demonstrou que a baixa adesão é mais frequente em estratos populacionais mais pobres $(\mathrm{D} / \mathrm{E}=32,6 \%)$, não brancos $(31,4 \%)$ e sem experiência de estudo formal (35,5\%) (TAVARES et al., 2016).

Para a Organização Mundial da Saúde (OMS) só há uso racional quando:

[...] os pacientes recebem medicamentos apropriados para suas condições clínicas, em doses adequadas às suas necessidades individuais, por um período adequado e ao menor custo para si e para a comunidade(WHO, 1987).

Nesse sentido, este trabalho pretende ampliar a análise das necessidades, avanços e perspectivas das políticas farmacêuticas para populações vulneráveis acometidas por doenças relacionadas à pobreza. 


\section{Objetivos}

Objetivo geral:

Analisar as políticas farmacêuticas brasileiras para doenças relacionadas à pobreza, suas características, estratégias, e as barreiras que impactam no acesso à medicamentos.

Objetivos específicos:

- Revisar estudos da literatura científica que tratem sobre os temas de políticas farmacêuticas e doenças da pobreza no Brasil;

- Caracterizar e analisar o perfil de pesquisas clínicas com medicamentos realizadas no país com enfoque nas que abordam doenças da pobreza;

- Analisar o panorama das ações de regulação sanitária de medicamentos e seu impacto no fomento do registro de medicamentos para doenças da pobreza;

- Verificar os atuais fluxos de incorporação de medicamentos no Sistema Único de Saúde, histórico e perspectivas para doenças da pobreza;

- Identificar as estratégias governamentais para financiamento e disponibilização de medicamentos para doenças da pobreza no Brasil;

- Avaliar as diretrizes de tratamento para essas doenças elaboradas pelo Ministério da Saúde. 


\section{Organização do Trabalho}

Este trabalho está organizado numa seção inicial com uma fundamentação teórica sobre o tema, que retrata um pouco do debate sobre os desafios de superação da pobreza no país, o papel do sistema brasileiro de saúde, o acesso a medicamentos e aspectos das principais doenças da pobreza elencadas pelo autor.

Na seção subsequente são elencados os métodos gerais utilizados nas investigações do trabalho, uma visão geral, que será abordada com mais detalhes nos capítulos seguintes.

Os resultados estão expressos em cinco capítulos, escritos em formato de artigos científicos: (i) o primeiro tratando sobre os resultados de uma revisão da literatura sobre o estudos que abordaram aspectos das políticas farmacêuticas de doenças da pobreza no Brasil; (ii) o segundo abordando uma análise das pesquisas clínicas com medicamentos realizadas no Brasil e, especificamente, a parcela que trata de doenças da pobreza; (iii) o terceiro, traz uma avaliação sobre as potenciais barreiras para o registro de medicamentos para doenças da pobreza no país e sua consequente incorporação no SUS; (iv) no quarto capítulo, identificamos as estratégias adotadas pelo SUS para o financiamento e aquisição de medicamentos para prevenção e tratamento de doenças da pobreza; e (iv) por último, no capítulo cinco, fazemos uma análise das diretrizes clínicas elaboradas pelo Ministério da Saúde, avaliando seu padrão de qualidade e adequação à normativas do SUS. 
FUNDAMENTAÇÃO TEÓRICA

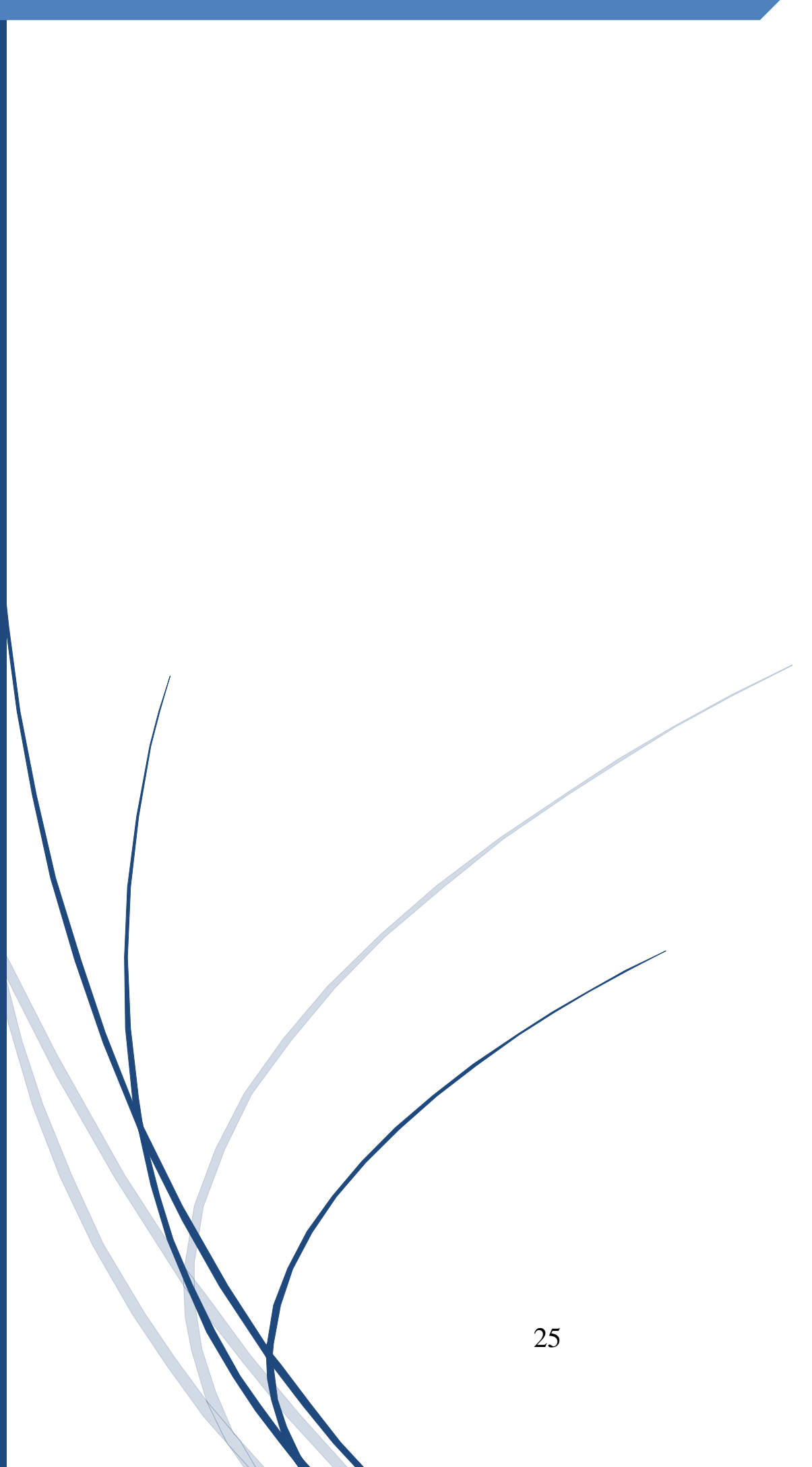




\section{FUNDAMENTAÇÃO TEÓRICA}

\section{Superação da Pobreza: um problema global, o maior dos desafios brasileiros.}

"A falta de amor é a maior de todas as pobrezas". Essa frase foi proferida por Madre Teresa de Calcutá, missionária e ativista que dedicou sua vida para minimizar a desigualdade e exclusão social humana. Numa interpretação inversa da citação poderíamos dizer também que a pobreza é consequência da falta de amor, ou seja, a resultado da indiferença de boa parte da comunidade global sobre a miséria no mundo.

Caracterizar uma situação de pobreza, por si só, já é uma tarefa complexa e que vem sendo modernizada ao longo dos anos entendendo que não se restringe apenas a carência de bens, mas a uma carência de direitos, oportunidades, recursos de sobrevivência e serviços governamentais (YAZBEK, 2012).

Alguns dos maiores especialistas mundiais que tratam sobre pobreza e desenvolvimento ampliaram a visão do que seria considerado pobreza. Amartya Sen defende que pobreza deve ser vista como "privação de capacidades" entendendo que a baixa renda é instrumentalmente importante, mas não seria a única causa de "pobreza real". Outros aspectos podem impedir um indivíduo de converter renda (mesmo que adequada) em capacidades, como: a idade da pessoa (necessidades específicas de idosos ou muito jovens), desigualdades culturais de gênero, discriminação de determinados grupos étnicos, vulnerabilidades relacionadas à localização (locais de inundação, secas, ou violência urbana), situação de saúde (presença de doenças endêmicas na região), ou mesmo possuir renda adequada, porém insuficiente para um país ou região rica (SEN, 2010).

Jeffrey Sachs (2005) distingue a pobreza em três níveis: (i) pobreza extrema ou absoluta (miséria) quando não são satisfeitas as necessidades básicas de sobrevivência, havendo fome crônica, falta de acesso à saúde, educação para os filhos, água potável ou esgoto, vestuário básico e na maioria das vezes moradia em abrigos rudimentares; (ii) 
pobreza moderada, quando as necessidades básicas são satisfeitas, porém com dificuldade ou vulnerabilidade iminente; e (iii) pobreza relativa quando a renda familiar está abaixo de uma determinada proporção da renda nacional (SACHS, 2005).

Governos de diversos países empregam o padrão do Banco Mundial (BM) que utiliza a renda de até U\$ 1 por dia para determinar a quantidade de pessoas miseráveis do mundo. Para uma pobreza moderada, considera-se uma renda entre U\$ 1 e U\$ 2 por dia. Por esses parâmetros estimou-se que na última década havia cerca de 1,1 bilhão de pessoas vivendo em pobreza extrema, apesar da redução comparada a 1981 quando se estimava 1,5 bilhão de miseráveis. Outro 1,6 bilhão vivia em estado de pobreza moderada. Em ambos os casos, as pessoas vivem em aproximadamente 91 países em desenvolvimento e a maior parte localizados na África subsaariana e Ásia (SACHS, 2005).

A partir de 2010, o Programa das Nações Unidas para o Desenvolvimento (PNUD) passa a utilizar o chamado Índice de Pobreza Multidimensional que leva em consideração 10 parâmetros de análise, em três categorias: (i) educação (anos de escolaridade, crianças na escola); (ii) saúde (mortalidade infantil, nutrição); (iii) padrão de vida (eletricidade, saneamento, água potável, solo da habitação, combustível doméstico, bens). Baseado nesses parâmetros, quanto maior o índice, maior a "intensidade de pobreza". Se o índice de privação for maior que $33,3 \%$ considera-se "multidimensionalmente pobre" e se estiver entre $20 \%$ e 33,3\% estão em condição de vulnerabilidade (PNUD, 2014).

O relatório de 2014 do PNUD, com atualizações do BM, demonstra que cerca de 1,2 bilhão de pessoas vivem com U\$1,25 ou menos por dia e estimou que 1,5 bilhão estão em estado de pobreza multidimensional (Figura 1), ou seja, com privações conjuntas de educação, saúde e padrão de vida. Cerca de 800 milhões de pessoas estão em situação de "quase pobreza", ou seja, sob risco de voltar à pobreza absoluta caso ocorram contratempos, 
totalizando então cerca de 2,2 bilhões de pessoas com privação de pelo menos dois parâmetros de pobreza multifatorial (UNDP, 2014).

\section{Figura 1 - Percentual de pobreza global baseado na renda e multidimensional}

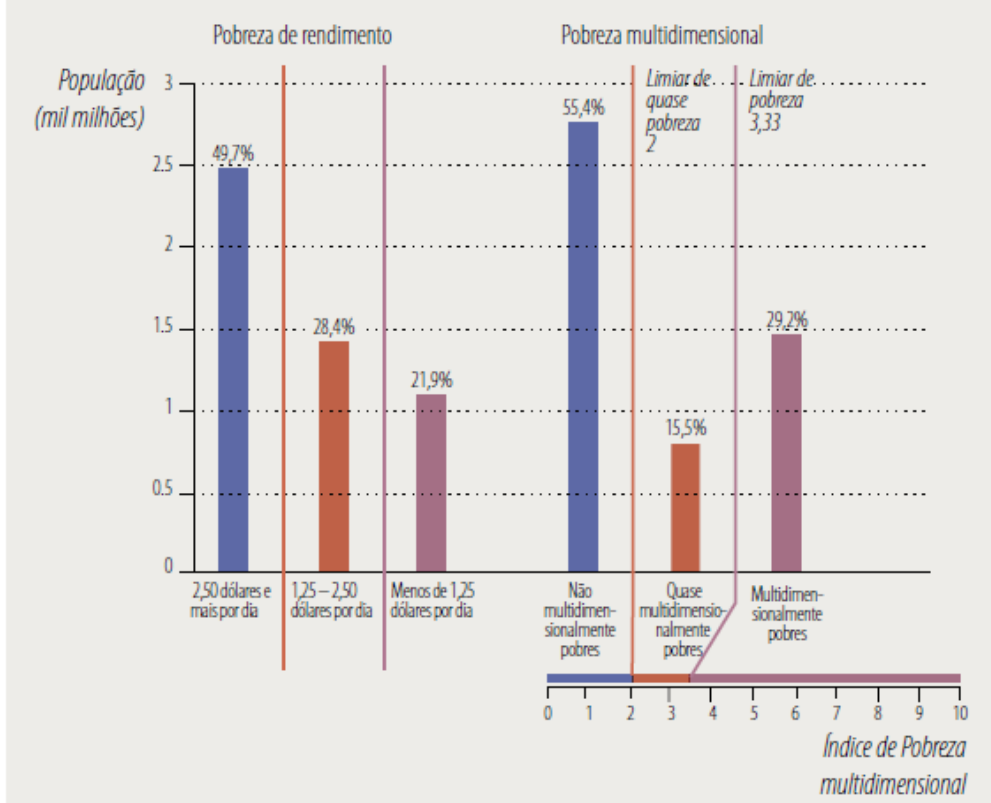

Fonte: Relatório PNUD 2014

Mesmo chocante, os números não conseguem materializar os impactos individuais das pessoas que vivem na pobreza, que possuem marcas do aviltamento do trabalho ou da falta dele, do desconforto da moradia precária e insalubre, da alimentação insuficiente, da ignorância, dos sentimentos de resignação, revolta, tensão, medo e falta de perspectiva de futuro. Para enfrentamento de um problema socioeconômico tão complexo são necessárias ações mais abrangentes que contribuam para o desenvolvimento comunitário, como investimentos em educação, saneamento básico, fortalecimento da seguridade social e instituição de políticas públicas de combate à exclusão social (ALVES; ESCOREL, 2012; YAZBEK, 2012). 
"Os que comem bem, dormem bem e têm boas casas acham que se gasta demais em política social" proferiu certa vez Pepe Mujica, que ficou famoso por ser o "presidente mais pobre do mundo" quando comandou a República do Uruguai (MUJICA, 2013).

Com grande reconhecimento internacional, o Brasil talvez seja um dos países em desenvolvimento que mais implantou políticas públicas de combate à pobreza. Um dos destaques dos dois últimos relatórios da Organização das Nações Unidas (ONU) sobre o desenvolvimento humano no mundo destaca o Programa Bolsa Família como um exemplo exitoso de programa social que com um recurso de apenas 0,3\% do PIB (2008-2009) contribui para a redução de $20 \%-25 \%$ da desigualdade e o crescimento do poder de consumo dos $40 \%$ mais pobres (UNDP, 2014).

No último Relatório do BM (2015) sobre a América Latina também há destaque dos resultados brasileiros com relação ao percentual da população vivendo em extrema pobreza que caiu de $10 \%$ para $4 \%$ (entre 2001 e 2013), e cerca de 25 milhões de pessoas saindo da pobreza extrema ou moderada, ou seja, a cada duas pessoas que saíram da pobreza na América Latina e no Caribe durante o período, uma era brasileira. O estudo ainda informa que de 1990 a 2009, cerca de $60 \%$ dos brasileiros passaram para um nível de renda maior (WORLD BANK GROUP, 2015).

Pelos dados do PNUD, no período de 2006 a 2012, a pobreza multidimensional no Brasil caiu de $4 \%$ para 3,1\% da população, ou seja, de 7,5 para 6 milhões de pessoas que ainda possuem mais de $33 \%$ dos indicadores de privação de capacidades. Já as pessoas consideradas pelo estudo como "quase pobres" ou com privação de mais de dois indicadores básicos passaram de 11,2\% para 7,4\%. O percentual de pobreza grave (mais de $50 \%$ de privações) também diminui de $0,7 \%$ para $0,5 \%$ (UNDP, 2014).

Os resultados brasileiros são explicados por três motivos segundo o mesmo estudo: (i) o crescimento econômico mais estável a partir de 2001; (ii) associado a políticas de 
distribuição de renda e erradicação da pobreza como o Bolsa Família e Brasil Sem Miséria; e (iii) a redução do desemprego e aumento do emprego formal (WORLD BANK GROUP, 2015).

É interessante destacar que diferente da maioria dos países, no Brasil a pobreza multidimensional do PNUD $(3,1 \%)$ é menor que a pobreza de rendimentos do BM (4\%), que indica que além dos programas de distribuição de renda outras medidas pontuais como acesso a saúde, educação e medidas de correção direta de desigualdades, a exemplo do Programa de Ações Afirmativas, estão influenciando na redução da pobreza (PIOVESAN, 2008; UNDP, 2014; WORLD BANK GROUP, 2015).

Teses mais críticas aos programas de transferência de renda como a criação do "fenômeno de armadilha da pobreza" ou o "estímulo a geração de filhos" tem sido refutadas quando se observam que cerca de 1,7 milhões de pessoas desistem dos auxílios voluntariamente por melhorarem de vida ou quando se observa que a queda na taxa de fertilidade é maior entre as beneficiarias do programa (IBGE, 2016).

No entanto, críticas relacionadas ao pouco investimento na área da educação como estratégia para redução da pobreza merecem cada vez mais atenção, pois diferentes análises demonstram que a falta investimentos sólidos nessa área, contribuem para o retorno dessas populações a zonas de pobreza, principalmente em crises econômicas cíclicas. O investimento maciço em educação resulta em acréscimo de produtividade, pelo ganho de habilidades cognitivas da população e se convertem num maior potencial de geração autônoma de renda (MARINHO et al, 2011).

A saúde também tem sido o indicador que mais contribui para os índices de pobreza multidimensional, onde as privações de educação contribuíram para 27,7\% do resultado, as condições de vida 33,9\% e as privações de saúde 38,4\% (UNDP, 2014). Isso representa um 
alerta, pois tão importante quanto inserir uma diretriz transversal de equidade nas políticas públicas é mantê-la como prioridade das ações governamentais.

\section{O Sistema Único de Saúde e a Equidade.}

A partir da luta por direitos da sociedade civil, num ambiente de redemocratização e embates entre a reforma sanitária e a reforma neoliberal, o assistencialismo sanitário passa por uma evolução constitucional que transforma a saúde em direito, com sua materialização no Sistema Único de Saúde (SUS). Este, vem ano a ano progredindo num projeto ambicioso de cobertura universal para um país de 200 milhões de habitantes, onde os serviços e medicamentos devem ser acessíveis a toda a população. Na última década, apesar do desafio de superar problemas como o subfinanciamento público, ineficiência da gestão, deficiência de recursos humanos e fortes desigualdades regionais, o sistema tem saído de um foco hospitalocêntrico para uma reorganização baseada na atenção primária (MACINKO; HARRIS, 2015; PAIM, 2013).

A expansão da Estratégia de Saúde da Família com foco nos municípios e nas regiões mais pobres tem desempenhado um papel importante na redução das desigualdades em saúde, havendo evidências de que tem inclusive melhorado a detecção de casos de doenças negligenciadas (MACINKO; HARRIS, 2015; PAIM et al., 2011).

A descentralização das ações e os mecanismos inovadores de tomada de decisão compartilhada são inovações do SUS que ampliam a discussão das necessidades de saúde e permitem ampla participação de estados e municípios. No entanto, a variabilidade de oferta e as disparidades regionais vão de encontro aos princípios de universalidade e equidade no acesso aos serviços.

Em análise ampla de conceitos, Vieira-da-Silva e Almeida Filho (2009) verificam que os termos "desigualdade" ou "iniquidade" podem ser interpretados como resultado de 
diferentes formas de tratamento a indivíduos ou grupos sociais associados muitas vezes à noção de "injustiça". A “equidade", então pode ser interpretada como o resultado de políticas que tratam indivíduos que não são iguais de forma diferente a fim de estabelecer um ideal de "justiça".

A equidade em saúde tem sido entendida como o trabalho para redução de desigualdades consideradas desnecessárias ou injustificáveis, para então poder realizar um tratamento realmente igualitário dos cidadãos brasileiros usuários do sistema. Viana et al. (2003) ressaltam que a simples inclusão do conceito de equidade na formulação de políticas públicas não garante a redução efetiva das iniquidades em saúde sem que esteja aliado a mudança na alocação de recursos financeiros e na definição da oferta de serviços (CHIEFFI; BARATA, 2009; VIANA; et al., 2003).

O retrato da operacionalização deste conceito é o avanço da cobertura da estratégia de saúde da família com presença maior nas faixas populacionais de menor renda, conforme pode se observar na Figura 2.

Figura 2 - Cobertura de saúde da família versus plano de saúde por renda familiar

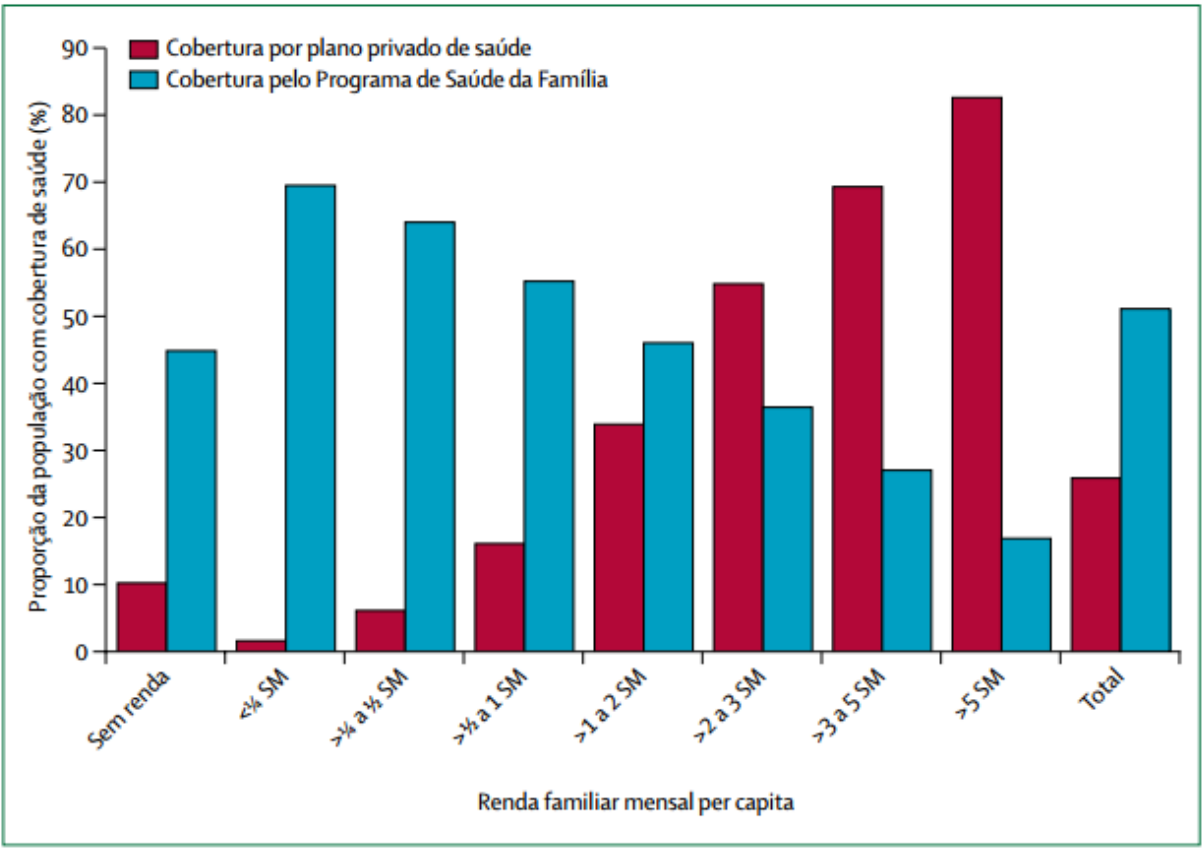

Fonte: Paim et al. (2011) 
Essa priorização pela cobertura das faixas mais pobres da população tem relação evidente com a falta de recursos e estruturação do serviço para atingir um ideal de universalidade e, como efeito colateral cria uma visão coletiva distorcida que o SUS é um sistema de saúde para pobres ou a única alternativa para quem é pobre. Como consequência os investimentos e serviços oferecidos tendem a condizer com o público (CUETO et al., 2014).

\section{Doenças da pobreza: um conceito que alerta sobre a vulnerabilidade sanitária.}

Caracterizadas principalmente pelo perfil endêmico, infecioso e o acometimento de populações pobres, o termo "doenças negligenciadas" foi cunhado pela primeira vez em 1970 pela Fundação Rockefeller alertando sobre a falta de interesse do mercado farmacêutico global no investimento de medicamentos para doenças próprias de países em desenvolvimento. Em 2001, a organização humanitária Médicos Sem Fronteiras (MSF, 2001) propôs a classificação das doenças que conhecemos em "globais", "negligenciadas" e "extremamente negligenciadas", para ressaltar o caráter crítico de escassez de acesso a terapias para algumas doenças como a doença de Chagas ou a doença do sono (ABC, 2010).

Também comumente chamadas de "doenças tropicais", "transmissíveis negligenciadas", "emergentes", "re-emergentes" parece haver uma convergência conceitual entre documentos da Organização Mundial de Saúde (OMS) (WHO, 2012), do Ministério da Saúde (BRASIL. MS. SVS, 2014a), algumas organizações não governamentais (HEALTH POVERTY ACTION, 2016; TDR, 2016) e estudiosos (PARKER; WILSON, 2000; SINGH; SINGH, 2008; STEVENS, 2008), de denominá-las de "doenças relacionadas à pobreza" ou simplesmente "doenças da pobreza". Esse conceito permite ampliar a atenção para agravos não transmissíveis como doenças relativas à subnutrição e anemias carenciais, causadas por déficit alimentar ou por perdas de sangue (decorrentes de verminoses, de 
hemorragias ou de alcoolismo), e dar ênfase a - cada vez mais evidente - relação destas doenças com as condições socioeconômicas da população (IOC, 2011).

O termo remete fundamentalmente para descrever problemas de saúde que são mais prevalentes entre os pobres do que entre as pessoas com maior poder aquisitivo. Em muitos casos, a pobreza é considerada o principal fator de risco ou fator determinante para tais doenças, e em alguns casos, as próprias doenças são identificados como obstáculos ao desenvolvimento econômico para acabar com a pobreza (PARKER; WILSON, 2000).

Não é recente que esse tipo de doença chama a atenção dos governantes, das autoridades sanitárias ou mesmo das discussões sociais. Diversos contextos históricos retratam a preocupação em combater as "doenças pestilentas do Brasil": seja em episódios icônicos como a "Revolta da Vacina" no início do século XX (HOCHMAN, 2009a); nos discursos e no programa de governo do Brasil desenvolvimentista de Juscelino Kubitschek (HOCHMAN, 2009b), ou mesmo em torno da construção de identidade nacional com o personagem Jeca Tatu de Monteiro Lobato (LOBATO, 2010).

É fato que essa preocupação teve efeitos positivos ao longo dos anos. Pois os investimentos em saúde e o próprio desenvolvimento do país acabaram por reduzir drasticamente o percentual de pessoas que morrem por conta desse tipo de doença. Atividades de prevenção como a vacinação em massa, o controle de vetores, a ampliação do diagnóstico e o acesso a medicamentos reduziram o percentual de mortes por doenças infecciosas de $50 \%$ na década de 30 para menos de 5\% em 2007. Esta redução vem acompanhada pelo incremento do percentual de doenças crônicas não transmissíveis, caracterizando a chamada "transição epidemiológica" (BARRETO et al., 2011; BRASIL. MDS, 2014). 
Quando se analisa não apenas a mortalidade, mas também os danos permanentes e transitórios que as doenças da pobreza podem causar verifica-se que o impacto percentual delas ainda tende a ser bastante significativo.

$\mathrm{Na}$ análise de "carga de doença", medida em anos de vida perdidos ajustados por incapacidade, as doenças infeciosas, parasitárias e desnutrição representam 14,7\% da carga brasileira e as doenças crônicas não transmissíveis representam 66,3\%. Essa coexistência danosa de transmissíveis e crônicas expõe a população a uma dupla carga de doenças ou tripla carga como referem alguns autores a chamar atenção para a carga por causas externas que representam 10,2\% (MENDES, 2010; SCHRAMM et al., 2004).

O retorno das discussões e ressignificação das chamadas doenças da pobreza tende a alertar para essa duplicação de cargas presente ainda em países em desenvolvimento. Porém, se há uma aparente convergência para a utilização do termo não há consenso em relação às doenças que fazem parte dessa classificação.

Alguns documentos da OMS e do Ministério da Saúde citam essencialmente as principais doenças infecciosas e parasitárias como relacionadas à pobreza que no contexto brasileiro seriam: dengue; doença de Chagas; esquistossomose; febre amarela e outras arboviroses; febre maculosa e outras rickettsioses; filariose; geohelmintíases e outras parasitoses intestinais; hanseníase; hantaviroses; leishmanioses; leptospirose; malária; raiva; tracoma; tuberculose; doenças sexualmente transmissíveis e doenças preveníveis por vacinação (BRASIL. MS. SVS, 2014a; WHO, 2012).

Outros documentos do Ministério do Desenvolvimento Social, Instituto Oswaldo Cruz e referências internacionais ampliam a sistematização incluído outras doenças e condições: deficiências relacionadas a fome e desnutrição, doenças diarreicas, febre reumática, alcoolismo e drogadição (BRASIL. MDS, 2014; IOC, 2011; PARKER; WILSON, 2000; STEVENS, 2008). 
A seguir, trataremos das principais doenças da pobreza descritas na literatura agrupadas em: (i) doenças infeciosas imunopreveníveis; (ii) doenças infeciosas e parasitárias não imunopreveníveis; e (iii) outras doenças relacionadas à pobreza (ou não infeciosas).

\section{Doenças infeciosas imunopreveníveis e o êxito da cultura vacinal no Brasil.}

A política de acesso a vacinas e imunobiológicos no Brasil, se configura como a primeira e mais efetiva política farmacêutica realizada pelo governo brasileiro e particularmente pelo Programa Nacional de Imunizações (PNI).

A ampliação contínua na oferta de vacinas, com facilidade de acesso nas unidades básicas de saúde foi responsável pela queda drástica dos casos de muitas doenças que atingiam principalmente populações pobres. De 1980 à 2007, o número de mortes por tétano caiu $81 \%$ e as mortes por coqueluche tiveram uma redução de $95 \%$, e muitas outras doenças foram consideradas eliminadas, com incidência considerada rara ou não detectável como a poliomielite e o sarampo, todas incluídas no calendário básico de vacinação (BARRETO et al., 2011; BRASIL. MS.SVS, 2013).

Essa história de êxito, começa com o olhar do poder público desde o período imperial quando, ainda em 1811, é criado a primeira “Junta Vacínica da Corte”, mas sem dúvida é com os surtos de varíola e febre amarela no final do século XIX e início do XX, que o investimento em vacinação passou a ser uma ação continua do poder público. Essa priorização estava motivada principalmente porque o principal porto de importação e exportação da época, o Rio de Janeiro, extremamente afetada por surtos dessas doenças, passava a ser considerado um local inseguro para passageiros e cargueiros (HOCHMAN, 2009a). 
Com o passar dos anos, os investimentos e ações de saúde, como campanhas, varreduras e bloqueios, culminaram com a eliminação da varíola no Brasil em 1973 e da febre amarela nas regiões urbanas em 1942 (BRASIL. MS. SVS, 2003).

Na edição de 2014 da Relação Nacional de Medicamentos Essenciais (Rename) estavam listados 25 diferentes tipos de vacinas, boa parte de uso amplo a população geral e algumas disponíveis para portadores de condições clínicas específicas atendidos nos centros de referência de imunobiológicos especiais (BRASIL. MS. SCTIE, 2015a).

Contribuindo para a prevenção de cerca de 20 doenças, sendo que destas $75 \%$ podem ser consideradas doenças relacionadas à pobreza por historicamente terem vitimado os seguimentos populacionais mais vulneráveis do país: sarampo, caxumba, rubéola, varicela, difteria, tétano, coqueluche, tuberculose, cólera, febre tifoide, febre amarela, meningites, poliomielite, raiva, rotavirose. Ofertadas rotineiramente em um total aproximado de $34 \mathrm{mil}$ salas de vacinas distribuídas por todos os municípios brasileiros. Uma ampla rede, que pela pulverização do acesso tem contribuído para a redução das desigualdades regionais (BRASIL, 2014; DOMINGUES; TEIXEIRA, 2013).

O aumento da oferta ao longo dos anos monitorado pelos índices de cobertura vacinal, está relacionado à própria estruturação do SUS. Pois se observa que na década de 80 até meados de 1990, a cobertura vacinal do calendário infantil estava geralmente abaixo de $50 \%$. E após esse período (2002 a 2011) atingiu-se praticamente todas as metas, com destaque para a superação de meta de cobertura para os menores de um ano (superiores a 90\%) (DOMINGUES; TEIXEIRA, 2013; TEMPORÃO, 2003).

A cada ano há um incentivo para a produção nacional de vacinas, com um olhar para a sustentabilidade do programa que após investimentos das últimas duas décadas passou em 2012, a produzir $96 \%$ das vacinas e 100\% dos soros ofertados no país (BARRETO et al., 2011; DOMINGUES; TEIXEIRA, 2013). Parte desse quadro é também explicado pelo 
limitado interesse da indústria farmacêutica global na produção e desenvolvimento de vacinas, que representa apenas cerca de $2 \%$ do mercado mundial, com um mercado consumidor potencial grande, porém nos países em desenvolvimento (SCHATZMAYR, 2003).

Todos esses resultados e investimentos não seriam possíveis sem a chamada "cultura da imunização" como designou Hochman (2011) sobre a característica nacional de intensa “adesão da população aos programas governamentais de imunização e pela demanda cada vez maior de que novas vacinas sejam oferecidas pelo poder público”. Essa observação se justifica quando se observa a superação de medidas coercitivas anteriores, ilustrada pela "Revolta da Vacina", que deu lugar a aceitação ampla e ativa da vacinação como um bem coletivo e um direito garantido pelo sistema público de saúde (HOCHMAN, 2011).

O campo das imunizações parece não ser afetado pelo fenômeno contemporâneo da judicialização da saúde e nem pelo movimento anti-vacinal presente em alguns países. Este último, motivado pelo debate ético do atual paradigma da vacinação em massa, que tem sofrido crescentes questionamentos sobre a potencial exposição a eventos adversos de um grande número de pessoas, quando se vive num ambiente de contínua melhoria das condições de saneamento e redução dos riscos de contágio (HOCHMAN, 2011; LESSA; DÓREA, 2013).

\section{Doenças infeciosas não imunopreveníveis, alguns avanços e muitos desafios.}

Designadas pelos órgãos sanitários como "endemias" ou "endemias rurais", alguns agravos infeciosos e parasitários constituíram a preocupação central da saúde pública brasileira por quase um século (SILVA, 2003).

De iniciativas pontuais e verticalizadas para acesso a antibióticos por meio de programas para controle de doenças até a estruturação do chamado componente estratégico 
da assistência farmacêutica, muitos avanços foram realizados na garantia do acesso a medicamentos para boa parte das chamadas doenças da pobreza.

A portaria GM/MS no 204 de 29 de janeiro de 2007 estabeleceu o componente estratégico da assistência farmacêutica como norma de financiamento da união, que adquire e distribui nacionalmente medicamentos para tratamento de HIV, Tuberculose, Hanseníase, Leishmanioses, Malária, entre outras doenças (VIEIRA, 2010). Boa parte dos medicamentos para tratamento das doenças da pobreza são financiados por esse componente, mas alguns itens em menor proporção também estão previstos para financiamento pelo componente básico da assistência farmacêutica, esse com aporte de recursos tripartite e aquisição municipal (BRASIL. MS, 2007).

A disponibilização desses medicamentos associada a outras estratégias sanitárias têm gerado diferentes resultados no controle de doenças da pobreza, discutidas brevemente a seguir.

A redução de $21,7 \%$ da incidência de Tuberculose é um dado exitoso para a saúde pública brasileira, passando 42,8 casos por 100 mil habitantes em 2001 para 33,5 casos em 2014. Porém, o Brasil ainda se destaca no cenário global com cerca de 73 mil casos novos por ano. Ao passo que a incidência diminui na população geral, parece se acentuar em determinados grupos vulneráveis. Pessoas privadas de liberdade representaram 7,2\% dos casos de tuberculose em 2012, mesmo correspondendo a apenas $0,2 \%$ da população. Na população indígena a incidência é três vezes maior que a média nacional e a incidência na população em situação de rua varia de 48 a 67 vezes mais que a média geral (BRASIL. MS. SVS, 2013, 2015a).

Preocupações em torno das falhas e abandono do esquema básico de tratamento são uma constante, pois resultam no não rompimento da cadeia de transmissão e aumentam os casos de multirresistência. A elevação das taxas de infecção conjunta de tuberculose e HIV 
pode se tornar uma ameaça ao processo de controle e assistência das duas doenças. Cerca de 10\% dos casos de tuberculose em 2014 apresentaram resultado positivo para o teste de HIV, o que tem representado um desafio para os cuidadores uma vez que há poucas alternativas de medicamentos adequados para o uso concomitante (BRASIL. MS. SVS, 2015a; JAMAL; MOHERDAUI, 2007; NUNN et al., 2005).

Segundo o boletim epidemiológico da OMS de 2010, 16 países no mundo notificaram mil ou mais casos de Hanseníase. Nas Américas, o Brasil é o único da lista com mais de 30 mil casos notificados anualmente, ficando em segundo lugar no ranking mundial (WHO, 2010).

Apesar do número de recidivas por ineficácia do tratamento da hanseníase ser pequeno, em torno de $0,1 \%$, o percentual de abandono é alto e varia de $20 \%$ a $30 \%$ por ano, o que reduziu o percentual de cura, em torno de $84 \%$ em 2013 e, consequentemente, o controle da doença (BRASIL. MS, 2016a; MOREIRA, 2003).

As referências bíblicas que tratam a antiga "lepra" não apenas como uma doença, mas também associada ao pecado ou a castigos divinos e a lembrança histórico-cultural dos antigos "leprosários" brasileiros da década de 30 e 40 resultam numa estigmatização do portador de hanseníase. E neste ponto pode-se observar a importância sócio-sanitária do desenvolvimento de medicamentos para esse tipo de doença, pois é a partir da utilização da sulfona e seus derivados que é extinto o modelo de cuidado por isolamento e passo a passo é alterada a representação coletiva da doença. Como destacado no discurso coletivo do exhanseniano: "acabou aquele tabu...antigamente as pessoas tinham pavor, os próprios pacientes se isolavam do mundo..., mas hoje em dia com esse novo tratamento, o pessoal acredita na cura...isso é muito importante"(ROCHA et al., 2011).

A Doença de Chagas é uma doença prevalente em populações rurais de alguns países da América Latina, sendo considerada uma enfermidade relacionada a iniquidades sociais 
afetando principalmente pessoas em zona de pobreza. Estima-se que haja entre 12 a 14 milhões de pessoas infectadas na América Latina (DIAS, 2007).

A área endêmica da Doença de Chagas no país, conhecida no final dos anos 70, incluía 18 estados com mais de 2.200 municípios. Hoje, o perfil epidemiológico da doença apresenta um novo cenário com a ocorrência de casos e surtos na Amazônia Legal basicamente por transmissão oral. Surtos relacionados à ingestão de alimentos contaminados (caldo de cana, açaí, bacaba, entre outros) e casos isolados por transmissão vetorial extradomiciliar. No período de 2000 a 2013, foram registrados no Brasil 1.570 casos de Doença de Chagas aguda. Destes, $1081(68,9 \%)$ foram por transmissão oral, $100(6,4 \%)$ por transmissão vetorial, e 372 (22\%) não foi identificada a forma de transmissão (BRASIL. MS. SVS, 2015b; BRASIL. MS. 2016e)

A escassez de opções terapêuticas é crítica na Doença de Chagas. No Brasil só há disponibilidade do benznidazol que é efetivo para a doença na fase aguda, mas sem evidências definitivas na fase crônica (REYES; VALLEJO, 2011). Complicações nessa fase são uma preocupação para a área assistencial como a miocardiopatia chagásica que se desenvolve em $10 \%$ e $30 \%$ das pessoas que estão cronicamente infectadas com este parasita (TANOWITZ et al., 2009).

Foi num ensaio sobre a transmissão da Cólera nas águas contaminadas de Londres, publicado em 1855, que John Snow deu os primeiros passos para o desenvolvimento da epidemiologia e vigilância em saúde moderna. Hoje, sabe-se o quanto a Cólera e outras doenças de veiculação hídrica estão intimamente relacionadas com as deficiências de acesso à agua das populações mais pobres (CERDA; VALDIVIA, 2007).

A sétima pandemia de Cólera chegou ao Brasil em 1991 e até 2001 atingiu todas as regiões do País, resultando em um total de 168.598 casos e 2.035 óbitos, maioria dos casos na região Nordeste. Entre 1992 a 1994, ocorreu uma importante redução no número de casos, 
sendo esta queda acentuada a partir de 1995. A partir de 2011 os registros oscilam entre nenhuma detecção de caso a detecção de um número muito pequeno, com destaque para 21 casos no município de São Bento do Una, situado no agreste de Pernambuco. Pela drástica diminuição dos casos, hoje o trabalho do SUS está voltado à prevenção da Cólera e de outras doenças de veiculação hídrica, com critérios de qualidade em estações de fornecimento e pela distribuição nacional de hipoclorito de sódio, principalmente para as regiões com dificuldade de acesso à água potável (BRASIL. MS, 2016c).

Apesar do controle dos casos de Coléra, outras formas de Doenças Diarreicas Agudas continuam merecendo ações contundentes das autoridades sanitárias e estão associadas principalmente a ingestão de água e alimentos contaminados. A diarreia é a segunda causa de morte em crianças menores de cinco anos no mundo, responsável por quase um em cada cinco mortes. Contribui mais para a mortalidade infantil que a AIDS, a malária e o sarampo juntos. No Brasil, apesar da redução significativa a partir da década de 80 com a introdução da terapia de reidratação oral, a doença diarreica aguda ainda é causa importante de morbimortalidade, devido a condições precárias de vida e saúde dos indivíduos, em consequência da falta de saneamento básico e desnutrição crônica, entre outros fatores (BRASIL. MS. SVS, 2014b; RAZZOLINI; GÜNTHER, 2008).

A cultura de utilização do "soro caseiro" para a reidratação oral nas Doenças Diarreicas Agudas talvez seja um tema que deve ser abordado pelas ações de assistência farmacêutica, uma vez que já estão largamente disponíveis no país alterativas de sais para reidratação com melhor controle de concentração e osmolaridade e, portanto melhor desempenho, eficácia e segurança na utilização. Carmo et al. (2012) verificou que mesmo os preparados do soro caseiro feitos por agentes comunitários de saúde, possuíam composição inadequada em todos os casos, independentemente do método de diluição utilizado. 
Com quase 30 mil casos anuais, as Leishmanioses ainda necessitam de atenção e estratégias de controle mais efetivas do sistema de saúde brasileiro. A OMS estima que 350 milhões de pessoas estejam expostas ao risco de infecção em todo o mundo e que ocorram aproximadamente 1,5 a 2 milhões de novos casos das diferentes formas clínicas ao ano (GARCIA, 2011).

No Brasil, os últimos estudos sobre o tema tem alertado para o fenômeno da urbanização da Leishmaniose na sua forma visceral, associada a regiões de maior vulnerabilidade social seja em grandes capitais como Belo Horizonte ou em capitais menores como Aracaju (GÓES et al., 2013; WERNECK, 2008).

As manifestações clínicas da doença são graves, principalmente na sua forma visceral, onde o tratamento possui muitos efeitos colaterais e a letalidade varia entre $10 \% \mathrm{e}$ 20\% (ORTIZ; ANVERSA, 2015).

A viabilização do acesso a miltefosina, primeira alternativa oral para tratamento etiológico da Leishmaniose promete ser um reforço na adesão ao tratamento e no controle da doença (CONITEC, 2017).

Sem dúvida, um dos maiores desafios globais é o combate da Malária, que inclusive foi incluída como principal doença de enfrentamento junto com o HIV nas metas do milênio da ONU. No Brasil, o quadro atual é bem diferente dos 5 milhões de casos por ano entre a década de 40 e 50, representando hoje cerca de 300 mil casos-ano. Se anteriormente compreendia todo o território nacional, hoje está concentrada na região da Amazônia legal, onde fatores geográficos, econômicos e sociais facilitam a transmissão e limitam a aplicação de medidas de controle padrão (BARRETO et al., 2011).

Apesar do razoável número de fármacos disponíveis, os esquemas e regimes terapêuticos são relativamente complexos. Problemas diagnósticos, uso inadequado de 
antimaláricos, lacunas de evidências científicas e desenvolvimento de resistência são empecilhos atuais ao êxito da terapia (FREITAS et al., 2007).

Com, até então, pouca visibilidade dos entes governamentais, nos últimos anos as Geohelmintíases e outras parasitoses intestinais têm integrado parte dos programas de controle de endemias do SUS, a exemplo do programa Saúde na Escola que iniciou a “implantação do tratamento coletivo para geohelmintíases em crianças em idade escolar (5 a 14 anos de idade)", conforme Portaria GM/MS n ${ }^{\circ}$ 2556, de 28 de outubro de 2011 (BRASIL. MS, 2011). A Esquistossomose também possui quimioprofilaxia prevista pela regulamentação do Ministério da Saúde. O tratamento preventivo (coletivo) para controle de helmintos é uma recomendação da OMS nas regiões com maior percentual de incidência que dispõem de deficiências nos serviços de saúde e alta taxa de prevalência (WHO, 2006).

As arboviroses talvez sejam o maior desafio dentre as doenças infeciosas no Brasil, com proporções nacionais e incidência ascendente, a Dengue caracteriza-se pela ineficácia das políticas de saúde e sucessivas epidemias desde 1986. Em 2013 foram registrados quase 1 milhão e meio de casos em todo o território nacional (BARRETO et al., 2011; BRASIL. MS, 2016d). A emergência do vírus Chikungunya, também transmitido pelo Aedes aegypti, já causava apreensão da comunidade científica pelos seus efeitos na morbimortalidade das arboviroses no país (BRASIL. MS. SVS, 2015c; VASCONCELOS, 2015). Porém, o país e o mundo se viram surpreendidos para emergência do vírus Zica e a sua associação com o grande aumento dos casos de microcefalia, fato que tem mobilizado pesquisadores e sistemas de saúde para elucidar os mecanismos de transmissão e o desenvolvimento de vacinas, métodos de diagnóstico e alternativas de tratamento (VALLE et al., 2016).

Outras endemias oscilam entre sua importância epidemiológica e investimentos de controle no serviço de saúde. Como a Filariose que caminha para uma eliminação nacional, atualmente restrita a região metropolitana de Recife em áreas de baixo nível socioeconômico 
(BRASIL. MS. SVS., 2009). De maneira semelhante, a Oncocercose apresenta-se em fase de pré-eliminação, sem casos novos detectados e com foco residual em alguns distritos indígenas (BRASIL. MS. SVS, 2012). O Tracoma ganha cada vez mais atenção das ações do Ministério da Saúde, principalmente dado o resultado do último inquérito nacional realizado entre de 2008 e 2015 em que se confirmou a existência da doença em todo o território nacional com uma prevalência média de 4,1\% das 3 milhões de pessoas investigadas (BRASIL. MS., 2016b).

Acidentes por animais peçonhentos, raiva e tétano pós exposição são outros agravos importantes que se caracterizam basicamente por atingir trabalhadores rurais em idade produtiva, conforme demonstraram Bochner e Struchiner (2003) num levantamento do perfil de atingidos ao longo dos últimos 100 anos. A disponibilidade dos soros antipeçonhentos é crucial para a sobrevida dos acidentados, associada a uma redução drástica da letalidade ao longo dos anos, de cerca de $25 \%$ para cerca de $1 \%$, quando compara-se o período de 1901 a 2000 (BOCHNER; STRUCHINER, 2002, 2003).

Ponto controverso nas classificações de Doenças da Pobreza é a Infeção pelo HIV e outras Infeções Sexualmente Transmissíveis (IST). Apesar de alguns autores internacionais elencarem HIV/Aids no rol de Doenças da Pobreza, dado sua ampla disseminação em países em desenvolvimento e pouca estruturação dos serviços de saúde como na região da África subsaariana, nesse estudo, por não conseguir localizar dados significativos dessa relação no país, optamos por encarar essa infeção como uma doença global. A grande estruturação dos serviços de saúde no país para o atendimento dos portadores do HIV e o elevado potencial de inovação da área contribuíram para essa decisão (BRASIL. MS. SVS, 2010; PARKER; WILSON, 2000; STEVENS, 2004)

Já outras IST como sífilis possuem um componente de associação com a pobreza mais claro e chegou a ser incluída na estratégia "Brasil sem Miséria" (IOC, 2011). Não 
relacionado a qualquer comportamento de promiscuidade, que erroneamente e de forma preconceituosa pode ser associado aos grupos populacionais mais pobres, mas sim a questões relacionadas a falta de informação sobre essas infeções, acesso a métodos de prevenção e dificuldades de tratamento (WELLINGS et al., 2006).

O desabastecimento nacional da penicilina ocorridos no ano de 2015 e 2016 chamou atenção da sociedade Brasileira e pode ter contribuído para triplicar o número de casos da doença (BRASIL. MS, 2015; COOPER et al., 2016).

\section{Doenças e agravos relacionados à pobreza não infeciosos}

Como relatado anteriormente, a utilização do termo Doenças da Pobreza além de centrar no componente social dessas doenças e agravos, também permite o olhar para outras condições não transmissíveis decorrentes de iniquidades em saúde, como deficiências nutricionais, abuso de drogas, violência doméstica ou doenças mais comuns a população negra por exemplo.

Os avanços nas políticas sociais e a ampliação do acesso a ações de saúde, como a Estratégia de Saúde da Família, têm contribuído para a redução contínua do quadro de desnutrição populacional, principalmente entre crianças que comumente são mais afetadas pela restrição alimentar, prejudicando seu estado geral de saúde e crescimento.

O estudo "Antropometria - estado nutricional de crianças, adolescentes e adultos no Brasil" realizado pelo Instituto Brasileiro de Geografia e Estatística (IBGE) demonstrou que de 1974-1975 para 2008-2009, a prevalência de déficit de altura em crianças de 5 a 9 anos de idade diminui de $29,3 \%$ para $7,2 \%$, no sexo masculino, e de $26,7 \%$ para $6,3 \%$, no sexo feminino. Porém a desigualdade socioeconômica ainda é definidora para o bem estar social das crianças brasileiras, pois em menores de 5 anos de idade e renda familiar menor que $1 / 4$ de salário mínimo per capita, o déficit de altura chega a 8,2\%, contrastando com as crianças 
da mesma faixa etária e com renda familiar superior a 5 salários mínimos, onde o déficit de altura é de 3,1\% (IBGE, 2010).

Apesar da Desnutrição infantil ter reduzido ao longo dos anos no país, em alguns grupos populacionais específicos há maior prevalência: especialmente entre indígenas (26\%), quilombolas $(11,6 \%)$ e beneficiários do Programa Bolsa Família (9,2\% na Região Norte) (BRASIL. MS. SAS, 2015).

Um estudo transversal envolvendo 2.001 crianças de dez municípios da Bahia ilustrou os efeitos dessa desigualdade quando observou que condições como ter pai desempregado, mãe com baixa escolaridade e dormir com mais de uma pessoa na cama estava associado à presença de anemia, déficit de consumo de lipídeos e retinol (ASSIS et al., 2007). Dados que corroboram com a tese de que a insegurança alimentar a que está exposta parte da população não tem relação com a produção de alimentos e sim com um problema crônico de desigualdade de um modelo econômico que privilegia o grande agronegócio e resultou na saída de mais de 30 milhões de pequenos agricultores do campo nos últimos anos (PEDRAZA, 2005).

Ações governamentais de acesso a alguns tipos de suplementos têm objetivado a redução de problemas nutricionais, a exemplo dos Programas de Suplementação de Ferro, Programa Nacional de Suplementação de Vitamina A e mais recentemente com a estratégia de fortificação da alimentação infantil com micronutrientes em pó (BRASIL. MS. SAS, 2016; Conitec, 2014).

Outro grave problema de saúde pública global que pode estar associado à pobreza é a Drogadição ou Toxicodependência. Segundo relatório do escritório das Nações Unidas sobre drogas e crime cerca de 246 milhões de pessoas ( $5 \%$ da população mundial entre 15 e 64 anos de idade) usaram drogas ilícitas em 2013. Destes 27 milhões são considerados 
"usuários problemáticos", ou seja, com algum transtorno mental ou comportamental grave associado ao uso da droga (UNODC, 2015).

O uso de drogas, sejam elas, lícitas ou ilícitas, é culturalmente generalizado nos diversos seguimentos populacionais brasileiros. Porém, o abuso das substâncias mais nocivas e os danos relacionados a dependência química é mais comum aos mais pobres. Exemplo disso é o consumo de crack no Brasil que possui atualmente cerca de 370 mil usuários regulares nas principais capitais do país. Sendo que o perfil do usuário é homem (78,7\%), não branco (80\%), a maioria sem trabalho regular (65\%), 40\% em situação de rua e 41,6\% foram detidos por delitos no último ano (BRASIL. MS. FIOCRUZ, 2014).

A condição de vulnerabilidade dessas pessoas sobrepõe a condição de dependência com outros agravos como a infecção pelo HIV, prevalente em $8 \%$ das mulheres e $4 \%$ dos homens usuários de crack. Mais da metade das mulheres ficaram grávidas pelo menos uma vez desde o início do uso da droga e 44,5\% das entrevistadas relataram histórico de violência sexual durante a vida (BRASIL. MS. FIOCRUZ, 2014).

Apesar de 79,8\% dos usuários de crack brasileiros desejarem passar por tratamento para a dependência, apenas $20 \%$ deles foram a algum serviço de saúde nos últimos 30 dias e somente 6,3\% acessaram especificamente um Centro de Atenção Psicossocial para atendimento a usuários de álcool, crack e outras drogas (Caps-AD) (BRASIL. MS. FIOCRUZ, 2014).

Outros agravos que atingem desfavoravelmente os mais pobres e necessitam de maior atenção do sistema de saúde são os decorrentes das violências doméstica, sexual e as agressões por parte de agentes públicos. O relatório de 2013, emitido pelo sistema de Vigilância de Violências e Acidentes (VIVA) do Ministério da Saúde demonstra uma diferença de gênero nos casos que chegam as emergências, sendo a violência doméstica a causa mais prevalente em mulheres $(47 \%)$ e a violência em via pública, parte delas 
acometida por agentes públicos, a causa mais prevalente entre os pacientes masculinos. Em ambos os casos os agressores são predominantemente homens 77,4\%. Schaiber et al., (2005) relata que os homens são mais susceptíveis ao envolvimento em situações de violência na esfera pública, por agravos de acidentes de trânsito e pela violência na modalidade de homicídios (BRASIL. MS. SVS, 2013c).

A associação entre gênero e etapas de vida também delineiam um perfil quanto os tipos de violências: onde os casos de violência sexual se sobressaem entre meninas na infância $(38,9 \%)$ e na adolescência $(33,9 \%)$; a violência psicológica destaca-se em mulheres adultas $(37,3 \%)$ e idosas $(35,5 \%)$; e a violência física é frequente em todas as etapas da vida, mas é na vida adulta que, independente do sexo, esta violência alcança as maiores proporções.

A Violência Doméstica e Sexual de mulheres se destaca pela subnotificação e por atingir grupos mais vulneráveis. A subnotificação da violência sexual é motivada também pela dificuldade da sociedade em lidar com a questão nos diferentes setores: no judiciário, na segurança pública e na saúde. É um problema que revela uma moral julgadora e por vezes culpabilizadora da mulher vítima de estupro e de outras formas de violência, que estão associadas à baixa renda, menor grau de escolaridade e história prévia de violência doméstica (SOUZA; ADESSE, 2005).

A estruturação de serviços de saúde capacitados para o atendimento de vítimas de violência sexual não tem sido uma tarefa simples. Além das queixas físicas e transtornos comportamentais decorrentes do evento traumático é necessário assegurar a rápida assistência para cuidado de doenças sexualmente transmissíveis e gravidez indesejada (VILLELA; LAGO, 2007).

A disponibilização oportuna de medicamentos é necessária para a correta assistência às vítimas de violência sexual. Antirretrovirais para a profilaxia pós-exposição de risco ao 
HIV é uma medida fundamental para evitar o contágio e a anticoncepção de emergência para prevenir uma gravidez. Ambas as intervenções devem ter início num período inferior a 72 horas para êxito e, portanto necessitam de uma estratégia de acesso rápida e eficaz (BRASIL. MS. SAS, 2011; BRASIL. MS. SVS, 2015d).

Questões críticas relacionadas aos locais e normas de acesso a esses medicamentos profiláticos começam a gerar debate e precisam de atenção da assistência farmacêutica. Entende-se que restringir o acesso a esses medicamentos em unidades básicas de saúde ou centros de referência com horários limitados de atendimento não suprem a demanda das vítimas de violência sexual que procuram o SUS (FAÚNDES et al., 2006; VILLELA; LAGO, 2007).

A pouca disponibilidade de profilaxia da infecção do HIV nas unidades de urgência do país e a exigência de receita médica para acesso a contracepção de emergência tanto em farmácias públicas quanto privadas tem sido apontadas como barreiras de acesso a esses medicamentos (FAÚNDES et al., 2006; PAIVA; BRANDÃO, 2012).

Desigualdades étnicas presentes na população brasileira, relacionadas principalmente a migração forçada de povos africanos, resultaram em iniquidades de saúde que precisam de atenção do SUS. A Anemia Falciforme e outras Doenças Falciformes são o principal conjunto de doenças de origem genética que atingem majoritariamente esse grupo populacional.

Pela dificuldade de superar desigualdades decorrentes de mais de 200 anos de escravidão é necessário um olhar equitativo para doenças que atingem a população negra. População que apresenta menor acesso a políticas públicos, com maior nível de analfabetismo e menor grau de escolaridade quando comparada a população geral. No que se refere à pobreza, estimativas revelam que os negros correspondem a $65 \%$ da população 
pobre e $70 \%$ da população extremamente pobre, embora representem $45 \%$ da população brasileira (BRASIL. MS. SGEP, 2013).

Doenças e agravos não infecciosos decorrentes das deficiências nutricionais, do uso de drogas de maior potencial de danos, da violência doméstica e sexual ou que atingem a população afrodescendente, mesmo atingindo desproporcionalmente os mais pobres, nem sempre estão articulados a programas de combate às iniquidades em saúde ou em políticas farmacêuticas para doenças da pobreza, apesar da crescente citação de pesquisadores e instituições sanitárias (ASSIS et al., 2007; BRASIL. MS. SVS, 2014a; BRASIL. MDS, 2014; IOC, 2011; PARKER; WILSON, 2000; SACHS, 2005; SCHRAMM et al., 2004; SOUZA; ADESSE, 2005; STEVENS, 2008). 


\section{METODOLOGIA}

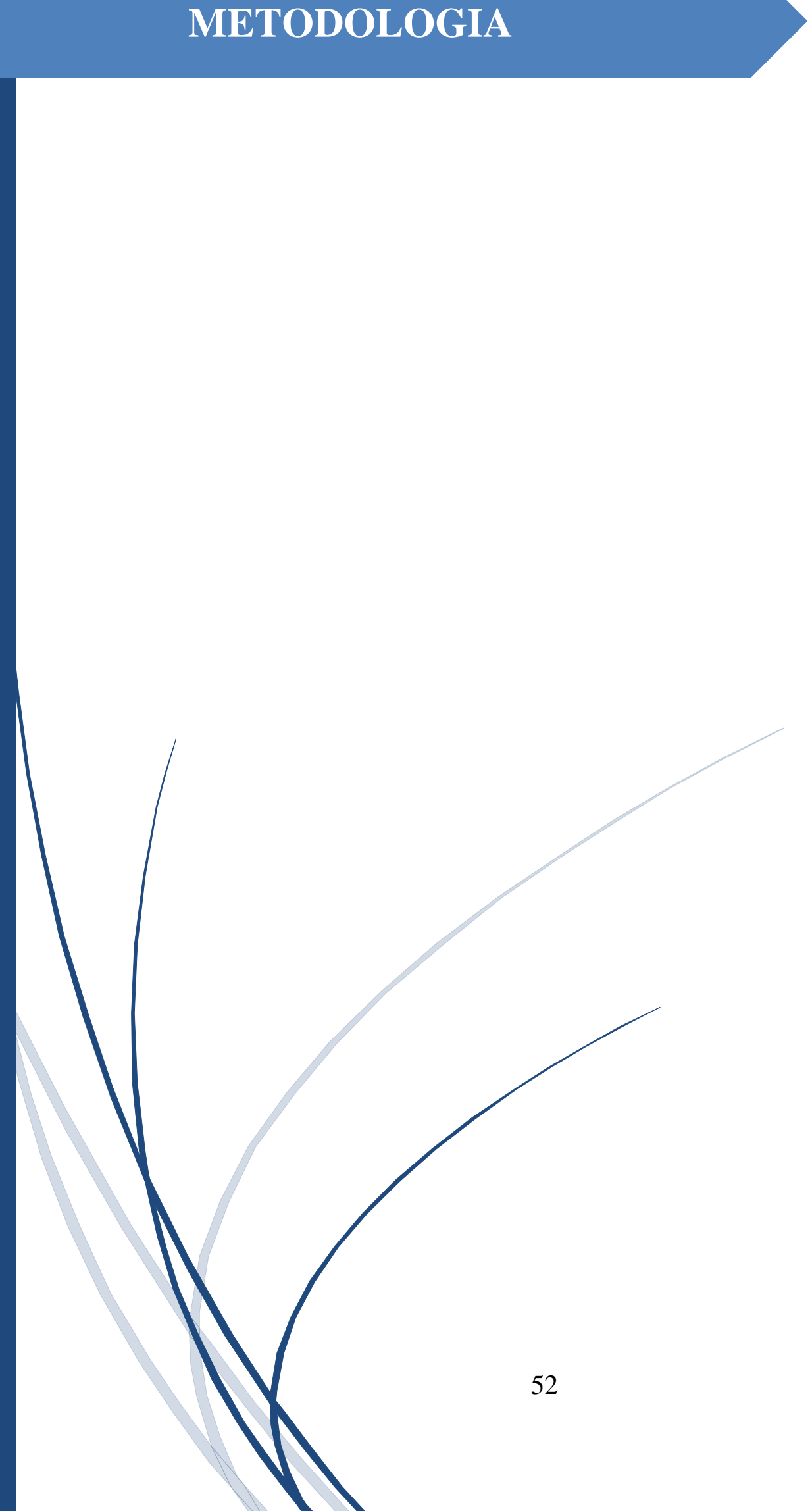




\section{METODOLOGIA}

Este trabalho é composto por ferramentas e estratégias metodológicas diversificadas comuns a chamada "pesquisa avaliativa" com o objetivo de ampliar a compreensão e analisar as políticas farmacêuticas para doenças relacionadas à pobreza. Esse tipo de metodologia é característico das pesquisas voltadas para a avaliação de serviços e políticas de saúde por conta da complexidade do fenômeno social investigado (CONTANDRIOPOULOS, 1997).

A pesquisa avaliativa, embora não se apresente com um consenso de modelo metodológico, se configura como uma estratégia que utiliza diferentes abordagens do conhecimento a fim de obter teses de pesquisa abrangentes, uma opção adequada para a análise de políticas e fenômenos sociais (MINAYO; SANCHES, 1993).

Este trabalho está estruturado em três fases: (i) uma fase exploratória onde foram realizadas buscas e análises da literatura científica sobre o tema, a fim de elaborar uma revisão integrativa das políticas de assistência farmacêutica para essas doenças (capítulo 1), além de subsidiar os aspectos mais relevantes para a fundamentação teórica deste trabalho; (ii) uma segunda fase de análise das políticas e ações prévias à efetivação do acesso a medicamentos, verificando os aspectos relacionados ao desenvolvimento de pesquisas clínicas para doenças da pobreza (capítulo 2), o panorama da regulação e incorporação de medicamentos no SUS (capítulo 3); e (iii) na última fase, análises relacionadas a efetivação do acesso a medicamentos para doenças da pobreza, abordando questões relacionadas ao financiamento e aquisição (capítulo 4), assim como o padrão de qualidade das diretrizes clínicas que disciplinam sua utilização (capítulo 5).

Nos diferentes capítulos adotou-se o padrão para classificação geral das doenças, a partir da adaptação de propostas anteriores da OMS e MSF (MSF, 2001; WHO, 2012):

1. Doenças e Agravos Globais Não Transmissíveis (Ex. Diabetes, Hipertensão); 
2. Doenças e Agravos Globais Transmissíveis (Ex. HIV, Hepatites);

\section{Doenças e Agravos Relacionados à Pobreza:}

3.1. Doenças Infeciosas Imunopreveníveis (Ex. Sarampo, Poliomielite);

3.2. Doenças Infeciosas Não Imunopreveníveis (Ex. Hanseníase, Leishmanioses);

3.3. Outras Doenças da Pobreza ou Não Infeciosas (Ex. Anemias Carenciais);

Abaixo uma visão geral dos processos metodológicos que serão mais detalhados nos capítulos subsequentes:

\section{Fase I - Exploratória: Revisão da literatura das políticas farmacêutica para doenças relacionadas à pobreza no Brasil.}

Nesta etapa foi realizada uma revisão da literatura com o objetivo de discutir e analisar aspectos relacionados às políticas farmacêuticas para doenças relacionadas à pobreza, discutindo o impacto das ações mercadológicas e governamentais na garantia do acesso integral.

Foi utilizado o método de revisão com uma abordagem que permite a inclusão de estudos com metodologias diversas (pesquisa experimental e não experimental; quantitativa ou qualitativa), com maior potencial de abrangência e apresentação de perspectivas variadas sobre um fenômeno, chamado por alguns autores de "revisão integrativa" ou "revisão de escopo" por outros (LEVAC et al, 2010; WHITTEMORE; KNAFL, 2005).

Como critério para busca, foram utilizados os seguintes descritores previamente selecionados nas bases Medical Subject Headings (MeSH) e Descritores em Ciências da Saúde (DeCS): “doenças negligenciadas" or "controle de doenças transmissíveis" or "doenças endêmicas" combinados com os descritores "assistência farmacêutica" and "Sistema Único de Saúde” and "políticas públicas de saúde” and "programas nacionais de 
saúde"; and "pesquisa clínica". Foram ainda incluídos os descritores não localizados no Mesh e DeCS: "doenças da pobreza"; "doenças relacionadas à pobreza".

Pela característica abrangente do método de revisão, as buscas foram realizadas no portal de pesquisas da Biblioteca Virtual de Saúde (BVS) que abrange um vasto número de bases de dados, como: Literatura Latino-Americana e do Caribe em Ciências da Saúde (Lilacs), Medical Literature Analysisand Retrieval System Online (Medline) e Scientific Electronic Library Online (Scielo), principais fontes dos estudos selecionados.

Durante a seleção dos estudos foi verificado se abordavam temas relacionados a doenças da pobreza, políticas de assistência farmacêutica ou determinantes sociais de saúde. Como critérios de exclusão estavam os artigos duplicados, não acessíveis em texto completo, resenhas, anais de congresso, cartas ao editor e artigos que não abordaram diretamente o tema deste estudo.

Foram analisados por etapas: o conteúdo dos títulos, resumos e então os textos completos mediante disponibilidade de acesso, descritos de maneira detalhada no Capítulo 1 deste documento.

\section{Fase II - Pré-Acesso: Análise das pesquisas clínicas com medicamentos com foco nas doenças da pobreza}

Para análise do quadro de pesquisas de doenças relacionadas à pobreza no país foram levantados os registros de ensaios clínicos de 2012 a 2015. Para isso foram levantados todos os registros de ensaios clínicos incluídos no Registro Brasileiro de Ensaios Clínicos (Rebec) e no clinicaltrial.gov.

Foram selecionados estudos que envolviam a pesquisa de novos fármacos melhoria ou avaliação dos tratamentos existentes. Para análise dos dados foram verificados os 
seguintes parâmetros: (i) doença ou agravo; (ii) patrocínio; (iv) local do estudo; (vi) fase do estudo.

\section{Fase II - Pré-Acesso: Panorama da regulação do mercado e incorporação de medicamentos para doenças da pobreza no SUS.}

Para investigação dessa fase, foram realizadas análises em 5 etapas:

Na primeira etapa, foram revisadas normas legais da Agência Nacional de Vigilância Sanitária (Anvisa) com potencial aplicação na regulação de medicamentos para doenças da pobreza.

$\mathrm{Na}$ segunda etapa, as normativas nacionais foram comparadas com normas de outras agências internacionais, a saber Food and Drug Administration (FDA) e European Medicines Agency (EMA).

$\mathrm{Na}$ terceira etapa, foram realizadas buscas por registros ativos dos medicamentos para doenças da pobreza, sendo utilizados os bancos de dados da Anvisa e da Câmara de Regulação do Mercado de Medicamentos (CMED).

$\mathrm{Na}$ quarta etapa, foram também revisados os itens incluídos nas diferentes edições da Relação Nacional de Medicamentos Essenciais - Rename. Foram analisadas as edições entre os anos 2006 a 2014 publicadas pelo Ministério da Saúde.

Por fim, na quinta etapa, foram revisados os relatórios de recomendação emitidos pela Comissão Nacional de Incorporação de Tecnologias no SUS (Conitec) no período entre 2012 (ano de início dos trabalhos desse comitê) a 2015. 
Fase III - Acesso: Estratégias de Financiamento e Aquisição de medicamentos para Doenças da Pobreza

Para análise do componente de financiamento e aquisição de medicamentos para doenças da pobreza foram verificadas informações do nível federal. Como este ente é o responsável pela maior parte do financiamento de medicamentos para essas doenças, foram analisadas as aquisições de medicamentos relacionadas na última década durante o período de 2005 a 2014.

Dentre os parâmetros analisados estão: (i) número de medicamentos; (ii) tipo de fornecedor/produtor; (iii) custo direto; (iv) custo médio por tratamento por tipo de doença. Comparações com aquisições para doenças globais transmissíveis e não transmissíveis serão realizadas, assim como identificação das estratégias governamentais para superar a escassez de oferta de medicamentos para doenças da pobreza.

\section{Fase III - Acesso: Padrões de cuidado e assistência terapêutica para doenças da pobreza.}

Foram levantados documentos vigentes com diretrizes clínicas para prevenção e tratamento de doenças e agravos relacionados à pobreza emitidas pelo Ministério da Saúde.

Não foram incluídas nas análises, documentos de estados, municípios ou outras instituições de saúde. Também não foram considerados cartazes, folderes ou documentos semelhantes com estrutura diversa de guias ou protocolos de cuidado, ainda que em alguns casos houvesse orientações de tratamento.

Para fins de comparação com as diretrizes alvo do estudo foram selecionadas outras diretrizes não relacionadas com agravos e doenças da pobreza, publicadas no ano de 2015 pelo Ministério da Saúde. 
Para avaliação da qualidade das diretrizes clínicas publicadas foi utilizada a ferramenta "Appraisal of Guidelines for Research and Evaluation" (AGREE). A última edição do AGREE II conta com 23 itens organizados em 6 diferentes domínios de qualidade.

As diretrizes selecionadas para este estudo foram avaliadas por quatro especialistas com experiências prévias na elaboração de diretrizes clínicas, de forma independente e seguindo orientações da versão em língua portuguesa do AGREE II (AGREE NEXT STEPS CONSORTIUM, 2009).

Foram realizados os testes estatísticos de kappa para verificação da conformidade de avaliação entre os juízes e o "teste $t$ ” para verificar diferença estatística entre os dados.

\section{Coleta de dados e aspectos éticos:}

Os dados foram coletados por meio de pesquisa documental, mediante acesso direto as bases de dados selecionados ou solicitação aos órgãos responsáveis via Lei $\mathrm{n}^{\mathrm{o}}$ 12.527/2011 que regulamenta a garantia de acesso a informações pelos órgãos da gestão pública.

Por não envolver sujeitos de pesquisa de qualquer tipo, não houve submissão do projeto em comitê de ética em Pesquisa em conformidade com a Resolução no 466/12 do Conselho Nacional de Saúde. 


$$
T
$$


"Somos muitos Severinos iguais em tudo na vida: na mesma cabeça grande que a custo é que se equilibra, no mesmo ventre crescido sobre as mesmas pernas finas e iguais também porque o sangue, que usamos tem pouca tinta. ....morremos de morte igual, mesma morte severina: que é a morte de que se morre de velhice antes dos trinta, de emboscada antes dos vinte de fome um pouco por dia - de fraqueza e de doença é que a morte severina ataca em qualquer idade, e até gente não nascida" (João Cabral de Melo Neto). 


\section{CAPÍTULO I - DOENÇAS DA POBREZA NO BRASIL: UMA REVISÃO DAS POLÍTICAS FARMACÊUTICAS PARA POPULAÇÕES VULNERÁVEIS}

\section{Resumo:}

O presente capítulo faz uma análise do panorama atual, avanços e desafios das políticas farmacêuticas brasileiras para populações acometidas de doenças relacionadas à pobreza relatados por diferentes autores. Com o intuito de ampliar a discussão sobre o tema, foi realizada uma revisão de escopo da literatura científica. Na fase final da revisão, 40 trabalhos foram incluídos nesse estudo. Os resultados e principais teses abordadas foram organizadas em três aspectos principais: (i) a pesquisa, desenvolvimento e produção de novos fármacos para essas doenças; (ii) as políticas de acesso aos medicamentos já disponíveis; (iii) e o direito à integralidade da assistência farmacêutica.

\section{Palavras-Chave:}

Pobreza; Doenças Negligenciadas; Equidade no Acesso; Integralidade em Assistência Farmacêutica; Vulnerabilidade;

\section{Introdução:}

As iniquidades em saúde se caracterizam como desigualdades que atingem indivíduos ou a coletividade de forma injusta, onde componentes socioeconômicos influenciam diretamente na condição de saúde-doença das pessoas e no seu acesso aos serviços de assistência. Exemplo maior dessas iniquidades são as chamadas doenças relacionadas com a pobreza (BUSS; PELLEGRINI FILHO, 2006; IOC, 2011; WHO, 2012).

Doenças que não são apenas consequência da pobreza, mas são estimuladoras da pobreza, pois retiram dos indivíduos sua força de trabalho, muitas vezes conferem incapacidades físicas e de aprendizado, diminuindo as chances de desenvolvimento humano. São doenças segregadoras, com distribuição desigual entre os brasileiros de diferentes classes sociais e regiões do país, que afetam decisivamente a vida das populações de regiões 
periféricas das grandes cidades, zonas rurais, comunidades carentes, com alto impacto na morbidade e mortalidade desses grupos (IOC, 2011).

Entende-se que para a superação desse grave problema de saúde pública são necessárias ações que vão além da realização de investimentos em novos medicamentos ou mesmo na melhoria dos sistemas de saúde. No entanto, este artigo estará centrado no campo dos medicamentos, que também possui características que seguem a lógica da desigualdade social e das iniquidades em saúde, com um simbólico paradoxo entre a falta de acesso e a medicamentalização a depender da doença em questão ou seguimento populacional (ROZENFELD, 2008).

A negligência da indústria farmacêutica no investimento de pesquisa e desenvolvimento de novos medicamentos tem sido continuamente apontado pela literatura. Ações e políticas governamentais possuem uma menor atenção da crítica e da pesquisa em geral (SANTANA; LEITE, 2016; STEVENS, 2004; TROUILLER et al., 2001).

Nesse sentido, este artigo tem como objetivo analisar como as políticas farmacêuticas brasileiras para doenças da pobreza têm sido abordadas na literatura científica, verificando o relato dos principais avanços, pontos críticos e necessidades levantadas pelos autores.

\section{Métodos:}

Foi utilizado o método de revisão de escopo ou "scoping study". Que se caracteriza pela atividade de "mapeamento" do tema investigado a fim de verificar a amplitude e profundidade do campo de estudo. Normalmente usada para assuntos que possuem múltiplas formas de abordagem nos trabalhos publicados, nem sempre com harmonização metodológica, comum a ensaios clínicos por exemplo. Esse tipo de revisão que permite a inclusão de estudos com metodologias diversas, com maior potencial de abrangência e apresentação de perspectivas variadas sobre um fenômeno aproxima-se mais do que tem se 
chamado por alguns estudos brasileiros de revisão integrativa (LEVAC et al., 2010; WHITTEMORE; KNAFL, 2005)

Como critério para busca, foram utilizados os seguintes descritores e suas versões em inglês, previamente selecionados nas bases Medical Subject Headings (MeSH) e Descritores em Ciências da Saúde (DeCS): "doenças negligenciadas" or "controle de doenças transmissíveis" or "doenças endêmicas" combinados com os descritores "assistência farmacêutica" and "Sistema Único de Saúde" and "políticas públicas de saúde" and "programas nacionais de saúde"; and "pesquisa clínica". Foram ainda incluídos os descritores não localizados no Mesh e DeCS: "doenças da pobreza”; "doenças relacionadas à pobreza".

Pela caraterística abrangente desse tipo de revisão, as buscas foram realizadas em agosto de 2015 no portal de pesquisas da Biblioteca Virtual de Saúde (BVS), que abrange um conjunto de bases de dados de interesse para o tema, como: Literatura Latino-Americana e do Caribe em Ciências da Saúde (Lilacs), Medical Literature Analysis and Retrieval System Online (Medline) e Scientific Electronic Library Online (Scielo), principais fontes dos estudos selecionados.

Durante a seleção dos estudos foram verificados como critérios de inclusão se esses abordavam temas relacionados a doenças relacionadas à pobreza e políticas de assistência farmacêutica, com abordagem em pelo menos um desses três subtemas:(i) pesquisa, desenvolvimento e produção de novos fármacos para essas doenças; (ii) políticas de acesso aos medicamentos já disponíveis; (iii) e integralidade da assistência farmacêutica.

Como critérios de exclusão estavam os trabalhos publicados há mais de 10 anos, duplicados, não acessíveis em texto completo, resenhas, anais de congresso, cartas ao editor, trabalhos que não abordaram nenhum dos subtemas deste estudo e que não tratavam da realidade brasileira. 


\section{Resultados:}

Após busca na base de dados foram verificados 269 trabalhos, que passaram então pelas fases de análise de títulos, resumos e finalmente leitura do texto completo (Figura 3).

Figura 3 - Fluxograma de tratamento dos estudos durante o processo de revisão

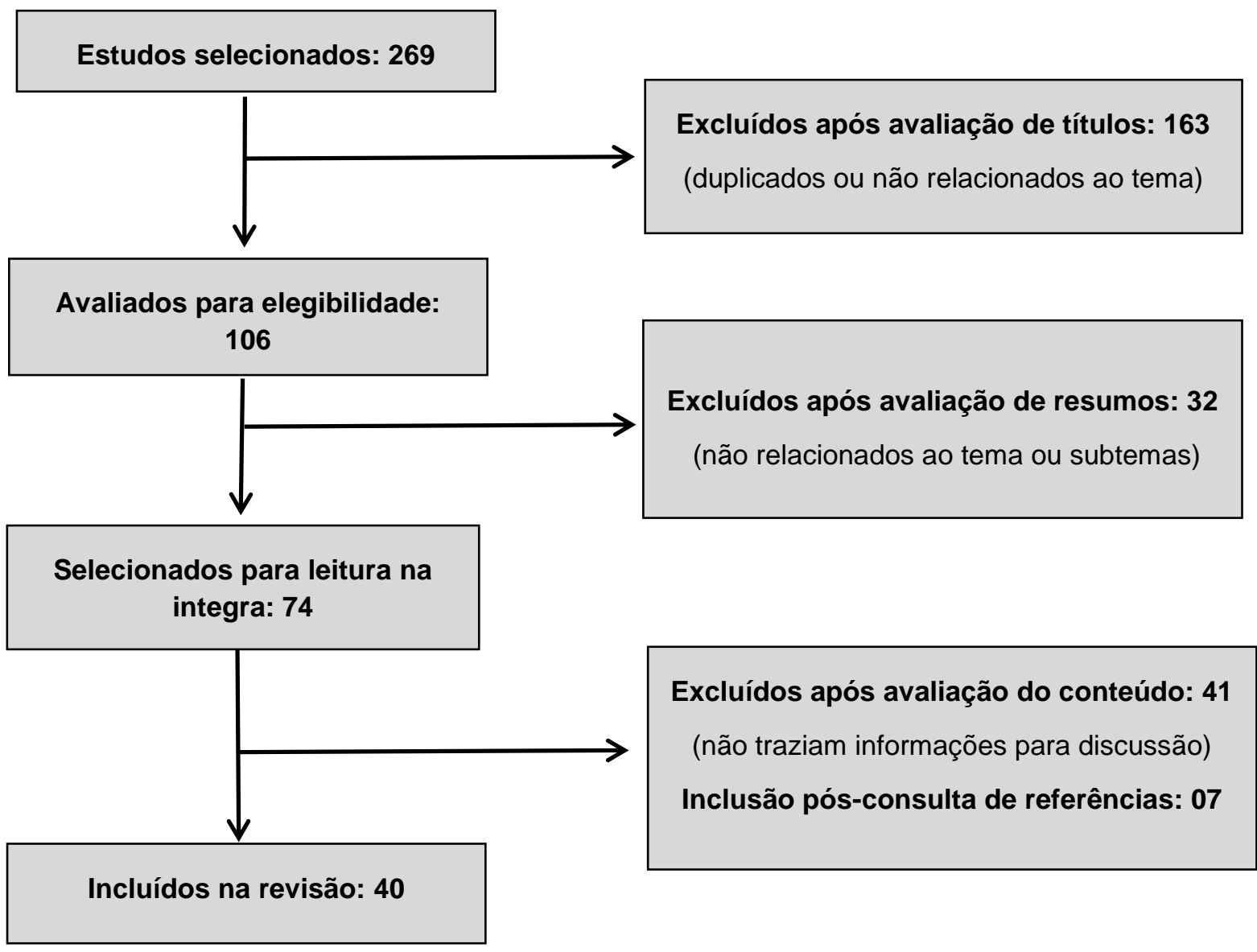

Fonte: O Autor

Em todas as etapas, 236 foram excluídos por estarem duplicados, não relacionados ao tema e subtemas ou que atendiam aos critérios de exclusão. Na leitura dos textos foram identificados nas referências dos trabalhos analisados mais 07 trabalhos que atendiam os critérios de inclusão e contribuíam para o estudo do tema. 
Foram incluídos nesta revisão então 40 estudos descritos na Tabela 1. Dentre os trabalhos selecionados 31 eram artigos publicados em periódicos científicos, 05 trabalhos de pós-graduação scritu sensu e 04 documentos de instituições que abordaram questões relacionadas a doenças da pobreza, a saber: Academia Brasileira de Ciências (ABC, 2010), Ministério da Saúde (BRASIL. MS. SVS, 2014a), iniciativa Medicamentos para Doenças Negligenciadas (DNDi, 2012), Instituto de Pesquisa Econômica Aplicada (GARCIA, 2011).

Tabela 1 - Caracterização dos trabalhos selecionados

Trabalhos Selecionados

Tipo de trabalho

Barreto et al (2011); Bastos (2006); Crispim et al (2014); De Paula et al (2009); DECIT (2010); Domingues et al (2005); Domingues e Teixeira (2013); Feijó e Sáfadi (2006); Gava et al (2010); Kornis et al (2014); Hochman (2009); Hochman (2009b); Hochman (2010); Hochman (2011); Jamal e Moherdaui (2007); Marco et al (2012); Nascimento (2011); Oliveira et al (2006); Osorio-deArtigo original publicado Castro et al (2009); Penna et al (2013); Perreira e Freitas (2008); em periódico científico Pontes (2009); Pontes et al (2010); Raw e Higashi (2008); Santos (2007); Santos et al (2012); Silva e Nicoletti (2013); Silveira e Junior (2011); Souza (2005); Vieira (2010); Waldman (2011);

Resende (2013); Witzel (2009); Magalhães (2010); Muniz (2013); Trabalho de pós-graduação Torres (2013); Stricto sensu

ABC (2010); Brasil (2014); DNDi (2012); Garcia (2011); Estudo/Relatório de instituições

Para análise do panorama das políticas farmacêuticas para doenças da pobreza as teses e temas abordados nos trabalhos foram organizados em três partes descritas a seguir:

\section{Pesquisa, desenvolvimento e produção de fármacos: direito negado pelo mercado.}

Conduzidas atualmente por grandes corporações de caráter global, historicamente as atividades de Pesquisa e Desenvolvimento (P\&D) de fármacos das indústrias farmacêuticas estão concentradas em alguns poucos países desenvolvidos com destaque para Estados Unidos, Alemanha, Suíça e Reino Unido. Apesar de haver uma relativa tendência de difusão 
da área para alguns países em desenvolvimento (KORNIS; BRAGA; PAULA, 2014; VARGAS et al., 2012).

Estima-se que a participação dos investimentos em testes clínicos em outros centros não tradicionais como Brasil, Índia e China tenha passado de 29\%, em 2001, para mais de 50\%, em 2011, com maior concentração em testes de fase III, mais longos, com maior número de participantes, mais caros, porém com menor densidade de conhecimento envolvido (BASTOS, 2006; GOMES et al., 2012).

Apesar dessa inserção, as pesquisas de novos medicamentos não atendem as reais necessidades da sociedade. Isso fica claro quando se observa nas últimas décadas, cerca de 90\% dos problemas de saúde recebem apenas $10 \%$ dos investimentos em pesquisa de medicamentos, ou quando se verifica que até 2004, apenas $1 \%$ dos fármacos registrados foram destinados às doenças tropicais ou relacionadas com a pobreza, mesmo representando aproximadamente $12 \%$ da carga global de doenças (BASTOS, 2006; CHIRAC; TORREELE, 2006; SANTOS et al., 2012).

A lógica baseada no lucro pressupõe o privilégio na busca de tratamentos para doenças crônicas degenerativas e para o atendimento de populações que possuam capacidade de pagamento ou de pressão por financiamento governamental.

Desse modo, é imperativo que os governos de países em desenvolvimento assumam o protagonismo da pesquisa e desenvolvimento de medicamentos para doenças da pobreza. Protagonismo este que muitas vezes foi assumido por países desenvolvidos, culminando com descoberta de medicamentos para diversas doenças infecciosas.

Investimentos frequentemente ligados às questões de colonização e envolvimento militar de países ricos em países tropicais, como no caso dos fármacos para tuberculose e vários outros antibióticos. A malária é um bom exemplo disso, pois seus principais medicamentos foram desenvolvidos após incentivos de pesquisa do governo e laboratórios 
norte-americanos, dado o grande número de baixas de soldados na primeira e segunda guerras mundiais. Nesta última, a malária foi responsável por mais de 21 mil internações hospitalares, superior inclusive as internações por ferimentos de combate com cerca de 17 mil casos (BASTOS, 2006; CAMPOS, 1999).

A dependência externa e pouca atuação brasileira na pesquisa de novos fármacos é uma tese constante nos artigos. Oliveira et al. (2006) destacam que de maneira geral, as atividades da indústria nacional não estão centradas no processo de $\mathrm{P} \& \mathrm{D}$, pois desde sua concepção estão associados ao atendimento de parte da demanda de assistência farmacêutica básica e à cobertura das lacunas existentes na produção nacional de vacinas e medicamentos essenciais (OLIVEIRA et al, 2006).

Vagas et al (2012) e George et al (2014) destacam que mesmo com o fomento governamental para fortalecimento da indústria nacional com programas específicos do Banco Nacional de Desenvolvimento Social (BNDS), ainda há pouco investimento na área de P\&D tanto em termos do padrão internacional do mercado farmacêutico como em relação a outros setores industriais do país que investem em média duas vezes mais que as indústrias farmacêuticas nacionais (KORNIS et al, 2014; VARGAS et al., 2012). Santos et al. (2012) e Bastos (2006) chamam atenção para o grande potencial produtivo dos laboratórios oficiais e sua função estratégica para o acesso a medicamentos para doenças da pobreza, porém destacam sua pouca contribuição para a pesquisa e inovação para essas doenças (BASTOS, 2006; SANTOS et al., 2012).

Para incentivar o desenvolvimento de pesquisas, o Ministério da Saúde desde 2003 tem lançando editais temáticos para doenças negligenciadas como malária, hanseníase e dengue, que já superam o valor acumulado de 90 milhões de reais (DECIT, 2010). Como líder em investimentos dentre os países em desenvolvimento, o Brasil tem aumentado os incentivos governamentais em P\&D para essas doenças, que estão em torno de R 75 
milhões ao ano, vindos principalmente do Ministério da Ciência, Tecnologia e Inovação, através de suas agências de fomento (PONTES, 2009). Apesar de louvável, a iniciativa do governo brasileiro ainda está longe de resolver o problema da falta de medicamentos, uma vez que os incentivos são difusos e insuficientes para o desenvolvimento de novos fármacos. Estima-se que o custo varie entre 10 e 40 milhões de euros para tratamentos melhorados e de 100 a 150 milhões de euros para uma nova entidade molecular (ABC, 2010; DNDi, 2012).

Com base no trabalho desenvolvido na última década, a iniciativa Medicamentos para Doenças Negligenciadas (DNDi) publicou um relatório com ações que considera essenciais, a longo prazo, para aumentar a P\&D das necessidades dos pacientes negligenciados nos países em desenvolvimento. São elas: inovação aberta e gestão de propriedade intelectual pró-acesso; mecanismos de financiamento sustentáveis; coordenação de P\&D com o compromisso de países endêmicos; e vias regulatórias inovadoras (DNDi, 2012).

Sem dúvida, uma importante fortaleza do país para garantia do acesso a medicamentos para doenças da pobreza é a existência de uma rede de laboratórios públicos responsável por grande parte da produção destes medicamentos. Estudo do Instituto de Pesquisa Econômica e Aplicada (IPEA) (GARCIA, 2011) demonstrou que doenças com grande importância epidemiológica como Tuberculose, Malária, Hanseníase e Doença de Chagas só possuem medicamentos disponíveis no SUS graças a produção por laboratórios oficiais. Raw e Higashi (2008) destacam que o hoje notável caminho brasileiro rumo a autossuficiência na produção de vacinas por laboratórios públicos foi motivado pela falta de continuidade da produção privada e o desinteresse do mercado nesses produtos. Programas de modernização do parque tecnológico desses laboratórios, bem como investimento em Parcerias para o Desenvolvimento Produtivo (PDP) são apontados por Oliveira et al (2006), Magalhaes (2010) e Resende (2013) como estratégias para superação da dependência externa 
e fortalecimento da indústria farmacêutica nacional para a produção de medicamentos para doenças da pobreza, apesar da cada vez menor participação de medicamentos para essas doenças no portfólio dos laboratórios oficiais (MAGALHÃES, 2010; OLIVEIRA et al, 2006; RESENDE, 2013).

$\mathrm{Na}$ área regulatória, Gava et al. (2010) demonstram que o perfil dos chamados medicamentos novos registrados na Anvisa não se caracterizam como reais inovações e tampouco atendem a necessidades regionais. Os produtos registrados referem-se em sua maioria a medicamentos para doenças crônicas e nenhum dos fármacos destinava-se a doenças da pobreza. O estudo, porém, destaca a estratégia de priorização da análise e concessão de registro desses medicamentos no país a partir de 2007 para doença rara, negligenciada, emergente ou re-emergente e de potencial interesse para o SUS (GAVA et al., 2010).

\section{Acessibilidade às terapias disponíveis: direito garantido?}

Se há uma grande parcela de responsabilidade do mercado farmacêutico pela falta de investimentos na pesquisa de medicamentos para doenças da pobreza, não é possível atribuir a mesma responsabilidade às falhas nos mecanismos de acesso aos medicamentos já disponíveis. É dever dos governos garantir acesso a tratamentos de saúde às populações vulneráveis.

No Brasil, há previsão constitucional para o acesso universal e igualitário das ações e serviços de saúde e o acesso específico à assistência farmacêutica, além de abordada em legislações complementares, é assegurado pela Política Nacional de Medicamentos e pela Política Nacional de Assistência Farmacêutica (DE PAULA et al., 2009).

É necessário ressaltar a importância da conquista de ter a assistência farmacêutica como direito previsto legalmente, pois nem sempre, a possibilidade de acesso a 
medicamentos pelo estado foi uma realidade no Brasil, mesmo em casos de emergência sanitária e apesar do clamor da população, como pode ser visto no trecho de um jornal baiano ao relatar a omissão do estado sobre a epidemia de malária que assolava a sociedade no início do século XX (SOUZA, 2005):

"O impaludismo lavra e o governo é indiferente. É uma reclamação de todos os dias. Desde os arrabaldes da Capital, o recôncavo, o litoral e o interior, até a zona opulenta do sul - o clamor é uníssono contra os estragos do impaludismo!

$\mathrm{Na}$ dificuldade em que nos achamos para levar avante o momentoso problema do saneamento da Bahia, lembramos que desde já, se poderia fazer alguma cousa no tocante ao impaludismo: a vendagem do quinino a preços módicos, entrando nesse serviço a fiscalização do Estado, não só quanto aos preços elevados, como quanto às falsificações. Não ignoram os que conhecem o interior, a impossibilidade em que se acham as populações pobres de obter o quinino. (A Tarde, 8/5/1918, p. 1, grifos de Souza, 2005).

$\mathrm{Na}$ contemporaneidade, a falta de acesso a medicamentos pode influenciar diretamente na vida das famílias brasileiras. É o que ficou demostrado no estudo de Boing et al. (2014) que analisaram os fatores de saúde que mais contribuíram para o empobrecimento das famílias brasileiras e identificou que o gasto com medicamentos foi responsável por $65,7 \%$ do aumento de domicílios abaixo da linha de pobreza.

No caso das doenças imunopreveníveis, é possível observar o continuo investimento do governo brasileiro na aquisição de tecnologias para prevenção de epidemias. Prova disso é o sucesso do Programa Nacional de Imunização (PNI) que vem alcançando uma das mais altas taxas de cobertura de imunização do mundo sem o uso de estratégias coercitivas, e com ótimos resultados no controle de doenças transmissíveis. Entre 1980 e 2007, o número de mortes por tétano caiu $81 \%$ e as mortes por coqueluche tiveram uma redução de $95 \%$, nenhuma morte foi registrada por difteria ou sarampo no ano de 2007; o país recebeu certificações internacionais de erradicação de doenças como a varíola e poliomielite e controle de doenças como caxumba e rubéola. A maioria dos autores atribuem esses resultados principalmente às características de sustentabilidade das ações do PNI, ao 
investimento na produção nacional de vacinas e à formação de uma cultura vacinal no país (BARRETO et al., 2011; DOMINGUES; TEIXEIRA, 2013; FEIJÓ; SÁFADI, 2006; HOCHMAN, 2011; NASCIMENTO, 2011).

A ampliação do acesso a antimicrobianos também, em certo grau, proporcionou a redução ou eliminação de determinadas doenças como observado, por exemplo, no Programa de Erradicação da Bouba no Brasil, centrada no uso da penicilina, durante o governo do presidente Juscelino Kubitschek (HOCHMAN, 2009b; MUNIZ, 2012). Outras tiveram reduções drásticas de novos casos e estão à beira da eliminação como esquistossomose, filariose, doença meningocócica e doença de Chagas (BARRETO et al., 2011; BRASIL. MS. SVS, 2014b). Outras doenças como tuberculose e hanseníase apesar de ainda possuírem um número alto de casos, estão em constante redução ano a ano, principalmente após a descentralização eficaz do tratamento de rotina, fomento ao monitoramento do uso pela equipe de saúde e da estruturação do sistema de vigilância em saúde (PEN et al., 2013; SANTOS, 2007).

Boa parte dos trabalhos ressalta a falta de prioridade política, a descontinuidade das estratégias de controle das doenças endêmicas e a pouca estruturação das ações de vigilância e assistência à saúde, como as principais barreiras para o controle e eliminação de algumas doenças da pobreza. Silveira e Junior (2011) observaram que a escassez de recursos e a demora da institucionalização de um programa nacional de controle da doença de Chagas favoreceu sua alta incidência até a década de 90 (SILVEIRA; PIMENTA JUNIOR, 2011). Hochman (2009) afirma que lentidão da resposta estatal nas ações de controle de epidemias foi decisiva para que o Brasil fosse o último país da América Latina a eliminar a varíola (HOCHMAN, 2009a). Souza (2005) relata que a tentativa de esconder o real quadro da epidemia de gripe espanhola e a pouca ação do estado prejudicou principalmente os trabalhadores mais pobres de cidades portuárias como Salvador (SOUZA, 2005). Hochman 
(2010), Barreto et al. (2011) e Silva et al. (2008) demonstram que alterações constantes nas estratégias de combate de epidemias transmitidas por mosquitos, que passam desde a utilização anterior de sal cloroquinado, uso de inseticidas para combate dos vetores, distribuição de mosquiteiros, aumento da distribuição e medicamentos ou mais recentes campanhas educativas resultam nos flutuantes 300 mil casos ano de malária e 1 milhão de casos anuais de dengue (BARRETO et al., 2011; HOCHMAN, 2010; SILVA; MARIANO; SCOPEL, 2008).

Atualmente, o acesso aos medicamentos para doenças da pobreza se dá principalmente com financiamento federal, por meio das vacinas e imunobiológicos do PNI e do Componente Estratégico da Assistência Farmacêutica (CESAF). Esse componente é responsável pela disponibilidade de medicamentos para doenças como tuberculose, hanseníase, malária, doença de Chagas, esquistossomose, anemias carenciais, entre outras.

Componente com ampla interface com laboratórios oficiais que chegam a corresponder a mais de $80 \%$ da produção de medicamentos para doenças da pobreza. A falta de interesse das multinacionais também explica parte desse envolvimento dos laboratórios públicos e a importância deles para a soberania nacional. O caso do medicamento benznidazol único tratamento disponível no Brasil para tratamento etiológico da doença de Chagas, exemplifica bastante esse quadro, onde a tecnologia para produção foi repassada gratuitamente pela Roche para o Laboratório Farmacêutico do Estado de Pernambuco (Lafepe) para que a mesma ficasse isenta da continuidade de produção (BASTOS, 2006; GARCIA, 2011).

Um quadro semelhante pode ser observado na produção de vacinas. Em 1992, aproximadamente $60 \%$ de todas as vacinas do PNI eram importadas; em 2002, $70 \%$ eram produzidas no Brasil e em 2012 quase de 96\% já produzidas no país e, grande parte, pelos 
laboratórios públicos da Fundação Oswaldo Cruz (Fiocruz) e Instituto Butantan (BARRETO et al., 2011; DOMINGUES; TEIXEIRA, 2013; RAW; HIGASHI, 2008).

Competindo diretamente com essa busca pela economia e indo de encontro às políticas nacionais de acesso a medicamentos está o fenômeno da judicialização, tema amplamente debatido entre especialistas de saúde coletiva e direito sanitário, com abordagem de impactos positivos e negativos dependendo do ângulo analisado. A íntima ligação das ações judiciais à indústria farmacêutica, sua contribuição para o aumento do quadro de mercantilização da saúde, comprometendo ações coletivas em detrimento de pequenos grupos são problemas apontados, porém é indiscutível que o acesso a medicamentos é um elemento fundamental do direito à saúde e do direito à vida e deve ser garantido mesmo que pelo ativismo judicial (HUNT; KHOSLA, 2008; VARGAS-PELÁEZ et al., 2014).

Nesse ponto, pode-se observar mais uma evidência da vulnerabilidade dos acometidos por doenças da pobreza quando se verifica que a maioria das demandas judiciais brasileiras para acesso a medicamentos é oriunda de pessoas que possuem condição de custear advogados particulares e destinada ao atendimento de doenças crônicas, com pouca ou nenhuma observação de ações para acesso a medicamentos de doenças infecciosas ou relacionadas com a pobreza. É certo que a escassez de produtos e a pouca interferência da indústria farmacêutica explica esse processo, porém é necessário destacar também que novos medicamentos que estão sendo produzidos internacionalmente como benznidazol em formulações solúveis (doença de Chagas), arterolane + piperaquine (malária), miltefosina (leishmanioses) ou a bedaquilina (tuberculose), no entanto, não possuem qualquer pressão por incorporação, tal qual ocorre com novos antineoplásicos, imunobiológicos ou medicamentos para o sistema nervoso e cardiovascular (TORRES, 2013). 


\section{Assistência farmacêutica integral: uma negligência?}

Outro ponto pouco abordado nos trabalhos sobre doenças da pobreza é o direito à uma assistência farmacêutica integral. A integralidade do cuidado ao usuário de medicamentos só é estabelecida quando a este é garantida a oportunidade de adequada dispensação e orientação de um profissional farmacêutico, que inclusive possa monitorar seu tratamento, articulando-se aos demais profissionais e serviços de saúde para o êxito no cuidado.

Talvez como herança de uma política campanhista, o foco das ações de assistência farmacêutica para combate a doenças da pobreza tenha se limitado à aquisição e distribuição de vacinas e outros medicamentos essenciais, o que já é uma conquista, porém aspectos relacionados ao monitoramento da eficácia e segurança dos medicamentos, bem como êxito da farmacoterapia ainda precisam de avanço.

Mesmo com a introdução do conceito de atenção farmacêutica, numa perspectiva ampliada de cuidado das necessidades medicamentosas do usuário, revisões da literatura como a de Perreira e Freitas (2008) e Witzel (2009) demonstram que os estudos brasileiros dessa área seguem a tendência norte-americana e europeia de estudos restritos a doenças e grupos populacionais específicos, sendo a maior parte dedicada ao cuidado de idosos e portadores de enfermidades crônico-degenerativas como hipertensão e diabetes. No entanto, poucos países além do Brasil poderiam explorar e evoluir tanto nos cuidados farmacêuticos de doenças da pobreza, e este pode ser inclusive um entrave importante no processo de controle e eliminação dessas doenças, uma vez que boa parte das vezes elas se caracterizam por possuírem tratamentos complexos, com elevado número de interações medicamentosas e reações adversas que necessitam de monitoramento constante e de incentivo permanente a adesão (PEREIRA; FREITAS, 2008; WITZEL, 2009). 
Na tuberculose, por exemplo, Santos (2007) destaca que para o controle mais efetivo da doença no país é preciso reforçar a abordagem do tratamento supervisionado, investir no monitoramento da terapia e reduzir as taxas de abandono. Jamal e Moherdaui (2007) reforçam que além dessas ações é preciso agora investir no monitoramento dos casos de coinfecção da tuberculose com o HIV que duplica as dificuldades de êxito da farmacoterapia (JAMAL; MOHERDAUI, 2007; SANTOS, 2007). Na Hanseníase, Pen et al. (2013) e Santos et al. (2015) destacam que a ampliação do acesso a terapia medicamentosa está contribuindo para a redução dos índices da doença, mas a prevenção do abandono e da resistência aos fármacos são os maiores desafios para as equipes de saúde (PEN et al.; PENNA, 2013; SANTOS et al., 2015).

Pontes et al. (2010) demonstraram também que o excesso de reações adversas ao benznidazol nos pacientes avaliados $(87,5 \%)$ levaram ao abandono do tratamento por cerca de 30\% dos participantes, um problema grave quando consideramos que não está disponível outra opção de tratamento no país (PONTES et al., 2010). O trabalho conclui que o acompanhamento farmacoterapêutico dos pacientes com doenças de Chagas é de grande relevância na prevenção e detecção precoce das reações adversas a medicamentos. Silva e Nicoletti (2013) apontam ainda problemas relacionados à resistência pela má utilização de antimáricos, toxicidade e falhas de eficácia no tratamento da esquistossomose e a necessidade de maior monitoramento da farmacoterapia da Leishmaniose, relacionada à danos hepáticos, renais e cardíacos (SILVA; NICOLETTI, 2013).

O monitoramento de reações adversas e a melhoria das ações de farmacovigilância também são atividades negligenciadas, principalmente quando se referem a doenças da pobreza. Com pouca participação da categoria farmacêutica nas campanhas de vacinação, cada vez mais o PNI e a Anvisa tem encarado como necessidade a melhoria dos processos de monitoramento pós-vacinal que mesmo com limitações próprias da vigilância passiva, 
tem obtido êxito na identificação de vacinas e lotes mais reatogênicos, de eventos pouco conhecidos ou não descritos na literatura (DOMINGUES et al., 2012; WALDMAN et al., 2011).

Osorio-de-Castro et al., (2009) propõem que ferramentas de planejamento e monitoramento das ações de assistência farmacêutica sejam incorporados nos serviços de saúde para doenças da pobreza, a exemplo da malária. No estudo, são elencados 25 indicadores relacionados a questões de prescrição, dispensação e adesão que podem ser utilizados para qualificação dos serviços farmacêuticos.

Qualificar a assistência farmacêutica com um olhar para a equidade das ações é fundamental para a melhoria dos resultados em saúde e para a superação de doenças da pobreza. Porém em determinados aspectos pode-se perceber que há discrepâncias de investimentos nas ações estatais. Enquanto verificamos a existência de protocolo específico para assistência farmacêutica em DST/AIDS (BRASIL. MS. SVS., 2010) prevendo ações de acompanhamento e monitoramento dos pacientes, realizadas de maneira individual ou coletiva por farmacêuticos dedicados à promoção do uso racional de antiretrovirais e terapia complementar, não observamos o mesmo tratamento nos programas para doenças da pobreza, que sequer possuem regulamentação da presença de farmacêuticos, a exceção do programa da hanseníase, porém com a obrigatoriedade vinculada mais a dispensação da talidomida que ao cuidado dos pacientes propriamente dito (BRASIL. ANVISA, 2011; VILLARINHO et al., 2013).

Este exemplo de iniquidade assistencial envolvendo as populações acometidas por doenças da pobreza explica-se de certo modo por esses grupos populacionais não possuírem a mesma capacidade de se organizarem e exigir melhoria nos serviços assistenciais, como é característico das associações e institutos de defesa dos portadores de HIV/AIDS, que de certa forma alcançaram um elevado grau de emancipação popular para garantia de direitos. 
Populações pobres de países em desenvolvimento com indicadores de saúde precários são grupos muito vulneráveis. A fragilidade destas populações geralmente reflete a fragilidade de todo um país em lidar com seus principais problemas educacionais, sociais e de garantia de acesso a serviços de saúde a todos (DINIZ et al., 2008). Nesse processo de fragilidade nacional, os grupos que possuem maior capacidade emancipatória conseguem maior êxito na luta pela garantia de direitos, o que é legitimo, porém invariavelmente resulta num quadro de duplo padrão de cuidado nos sistemas de saúde.

\section{Considerações Finais:}

Pela revisão elaborada podemos observar que boa parte dos trabalhos selecionados reforçam que a falta de interesse do mercado farmacêutico afeta decisivamente o campo da pesquisa e desenvolvimento de fármacos para doenças da pobreza, reduzindo as expectativas de melhoria dos seus tratamentos, porém parte dos estudos criticam a falta de protagonismo do SUS e dos países em desenvolvimento em superar esse quadro.

Verificou-se que avanços importantes foram alcançados no estímulo à produção nacional de vacinas e demais medicamentos para doenças da pobreza, muitos deles graças ao fortalecimento dos laboratórios públicos.

As ações para ampliação do acesso a medicamentos para estas doenças com garantia de financiamento federal foram destaque nos estudos selecionados, atribuindo-se a esta política uma contribuição decisiva na redução significativa de casos de doença da pobreza, com destaque para as imunopreveníveis.

No entanto, entraves importantes ainda foram levantados pelos estudos e precisam ser superados pelas políticas e serviços de saúde como o monitoramento da qualidade dos tratamentos ofertados e de seus eventos adversos e a garantia de cuidados farmacêuticos para 
melhoria do cuidado em saúde e prevenção de fracassos terapêuticos num campo já escasso de possibilidades.

Percebe-se que a "negligência" no campo dos medicamentos para doenças da pobreza está de fato ligada a uma lógica de mercado perversa, mas está longe de ser culpa exclusiva dos produtores globais, e deve ser foco de reflexão e de ações proativas dos sistemas de saúde de países em desenvolvimento para garantia de um cuidado terapêutico exitoso e, acima de tudo, contribuir para a emancipação social de populações historicamente marginalizadas. 
CAPÍTULO II - PRIORIDADES DE PESQUISA COM MEDICAMENTOS NO BRASIL E AS DOENÇAS DA POBREZA 
"A idéia de que algumas vidas importam menos é a raiz de tudo o que há de errado com o mundo...está claro que a indústria não está de forma alguma fazendo com que os mais pobres tenham acesso a uma atenção médica adequada" (Paul Farmer) 


\section{CAPITULO II - PRIORIDADES DE PESQUISA COM MEDICAMENTOS NO \\ BRASIL E AS DOENÇAS DA POBREZA}

\section{Resumo:}

Há alguns anos a literatura científica vem relatando a falta de investimentos globais na descoberta e melhoria de tratamentos para algumas doenças consideradas "negligenciadas". Atualmente, discute-se que o fato de essas doenças serem perpetuadoras e decorrentes da pobreza seja o principal motivo para a negligência do mercado farmacêutico e para a falta de protagonismo dos países em desenvolvimento. Neste artigo, foi realizado uma análise do panorama dos ensaios clínicos realizados no Brasil nos últimos anos. $\mathrm{O}$ estudo verifica quais as principais doenças pesquisadas, quem conduz e financia esses ensaios e o nível de prioridade que está sendo dado para as doenças da pobreza, diretamente relacionadas com iniquidades sociais. Os resultados traçam um perfil de estudos caracterizados pela grande influência mercadológica, com consequente concentração de investimentos em doenças e medicamentos de grande impacto orçamentário nos serviços de saúde e um baixíssimo investimento em doenças da pobreza que ainda tomam grande importância na carga de doenças brasileira.

\section{Palavras-Chave:}

Pobreza; Doenças Negligenciadas; Ensaios Clínicos; Iniquidades em Saúde;

\section{Introdução:}

No campo das pesquisas clínicas para novos medicamentos pode-se constatar que se vive um quadro global de "imperialismo científico", onde os Estados Unidos ainda lideram a realização de ensaios clínicos, sendo responsável por $47 \%$ dos quase 40 mil estudos em fase de recrutamento até fevereiro de 2016. Apesar disso, desde 2002, o número de pesquisadores anualmente registrados no Food and Drug Administration (FDA) fora desse país tem crescido $15 \%$, enquanto que o número de investigadores norte-americanos caiu 5,5\%. O número de publicações de ensaios clínicos realizados fora dos EUA nos principais 
periódicos internacionais também duplicou em 10 anos (ANDREWS, 2009; PETRYNA, 2011; U.S. NIH, 2016a).

Boa parte dessa migração está sendo realizada para países em desenvolvimento. Apesar da interessante oportunidade de transferência de tecnologia, o que parece motivar essa mudança de investimentos para esses locais são os menores custos de realização das pesquisas, a maior rapidez na captação de participantes e os menores entraves regulatórios quando comparados com os países desenvolvidos (ANDREWS, 2009; GARRAFA; LORENZO, 2009).

Mesmo com a mudança da rota de pesquisa para países em desenvolvimento, a OMS tem alertado sobre a continuidade do extensivo impacto das chamadas doenças da pobreza na carga de doença de países mais pobres. Estas doenças, que atingem desproporcionalmente as populações mais vulneráveis, apresentam diversas lacunas de tratamento e, no entanto, ainda representam mundialmente baixos investimentos em pesquisas (CHIRAC; TORREELE, 2006; WHO, 2012).

É sabido que a indústria farmacêutica vive uma contínua escassez de novas descobertas para suas doenças eleitas como prioritárias. Isso é percebido com a queda continua de medicamentos com patente vigente a cada ano. Só em 2012, mais de 40 medicamentos perderam sua proteção patentária no mundo. De 2008 a 2012 esses produtos representavam um valor de vendas de mais de U\$ 150 bilhões nos principais países desenvolvidos, a expectativa é que até 2017 o número de medicamentos com patente ativa e consequentemente seu volume de vendas caia em torno de 20\% (GOMES et al., 2014).

Era de se esperar então que o mercado mundial agora se voltasse para doenças que ainda precisam de melhores tratamentos, porém segundo Cohen et al. (2010) dos mais de 1500 novos medicamentos lançados no mercado até 2009, apenas 72 estavam relacionadas a doenças que desproporcionalmente atingem os países mais pobres (CHIRAC; 
TORREELE, 2006; COHENet al, 2010). Há um aumento dos investimentos em pesquisa para essas doenças, porém ainda assim, a maior parte desses recursos são focadas basicamente em três doenças: HIV/AIDS, tuberculose e malária. Há limitados investimentos na pesquisa de outras doenças como a esquistossomose, doença de Chagas ou doença do sono (COHENet al, 2010; WHO, 2012).

Estes são resultados previsíveis quando observa-se a grande dependência de capital privado na área de pesquisa de medicamentos, onde mais de $90 \%$ do financiamento dos ensaios clínicos mundiais são oriundos da indústria farmacêutica (TUNISet al, 2003). E como a lógica de retorno desses investimentos se dá pelo sucesso na obtenção de uma patente, quem poderia esperar que o mercado buscasse patentes de medicamentos para doenças passíveis de eliminação?

A pesquisa e produção de fármacos está orientada para atender a um mercado consumidor que aparente sustentabilidade de financiamento, o que resulta em desigualdades de acesso. Em países ricos, a média de gastos em medicamentos por pessoa é 100 vezes maior do que em países pobres: cerca de US\$ 400 em comparação a US\$ 4 médios. A OMS estima que $15 \%$ da população mundial consome mais do que $90 \%$ da produção farmacêutica (HUNT; KHOSLA, 2008).

Exemplo mais evidente da dependência global por alternativas terapêuticas para doenças da pobreza é a contemporânea epidemia de ebola que se alastrou velozmente pela África Ocidental. Os fracassos nas medidas de contenção, o acometimento de vítimas americanas e a chance real de globalização de uma doença até então restrita a zonas rurais isoladas da África tem deslocado esforços de centros de pesquisa de medicamentos e do governo dos EUA. Mobilização que chega tarde e evidencia anos de negligência, principalmente quando observamos os milhares de mortos e afetados desde a descoberta do vírus em 1976 (COHEN, 2014). 
Para solucionar essa dependência global e mudar o quadro de prioridades de pesquisa é preciso maior protagonismo dos países em desenvolvimento, principais interessados no controle e eliminação de doenças da pobreza.

A iniciativa Medicamentos para Doenças Negligenciadas (DNDi, na sigla em inglês), criada em 2003, é uma parceria global que envolve vários países em desenvolvimento, inclusive o Brasil, com o objetivo de pesquisar e desenvolver novos tratamentos para as doenças mais negligenciadas (DNDi, 2012; PONTES, 2009).

O Ministério da Saúde brasileiro, em parceria com o Ministério da Ciência, Tecnologia e Inovação, agências e fundações de fomento à pesquisa tem definido algumas prioridades e iniciado alguns investimentos para doenças negligenciadas. Em 2004, durante a II Conferência Nacional de Ciência, Tecnologia e Inovação em Saúde foram definidas doenças prioritárias para a agenda de pesquisa, a saber: dengue, doença de Chagas, leishmaniose, hanseníase, malária, esquistossomose e tuberculose. O incentivo à formação de redes de pesquisa como a Rede Malária e Rede Tuberculose também foi uma estratégia adotada para fortalecer e interligar iniciativas nacionais nessa área. (ABC, 2010; DECIT, 2010; DNDi, 2012).

Diante deste cenário, o objetivo desse capítulo concentra-se na análise do panorama dos ensaios clínicos com medicamentos realizados no pais, suas características e potencial de atendimento das necessidades nacionais, particularmente as doenças da pobreza.

Pretende-se verificar especificamente a proporção de pesquisas de medicamentos para doenças da pobreza na agenda de ensaios clínicos brasileiros, suas características, o perfil de instituições que conduzem e financiam e ainda a relação de tais ensaios clínicos com a carga de doença do país. 


\section{Métodos:}

Foi realizada uma ampla análise dos ensaios clínicos com medicamentos realizados no país durante o período de 2012 a 2015. Para tanto foram levantados todos os registros de ensaios clínicos incluídos no Registro Brasileiro de Ensaios Clínicos (ReBEC) e no clinicaltrial.gov.

O ReBEC é uma plataforma nacional, virtual, de acesso livre para registro de ensaios clínicos realizados em seres humanos e conduzidos no Brasil. É um projeto iniciado em 2011 numa parceria entre o Ministério da Saúde, da Organização Pan-americana de Saúde (Opas) e da Fundação Oswaldo Cruz (Fioruz) (BRASIL, 2016f).

O clinicaltrial.gov é outra plataforma virtual, também de acesso livre para registro de ensaios clínicos, porém com abrangência global, mantido pelo National Institutes of Health (NIH) do governo norte americano (US. NIH, 2016b).

Foram selecionados estudos de intervenção que envolviam a pesquisa de novos fármacos, melhoria ou avaliação dos tratamentos existentes; com resultados finalizados ou em andamento, independentemente do tipo de fase ou tipo de participante envolvido. Foram excluídos das análises, estudos observacionais, estudos com status desconhecido, que não possuíam medicamentos envolvidos, não realizados no Brasil ou fora do período selecionado.

Para análise dos dados foram verificados os seguintes parâmetros: (i) doença ou agravo de acordo por grau de iniquidade; (ii) doença ou agravo de acordo com classificação de carga de doenças; (iii) entidade responsável pelo estudo (iv) tipo de financiamento; (v) fase do estudo.

Para categorização das doenças e agravos foi seguida a classificação proposta em estudos de análise de carga global de doenças do Brasil (SCHRAMM et al., 2004) e internacionais (MURRAY et al., 2012). Os dados de carga de doença do Brasil e OMS usam 
o indicador DALY (Disability Adjusted Life of Years - Anos de Vida Perdidos Ajustados por Incapacidade) que procura medir simultaneamente o impacto da mortalidade e dos problemas de saúde que afetam a qualidade de vida dos indivíduos. A escolha dessa forma de classificação foi considerada mais adequada pelos autores pois boa parte das chamadas doenças da pobreza atualmente apresentam uma menor taxa de mortalidade, porém uma grande morbidade. $\mathrm{O}$ uso desse parâmetro permite ainda uma comparação relativa entre os percentuais de ensaios pesquisados no país e as principais doenças e agravos que atingem os brasileiros.

Para melhor identificação das doenças relacionadas à pobreza, os agravos e doenças foram agrupados ainda em três categorias de acordo com o grau de iniquidade. Esta classificação foi proposta pelos pesquisadores a partir de adaptação de proposições anteriores da organização Médicos Sem Fronteiras (MSF) e OMS: (i) doenças globais não transmissíveis (ii) doenças globais transmissíveis; e (iii) doenças relacionadas com a pobreza (MSF, 2001; WHO, 2012). Destaca-se que o termo "global”, já utilizado nas referências citadas que faz referência à propriedade de abrangência dessas doenças e agravos, não havendo clara desproporcionalidade de atingir um grupo social específico, como ocorre com as chamadas doenças da pobreza.

As entidades responsáveis pelo estudo foram classificadas em (i) instituições de ensino superior e pesquisa acadêmica (universidades, institutos de pesquisa governamentais); (ii) entidades que prestam serviços de saúde (hospitais, clínicas e unidades de saúde em geral) ou (iii) indústrias e instituições de pesquisa clínica (laboratórios farmacêuticos, empresas de execução de ensaios clínicos).

No parâmetro de financiamento/patrocínio foi verificado quais as instituições que custeavam os estudos e se esse financiamento era proveniente de recursos públicos, privados ou misto (parcerias público-privada). 
Quanto as fases do ensaio clinico foi verificado se tratava-se de estudo de fase I (avaliação inicial em humanos, tolerância em voluntários saudáveis), fase II (estudo terapêutico inicial, foco na eficácia), fase III (estudo terapêutico ampliado, foco no risco/benefício) e fase IV (estudo pós-registro).

\section{Resultados e Discussão:}

Foram identificados nas bases pesquisadas, 1922 registros de ensaios clínicos, durante o período de 2012 a 2015. Desse total foram excluídos registros repetidos e que não atenderam aos critérios do estudo. Ao final, foram identificados 866 ensaios clínicos registrados durante o período, 88 deles no ReBEC e 778 deles no clinicaltrial.gov.

Dentre os 866 estudos analisados pode-se verificar a menor proporção de pesquisas com doenças relacionadas à pobreza (4\%) e uma predominância de estudos para doenças globais não transmissíveis (Figura 4).

\section{Figura 4 - Proporção de temas pesquisados por categoria de vulnerabilidade}

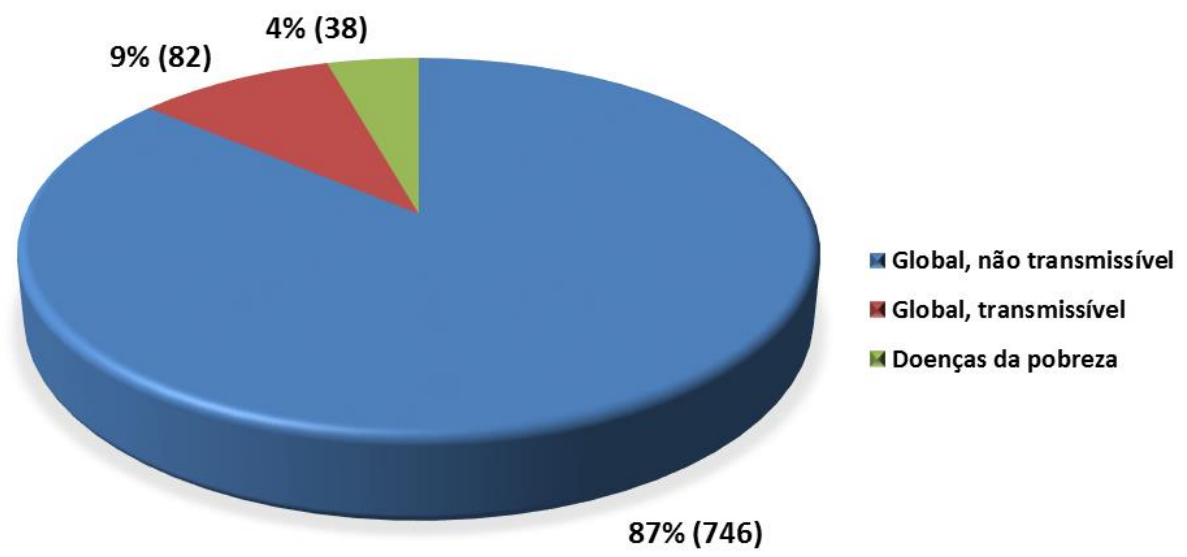

Fonte: O Autor

Essa constatação de pouco investimento nas doenças que atingem populações mais vulneráveis está em consonância com as verificações de especialistas e entidades de saúde. 
A substituição gradual do termo "doenças negligenciadas" por "doenças da pobreza" é fruto do avanço das análises de componentes sociais na dinâmica da saúde, que verificaram que a incidência dessas doenças está fortemente relacionada com a vulnerabilidade de determinadas populações e disparidades de acesso a medicamentos e serviços de saúde (MANDERSON et al., 2009).

A falta de pesquisas para essas doenças gera como consequência um baixo número de inovações terapêuticas, conforme evidenciado por Chirac e Torreele (2006) que observaram que apenas $1,3 \%$ dos 1556 novos medicamentos registrados entre 1975 e 2004 estavam relacionados a doenças típicas de regiões mais pobres. Cohen et al, utilizando-se de outros métodos de identificação de medicamentos para essas doenças e incluído então alguns medicamentos para HIV/AIDS e doenças diarreicas, estimam que essa porcentagem pode chegar a 4,6\% dos lançamentos. Desde o ano 2000 o número de lançamentos vem crescendo, porém, os dois trabalhos observaram que não houve lançamentos significativos para algumas doenças com maior necessidade de medicamentos como úlcera de buruli, dengue, febre tifoide ou febre reumática (CHIRAC; TORREELE, 2006; COHEN et al, 2010).

Na Tabela 2 podemos verificar mais detalhadamente as categorias de doenças da pobreza abordados nos estudos brasileiros. Foram identificados majoritariamente estudos com doenças infectocontagiosas não preveníveis por vacinação. Destas, cinco coincidem com as sete prioridades de pesquisa em doenças negligenciadas definidas pelo Ministério da Saúde em 2008, a saber: Doença de Chagas, Dengue, Leishmanose, Malária, Tuberculose (DECIT, 2010). 
Tabela 2 - Doenças da pobreza $(\mathbf{n = 3 8})$ nos ensaios clínicos brasileiros (2012-2015)

\begin{tabular}{lcc}
\hline \multicolumn{1}{c}{ Doenças da Pobreza } & Percentual & Principais Temas \\
\hline Doenças Infeciosas Imunopreveníveis & $8 \%(3)$ & $\begin{array}{c}\text { Sarampo, Caxumba, Rubéola, } \\
\text { Varicela, Meningites. }\end{array}$ \\
\hline $\begin{array}{l}\text { Doenças Infeciosas Não } \\
\text { Imunopreveníveis }\end{array}$ & $61 \%(23)$ & $\begin{array}{c}\text { Doença de Chagas, Dengue, Diarreias } \\
\text { Agudas, Leishmaniose, Malária, } \\
\text { Tuberculose, Parasitoses Intestinais }\end{array}$ \\
\hline Outras Doenças da Pobreza & $32 \%(12)$ & $\begin{array}{c}\text { Dependência de álcool, crack e } \\
\text { cocaína, Doença Falciforme, } \\
\text { Deficiências Nutricionais }\end{array}$ \\
\hline \multicolumn{1}{c}{ Total } & $100 \%(38)$ & \\
\hline
\end{tabular}

Os bons resultados para as doenças que possuem vacinas efetivas disponíveis pode ser a principal justificativa para o menor percentual de pesquisas nesse grupo. Já as doenças infectocontagiosas, que ainda não contam com vacinas efetivas destacam-se como o principal alvo das iniciativas de pesquisa em doenças da pobreza. E o desenvolvimento de vacinas é justamente o principal objetivo dos pesquisadores.

Dentre os estudos analisados destaca-se o desenvolvimento de uma vacina contra a dengue conduzido por um laboratório francês, recentemente registrada na Anvisa e outro estudo conduzido pelo governo brasileiro também para o desenvolvimento de uma vacina tetravalente para a dengue. Pesquisas com grande potencial de relevância para a saúde pública, uma vez que se vive atualmente um quadro hiperendêmico de dengue no Brasil, com quatro sorotipos circulando por regiões urbanas e rurais, além da emergência de novos vírus transmitidos pelo Aedes aegypti como zika e chikungunya (VALLE et al., 2015; HADINEGORO et al., 2015).

Estudos que investigam novas formas de tratamento para fase crônica da doença de Chagas também destacaram-se e estavam focadas na busca de melhorias nas complicações da doença, que nessa fase não conta com um tratamento efetivo de cura (REYES; VALLEJO, 2011; TANOWITZ et al., 2009). Outras pesquisas abordam alternativas terapêuticas para o 
tratamento da co-infeção de HIV e tuberculose, situação que coloca em risco as estratégias de controle de ambas as doenças (BRASIL, 2015; JAMAL; MOHERDAUI, 2007).

Estudos anteriores sempre questionaram se a proporção de pesquisas realizadas no mundo é condizente com a carga de doenças. Como relatado anteriormente, pesquisadores demonstraram que a proporção de medicamentos lançados no mundo para o combate de doenças da pobreza é inferior a 5\% desde a década de 1970, mesmo estas representando 11,4\% da carga global de doenças (CHIRAC; TORREELE, 2006; COHEN et al, 2010).

Na Tabela 3, pode-se observar os percentuais de ensaios clínicos classificados conforme Schramm et al. (2004), comparados com distribuição de DALY obtidos no Relatório Final do Projeto de Estimativa de Carga de Doenças no Brasil com dados de 1998 e estimativa de 2013 (GADELHA et al, 2002; LEITE et al., 2013; SCHRAMM et al., 2004).

Tabela 3 - Comparação entre percentual de ensaios clínicos $(n=866)$ registrados no Brasil (2012-2015) e carga de doenças

\begin{tabular}{llcc}
\hline \multicolumn{1}{c}{ Grupo } & $\begin{array}{c}\text { Ensaios } \\
\text { Clínicos }\end{array}$ & $\begin{array}{c}\text { Carga de } \\
\text { Doenças } \\
\text { (DALY 1998) }\end{array}$ & $\begin{array}{c}\text { Carga de } \\
\text { Doenças } \\
\text { (DALY 2013)* }\end{array}$ \\
\hline $\begin{array}{l}\text { Grupo I - Doenças infeciosas/ } \\
\text { parasitárias, maternas, perinatais } \\
\text { e nutricionais }\end{array}$ & $14,4 \%(125)$ & $23,5 \%$ & $17,11 \%$ \\
\hline $\begin{array}{l}\text { Grupo II - Doenças não-transmissíveis } \\
\text { Grupo III - Causas externas }\end{array}$ & $84,8 \%(734)$ & $66,3 \%$ & $74,09 \%$ \\
\hline * Projeção realizada a partir do relatório de 2002 (Leite et al, 2013) & & $8,80 \%$ \\
\hline
\end{tabular}

Pelos dados é possível perceber que os ensaios clínicos realizados no país durante o período seguem uma tendência de maior abordagem de doenças não-transmissíveis (grupo II), em concordância com as proporções de carga de doença.

Destaca-se o percentual baixo de ensaios clínicos classificados no Grupo III de causas externas. Esse resultado pode ser atribuído a dificuldade de identificar as condições 
decorrentes de causas externas como lesões por acidentes de trânsito ou violência, certamente incluídas em outras categorias de ensaios clínicos como condições musculoesqueléticas ou neurológicas por exemplo. No entanto, mesmo condições com maior facilidade de identificação nesta categoria, como envenenamentos ou outros tipos de intoxicações, não estavam presentes nos estudos selecionados.

Ativistas e estudiosos denunciam que apenas $10 \%$ das pesquisas globais em saúde são dedicadas a doenças e agravos que correspondem a 90\% da carga global de doenças, quadro que ficou conhecido em todo o mundo como “desequilíbrio 90/10”. Esse resultado é explicado porque grande parte das doenças prevalentes de países de baixa renda são consideradas "negligenciadas", e sendo esses países normalmente populosos acabam contribuindo significativamente para a carga global de doenças. Contrastando com essa necessidade, a pesquisa de medicamentos está concentrada em países desenvolvidos e conduzida pelo mercado farmacêutico que centraliza seus investimentos em condições que atingem países e populações com maior renda (LUCHETTI, 2014; MSF, 2001).

No Brasil, pelos dados levantados é possível observar que este paradoxo não foi seguido e esta tese não pode ser comprovada, uma vez que o percentual de ensaios clínicos brasileiros é condizente com o percentual de carga global de doenças do país e parece estar se aproximando cada vez mais ao longo das medidas de carga de doenças (Tabela 3). O percentual de ensaios para doenças infeciosas e condições materno perinatais (grupo I) que representou $14,4 \%$, ainda representa um valor inferior as estimativas de carga global tanto para $1998(23,5 \%)$ quanto para 2013 (17\%), o que não aconteceu com o grupo II com 84,8\% dos ensaios e representando cerca de 74\% da projeção de carga de doença para 2013.

É necessário destacar também que apenas a análise do percentual de ensaios não permite tirar conclusões sobre os valores investidos nessas pesquisas, nem tampouco sobre seu potencial de gerar medicamentos para as necessidades nacionais, mas demonstram uma 
certa coerência entre os temas pesquisados e as necessidades de saúde de um país em processo de transição epidemiológica.

Tabela 4 - Proporção de ensaios registrados por tipo de doença

\begin{tabular}{|c|c|c|}
\hline Tipo de Doenças e Agravos & Ensaios Clínicos & $\begin{array}{c}\text { Carga de } \\
\text { Doenças } \\
\text { (DALY 1998) }\end{array}$ \\
\hline Anomalias congênitas & $2,4 \%(21)$ & $1,8 \%$ \\
\hline Câncer & $20,3 \%(176)$ & $6,4 \%$ \\
\hline Causas Externas & $0,7 \%(5)$ & $10 \%$ \\
\hline Condições materno e perinatais & $2 \%(17)$ & $8,8 \%$ \\
\hline Condições orais & $5 \%(43)$ & $1,2 \%$ \\
\hline Deficiências nutricionais & $0,2 \%(2)$ & $2.1 \%$ \\
\hline Diabetes & $5,2 \%(45)$ & $5,1 \%$ \\
\hline Doenças cardiovasculares & $12,4 \%(107)$ & $13,3 \%$ \\
\hline Doenças do aparelho digestivo & $3,7 \%(32)$ & $2,7 \%$ \\
\hline Doenças endócrinas e metabólicas & $4,8 \%(42)$ & $1,5 \%$ \\
\hline Doenças de pele & $1,8 \%(16)$ & $0,1 \%$ \\
\hline Doenças gênito-urinárias & $6,4 \%(55)$ & $0,8 \%$ \\
\hline Doenças infecciosas e parasitárias & $10,7 \%(93)$ & $9,2 \%$ \\
\hline Doenças musculoesqueléticas & $6,5 \%(56)$ & $5,5 \%$ \\
\hline Doenças neuropsiquiátricas & $8,7 \%(75)$ & $18,5 \%$ \\
\hline Doenças respiratórias & $4,3 \%(37)$ & $8,4 \%$ \\
\hline Doenças dos órgãos dos sentidos & $3,3 \%(29)$ & $1,1 \%$ \\
\hline Infecções respiratórias & $1,5 \%(13)$ & $3,5 \%$ \\
\hline Total & $100 \%(866)$ & $100 \%$ \\
\hline
\end{tabular}

Na Tabela 4 é possível identificar com mais detalhes a proporção dos temas pesquisados. Os cinco maiores percentuais de pesquisa são para o câncer, doenças cardiovasculares, infeciosas, neuropsiquiátricas e musculoesqueléticas. Juntas elas representam quase $60 \%$ dos ensaios clínicos com fármacos realizados no país durante o período analisado. O percentual de carga de doenças verificado foi de 52,9\% para as mesmas doenças. 
É necessário discorrer sobre a influência mercadológica na definição dos estudos pesquisados no Brasil. O tema mais pesquisado e com a maior discrepância entre os dados de carga de doenças foi o câncer. Um resultado esperado, dado o elevado custo do tratamento oncológico, tanto para a assistência direta do SUS quanto para a saúde suplementar (NOBREGA; LIMA, 2014), sendo os antineoplásicos os principais medicamentos das ações judicializadas contra o estado para garantia de acesso (LOPES et al, 2010).

Dos 56 estudos classificados na categoria de doenças musculoesqueléticas, 60\% (34) tratavam de pesquisas sobre a farmacoterapia das Artrites. Não por acaso, os medicamentos desta doença são os que mais oneram o chamado Componente Especializado da Assistência Farmacêutica (Ceaf), com custos superiores a 1 bilhão de reais ano, sendo os principais itens alvo da pressão para incorporação na relação de medicamentos ofertados pelo SUS (BRASIL. MS. SCTIE, 2014; CHIEFFI; BARATA, 2010).

Na categoria doenças infecciosas e parasitárias, mesmo com um grande número de diferentes patologias, o foco principal dos trabalhos tem sido basicamente dois temas: hepatites e infecção pelo HIV correspondendo a 35,4\% (33) dos ensaios clínicos.

Diferente da maioria das enfermidades transmissíveis, essas duas doenças, talvez por suas características de cronicidade e melhores programas de acesso, despertam atenção e investimentos por parte do mercado farmacêutico.

Como parte de um programa consolidado, o acesso a antirretrovirais no Brasil é uma referência internacional e vem demonstrando uma característica de rápida absorção das inovações (DUARTE et al, 2011). Do mesmo modo, novos medicamentos para tratamento da hepatite $\mathrm{C}$, que inclusive aqueceram o debate sobre a sustentabilidade dos sistemas de saúde, dado os seus custos elevados, foram não só incorporados na lista do SUS, como na própria lista da OMS e em diferentes sistemas de saúde (CANARY et al, 2015). 
Essa influência do interesse mercadológico na definição das doenças que serão pesquisadas pode ser explicada pelo perfil das instituições que conduzem e financiam esses ensaios clínicos: majoritariamente realizados por indústrias farmacêuticas e com patrocínio privado, conforme pode ser observado nas Tabelas 5 e 6 .

Tabela 5 - Instituições responsáveis pela condução dos ensaios clínicos (2012-2015)

\begin{tabular}{|c|c|c|c|c|}
\hline $\begin{array}{c}\text { Entidade responsável pelo } \\
\text { estudo }\end{array}$ & $\begin{array}{l}\text { Global, não } \\
\text { transmissível }\end{array}$ & $\begin{array}{c}\text { Global, } \\
\text { transmissível }\end{array}$ & $\begin{array}{c}\text { Doenças da } \\
\text { Pobreza } \\
\end{array}$ & Total \\
\hline $\begin{array}{l}\text { Instituições de ensino superior e } \\
\text { pesquisa acadêmica }\end{array}$ & $31,8 \%(237)$ & $25,6 \%(21)$ & $34,2 \%(13)$ & $31,3 \%$ \\
\hline Serviços de saúde & $13,5 \%(101)$ & $11 \%(09)$ & $15,8 \%(06)$ & $13,4 \%(116)$ \\
\hline $\begin{array}{l}\text { Indústrias farmacêuticas e } \\
\text { empresas de pesquisa clínica. }\end{array}$ & $54,7 \%(408)$ & $63,4 \%(52)$ & $50 \%(19)$ & $55,3 \%(479)$ \\
\hline Total & $100 \%(746)$ & $100 \%(82)$ & $100 \%(38)$ & $100 \%(866)$ \\
\hline
\end{tabular}

A indústria farmacêutica é a grande responsável pelo desenvolvimento de ensaios clínicos de medicamentos. Ainda que com uma proporção menor para as doenças da pobreza, os laboratórios privados se destacam como responsáveis pela condução de mais de $50 \%$ dos estudos, independente da categoria de doença.

Nas doenças da pobreza, observa-se uma maior participação de estudos conduzidos por universidades e serviços de saúde representando $50 \%$ das entidades, apesar do predomínio da indústria farmacêutica.

Petryna (2011) relata que mesmo com a aparente estagnação do crescimento da indústria farmacêutica e o menor número de lançamento dos chamados "medicamentos blockbusters" (vendas superiores a US\$ 1 bilhão por ano), o mercado farmacêutico investe cada vez mais numa grande cadeia de atividades empresariais de ensaios clínicos, com gestão de patrocinadores, companhias de recrutamento de pacientes, consultores de ética em pesquisa, centros de pesquisa clínica. 
Esse investimento pode ser confirmado também nos dados de financiamento dos ensaios clínicos brasileiros. Na Tabela 6 , pode-se observar que a iniciativa privada é responsável por quase $60 \%$ do custeio dos ensaios de pesquisas globais, transmissíveis e não transmissíveis. Essa proporcionalidade não se confirma quando analisamos os ensaios das doenças da pobreza que são majoritariamente $(63,1 \%)$ financiados por recursos públicos.

Tabela 6 - Tipo de financiamento dos ensaios clínicos (2012-2015)

\begin{tabular}{|c|c|c|c|c|}
\hline Tipo de Financiamento & $\begin{array}{l}\text { Global, não } \\
\text { transmissível }\end{array}$ & $\begin{array}{c}\text { Global, } \\
\text { transmissível }\end{array}$ & $\begin{array}{l}\text { Doenças da } \\
\text { Pobreza }\end{array}$ & Total \\
\hline Patrocínio Público & $37,1 \%(277)$ & $35,3 \%(29)$ & $63,1 \%(24)$ & $38,1 \%(330)$ \\
\hline Patrocínio Privado & $58,3 \%(435)$ & $59,7 \%(49)$ & $28,9 \%(11)$ & $57,1 \%(495)$ \\
\hline Patrocínio Público-Privado & $4,6 \%(34)$ & $5 \%(4)$ & $8 \%(3)$ & $4,8 \%(41)$ \\
\hline Total & $100 \%(746)$ & $100 \%(82)$ & $100 \%(38)$ & $100 \%(866)$ \\
\hline
\end{tabular}

Esse perfil predominantemente mercadológico dos ensaios clínicos brasileiros é um reflexo da globalização de pesquisas e inclusão dos países em desenvolvimento. Apesar da pior posição entre os BRICS, o Brasil cada vez mais entra na rota de investimentos dos ensaios multicêntricos de novos fármacos (GOMES et al., 2012). Contudo, assim como nos demais países em desenvolvimento, nota-se que essas pesquisas não abordam necessidades locais e caracterizam-se pela continuidade dos trabalhos iniciados nos países desenvolvidos.

A predominância das fases finais dos ensaios clínicos exemplifica isso e no Brasil não é diferente. Foi observada a predominância do desenvolvimento de Fases II e III dos ensaios clínicos em 70,5\% (610), com uma menor proporção estudos de fase I em 8,5\% (73) e de fase IV em 21\% (183) dos ensaios clínicos analisados. Estas fases envolvem um maior número de participantes e possíveis facilidades de captação de pessoas, além de menor custo de realização podem atrair a escolha de países em desenvolvimento, expondo estes países a maiores conflitos éticos. A Fase I, que geralmente envolve maior conhecimento tecnológico, 
geralmente está restrita aos países desenvolvidos de origem (CABRAL et al, 2006; GARRAFA; LORENZO, 2009; GOMES et al., 2014).

\section{Considerações Finais:}

Pelos resultados deste estudo, pode-se verificar que a proporção de temas dos ensaios clínicos realizados no Brasil nos últimos anos possui relativa conformidade com a proporção de carga de doenças, não se evidenciando então a tese do “desequilíbrio 90/10”. Porém, quando os temas são estratificados por classificação de vulnerabilidade identifica-se um número reduzido de pesquisas (4\%) para doenças relacionadas à pobreza, mesmo estas caracterizando-se pela grande necessidade de melhoria dos tratamentos.

O foco geral dos ensaios conduzidos no Brasil está marcado pela grande influência mercadológica, com condução majoritária pela indústria farmacêutica, com financiamento privado e como extensões de pesquisas originárias em outros países. Os temas mais pesquisados envolvem medicamentos de alto custo para doenças com caráter crônico e bom nível de internalização governamental como os diversos tipos de câncer, artrites, HIV e Hepatites Virais.

Já o perfil dos reduzidos ensaios para doenças da pobreza, caracteriza-se por um majoritário financiamento público, com foco nas doenças transmissíveis não imunopreveníveis, como doença de chagas, dengue, malária, leishmaniose, dentre outras.

As informações revelam a falta de prioridade dessas doenças nos ensaios clínicos conduzidos no país, apesar de registradas iniciativas importantes capitaneadas por instituições públicas. Estudos adicionais são necessários para verificar o potencial dessas pesquisas em gerar novos medicamentos e mudanças nos tratamentos. Um maior protagonismo governamental na condução e incentivo a pesquisas dessas doenças é necessário. 


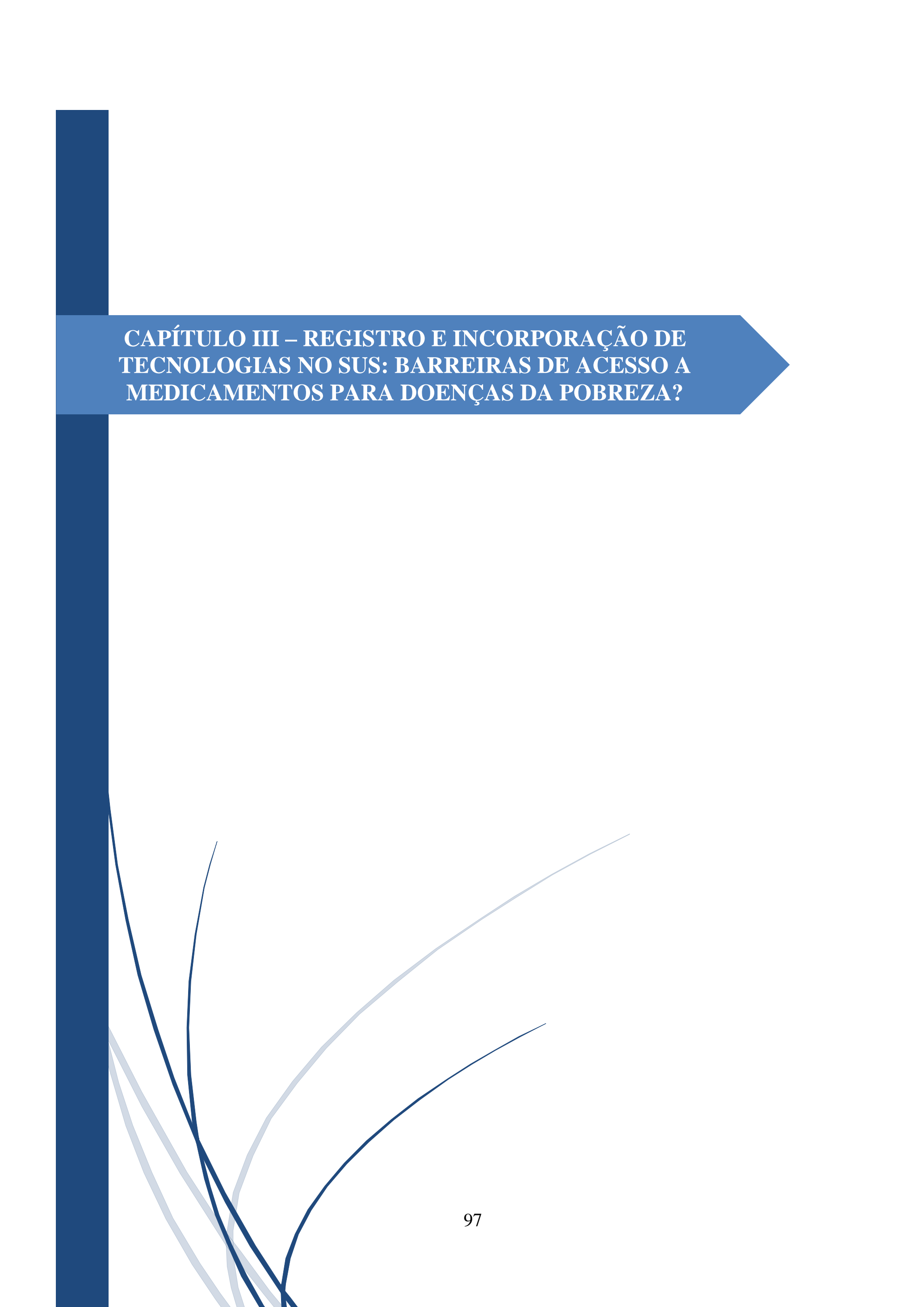


"A verdade é que a saúde, teoricamente fundada na observação, é tão sensível a influências políticas como um barômetro é sensível a atmosfera" (Oliver Holmes) 


\section{CAPÍTULO III - REGISTRO E INCORPORAÇÃO DE TECNOLOGIAS NO SUS: \\ BARREIRAS DE ACESSO À MEDICAMENTOS PARA DOENÇAS DA}

POBREZA?

\section{Resumo:}

O trabalho buscou verificar os aspectos relacionados ao registro sanitário e à incorporação de medicamentos no SUS para as doenças da pobreza. Trata-se de estudo exploratório, descritivo, desenvolvido entre janeiro e maio de 2016, em que foram realizados levantamentos e análises de documentos nos sítios eletrônicos da Anvisa, FDA, European Medicines Agency (EMA), Conitec e Sistema Saúde Legis. Infere-se que o Brasil precisa avançar na regulação de medicamentos sem interesse mercadológico, agenda inconclusa, que pode gerar barreiras de acesso às tecnologias para as populações vulneráveis. Verificouse um total de 132 medicamentos listados na Rename 2014 para atendimento específico das doenças da pobreza, sendo que mais de um terço (49) possuem apenas um produtor nacional e outros 24 não possuem registro no país. No período de 2006 a 2014, houve crescimento de 46\% do número de medicamentos na Rename para tais doenças. Apesar dos avanços do SUS nos campos da regulação e incorporação de tecnologias, dado o desinteresse de mercado e a condição de negligência para as doenças da pobreza, a atuação do Estado é imprescindível para garantir o acesso às melhores terapias disponíveis, visando à redução das iniquidades em saúde.

\section{Palavras-chave:}

Assistência farmacêutica; Doenças Negligenciadas; Registro de Produtos;

\section{Introdução:}

No Brasil, há previsão constitucional para o acesso universal e igualitário às ações e serviços de saúde. O acesso específico à assistência farmacêutica, além de abordado em legislações complementares, é assegurado por duas políticas de estado: a Política Nacional de Medicamentos e a Política Nacional de Assistência Farmacêutica.

Para viabilização do acesso a medicamentos fica ainda mais clara a prerrogativa do SUS de "formulação e execução de políticas econômicas e sociais" (BRASIL. 
PRESIDÊNCIA DA REPÚBLICA, 1990), uma vez que se trata de uma área profundamente influenciada por práticas comerciais e interesses mercadológicos diversos, muitas vezes conflitantes com o interesse público.

A criação da Anvisa em 1999 e o avanço no arcabouço jurídico-normativo regulatório materializa a intervenção do SUS no mercado para garantia da qualidade e segurança dos medicamentos produzidos no país (AITH; DALLARI, 2014).

Ressalta-se, porém, o papel abrangente da Anvisa, pois trata do registro e autorização de medicamentos em todo o mercado nacional e não necessariamente no SUS, que irá se realizar num passo posterior, sob a responsabilidade da Conitec, que assessora o Ministério da Saúde nas atribuições de incorporação, exclusão ou alteração de tecnologias em saúde no SUS.

Instituída com a promulgação da Lei n 12.401 , de 28 de abril de 2011, pode-se dizer que a Conitec é um órgão estratégico do sistema público de saúde brasileiro no que se refere à Avaliação de Tecnologias em Saúde (ATS). A Comissão foi posteriormente regulamentada pelo Decreto $\mathrm{n}^{\mathrm{0}} 7.646 / 2011$, tendo como competências principais: (i) a emissão de relatórios sobre a incorporação, exclusão ou alteração pelo SUS de tecnologias em saúde, e a constituição ou alteração de protocolos clínicos e diretrizes terapêuticas; (ii) a atualização da Rename.

No entanto, a definição e o escopo da lista nacional de medicamentos têm gerado opiniões divergentes. Por um lado, alguns autores entendem que houve uma harmonização entre as "listas de recomendação" e as "listas de financiamento" a partir desses e de outros atos normativos, com institucionalização de avaliações de eficácia, segurança e custoefetividade e, ao mesmo tempo, definição da responsabilidade de financiamento (SANTANA; CATANHEIDE, 2015). Por outro lado, há autores que apontam retrocessos com o distanciamento do conceito de essencialidade, na definição da Rename, 
recomendando a priorização do acesso a medicamentos de acordo com a carga de doenças brasileira e com o interesse sanitário (FIGUEIREDO et al., 2014).

Ainda se torna um desafio da área de regulação e incorporação de tecnologias em saúde a garantia de que também sejam realizados registros e disponibilização de itens com pouco interesse do mercado farmacêutico como medicamentos para doenças raras ou doenças típicas de populações pobres (BRASIL. MS. SVS, 2014a; STEVENS, 2008; WHO, 2012).

Alvo de inúmeros trabalhos que alertam sobre a falta de investimentos na área de pesquisa de medicamentos, as chamadas doenças negligenciadas ou doenças tropicais são reflexos das iniquidades em saúde e, no sentido de ampliar a identificação de sua característica de vulnerabilidade, têm sido denominadas atualmente como "doenças relacionadas à pobreza" ou simplesmente "doenças da pobreza"(BRASIL. MS. SVS, 2014a; STEVENS, 2008; WHO, 2012).

No período de 2000 a 2011, revisão de Pedrique et al. (2013) constatou que, dos 850 novos produtos terapêuticos aprovados pelas principais agências reguladoras do mundo, apenas $37(4 \%)$ eram destinados às doenças da pobreza, sendo 29 medicamentos e 8 vacinas. Impressiona ainda que, desse número, somente 4 produtos foram classificados como nova entidade química.

Apesar de o mercado farmacêutico ser orientado para determinadas doenças crônicas que geram fármacos altamente rentáveis e, tendo em vista a necessidade de incentivos em pesquisa e desenvolvimento de medicamentos para doenças da pobreza, a responsabilidade do Estado em garantir o acesso às melhores terapias disponíveis ganha papel de destaque e revela-se imprescindível para redução das iniquidades, ponto esse abordado com menor frequência nos trabalhos acadêmicos (IOC, 2011; STEVENS, 2008). 
Nesse sentido, este artigo pretende investigar os aspectos relacionados ao registro sanitário e à incorporação de tecnologias no SUS para as doenças da pobreza.

\section{Métodos}

Trata-se de estudo exploratório, descritivo, em que foram realizados levantamentos e análises de documentos relativos ao registro sanitário e à incorporação de medicamentos no SUS para tratamento das doenças relacionadas à pobreza. O percurso metodológico adotado compreendeu 5 etapas, realizadas entre janeiro e maio de 2016, conforme apresentado a seguir.

$\mathrm{Na}$ etapa 1, realizou-se pesquisa direta por atos normativos e regulamentações nacionais específicas sobre registro de medicamentos para doenças da pobreza no sítio eletrônico da Anvisa e no Sistema Saúde Legis, Sistema de Legislação do Ministério da Saúde. Os termos empregados foram: “doenças da pobreza”, “doenças negligenciadas”, “medicamentos órfãos” e "medicamentos estratégicos".

$\mathrm{Na}$ etapa 2, para fins de comparação com normas internacionais, foram realizadas buscas semelhantes nos sítios da agência norte-americana FDA e do órgão europeu EMA.

A etapa 3, compreendeu buscas por registros ativos dos medicamentos para doenças da pobreza, sendo utilizados os bancos de dados da Anvisa e da Câmara de Regulação do Mercado de Medicamentos (CMED). Como critério prévio para a busca, foram considerados todos os medicamentos utilizados na prevenção e tratamento etiológico de doenças e agravos relacionados à pobreza que constavam na Rename 2014 (versão atualizada em Junho/2015).

Na etapa 4, realizou-se uma revisão dos medicamentos para doenças relacionadas à pobreza incluídos nas edições da Rename de 2006, 2008, 2010, 2012 e 2014, com o objetivo de aferir a capacidade de incorporação destes itens ao longo dos anos no SUS. 
Com a etapa 5, foi realizado um levantamento do percentual de incorporação no SUS de medicamentos e outras tecnologias para doenças relacionadas à pobreza, a partir da instituição da Conitec pela Lei $\mathrm{n}^{\circ}$ 12.401/2011. Assim, todos os relatórios emitidos pela comissão no período de 2012 a 2015 foram analisados quanto à tecnologia, demandante e recomendação final. Adicionalmente, foram verificadas também no sítio eletrônico da comissão as normas para incorporação que pudessem impactar nos pedidos de inclusão de medicamentos para doenças da pobreza no SUS.

\section{Resultados e Discussão}

Autorizar a comercialização de um medicamento no país ou sua distribuição num sistema público é, sem dúvida, uma grande responsabilidade sanitária e social. Diversos exemplos históricos de problemas associados ao uso comunitário de medicamentos inseguros são conhecidos: desde períodos pré-regulatórios como no caso da focomelia causada pela talidomida na década de 50 e 60, passando pelas propriedades abortivas do misoprostol descobertas pós-liberação de mercado (década de 90), até se chegar no caso recente de retirada do rolecoxibe do mercado por estar associado ao aumento dos casos de doenças coronarianas, fato não previsto, mesmo pelos critérios regulatórios atuais (VASEN, 2008).

O Brasil vem, nesse sentido, modernizando seus mecanismos de regulação, garantindo melhor perfil de eficácia e segurança dos medicamentos autorizados pela Anvisa, ou mesmo incorporados pelo SUS por meio das recomendações da Conitec.

No entanto, é necessário ponderar que para tecnologias com pouco interesse do mercado, a adequação a determinados parâmetros regulatórios pode ser um impeditivo para a garantia do acesso e resultar em agravamento do quadro de escassez de tratamentos para 
doenças da pobreza. Nas seções a seguir, são citadas algumas barreiras e proposições para se avançar na agenda da saúde.

\section{Brasil precisa avançar em normas e incentivos para regulação de medicamentos sem interesse mercadológico, seguindo estratégias internacionais}

Condições negligenciadas pelo mercado farmacêutico não podem ser igualmente ignoradas pelos órgãos regulatórios. Por isso, agências reguladoras como o FDA e EMA já desenvolveram normas diferenciadas (Tabela 7) para fomentar a pesquisa e registro desses medicamentos, com destaque para os chamados "medicamentos órfãos", próprios de doenças raras, ou para o desenvolvimento de fármacos e formulações de uso pediátrico (PARRA, 2015; SEOANE-VAZQUEZ et al., 2008).

Tabela 7 - Comparação entre normas e incentivos regulatórios das agências Anvisa, FDA e EMA.

\section{Incentivos regulatórios}

Anvisa FDA EMA

\begin{tabular}{lccc}
\hline $\begin{array}{l}\text { Norma específica para registro de medicamentos "órfãos” e } \\
\text { medicamentos pediátricos }\end{array}$ & NÃO & SIM & SIM \\
\hline $\begin{array}{l}\text { Assistência da agência reguladora para elaboração de protocolos } \\
\text { de investigação }\end{array}$ & NÃO & SIM & SIM \\
\hline Redução ou isenção de taxas e incentivos fiscais & NÃO & SIM & SIM \\
\hline $\begin{array}{l}\text { Processo de análise comum entre agências reguladoras } \\
\text { Mecanismos de ampliação da exclusividade de mercado }\end{array}$ & NÃO & SIM & SIM \\
\hline $\begin{array}{l}\text { Comissões governamentais para definição de medicamentos } \\
\text { prioritários, suas normas e incentivos }\end{array}$ & NÃO & SIM & SIM \\
\hline $\begin{array}{l}\text { Previsão de "autorização condicional" para medicamentos que } \\
\text { ainda necessitam de mais estudos para elucidação de evidências }\end{array}$ & NÃO* & SIM & SIM \\
\hline $\begin{array}{l}\text { Norma para importação de medicamentos não registrados no país } \\
\text { para condições especiais }\end{array}$ & SIM & SIM & SIM \\
\hline $\begin{array}{l}\text { Norma para priorização da análise para medicamentos de } \\
\text { interesse do serviço de saúde (fasttrack) }\end{array}$ & SIM & SIM & SIM \\
\hline $\begin{array}{l}* \text { Vale ressaltar que há regulamento específico para os programas de acesso expandido, uso compassivo e } \\
\text { fornecimento de medicamento pós-estudo, conforme RDC no 38, de 12 de agosto de 2013. } \\
\text { Fonte: fda.gov; ema.europa.eu; anvisa.gov.br; Parra (2015); Seoane-Vazquez et al. (2008) }\end{array}$ & \\
\hline
\end{tabular}


Assim, infere-se que o Brasil deve avançar no marco regulatório para condições que não são atrativas ao mercado farmacêutico, sejam elas doenças relacionadas à pobreza, doenças raras ou mesmo condições específicas da população pediátrica. Na Tabela 7 podese observar diferenças nas normas da Anvisa, FDA e EMA que apontam agendas inconclusas no marco regulatório brasileiro.

A definição de norma para fomento da pesquisa e registro de medicamentos sem interesse comercial é uma estratégia adotada para os chamados medicamentos "órfãos" desde 1983, pelo “Orphan Drug Act” nos EUA e posteriormente adotada pelo Japão (1993), Austrália (1997) e pelo parlamento europeu em 1999. Em 2007, o FDA e EMA acordaram conciliar formulários e fluxos comuns para o registro de medicamentos órfãos, o que facilita o processo junto ao setor regulado, apesar dos processos decisórios ainda serem separados (PARRA, 2015).

As agências reguladoras internacionais entendem que, para um fármaco ser considerada órfão, deve: (i) atender ao diagnóstico, prevenção ou tratamento de uma doença que ameace a vida ou seja incapacitante; (ii) sem alternativa terapêutica satisfatória para a enfermidade em questão ou que se configure como novo benefício considerável ao tratamento; (iii) prevalência relativamente baixa para doença em questão, não sendo maior que 5/10.000 na união europeia e 6,3/10.000 habitantes nos EUA (EMA, 2016; FDA, 2016).

Mesmo não tratando especificamente de doenças relacionadas com a pobreza é possível observar que a prerrogativa de drogas órfãs pode contribuir no desenvolvimento de medicamentos para boa parte dessas enfermidades. Um exemplo característico é a doença de Chagas, típica do continente latino americano, extremamente incapacitante, com apenas uma droga terapêutica pouco eficaz na forma aguda e ineficaz na forma crônica da doença e, atualmente, com dados compatíveis com determinadas "doenças raras", com incidência 
de 0,61 casos/10.000 habitantes (formas agudas), apesar da alta prevalência das formas crônicas, fruto de quadros epidemiológicos anteriores (BRASIL. MS. SVS., 2015c).

A existência dessa norma regulatória no FDA tem levado, inclusive, ao registro de medicamentos para doenças de populações vulneráveis nos EUA, mas não no Brasil, mesmo esse último país possuindo uma maior prevalência e, consequentemente, um maior mercado consumidor. A seguir, são citados dois exemplos.

A miltefosina, único medicamento via oral disponível no mercado global para o tratamento das leishmanioses, foi beneficiada com a norma de medicamentos órfãos do FDA e está registrada no órgão desde 2013, mesmo os EUA possuindo casos normalmente relacionados a fluxos migratórios e restritos a estados como Texas e Oklahoma. Já no Brasil, ainda não há registro, nem importação do medicamento para uso no Programa Nacional de Controle das Leishmanioses, mesmo com detecção de 20 mil casos/ano para forma tegumentar e cerca de 4 mil casos/ano para a forma visceral. Vale ressaltar que a miltefosina está incluída na lista de medicamentos essenciais da OMS e está no guia de recomendações de tratamento das américas (FDA, 2016; OPAS, 2013).

Outro exemplo é a hidroxiureia, utilizada no tratamento crônico da doença falciforme, uma enfermidade congênita que atinge entre 25 mil a 50 mil brasileiros, em sua maioria a população negra e em estado de vulnerabilidade social. Esse fármaco também se beneficiou da normativa de medicamentos órfãos do FDA e EMA, há quase uma década, com registro de formulações em cápsulas de 200 mg, 300 mg e 400 mg, mesmo com estimativa de 22 mil pacientes em toda a Europa. No Brasil, há apenas um registro de cápsula de $500 \mathrm{mg}$ com indicação restrita a determinados tipos de câncer. Seu uso e financiamento para doença falciforme no SUS está regulamentado de forma off-label (EMA, 2008; PLATT, 2008). 
Seoane-Vazquez et al. (2008) demonstraram que os incentivos realizados pelo FDA para fomentar a pesquisa e registro de drogas com pouco interesse do mercado resultaram em 322 novas aprovações com esse mecanismo durante o período de 1983 a 2007. O estudo justificou como as principais estratégias exitosas: (i) subsídios de bolsas para pesquisadores; (ii) crédito fiscal de 50\% para gastos na fase de testes clínicos; e (iii) exclusividade de mercado por 7 anos após aprovação do registro

Estratégias semelhantes também são adotadas pela EMA, destacando-se que esses períodos de exclusividade aumentam em dois anos caso sejam encaminhadas investigações para uso pediátrico, independente se resultará ou não em registro de indicação adicional para esse público (EMA, 2008).

Alguns dos itens aprovados receberam uma chamada "autorização condicional" onde se prevê em um tempo breve o encaminhamento de novos estudos para então conceder um registro normal. Alguns estudiosos ponderam que essas estratégias também podem gerar autorizações com baixa qualidade de evidência clínica, além de fomentar que muitas empresas tentem induzir a entrada de medicamentos no mercado por esses mecanismos facilitados, mesmo com justificativas questionáveis. Atualmente, quase $25 \%$ dos itens registrados na EMA são classificados como órfãos. Por outro lado, a taxa de sucesso na aprovação de itens classificados por essa via $(62,9 \%)$ é menor que os não-órfãos (70\%) (DUPONT; WILDER, 2011; PARRA, 2015).

Poucos incentivos, poucos registros e insegurança na sustentabilidade da produção de medicamentos para as populações mais vulneráveis

Alguns autores já discutem a dificuldade das agências regulatórias em barrar registros de medicamentos que não trazem, a rigor, benefícios adicionais aos tratamentos já ofertados. No Brasil, isso também é uma realidade, como demostrado por Botelho et al. (2017) que 
identificaram, entre 2003 e 2013, 159 medicamentos novos registrados e apenas $28(17,6 \%)$ foram considerados como inovação terapêutica importante.

Além dessa dificuldade as agências também possuem, com atuais mecanismos regulatórios, pouca capacidade de equilibrar o número de registros entre as diferentes classes de medicamentos.

Em levantamento dos itens incluídos na Rename 2014, observa-se um total de 132 medicamentos que podem ser utilizados para a prevenção e tratamento de doenças e agravos relacionados à pobreza. Mesmo possuindo mecanismos estabelecidos de financiamento para todos os itens, esses medicamentos possuem média de apenas 3 produtores com registro ativo na Anvisa. Mais de um terço deles (49) possuem apenas um único produtor nacional, o que traz um potencial risco de desabastecimento, caso ocorra qualquer contratempo no processo regulatório ou produtivo. Ainda mais preocupante é o fato de que outros 24 (18\%) medicamentos não possuem qualquer registro no país, boa parte deles adquiridos pelo Ministério da Saúde por meio de importação via organismos internacionais. Essas duas últimas situações somadas representam 54,8\% (73) dos medicamentos utilizados para essas doenças (Figura 5).

Para itens que não possuem registro no país, a produção magistral não parece ser uma alternativa facilitada pela Agência, pois, a rigor, de acordo com o estabelecido na RDC ${ }^{\circ}$ 204/2006, "ficam proibidas a importação e comercialização de insumos farmacêuticos destinados à fabricação de medicamentos que ainda não tiverem a sua eficácia terapêutica avaliada pela Anvisa". Não fica claro, porém, se essa avaliação prévia trata-se de um registro anterior descontinuado, uma análise específica do insumo ou mesmo a vigência de um registro ativo (BRASIL. ANVISA, 2006). 


\section{Figura 5 - Número de registros ativos de medicamentos na Anvisa para doenças da pobreza $(n=132)$.}

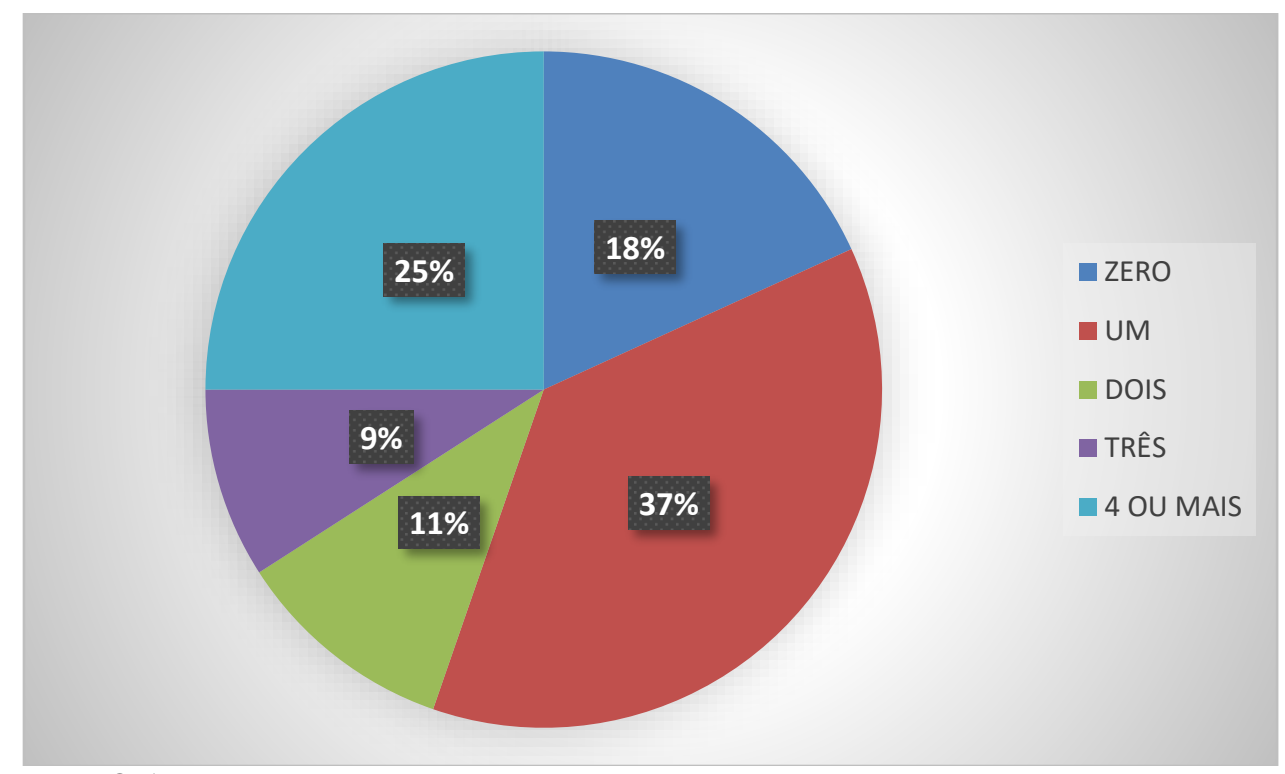

Fonte: O Autor

Como exemplo dessa situação, em resposta ao questionamento sobre o uso do hidrato de cloral (sedativo amplamente utilizado em procedimentos pediátricos), a Anvisa interpretou que mesmo estando na lista de medicamentos sujeitos a controle especial, pelo fato de não possuir medicamento com este princípio ativo registrado no país, "a importação do insumo não está autorizada" para manipulação em farmácias (BRASIL. ANVISA, 2006;2015).

A insegurança na sustentabilidade de medicamentos para doenças da pobreza fica evidente quando se verifica o contraste do número de registros de medicamentos para doenças globais não transmissíveis incluídos no Programa Farmácia Popular do Brasil, por exemplo, com uma média de 31 produtores para anti-hipertensivos e 29 produtores para antidiabéticos.

Já é notório a predileção da indústria farmacêutica pela pesquisa de determinadas doenças em detrimento de outras (CHIRAC; TORREELE, 2006; SANTOS et al., 2012), porém a falta de incentivos direcionados nas políticas de regulação e entraves burocráticos podem deixar ainda mais agudo esse desequilíbrio. 


\section{Tradição de incorporação de medicamentos na lista nacional para doenças da pobreza é uma conquista do SUS e deve ser mantida}

Avanços importantes na oferta de opções terapêuticas podem ser observados nas políticas de medicamentos essenciais do Brasil ao longo dos anos, como pode ser observado na Tabela 8. Observa-se um crescimento de $46 \%$ na inclusão de medicamentos para esse conjunto de doenças e agravos na Rename, durante o período de 2006 a 2014.

Tabela 8 - Número de medicamentos para doenças da pobreza contemplados nas edições da Rename (2006-2014).

\begin{tabular}{lcccccc}
\hline Grupo & $\begin{array}{c}\text { Rename } \\
\mathbf{2 0 0 6}\end{array}$ & $\begin{array}{c}\text { Rename } \\
\mathbf{2 0 0 8}\end{array}$ & $\begin{array}{c}\text { Rename } \\
\mathbf{2 0 1 0}\end{array}$ & $\begin{array}{c}\text { Rename } \\
\mathbf{2 0 1 2}\end{array}$ & $\begin{array}{c}\text { Rename } \\
\mathbf{2 0 1 4}\end{array}$ & $\begin{array}{c}\text { Principais Doenças e } \\
\text { Agravos }\end{array}$ \\
\hline $\begin{array}{l}\text { Doenças Infectocontagiosas } \\
\text { Imunopreveníveis }\end{array}$ & 15 & 16 & 16 & 23 & 26 & $\begin{array}{c}\text { Caxumba, Difteria, Febre Amarela, } \\
\text { Meningites, Poliomielite, Sarampo, } \\
\text { Raiva, Rubéola, Varicela. }\end{array}$ \\
\hline $\begin{array}{l}\text { Doenças Infectocontagiosas } \\
\text { Não Imunopreveníveis }\end{array}$ & 68 & 68 & 77 & 90 & 92 & $\begin{array}{c}\text { Acidentes com Animais } \\
\text { Peçonhentos, Doença de Chagas, } \\
\text { Miarreias Agudas, Febre } \\
\text { Maculosa, Geo-helmitíases, } \\
\text { Hanseníase, Leishmanoses, } \\
\text { Malária, Tuberculose }\end{array}$ \\
\hline Tutras Doenças da Pobreza & 7 & 10 & 10 & 13 & 14 & $\begin{array}{c}\text { Doença Falciforme, Deficiências } \\
\text { Nutricionais, Agravos decorrentes } \\
\text { de Violência Sexual }\end{array}$ \\
\hline Total & 90 & 94 & 103 & 126 & 132 & -- \\
\hline
\end{tabular}

A contínua incorporação de medicamentos para doenças da pobreza na lista nacional é, sem dúvida, uma estratégia decisiva que contribuiu para o acesso ao tratamento de doenças com poucas alterativas terapêuticas adequadas. A adoção dessa conduta pelo SUS segue uma tendência internacional. Cohen et al. (2010) identificou que dos 46 novos medicamentos para doenças negligenciadas lançados entre 1975 e 1999, a OMS incluiu 85\% deles na sua Lista Modelo de Medicamentos Essenciais (LME). No período de 2000 a 2009, 26 novos 
medicamentos e vacinas para estas doenças foram comercializados e metade deles foi incluído na lista da OMS (COHEN et al., 2010).

O Brasil já possuiu tradição de viabilização do acesso a algumas dessas tecnologias. O melhor exemplo refere-se à ampliação do acesso às vacinas, com um programa consolidado, com mais de 40 anos, disponibilizando $100 \%$ das vacinas recomendadas pela OMS para as doenças encontradas no Brasil, e que conta 20 apresentações na última edição da Rename 2014.

A ampla cobertura vacinal conquistada na última década, superior a 90\% para a maioria das vacinas do calendário infantil, é resultado de uma política de saúde de referência para muitas regiões do mundo que ainda não conseguiram garantir o mesmo acesso. Mesmo com avanços na incorporação de vacinas em diferentes países africanos e estruturação de campanhas de vacinação, em média, uma em cada cinco crianças africanas não possuem acesso a vacinas e apenas nove países registram seus percentuais de coberturas (MIHIGO et al., 2015; WHO, 2016).

Agenda de avaliação de tecnologias está centrada na alta tecnologia e pode dificultar a pauta de novos medicamentos para doenças da pobreza

No levantamento realizado a partir dos relatórios de recomendação da Conitec, observou-se que das 162 recomendações emitidas pela Comissão durante o período do início dos seus trabalhos em 2012 até final de 2015, 131 estavam relacionadas às doenças globais, não transmissíveis, o que representa $81 \%$ da demanda avaliada pela Comissão (Figura 6).

Essa predominância de recomendações relacionadas às doenças globais não transmissíveis explica-se pelos próprios métodos e tendências do processo de ATS, que está centrado na alta tecnologia e na análise das inovações, com pouca abertura para a avaliação de tecnologias leves ou de baixo custo. No Brasil, a pressão do mercado pelas inovações 
soma-se ao fenômeno da judicialização em saúde que, continuamente interfere nos orçamentos públicos e consolida o dilema entre os princípios de integralidade e equidade no SUS (GUIMARÃES, 2014).

\section{Figura 6 - Número de recomendações da Conitec quanto às tecnologias avaliadas no período de 2012 a 2015, classificadas por tipo de doença.}

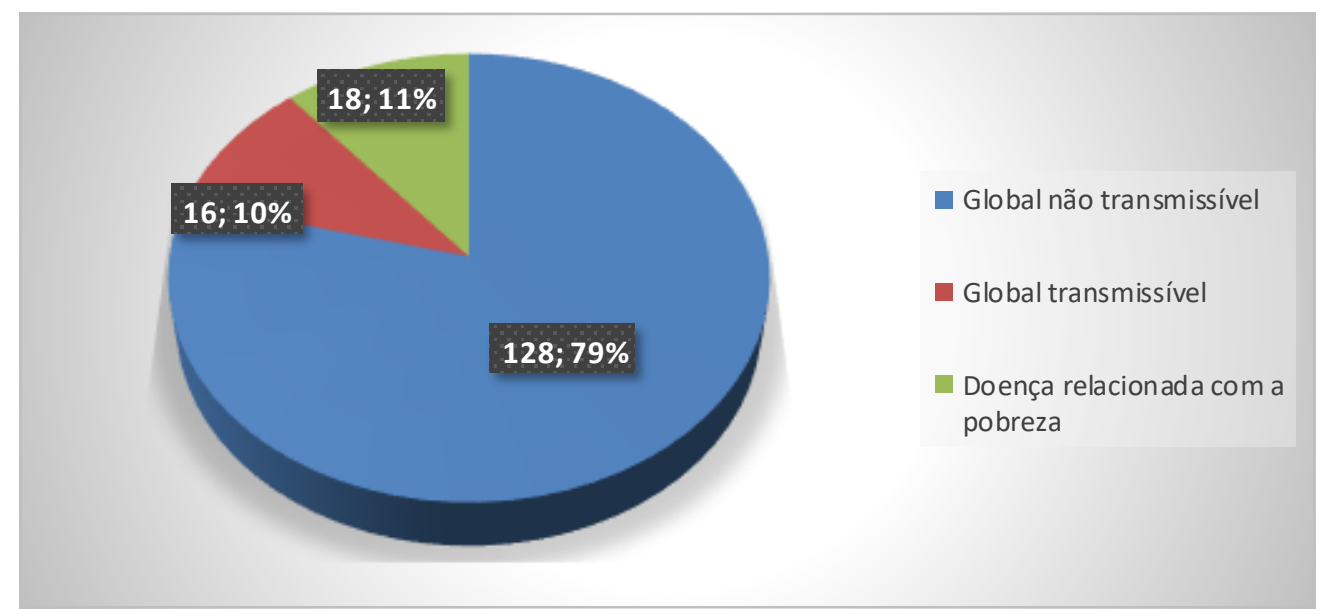

Fonte: O Autor

A presença expressiva da demanda oriunda de indústrias farmacêuticas, observada em 40,7\% (66) dos relatórios emitidos, demonstra essa pressão mercadológica sofrida pelo SUS. Poder judiciário e associações relacionadas à saúde representaram cerca de 4,3\% (7) dos demandantes da avaliação no período avaliado. Ainda assim, há um esforço para que cada vez mais ocorra um aumento das demandas de entes do próprio SUS (programas do Ministério da Saúde, secretarias estaduais e municipais de saúde) mantendo os fluxos, critérios e transparência das análises da Conitec, com padrão de trabalho comparado a outras experiências internacionais (PEREIRA; SALOMON; SOUZA, 2015).

As avaliações de tecnologias para doenças globais transmissíveis representaram $10 \%$ da demanda e estavam centradas em basicamente dois temas específicos: hepatites e HIV, com 13 das 16 demandas avaliadas pela Conitec. O alto grau de inovação característico dessas doenças, a histórica estruturação de programas e as redes exclusivas de cuidado 
ampliam a pressão pela rápida e contínua incorporação de novos medicamentos, tanto no SUS como internacionalmente (CANARY et al., 2015; DUARTE et al., 2011).

Apesar de em menor número, há presença de decisões sobre itens relacionados à pobreza em cerca de $11 \%$ dos relatórios emitidos durante o período avaliado. Das 18 recomendações emitidas, 15 referiam-se a análises de medicamentos, duas de testes diagnósticos e uma de procedimento de saúde. Na Tabela 9 pode-se verificar em detalhes essas recomendações de medicamentos e demais tecnologias para doenças relacionadas à pobreza.

Tabela 9 - Relatórios de recomendação da Conitec relacionados às doenças da pobreza (2012-2015)

\begin{tabular}{|c|c|c|}
\hline Grupo & $\begin{array}{l}\text { Recomendações } \\
(n=15)\end{array}$ & Número do relatório e principais doenças e agravos \\
\hline $\begin{array}{l}\text { Doenças } \\
\text { Infectocontagiosas } \\
\text { Imunopreveníveis }\end{array}$ & 03 & $\begin{array}{l}\text { Relatório } 46 \text { - Vacina adsorvida difteria, tétano e pertussis (acelular) } \\
\text { - dTpa - para vacinação de gestantes } \\
\text { Relatório } 21 \text { - Vacina Tetraviral (varicela, sarampo, caxumba e } \\
\text { rubéola) } \\
\text { Relatório } 131 \text {-Azitromicina 250mg para tratamento ou } \\
\text { quimioprofilaxia da coqueluche }\end{array}$ \\
\hline $\begin{array}{l}\text { Doenças } \\
\text { Infectocontagiosas Não } \\
\text { Imunopreveníveis }\end{array}$ & 07 & $\begin{array}{l}\text { Relatório } 96 \text {-Doxicilina injetável e o Cloranfenicol suspensão para } \\
\text { terapêutica da febre maculosa brasileira e outras riquetsioses } \\
\text { Relatório } 150 \text {-Penicilina benzantina para prevenção da sífilis } \\
\text { congênita } \\
\text { Relatório } 165 \text {-Quimioprofilaxia de contatos de doentes de } \\
\text { hanseníase com rifampicina em dose única } \\
\text { Relatório } 157 \text {-Doxiciclina } 100 \mathrm{mg} \text { comprimidos para tratamento de } \\
\text { sífilis } \\
\text { Relatório } 153 \text {-Ceftriaxona 500mg injetável para o tratamento de } \\
\text { sífilis } \\
\text { Relatório } 154 \text {-Ceftriaxona 500mg injetável para o tratamento de } \\
\text { gonorreia resistente à ciprofloxacina } \\
\text { Relatório } 199 \text {-Pentoxifilina } 400 \mathrm{mg} \text { em associação ao antimonial } \\
\text { para o tratamento da leishmaniose tegumentar mucosa }\end{array}$ \\
\hline $\begin{array}{l}\text { Outras Doenças da } \\
\text { Pobreza }\end{array}$ & 05 & $\begin{array}{l}\text { Relatório } 130 \text { - Suplemento alimentar em pó - NutriSUS com } \\
\text { múltiplos micronutrientes } \\
\text { Relatório } 57 \text {-Hidroxiureia para crianças com doença falciforme } \\
\text { Relatório } 56 \text { - Penicilina oral para profilaxia de infecção em } \\
\text { crianças menores de } 5 \text { anos com doença falciforme } \\
\text { Relatório } 137 \text {-Risperidona no tratamento da dependência de } \\
\text { cocaína/crack } \\
\text { Relatório } 147 \text { - Eritropoietina para o tratamento da doença } \\
\text { falciforme }\end{array}$ \\
\hline
\end{tabular}


Com pouco foco de inovação e interesse do mercado, as demandas para essas doenças são essencialmente realizadas pelo próprio Ministério da Saúde, demandante em 86\% (13) desses relatórios, com atendimento do pleito para incorporação ou ampliação do uso em $80 \%$ (12) dos casos.

Pode-se observar que, efetivamente, poucos itens são realmente novos na lista, sendo a maioria caracterizada pela ampliação de uso dos medicamentos já utilizados em outras doenças ou pequenas modificações nos esquemas de tratamentos estabelecidos nos documentos oficiais. Porém, alguns itens merecem destaque pelo seu impacto na qualificação da assistência prestada.

Duas vacinas foram incorporadas pelo SUS no período estudado, uma delas substituindo a tríplice viral pela tetraviral, com inclusão de proteção contra varicela no calendário infantil de vacinação. A inclusão de suplementação de micronutrientes para crianças em idade escolar também se configura como uma incorporação de destaque, dado o seu potencial de contribuição ao enfrentamento das anemias carenciais na infância e para auxiliar no pleno desenvolvimento da criança. A incorporação da penicilina oral para prevenção de infecções na criança com doença falciforme revela-se um avanço, possibilitando melhorias na qualidade de vida desses pacientes (BRASIL. MS. SGEP, 2013; CONITEC, 2013, 2014).

Ampliação de uso ou ratificação de profilaxia e tratamento para hanseníase, leishmaniose, coqueluche e febre maculosa, também possuem potencial para garantir a assistência aos usuários, apesar de não se configurarem como inovações ou melhorias significativas. Três recomendações estavam relacionadas, ainda, à tentativa de estabelecer alternativas para o tratamento dos casos de sífilis, dado o quadro de desabastecimento de penicilina que ocorreu no país, situação preocupante que foi objeto de audiência pública no Congresso Nacional em 2015 e que levou o Ministério da Saúde a definir medidas de 
priorização de acesso e a realizar aquisição de penicilinas no mercado internacional (XAVIER, 2015; BRASIL, 2015).

Ressalta-se que os critérios de submissão de evidências para avaliação pela Conitec podem prejudicar o envio de demandas para doenças da pobreza, uma vez que não contam com o mesmo investimento científico e há muitas lacunas de qualidade das provas científicas quando se compara com tecnologias de alto custo, uma vez que o foco de produção da evidência científica mundial está centrada nas pesquisas de doenças crônicas, com pouca participação dos países em desenvolvimento e suas doenças típicas (GOMES et al., 2012).

Apesar do esforço da Conitec em orientar as principais áreas demandantes sobre os documentos de admissibilidade e criar estratégias para redução de demandas não conformes ao longo dos anos, não há formalmente nenhum fluxo ou regra diferenciada para análise de produtos com pouco interesse do mercado, o que, na prática, não fomenta a submissão desse tipo de demanda, principalmente por laboratórios farmacêuticos (RABELO et al., 2015).

A exigência prévia de registro na Anvisa pode ser um dos principais entraves para a submissão de propostas por laboratórios farmacêuticos (demanda externa) pois, como verificado anteriormente, além das barreiras regulatórias desses medicamentos no país, é pouco estratégico para empresa iniciar um pedido de registro sem ter certeza que será absorvido em determinados programas nacionais de saúde, como tuberculose, malária, hanseníase, leishmaniose, caracterizados por um financiamento historicamente centralizado e com acesso exclusivo de tratamento via SUS.

Alguns produtos lançados nos últimos anos por indústrias farmacêuticas para essas doenças já estão incluídos em listas de alguns países, mas ainda não foram submetidos à avaliação do SUS como a miltefosina para leishmaniose, bedaquilina para tuberculose, arterolana + piperaquina para malária ou mesmo novas formulações solúveis de benznidazol para a doença de Chagas, todos sem registro no Brasil. 
Apesar da exigência de registro prévio, a via alternativa parece ser a análise via demanda interna do próprio Ministério da Saúde, pois, dos itens demandados para estas doenças, cinco medicamentos não possuíam registro e necessitariam passar por processos de importação via organismo internacional para disponibilização no SUS.

Esse quadro de negligência tecnológica pode ser explicado por três principais motivos: (i) o baixo número de pesquisas realizadas para doenças da pobreza e consequentemente menor número de inovações; (ii) a pouca mobilização do mercado farmacêutico e da sociedade para demandar a incorporação ou revisão dos tratamentos para esse tipo de doença; e (iii) processo de ATS não adaptado à análise de tecnologias de baixo custo ou de doenças da pobreza.

Uma postura proativa para fomentar a análise de itens como esses poderia resultar na ampliação do acesso e na melhoria no tratamento de doenças que atingem pessoas com menor poder de mobilização social e, consequentemente, não conseguem pressionar o sistema de saúde. Uma proposta de ação equitativa para análise de tecnologias pode ser centrada no desenvolvimento pelo SUS de atividades conhecidas como "Monitoramento do Horizonte Tecnológico" (MHT) para doenças relacionadas à pobreza.

Vital et al. (2013) apontam que, com a estruturação de atividades de MHT no âmbito do Ministério da Saúde, é possível contribuir para a definição das tecnologias prioritárias para o SUS e para a orientação de investimentos em pesquisa e desenvolvimento de medicamentos que atendam às necessidades nacionais 


\section{Considerações Finais}

Apesar dos avanços do Brasil nos campos da regulação e incorporação de tecnologias em saúde, dado o desinteresse de mercado e a condição de negligência em relação às doenças da pobreza, a atuação do Estado revela-se imprescindível para garantir o acesso às melhores terapias disponíveis, visando à redução dos descasos em saúde.

A criação da Anvisa, em 1999, e da Conitec, em 2011, refletem o amadurecimento das políticas públicas que materializam o aprimoramento do SUS. Entretanto, o presente trabalho apontou a necessidade de se avançar na regulação de medicamentos sem interesse mercadológico, situação essa que pode gerar barreiras de acesso às tecnologias para as populações vulneráveis. Aprimorar os mecanismos para avaliação de tecnologias e incentivar a demanda dos entes do SUS para submissão de propostas na Conitec sobre doenças da pobreza também se revela etapa precípua para qualificar a assistência à saúde.

Por fim, pode-se afirmar a agenda de saúde sobre doenças da pobreza merece especial atenção e investimento do Estado brasileiro, seja no campo da pesquisa, desenvolvimento e produção de medicamentos, na ampliação do acesso da população às tecnologias já incorporadas, seja na criação e aperfeiçoamento do arcabouço jurídico-sanitário. 
CAPÍTULO IV - ESTRATÉGIAS PARA GARANTIA DO ACESSO E O GASTO FEDERAL COM MEDICAMENTOS PARA DOENÇAS DA POBREZA 
"Os que comem bem, dormem bem e possuem boas casas, possivelmente pensam que se gastam demais com políticas sociais" (Pepe Mujica) 


\section{CAPÍTULO IV - ESTRATÉGIAS PARA GARANTIA DO ACESSO E O GASTO FEDERAL COM MEDICAMENTOS PARA DOENÇAS DA POBREZA}

\section{Resumo:}

O financiamento para acesso a medicamentos tem sido um dos grandes desafios do sistema de saúde em todo o mundo. Para doenças que possuem menor interesse e oferta de medicamentos pelo mercado esse desafio se torna maior. Este trabalho pretendeu levantar as principais estratégias adotadas pelo governo brasileiro para garantir o acesso às chamadas doenças relacionadas à pobreza. Foram analisadas as aquisições realizadas pelo governo federal durante 10 anos (2005 a 2014) a partir dos bancos de dados do Ministério da Saúde. Foram identificadas três estratégias principais para efrentar as dificuldades de garantir o acesso a esses medicamentos: (i) aquisição via organismos internacionais; (ii) centralização do financiamento e da aquisição para a grande maioria dos medicamentos; e (iii) utilização dos laboratórios oficiais para sustentabilidade da produção. A observação dessas estratégias permite verificar os avanços e pontos de melhoria da política de assistência farmacêutica brasileira, evitando retrocessos em momentos de crise e auxiliando na definição de políticas de outros países.

\section{Palavras-chave:}

Pobreza; Doenças Negligenciadas; Acesso a Medicamentos; Iniquidades em Saúde.

\section{Introdução:}

Nos momentos de crise econômica, a área da saúde sempre se vê ameaçada com os discursos de cortes financeiros e ações de austeridade fiscal. Porém, nesses momentos, as políticas de proteção social, como o SUS, passam a ter papel estratégico para lidar com o aumento da prevalência de condições relacionadas ao sofrimento mental, determinadas condições crônicas e doenças relacionadas à pobreza. $\mathrm{O}$ contingente de pessoas que deixam de possuir recurso para custear atendimentos particulares ou planos de saúde, ocasiona o 
aumento da demanda pela assistência à saúde prestada pelo Estado (VIEIRA, 2016; VIEIRA; BENEVIDES, 2016).

O financiamento do SUS tem se configurado como um tema que mobiliza os três poderes da república evidenciados nas disputas por ampliação e cortes de orçamento nas proposições legislativas, no discurso dicotômico de subfinanciamento e melhoria na gestão do SUS e no crescente fenômeno da judicialização da saúde (SANTOS et al., 2016).

Segundo informações do Ministério da Saúde, o impacto da judicialização da saúde pode chegar a R \$ 7 bilhões para a união, estados e municípios (PENIDO, 2016). Um gasto não previsto nas leis orçamentárias que requer o remanejamento das contas públicas para atendimento e que possui como principal demanda à garantia de acesso a medicamentos.

Revisões sistemáticas (LEITÃO et al., 2014; TORRES, 2013) sobre o acesso a medicamentos por via judicial demonstram que a maior parte dos itens demandados estão relacionados a doenças crônicas, tecnologias novas não disponíveis no SUS, mas também há um percentual significativo de medicamentos presentes nas listas de financiamento do sistema (19,6\% a 98,4\%). Nos diferentes estudos analisados não se observa, no entanto, a presença de medicamentos comuns a determinadas doenças transmissíveis, de doenças consideradas negligenciadas ou relacionadas à pobreza.

O baixo número de inovações e o pouco acesso dos acometidos por essas doenças ao poder judiciário podem ser hipóteses possíveis, porém a estruturação do financiamento e acesso a medicamentos para essas doenças no Brasil pode também contribuir para esse quadro e será abordado neste capítulo.

A definição de políticas de financiamento para doenças relacionadas à pobreza se configura como estratégias de equidade em saúde, que vem sendo ameaçada pela agenda de austeridade governamental e pelo pouco interesse de economistas e pesquisadores sobre o tema. McLntyre e Mooney (2014) demonstram a nítida redução do debate e do investimento 
em pesquisas sobre ações de equidade na saúde, a prevalência de estudos econômicos mais restritos a determinados desfechos clínicos em detrimento de estudos que avaliem custos e benéficos ampliados, incluindo parâmetros de determinantes sociais da saúde.

Stevens (2008) é ainda mais enfático, ao defender que a falta de acesso a boa parte dos medicamentos para doenças da pobreza não pode ser apenas atribuído a falta de pesquisas clínicas ou investimentos da indústria, mas também a falhas nos mecanismos de definição de políticas públicas de financiamento e acesso a medicamentos que já estão disponíveis. É necessário ainda, garantir acessibilidade as diferentes regiões do país, a um custo sustentável, evitando falsificações, desvios de qualidade e adoção de orientação adequada (HUNT; KHOSLA, 2008).

Diante dessa seara de conflitos de financiamento e definição de prioridades nas políticas públicas de saúde, este capítulo pretende contribuir com uma análise da estratégia brasileira de financiamento e oferta de medicamentos para doenças da pobreza.

\section{Métodos:}

Realizou-se um estudo exploratório, com aspectos descritivo-analíticos, com percurso metodológico organizado em 3 etapas.

$\mathrm{Na}$ primeira etapa, foi realizado um levantamento dos medicamentos incluídos na Relação Nacional de Medicamentos vigente (Rename 2014) utilizados para a prevenção e tratamento de doenças relacionadas à pobreza.

Como há alguns dissensos na definição dessas doenças, os pesquisadores adotaram classificação de estudos anteriores (SANTANA; LEITE, 2016; SANTANA et al, 2017), baseados na adaptação de conceitos da Organização Mundial da Saúde (OMS) e da organização Médicos Sem Fronteiras (MSF), categorizando-as em: (i) doenças globais não transmissíveis, (ii) doenças globais transmissíveis e (iii) doenças relacionadas com a pobreza (MSF, 2001; WHO, 2012). 
De posse do elenco de medicamentos para doenças da pobreza, foi realizada uma busca na base de dados de registros da Anvisa e da CMED, com intuito de verificar a disponibilidade de registros de laboratórios farmaceuticos para produção nacional. Foram consideradas as apresentações com registro ativo durante as buscas realizadas em agosto de 2016.

Na segunda etapa, foi realizado o levantamento dos dados orçamentários e processos de aquisição desses medicamentos em nível federal na última década (período de janeiro de 2005 a dezembro de 2014). Utilizaram-se para isso registros internos do Departamento de Assistência Farmacêutica do Ministério da Saúde, informações do Sistema de Informação de Insumos Estratégicos (SIES) e informações dos próprios contratos firmados entre o Ministério e os fornecedores. Foram coletadas informações realicionadas ao fornecedor/produtor contratado (laboratórios oficias; laboratórios prívados; e organismos internacionais) e aos valores contratados. A evolução de gastos foi comparada a evolução de orçamentos para o programa de HIV/Aids, do componente especializado da assistência farmacêutica e de gastos com processos de judicialização dos medicamentos.

Todos os valores foram atualizados de acordo com os preços referentes a novembro de 2016 por meio do Índice de Preços ao Consumidor Amplo (IPCA), e do Instituto do Brasileiro de Geografia e Estatística (IBGE). Esse índice foi o escolhido por ser o utilizado pelo Governo Federal para atualizar preços de medicamentos (IBGE, 2017). Nos contratos internacionais que apresentavam valores de aquisição em dólar foi realizada conversão utilizando os valores padrão de conversão definidos nos próprios contratos.

\section{Resultados e Discussão:}

Foram identificados 132 medicamentos incluídos na Rename vigente, utilizados na prevenção e tratamento das doenças relacionadas à pobreza. Pelo levantamento das empresas 
com registro no país é possível observar um limitado número de produtores de medicamentos. Mais da metade $(55,3 \%)$ dos itens apresentam apenas um produtor nacional ou só podem ser obtidos por meio de aquisição internacional para atendimento de programas consolidados como tuberculose, hanseníase, malária ou mesmo para prevenção de doenças nutricionais e para ações de imunização (Tabela 10).

Tabela 10 - Medicamentos para doenças da pobreza e respectivo número de empresas com registro no Brasil em agosto de 2016

\begin{tabular}{cccccccc}
\hline \multicolumn{1}{c}{ Doenças da Pobreza } & $\begin{array}{c}\text { Média de } \\
\text { Registros }\end{array}$ & $\begin{array}{c}\text { Sem } \\
\text { Registro }\end{array}$ & $\begin{array}{c}\mathbf{0 1} \\
\text { registro }\end{array}$ & $\begin{array}{c}\mathbf{0 2} \\
\text { registros }\end{array}$ & $\begin{array}{c}\mathbf{0 3} \\
\text { registros }\end{array}$ & $\begin{array}{c}\mathbf{0 4} \text { ou + } \\
\text { registros }\end{array}$ & Total \\
\hline $\begin{array}{l}\text { Doenças Infectocontagiosas } \\
\text { Imunopreveníveis }\end{array}$ & 2,28 & 05 & 09 & 06 & 02 & 04 & 26 \\
\hline $\begin{array}{l}\text { Doenças Infectocontagiosas } \\
\text { Não Imunopreveníveis }\end{array}$ & 3,41 & 16 & 34 & 08 & 09 & 25 & 92 \\
\hline $\begin{array}{c}\text { Outras Doenças da Pobreza } \\
\text { Total }\end{array}$ & 2,61 & 03 & 06 & 00 & 01 & 04 & 14 \\
\hline \multicolumn{1}{c}{} & $\mathbf{3 , 0 5}$ & $24(18,2 \%)$ & $49(37,1 \%)$ & $14(10,6 \%)$ & $12(9,1 \%)$ & $33(25 \%)$ & 132 \\
\hline
\end{tabular}

Entende-se que a existência de poucos ou nenhum produtor nacional gera um quadro de insegurança na oferta desses produtos, uma vez que problemas regulatórios e produtivos no Brasil ou no país de origem pode gerar um quadro eminente de desabastecimento.

Bolelho et al. (2016) demonstrou que os últimos medicamentos registrados no país se caracterizam por itens em desacordo com a carga de doenças brasileira, sendo apenas $17 \%$ deles classificados como inovação terapêutica importante. Santana et al. (2017) reforçam ainda que apesar da ampliação da oferta de medicamentos para doenças da pobreza na Rename nos últimos anos, a escassez de registros para essas tecnologias coloca em risco a sustentabilidade de programas estratégicos do SUS. Ambos afirmam que estratégias de direcionamento da pesquisa de medicamentos para atendimento das necessidades nacionais e fomento ao registro de medicamentos com pouco apelo comercial devem ser ações das políticas públicas de saúde. 


\section{Estratégia 01 - Aquisição de medicamentos via Organismo Internacional}

Para solução imediata do acesso a itens que não possuem registro, o país recorre à estratégia de importação via organismos internacionais.

A importação de medicamentos sem registro no país se sustenta em normativas como da Lei $\mathrm{n}^{\circ} 9.782$ de 1999 que diz:

"A Agência poderá dispensar de registro os imunobiológicos, inseticidas, medicamentos e outros insumos estratégicos quando adquiridos por intermédio de organismos multilaterais internacionais, para uso em programas de saúde pública pelo Ministério da Saúde" (BRASIL. PRESIDÊNCIA DA REPÚBLICA, 1999).

A Lei n 10.191 de 2001 corrobora ainda destacando que essas aquisições "poderão ser realizadas por intermédio de organismos multilaterais internacionais, de que o Brasil faça parte e obedecerão aos procedimentos por eles adotados" (BRASIL. PRESIDÊNCIA DA REPÚBLICA, 2001).

Mesmo com essa previsão legal, entende-se que a existência de pouco ou nenhum produtor nacional gera um quadro de insegurança na oferta desses produtos, uma vez que problemas regulatórios e produtivos no Brasil ou no país de origem podem gerar um quadro eminente de desabastecimento.

Para os itens importados a principal forma de aquisição é via termos de cooperação técnica com a Organização Pan-americana da Saúde (Opas), que se utiliza do chamado Fundo Estratégico para Medicamentos, responsável pela aquisição, principalmente, de vacinas, antirretrovirais e medicamentos para tratamento de doenças relacionadas pobreza no continente americano (HORST; SOLER, 2010).

Para os itens produzidos no país, a oferta é essencialmente garantida pela rede de laboratórios oficiais. Em 2014, por exemplo, esses laboratórios públicos foram responsáveis 
pelo fornecimento de 50\% (32) das compras realizadas pelo Ministério da Saúde para doenças da pobreza.

\section{Estratégia 02 - Centralização do financiamento e aquisição}

Dos 132 medicamentos identificados na edição da Rename 2014, 79\% (105) possuem financiamento de responsabilidade da união (Figura 7). O recurso é proveniente basicamente do chamado componente estratégico da assistência farmacêutica. Estabelecido pela Portaria n 204 de 2007 que define os blocos de financiamento do SUS. Esse componente destina-se à garantia do acesso a medicamentos para doenças e agravos de perfil endêmico, com importância epidemiológica, impacto socioeconômico ou que acometem populações vulneráveis, contemplados em programas estratégicos do SUS (BRASIL. PRESIDÊNCIA DA REPÚBLICA, 2007; MARQUES et al, 2016).

Em outros países em desenvolvimento, cerca de 50\% a 90\% dos medicamentos essenciais precisam ser adquiridos pelo próprio paciente, o que pode ser inviável quando se tratam de doenças que atingem populações vulneráveis e para o custeio de tratamentos novos de tuberculose, HIV/AIDS ou malária, por exemplo (OMS, 2004).

A responsabilização federal pela aquisição da maioria dos medicamentos para Doenças da Pobreza configura-se como uma estratégia exitosa, modelo para políticas de outros países ou para estruturação de colaborações regionais, uma vez que nem sempre a demanda de produção desses medicamentos é custo-efetiva para um ganho de escala de um laboratório. Por isso, a centralização do financiamento, planejamento e concentração da demanda e fluxo único de atendimento ao Ministério da Saúde é estratégia crucial para que os laboratórios públicos possam atender a necessidades desses tipos de tratamento. 


\section{Figura 7 - Elenco de medicamentos para doenças da pobreza por tipo de aquisição}

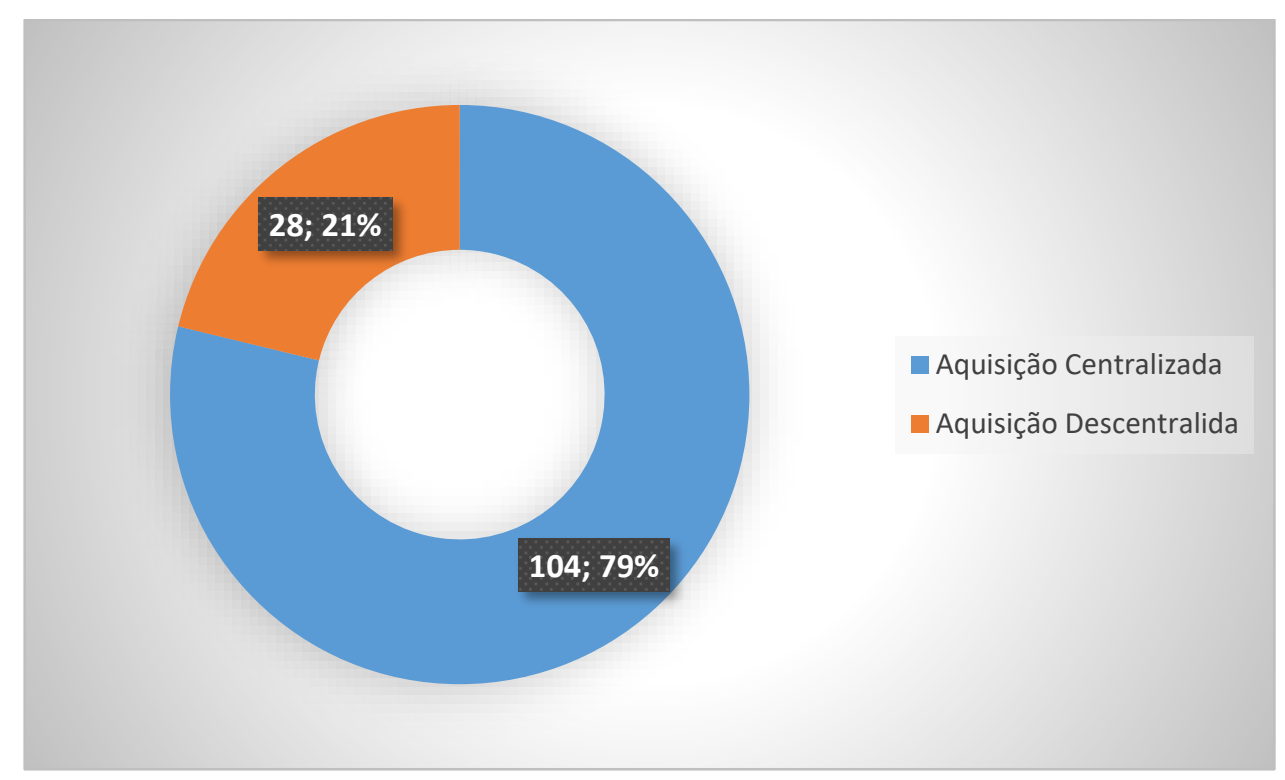

Fonte: O Autor

Souza et al. (2015) demonstram que essa estratégia de centralização do financiamento, informações e demanda no Ministério da Saúde contribuem para efetivação do fornecimento de medicamentos ao SUS por meio de laboratórios oficiais, tendo o ente federal como principal cliente. A não estruturação de um adequado fluxo de informações de demanda e canais de distribuição talvez justifique o fato desse mesmo êxito não ser alcançado para atendimento de estados e municípios.

\section{Estratégia 03 - Fortalecimento e utilização dos laboratórios oficiais}

No Brasil, as ações de fortalecimento dos laboratórios públicos foram essenciais para a garantia de oferta de medicamentos para doenças da pobreza. Como pode ser verificado na figura 8 , os laboratórios oficiais foram responsáveis pelo atendimento de quase dois terços das aquisições realizadas pelo Ministério da Saúde na última década. 


\section{Figura 8 - Vias de fornecimento de medicamentos para Doenças da Pobreza na última década (2005 a 2014) por número de aquisições}

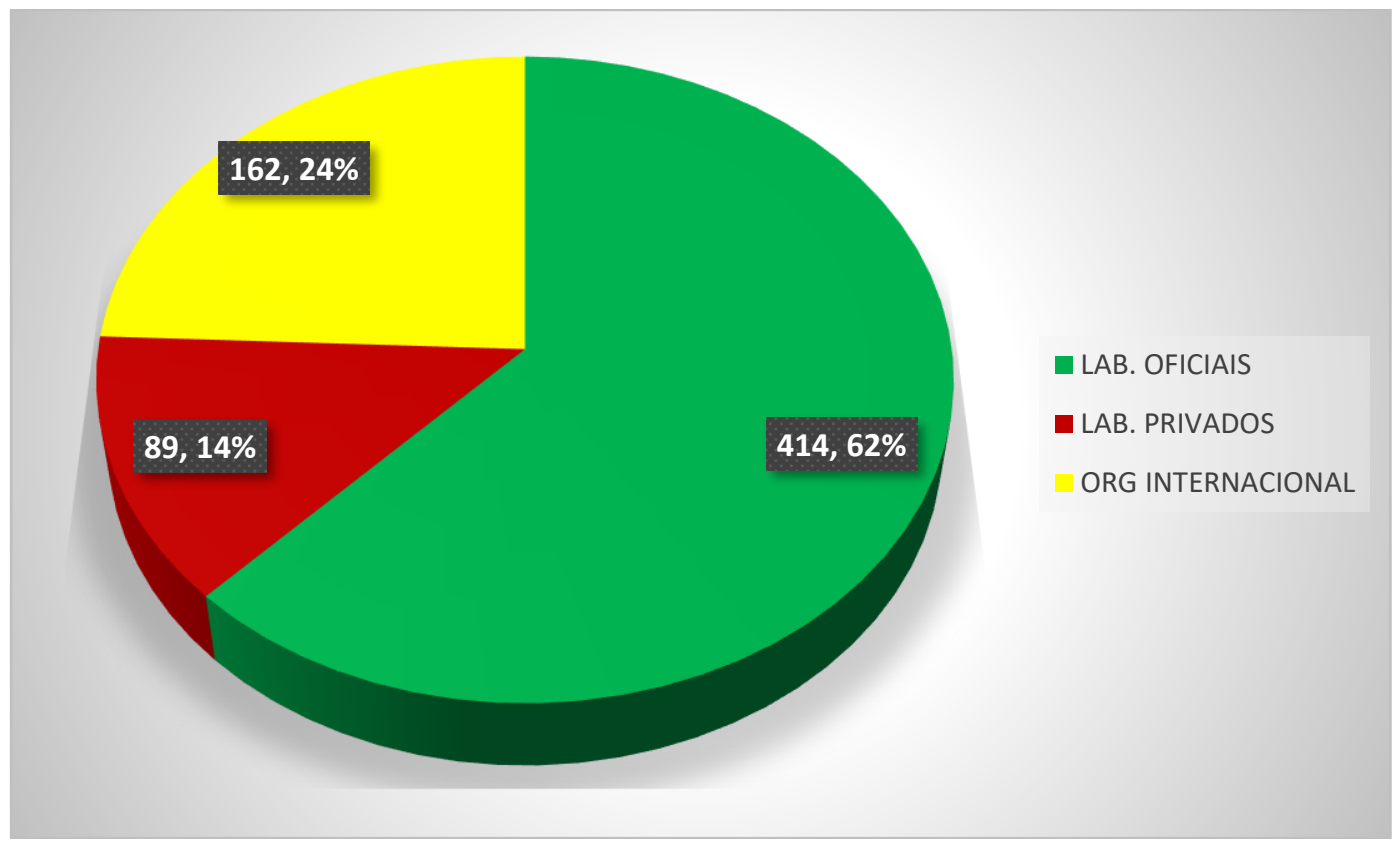

Fonte: O Autor

A partir de 2000 com a organização da Rede Brasileira de Produção Pública de Medicamentos e com a estruturação do mecanismo de aquisições centralizadas para medicamentos considerados estratégicos para o SUS pelo Ministério da Saúde foi possível ao mesmo tempo investir na integração e capacidade tecnológica dos laboratórios oficiais e também dimensionar adequadamente a demanda nacional de medicamentos para atendimento (MAGALHÃES et al., 2011).

O reduzido percentual de participação dos laboratórios privados no fornecimento de medicamentos para doenças da pobreza (14\%) contrasta com a ampla participação no fornecimento de medicamentos de alto custo. Em 2014, laboratórios privados foram responsáveis por $68,7 \%$ (22) das aquisições centralizadas de medicamentos do componente especializado da assistência farmacêutica.

A lógica de investimentos em pesquisa dos laboratórios privados está centrada no atendimento de programas de saúde que se utilizam de medicamentos de alto custo, especialmente doenças crônicas não transmissíveis como câncer e artrite reumatoide ou 
mesmo transmissíveis com perfil de cronicidade e grande instucionalização governamental como HIV e hepatites virais (SANTANA; LEITE, 2016).

O contraste de participação dos laboratórios privados com os públicos também pode ser observado em relação aos gastos do Ministério da Saúde ao longo desses anos, como demonstrado na Figura 9.

Figura 9 - Vias de fornecimento de medicamentos para Doenças da Pobreza na última década (2005 a 2014) por volume de recurso.

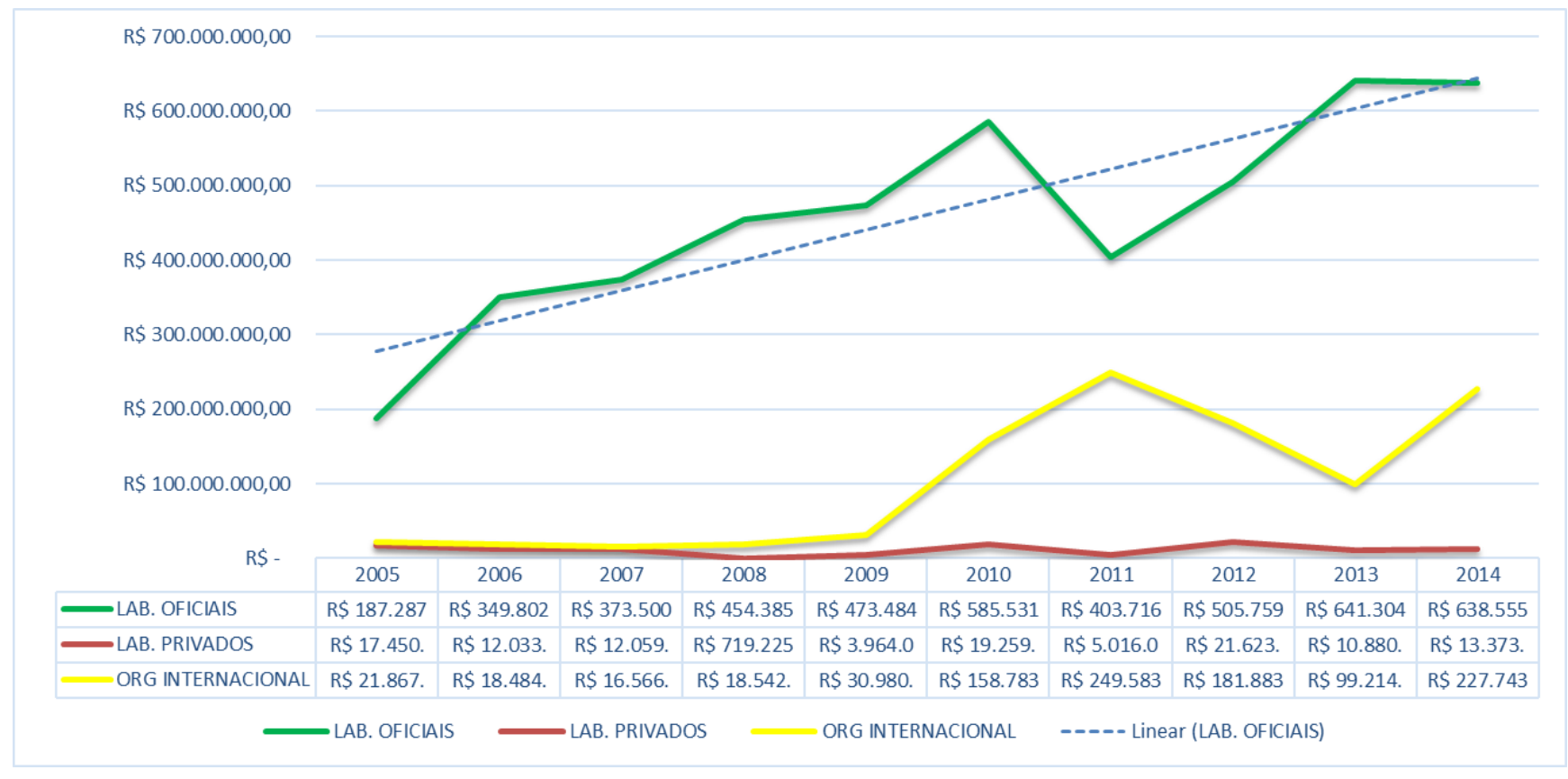

Fonte: O Autor

Pode-se observar que a participação de laboratórios privados no volume de recursos destinados a esse grupo de medicamentos é constante e pouco expressiva, representando menos de $2 \%$ (R $\$ 121$ milhões) das aquisições realizadas durante o período.

As aquisições por organismo internacional foram responsáveis por quase $23 \%$ das aquisições ( $\mathrm{R}$ \$ 1,6 bilhão), caracterizada por oscilações de crescimento e queda no percentual de compras, a depender das demandas de incorporação. Isso porque, a aquisição por importação é geralmente a estratégia utilizada quando ocorre inclusão de uma 
determinada tecnologia no SUS, ainda não produzida no país. O percentual dessa via de aquisição se reduz quando a produção passa a ser realizada por um laboratório público nacional. O Impacto da inclusão da vacina para prevenção da meningite no calendário vacinal a partir de 2010 e 2011, até então obtida via Opas, pode ser observado nitidamente na Figura 9.

A participação dos laboratórios públicos também apresenta algumas oscilações, mas com uma tendência geral de crescimento, representando cerca de $75 \%$ do total de aquisições durante o período avaliado ( $\mathrm{R} \$ 5,3$ bilhões).

Contradições na divisão do orçamento: uma ameaça a sustentabilidade do

\section{financiamento?}

Mesmo com as estratégias descritas pela política de assistência farmacêutica brasileira para as doenças da pobreza, não é possível fugir da reprodução dos contrates sociais quando observamos os gastos com outros medicamentos.

Na Figura 10 é possível observar o crescimento acentuado do orçamento destinado aos medicamentos excepcionais (componente especializado), já alcançando a marca de 5,5 bilhões anuais, e, portanto, a cada ano, superando os gastos de uma década de aquisições para medicamentos das doenças da pobreza. 


\section{Figura 10 - Comparação da evolução dos gastos de medicamentos para doenças da pobreza, com orçamentos de HIV/AIDS, excepcionais e demanda judicial.}

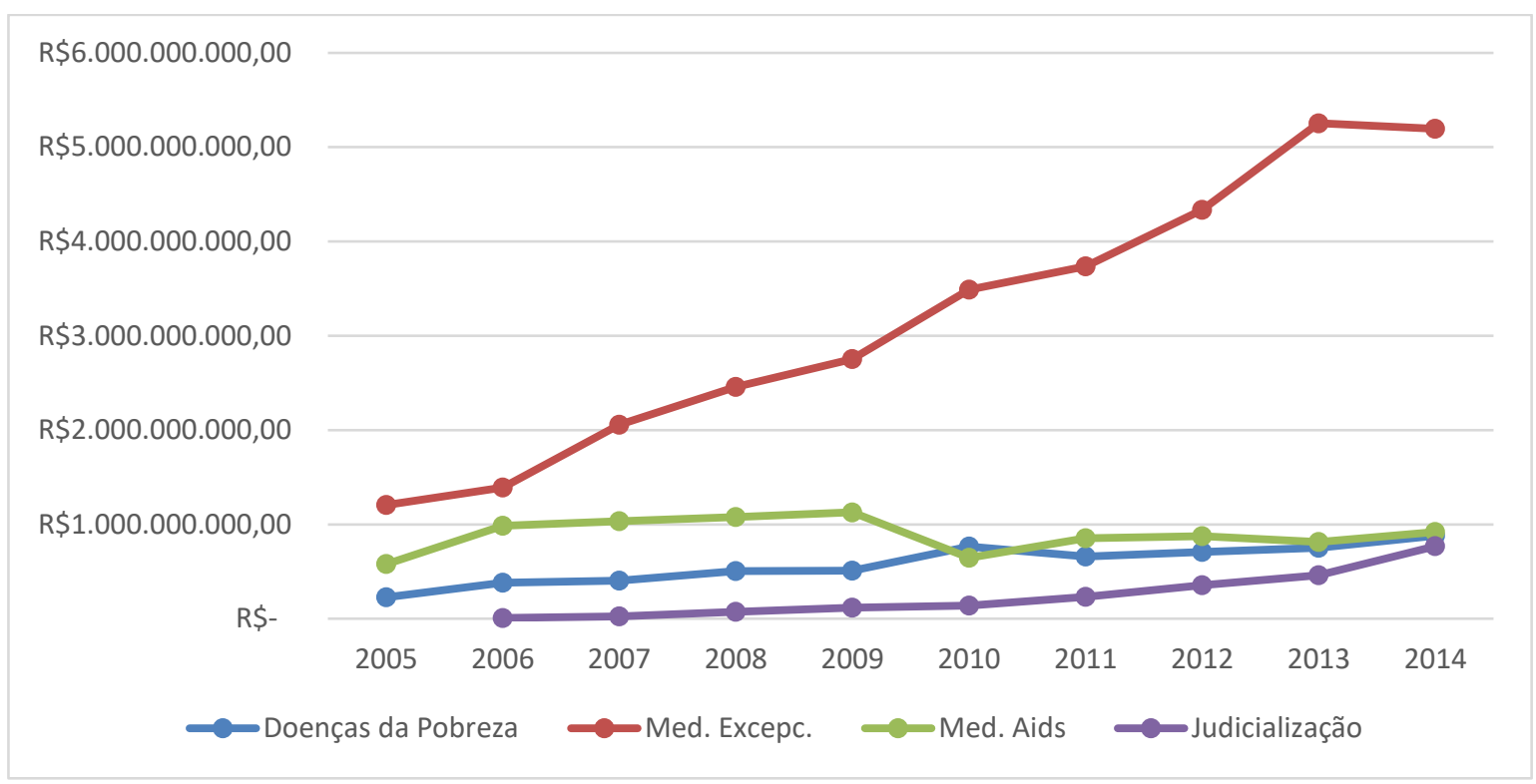

Fonte: O Autor

Em 2004 os gastos médios com medicamentos para cada paciente do componente especializado já variavam em torno de $\mathrm{R} \$$ 4.794,34 (BRANDÃO et al., 2011). Porém incorporações recentes causaram impacto significativo no orçamento, como por exemplo os novos tratamentos para Hepatite C. Mesmo sendo destaque de êxito na negociação de compra o Brasil gasta entre U\$ 11 a U\$ 22 mil por tratamento (ANDRIEUX-MEYER et al., 2015).

Da mesma forma, o crescimento dos gastos com processos judiciais, também representa riscos, uma vez que não há orçamento previsto e, portanto, força a união a realocar recursos de outros programas. E essa realocação não planejada custa caro as políticas de saúde, como demonstrou Chieffi e Barata, (2009) na experiência do estado de São Paulo, onde os gasto médio por paciente na judicialização representou quase 10 vezes o valor do paciente do programa de alto custo, o que levou a um debate inclusive sobre questões de equidade na assistência farmacêutica. 
Os gastos com aquisição de antirretrovirais para portadores de HIV/AIDS, chegando próximo a $\mathrm{R} \$ 1$ bilhão/ano, superam os gastos anuais com medicamentos para doenças da pobreza ( $\mathrm{R} \$ 800$ milhões/ano).

Estudo anterior do IPEA já havia demonstrado essa discrepância, ao verificar que gastos de tratamento para tuberculose, hanseníase, malária e leishmaniose representaram apenas 4,6\% da despesa com os antirretrovirais do HIV/AIDS. Mesmo o número de casos das quatro primeiras doenças sendo 3,4 vezes maior (GARCIA, 2011).

Na Figura 11 pode-se observar por meio de um gráfico de dispersão a discrepância de investimento por população atendida (per capta). A malária por exemplo que em 2014 teve um número de atingidos (143.552) próximo a população atendida para tratamento de Artrite Reumatoide (120.483) possui investimentos per capta com medicamentos $(\mathrm{R} \$ 6,13)$ muito menores quando comparadas a esta última ( $\mathrm{R}$ 9.792,93) (BRASIL. MS. SCTIE, 2014; BRASIL. MS. SVS, 2015).

Figura 11 - Comparação entre população atendida (x), gastos com medicamentos (y) e valor per capita (tamanho da bola).

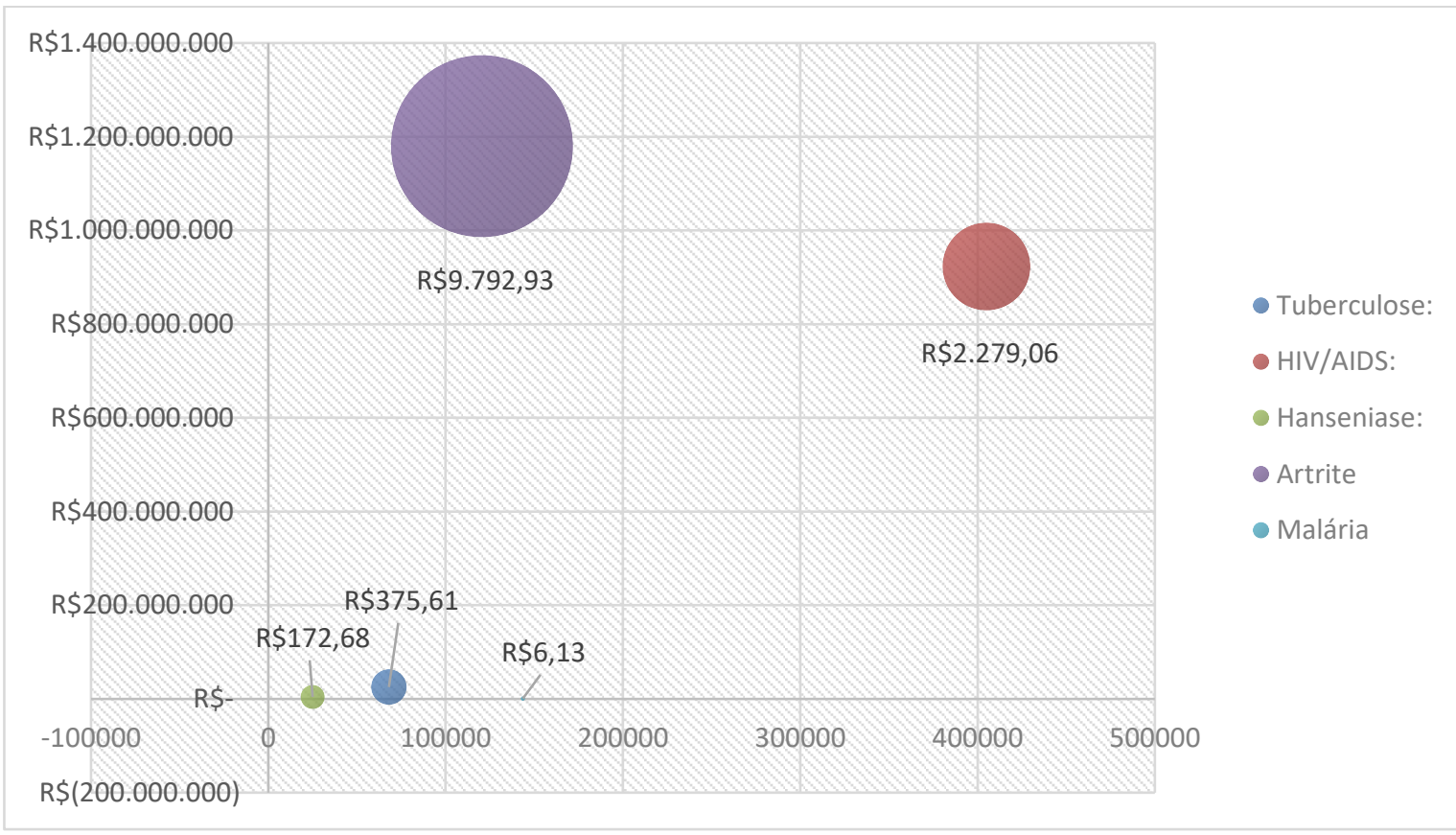

Fonte: O Autor 
Essa diferença é explicada pela dinâmica dos investimentos públicos e privados na área de medicamentos. Haja vista que as doenças da pobreza possuem pouco percentual de inovação, são caracterizados por tratamentos antigos e em sua maioria produzidos por laboratórios públicos ou adquiridos por importação. Já medicamentos para doenças crônicas como Artrite Reumatoide, HIV/AIDS ou Hepatites Virais possuem grandes investimentos em inovação, lançamentos contínuos de novos produtos com patentes e pouca produção nacional por laboratórios públicos (ANDRIEUX-MEYER et al., 2015; DUARTE et al., 2011; GARCIA, 2011).

\section{Considerações Finais:}

Os achados desse trabalho permitem verificar que diferentes estratégias foram adotadas pelo governo brasileiro na última década com intuito de contornar as deficiências na oferta de medicamentos para doenças da pobreza.

A utilização da colaboração com organismos internacionais permitiu o rápido acesso a medicamentos indisponíveis no país e muitas vezes sem interesse de produção pela indústria farmacêutica nacional.

A centralização do financiamento pelo ente nacional e a utilização dos laboratórios públicos permitem a sustentabilidade desse acesso, uma vez que aquisição de insumos em quantidades menores e de baixo custo é prejudicada num contexto de descentralização para estados e municípios, assim como não há interesse para empresas farmacêuticas privadas.

A utilização dessas estratégias para outros tipos de medicamentos deve ser considerada nas estratégias de economia de recursos para evitar que a competição por recursos orçamentários traga prejuízos a ações exitosas da política de assistência farmacêutica. 
CAPÍTULO V - O DUPLO PADRÃO DE DIRETRIZES CLÍNICAS DO SUS: DOENÇAS DE ALTO CUSTO VERSUS DOENÇAS DA POBREZA 
"De todas as formas de desigualdade, a injustiça na área da saúde é a mais chocante e mais desumana." (Martin Luther King, Jr.) 


\section{CAPÍTULO V - O DUPLO PADRÃO DE DIRETRIZES CLÍNICAS DO SUS: DOENÇAS DE ALTO CUSTO VERSUS DOENÇAS DA POBREZA}

\section{Resumo:}

A cada ano verifica-se que as diretrizes clínicas baseadas em evidências ganham mais espaço na prática dos profissionais de saúde e na organização dos serviços. Com a escassez de produção científica, o desenvolvimento de diretrizes clínicas bem fundamentadas ganha ainda mais importância para as doenças da pobreza. Por isso, esse trabalho procurou avaliar a qualidade das diretrizes brasileiras para essas doenças. Foi utilizada a ferramenta AGREE II para avaliação de 16 diretrizes selecionadas para doenças relacionadas à pobreza (DRP) e para 16 diretrizes de doenças globais que utilizam tecnologias de alto custo (GAC) com fins de comparação dos resultados. Observou-se que de uma maneira geral o padrão de qualidade na elaboração é maior para as GAC quando comparado às DRP, com destaque para os critérios de "rigor do desenvolvimento" (48\% e 7\%) e "independência editorial" (43\% e 1\%) que apresentaram as maiores discrepâncias. As diretrizes GAC apresentam resultados próximos ou superior as médias internacionais, já as diretrizes DRP apresentaram resultados inferiores nos 6 domínios de avaliação do AGREE II. Um redirecionamento das prioridades de elaboração dos protocolos clínicos é necessário para qualificar os guias que definem o cuidado e a organização da assistência de populações vulneráveis.

\section{Palavras-Chave:}

Guias de Prática Clínica; AGREE; Doenças Negligenciadas; Assistência Farmacêutica;

\section{Introdução:}

O avanço da saúde baseada em evidências impactou positivamente no cuidado em saúde, promovendo maior precisão nos diagnósticos, orientando profissionais de saúde sobre os tratamentos mais eficazes e reduzindo a exposição dos pacientes a intervenções ineficazes ou mesmo inseguras (ROSENFELD; SHIFFMAN, 2009).

Pelo grande avanço de estudos científicos na área da saúde, pode-se dizer inclusive que ter acesso a melhor evidência disponível é um direito do profissional de saúde e do paciente alvo das intervenções sanitárias. Diretrizes Clínicas bem elaboradas possuem então 
o poder de intermediar interesses diversos das políticas de saúde, dos exercícios profissionais, financiamento governamental, contextos regionais e escolhas dos pacientes (KREDO et al., 2016).

Porém, o intenso número de diretrizes clínicas produzidas continuamente sem um padrão de qualidade aceitável que dê suporte as suas recomendações contribui para o descrédito desse mecanismo fundamental de qualificação do cuidado em saúde. Diretrizes diversas para o cuidado de uma mesma doença, elaboradas com diferentes métodos e objetivos, pode gerar uma desnecessária competição de orientações e um complexo sistema de condutas e intervenções conflitantes (RIBEIRO, 2010).

No Brasil, desde o ano 2000, iniciou-se um movimento de qualificação das diretrizes clínicas produzidas a partir da definição de métodos estruturados para a elaboração e publicação dos chamados "Protocolos Clínicos e Diretrizes Terapêuticas (PCDT)". Que inicialmente estavam restritos a um pequeno número de doenças e com um viés de controle do uso de medicamentos de alto custo, incluídos no componente especializado da assistência farmacêutica (MEGA et al., 2015).

Com a promulgação da lei $\mathrm{n}^{\circ} 12.401$ de 2011 e o decreto $\mathrm{n}^{\circ} 7.508$ de 2011, os PCDT ganham legitimidade institucional e aumento de abrangência, configurando-se como documento de referência para o diagnóstico da doença ou agravo, tratamento farmacológico e não farmacológico, acompanhamento do usuário e verificação dos resultados terapêuticos.

Boa parte das condições negligenciadas ou atualmente denominadas de "doenças e agravos relacionados com a pobreza”, no entanto, ainda são tratadas por diferentes tipos de guias e diretrizes de cuidado, com metodologias diversas, não estruturadas no formato dos PCDT. 
Este artigo pretende avaliar a qualidade metodológica dessas publicações como forma de verificar sua adequação aos padrões de saúde baseada em evidências e consequentemente às necessidades dos profissionais de saúde, cuidadores e pacientes.

\section{Métodos:}

\section{Identificação das diretrizes clínicas}

Foram levantados documentos vigentes com diretrizes clínicas para prevenção e tratamento de doenças e agravos relacionados à pobreza emitidas pelo Ministério da Saúde brasileiro.

Para definição das doenças e agravos que se enquadrariam como "doenças da pobreza", os pesquisadores seguiram padrão de classificação adotado em outros dois estudos anteriores (SANTANA; LEITE, 2016; SANTANA et al., 2016) que basearam-se em proposições anteriores da organização Médicos Sem Fronteiras (MSF) e OMS. Comparativamente também foi adotado o conceito de "doença global”, para classificar aquelas que não teriam o viés de vulnerabilidade socioeconômica como determinante fundamental (MSF, 2001; WHO, 2012).

Não foram incluídas nas análises, documentos de estados, municípios ou outras instituições de saúde. Também não foram considerados cartazes, folders ou documentos semelhantes com estrutura diversa de guias ou protocolos de cuidado, ainda que em alguns casos houvesse orientações de tratamento.

Dado o grande número de diferentes documentos identificados, foram considerados para avaliação da qualidade o documento de referência mais atual para aquela determinada doença ou agravo e que abrangesse de forma mais completa a doença (maior número de formas, manifestações e grupos afetados). 
O levantamento inicial realizado pelos pesquisadores demonstrou o grande número e variabilidade de publicações do Ministério da Saúde com recomendações de cuidado a doenças da pobreza, conforme pode ser visto na Tabela 11.

Tabela 11 - Diretrizes Clínicas do Ministério da Saúde para doenças e agravos relacionados com a Pobreza

Doença ou Agravo

Documentos com diretrizes de assistência terapêutica

\begin{tabular}{|c|c|}
\hline $\begin{array}{l}\text { Abuso de álcool e } \\
\text { drogas }\end{array}$ & Cadernos de Atenção Básica: saúde mental (2013)* \\
\hline $\begin{array}{l}\text { Acidentes por animais } \\
\text { peçonhentos }\end{array}$ & $\begin{array}{l}\text { Cadernos de Atenção Básica: vigilância em zoonoses (2009) } \\
\text { Guia de doenças infecciosas e parasitárias (2010) } \\
\text { Guia de vigilância em saúde (2014)* } \\
\text { Manual de Diagnóstico e Tratamento de Acidentes por Animais } \\
\text { Peçonhentos (2001) }\end{array}$ \\
\hline Brucelose & Guia de doenças infecciosas e parasitárias (2010)* \\
\hline Botulismo & $\begin{array}{l}\text { Guia de doenças infecciosas e parasitárias (2010) } \\
\text { Guia de vigilância em saúde (2014)* } \\
\text { Manual Integrado de Vigilância Epidemiológica do Botulismo (2006) }\end{array}$ \\
\hline $\begin{array}{l}\text { Cólera e outras } \\
\text { doenças diarreicas } \\
\text { agudas }\end{array}$ & $\begin{array}{l}\text { Guia de vigilância em saúde (2014)* } \\
\text { Guia de doenças infecciosas e parasitárias (2010) } \\
\text { Manual integrado de prevenção e controle de doenças transmitidas } \\
\text { por alimentos (2010) }\end{array}$ \\
\hline $\begin{array}{l}\text { Coqueluche } \\
\text { (pertussis) }\end{array}$ & $\begin{array}{l}\text { Guia de doenças infecciosas e parasitárias (2010) } \\
\text { Guia de vigilância em saúde (2014)* } \\
\text { Novas Recomendações para Vigilância Epidemiológica da } \\
\text { Coqueluche (2011) }\end{array}$ \\
\hline $\begin{array}{l}\text { Deficiências } \\
\text { Nutricionais }\end{array}$ & $\begin{array}{l}\text { Cadernos de Atenção Básica: Carências de Micronutrientes (2007) } \\
\text { Guia de Consulta para Vigilância Epidemiológica, Assistência e } \\
\text { Atenção Nutricional dos Casos de Beribéri (2012)* } \\
\text { NutriSUS: guia de evidências: estratégia de fortificação da } \\
\text { alimentação infantil com micronutrientes (vitaminas e minerais) em } \\
\text { pó (2015)* } \\
\text { Manual de condutas gerais do Programa Nacional de Suplementação } \\
\text { de Vitamina A (2013)* } \\
\text { Programa Nacional de Suplementação de Ferro: manual de condutas } \\
\text { gerais (2013)* }\end{array}$ \\
\hline Dengue & $\begin{array}{l}\text { Caderno de Atenção Básica: Vigilância em Saúde na dengue, } \\
\text { esquistossomose, hanseníase, malária, tracoma e tuberculose (2008) } \\
\text { Dengue: diagnóstico e manejo clínico - adulto e criança, 5ed. (2016)* } \\
\text { Guia de doenças infecciosas e parasitárias (2010) } \\
\text { Guia de vigilância em saúde (2014). }\end{array}$ \\
\hline Difteria & $\begin{array}{l}\text { Guia de doenças infecciosas e parasitárias (2010) } \\
\text { Guia de vigilância em saúde (2014)* }\end{array}$ \\
\hline Doença de Chagas & Consenso Brasileiro da Doença de Chagas (2005) \\
\hline
\end{tabular}


Cadernos de Atenção Básica: vigilância em zoonoses (2009)

Doença de Chagas: Guia para vigilância, prevenção, controle e manejo clínico da doença de chagas aguda transmitida por alimentos (2009).

Guia de doenças infecciosas e parasitárias (2010)

Guia de vigilância em saúde (2014)*

Doença falciforme: condutas básicas para tratamento (2012)*

Doença Falciforme Protocolos Clínicos e Diretrizes Terapêuticas (PCDT) da Doença Falciforme (2010)

\begin{tabular}{|c|c|}
\hline $\begin{array}{l}\text { Doença } \\
\text { Meningocócica e } \\
\text { outras meningites }\end{array}$ & $\begin{array}{l}\text { Guia de doenças infecciosas e parasitárias (2010) } \\
\text { Guia de vigilância em saúde (2014)* }\end{array}$ \\
\hline $\begin{array}{l}\text { Escabiose e outras } \\
\text { ectoparasitoses }\end{array}$ & Guia de doenças infecciosas e parasitárias (2010)* \\
\hline Esquistossomose & $\begin{array}{l}\text { Caderno de Atenção Básica: Vigilância em Saúde na dengue, } \\
\text { esquistossomose, hanseníase, malária, tracoma e tuberculose (2008) } \\
\text { Guia de doenças infecciosas e parasitárias (2010) } \\
\text { Guia de vigilância em saúde (2014) } \\
\text { Vigilância da Esquistossomose Mansoni: diretrizes técnicas (2014)* }\end{array}$ \\
\hline $\begin{array}{l}\text { Febre Maculosa e } \\
\text { outras transmitidas } \\
\text { por carrapatos }\end{array}$ & $\begin{array}{l}\text { Guia de doenças infecciosas e parasitárias (2010) } \\
\text { Guia de vigilância em saúde (2014)* }\end{array}$ \\
\hline Febre Amarela & $\begin{array}{l}\text { Cadernos de Atenção Básica: vigilância em zoonoses (2009) } \\
\text { Guia de doenças infecciosas e parasitárias (2010) } \\
\text { Guia de vigilância em saúde (2014)* }\end{array}$ \\
\hline Febre Tifoide & $\begin{array}{l}\text { Guia de doenças infecciosas e parasitárias (2010) } \\
\text { Guia de vigilância em saúde (2014)* } \\
\text { Manual Integrado de Vigilância e Controle da Febre Tifoide (2010) } \\
\text { Manual integrado de prevenção e controle de doenças transmitidas } \\
\text { por alimentos (2010) }\end{array}$ \\
\hline $\begin{array}{l}\text { Febre de } \\
\text { Chikungunya }\end{array}$ & $\begin{array}{l}\text { Guia de vigilância em saúde (2014) } \\
\text { Febre de chikungunya: manejo clínico (2015)* }\end{array}$ \\
\hline Febre do Zika Vírus & $\begin{array}{l}\text { Protocolo de Atenção à Saúde e Resposta à Ocorrência de } \\
\text { Microcefalia Relacionada à Infecção pelo Vírus Zika (2016)* } \\
\text { Protocolo de vigilância dos casos de manifestações neurológicas de } \\
\text { infecção viral prévia (2015) }\end{array}$ \\
\hline Filariose & $\begin{array}{l}\text { Guia de doenças infecciosas e parasitárias (2010) } \\
\text { Guia de Vigilância Epidemiológica e Eliminação da Filariose } \\
\text { Linfática (2009)* }\end{array}$ \\
\hline $\begin{array}{l}\text { Geo-helmintíases e } \\
\text { outras parasitoses } \\
\text { intestinais }\end{array}$ & $\begin{array}{l}\text { Guia de doenças infecciosas e parasitárias (2010) } \\
\text { Guia de vigilância em saúde (2014)* }\end{array}$ \\
\hline Hanseníase & $\begin{array}{l}\text { Caderno de Atenção Básica: Vigilância em Saúde na dengue, } \\
\text { esquistossomose, hanseníase, malária, tracoma e tuberculose (2008) } \\
\text { Manual Técnico Operacional - Diretrizes para vigilância, atenção e } \\
\text { eliminação da hanseníase como problema de saúde pública (2016)* } \\
\text { Talidomida: Orientação Sobre o Uso Controlado (2014) } \\
\text { Guia de doenças infecciosas e parasitárias (2010) } \\
\text { Guia de vigilância em saúde (2014) }\end{array}$ \\
\hline Hantaviroses & Manual de vigilância, prevenção e controle das hantaviroses (2013) \\
\hline
\end{tabular}




\begin{tabular}{|c|c|}
\hline & $\begin{array}{l}\text { Guia de doenças infecciosas e parasitárias (2010) } \\
\text { Guia de vigilância em saúde (2014)* }\end{array}$ \\
\hline $\begin{array}{l}\text { Infecções fúngicas } \\
\text { sistêmicas }\end{array}$ & $\begin{array}{l}\text { Guia de doenças infecciosas e parasitárias (2010) } \\
\text { Guia de vigilância em saúde (2014)* }\end{array}$ \\
\hline $\begin{array}{l}\text { Leishmaniose } \\
\text { Tegumentar } \\
\text { Americana e } \\
\text { Leishmaniose } \\
\text { Visceral }\end{array}$ & $\begin{array}{l}\text { Cadernos de Atenção Básica: vigilância em zoonoses (2009) } \\
\text { Guia de doenças infecciosas e parasitárias (2010) } \\
\text { Guia de vigilância em saúde (2014) } \\
\text { Manual de Vigilância da Leishmaniose Tegumentar Americana } \\
\text { (2007) } \\
\text { Manual de Vigilância e Controle da Leishmaniose Visceral (2006) } \\
\text { Recomendações Clínicas para Redução da Letalidade de } \\
\text { Leishmaniose Visceral - LV (2011)* }\end{array}$ \\
\hline Leptospirose & $\begin{array}{l}\text { Cadernos de Atenção Básica: vigilância em zoonoses (2009) } \\
\text { Guia de doenças infecciosas e parasitárias (2010) } \\
\text { Guia de vigilância em saúde (2014) } \\
\text { Leptospirose: Diagnóstico e Manejo Clínico (2014)* }\end{array}$ \\
\hline Malária & $\begin{array}{l}\text { Caderno de Atenção Básica: Vigilância em Saúde na dengue, } \\
\text { esquistossomose, hanseníase, malária, tracoma e tuberculose (2008) } \\
\text { Guia de doenças infecciosas e parasitárias (2010) } \\
\text { Guia de vigilância em saúde (2014)* } \\
\text { Guia prático de tratamento da malária no Brasil (2010) }\end{array}$ \\
\hline Oncocercose & Guia de doenças infecciosas e parasitárias (2010)* \\
\hline Peste & $\begin{array}{l}\text { Guia de doenças infecciosas e parasitárias (2010) } \\
\text { Guia de vigilância em saúde (2014)* } \\
\text { Manual de Vigilância e Controle da Peste (2008) }\end{array}$ \\
\hline Poliomielite & $\begin{array}{l}\text { Guia de doenças infecciosas e parasitárias (2010) } \\
\text { Guia de vigilância em saúde (2014) }\end{array}$ \\
\hline Raiva & $\begin{array}{l}\text { Guia de doenças infecciosas e parasitárias (2010) } \\
\text { Guia de vigilância em saúde (2014)* } \\
\text { Protocolo de Tratamento da Raiva Humana no Brasil (2011) } \\
\text { Normas Técnicas da Profilaxia da Raiva Humana (2011) }\end{array}$ \\
\hline $\begin{array}{l}\text { Rubéola e síndrome } \\
\text { da rubéola congênita }\end{array}$ & $\begin{array}{l}\text { Guia de doenças infecciosas e parasitárias (2010) } \\
\text { Guia de vigilância em saúde (2014)* }\end{array}$ \\
\hline Sarampo & $\begin{array}{l}\text { Guia de doenças infecciosas e parasitárias (2010) } \\
\text { Guia de vigilância em saúde (2014)* }\end{array}$ \\
\hline $\begin{array}{l}\text { Sífilis e outras } \\
\text { doenças sexualmente } \\
\text { transmissíveis }\end{array}$ & $\begin{array}{l}\text { Guia de doenças infecciosas e parasitárias (2010) } \\
\text { Guia de vigilância em saúde (2014) } \\
\text { Protocolo Clínico e Diretrizes Terapêuticas para Prevenção da } \\
\text { Transmissão Vertical de HIV, Sífilis e Hepatites Virais (2015) } \\
\text { Protocolo Clínico e Diretrizes Terapêuticas para Atenção Integral às } \\
\text { Pessoas com Infecções Sexualmente Transmissíveis (2016)* }\end{array}$ \\
\hline $\begin{array}{l}\text { Tétano acidental e } \\
\text { neonatal }\end{array}$ & $\begin{array}{l}\text { Guia de doenças infecciosas e parasitárias (2010) } \\
\text { Guia de vigilância em saúde (2014)* }\end{array}$ \\
\hline Toxoplasmose & $\begin{array}{l}\text { Guia de doenças infecciosas e parasitárias (2010)* } \\
\text { Protocolos da Atenção Básica: Saúde das Mulheres (2016) } \\
\text { Caderno de Atenção Básica: Vigilância em Saúde na dengue, } \\
\text { esquistossomose, hanseníase, malária, tracoma e tuberculose (2008) } \\
\text { Guia de doenças infecciosas e parasitárias (2010) } \\
\text { Guia de vigilância em saúde (2014) }\end{array}$ \\
\hline
\end{tabular}




\begin{tabular}{ll}
\hline & $\begin{array}{l}\text { Manual de vigilância do tracoma e sua eliminação como causa de } \\
\text { cegueira (2014)* }\end{array}$ \\
& $\begin{array}{l}\text { Caderno de Atenção Básica: Vigilância em Saúde na dengue, } \\
\text { esquistossomose, hanseníase, malária, tracoma e tuberculose (2008) } \\
\text { Guia de doenças infecciosas e parasitárias (2010) } \\
\text { Tuberculose }\end{array}$ \\
& $\begin{array}{l}\text { Manua de vigilância em saúde (2014)* } \\
(2011)\end{array}$ \\
\hline Varicela e varicela & Guia de doenças infecciosas e parasitárias (2010) \\
zoster & Guia de vigilância em saúde (2014)* \\
\hline & $\begin{array}{l}\text { Profilaxia antirretroviral pós-exposição a risco para infecção pelo } \\
\text { HIV (2015) }\end{array}$ \\
Violência sexual e & $\begin{array}{l}\text { Prevenção e tratamento dos agravos resultantes da violência sexual } \\
\text { contra mulheres e adolescentes (2012)* }\end{array}$ \\
doméstica & Anticoncepção de Emergência: perguntas e respostas para \\
profissionais de saúde (2011) & Protocolos da Atenção Básica: Saúde das Mulheres (2016) \\
\hline
\end{tabular}

* Destaque para o item selecionado

Como critério para comparação com diretrizes de doenças globais, foram também

incluídos na amostra do estudo todos os PCDT emitidos pela Conitec no ano de 2015.

Tradicionalmente, os PCDT focam em doenças consideradas de "alto custo", na sua

maioria pertencentes ao chamado componente especializado da assistência farmacêutica. As

32 diretrizes selecionadas para o estudo estão descritas na Tabela 12:

Tabela 12 - Diretrizes Clínicas do Ministério da Saúde selecionadas para o estudo

\begin{tabular}{cl}
\hline & \multicolumn{1}{c}{ Diretriz Selecionada } \\
\hline DRP 01 & Guia de vigilância em saúde (2014) \\
\hline DRP 02 & Guia de doenças infecciosas e parasitárias (2010) \\
\hline DRP 03 & $\begin{array}{l}\text { Guia de Consulta para Vigilância Epidemiológica, Assistência e } \\
\text { Atenção Nutricional dos Casos de Beribéri (2012) }\end{array}$ \\
\hline DRP 04 & $\begin{array}{l}\text { NutriSUS: guia de evidências: estratégia de fortificação da alimentação } \\
\text { infantil com micronutrientes (vitaminas e minerais) em pó (2015) }\end{array}$ \\
\hline DRP 05 & $\begin{array}{l}\text { Manual de condutas gerais do Programa Nacional de Suplementação de } \\
\text { Vitamina A (2013) }\end{array}$ \\
\hline DRP 06 & $\begin{array}{l}\text { Programa Nacional de Suplementação de Ferro: manual de condutas } \\
\text { gerais (2013) }\end{array}$ \\
\hline DRP 07 & $\begin{array}{l}\text { Dengue: diagnóstico e manejo clínico - adulto e criança (2016) } \\
\text { DRP 08 }\end{array}$ \\
\hline DRP 09 & Vigilância da Esquistossomose Mansoni: diretrizes técnicas (2014) \\
\hline DRP 10 & $\begin{array}{l}\text { Protocolo de Atenção à Saúde e Resposta à Ocorrência de Microcefalia } \\
\text { Relacionada à Infecção pelo Vírus Zika (2016) }\end{array}$ \\
\hline
\end{tabular}




\begin{tabular}{|c|c|}
\hline DRP 11 & $\begin{array}{l}\text { Guia de Vigilância Epidemiológica e Eliminação da Filariose Linfática } \\
\text { (2009) }\end{array}$ \\
\hline DRP 12 & $\begin{array}{l}\text { Manual Técnico Operacional - Diretrizes para vigilância, atenção e } \\
\text { eliminação da hanseníase como problema de saúde pública (2016) }\end{array}$ \\
\hline DRP 13 & Leptospirose: Diagnóstico e Manejo Clínico (2014) \\
\hline DRP 14 & $\begin{array}{l}\text { PCDT para Atenção Integral às Pessoas com Infecções Sexualmente } \\
\text { Transmissíveis (2016) }\end{array}$ \\
\hline DRP 15 & $\begin{array}{l}\text { Manual de vigilância do tracoma e sua eliminação como causa de } \\
\text { cegueira (2014) }\end{array}$ \\
\hline DRP 16 & $\begin{array}{l}\text { Prevenção e tratamento dos agravos resultantes da violência sexual } \\
\text { contra mulheres e adolescentes (2012) }\end{array}$ \\
\hline GAC 17 & PCDT Artrite Reumatoide (2015) \\
\hline GAC 18 & PCDT Hepatite Viral C Crônica e coinfecções (2015) \\
\hline GAC 19 & PCDT Câncer de Mama (2015) \\
\hline GAC 20 & PCDT Artrite Reativa (2015) \\
\hline GAC 21 & PCDT Câncer de Cabeça e Pescoço (2015) \\
\hline GAC 22 & PCDT Doença Celíaca (2015) \\
\hline GAC 23 & PCDT Esclerose Lateral Amiotrófica (2015) \\
\hline GAC 24 & PCDT Esclerose Múltipla (2015) \\
\hline GAC 25 & PCDT Hiperprolactinemia (2015) \\
\hline GAC 26 & PCDT Hipotireoidismo Congênito (2015) \\
\hline GAC 27 & PCDT Ictioses Hereditárias (2015) \\
\hline GAC 28 & PCDT Insuficiência Adrenal Primária (2015) \\
\hline GAC 29 & PCDT Miastenia Gravis (2015) \\
\hline GAC 30 & PCDT Mieloma Múltiplo (2015) \\
\hline GAC 31 & PCDT Síndrome de Guillain-Barré (2015) \\
\hline GAC 32 & PCDT Uveítes Posteriores Não-Infecciosas (2015) \\
\hline
\end{tabular}

\section{Avaliação da qualidade metodológica: instrumento Agree II}

A análise da qualidade das diretrizes clínicas selecionadas foi realizada por meio da ferramenta "Appraisal of Guidelines for Research and Evaluation" (AGREE), um instrumento elaborado a partir da análise de mais de 100 diretrizes selecionadas e avaliadas de forma independente por mais de 200 avaliadores de diversas partes do mundo. A última edição do AGREE II conta com 23 itens organizados em 6 diferentes domínios de qualidade. É o instrumento de referência para análise da qualidade de diretrizes da OMS e das principais 
agências de incorporação de tecnologias do mundo (BROUWERS et al., 2010; RONSONI et al., 2015).

As diretrizes selecionadas para este estudo foram avaliadas por quatro especialistas com experiências prévias na análise de diretrizes clínicas, de forma independente e seguindo orientações da versão em língua portuguesa do AGREE II (AGREE NEXT STEPS CONSORTIUM, 2009). Comumente verifica-se que trabalhos semelhantes tem optado por utilizar dois ou três juízes, a adoção de quatro juízes para análise é considerado ideal pelo grupo que elaborou o instrumento (AGREE NEXT STEPS CONSORTIUM, 2009; ALONSO-COELLO et al., 2010; MOLINO et al., 2016; RONSONI et al., 2015).

\section{Extração, manejo e análise dos dados}

Foram coletados dados de análise dos seis domínios de avaliação descritos pelo AGREE II: (i) escopo e finalidade; (ii) envolvimento das partes interessadas; (iii) rigor do desenvolvimento; (iv) clareza da apresentação; (v) aplicabilidade; (vi) independência editorial. O instrumento prevê a adoção de notas entre 1 (discordância total ou ausência da informação) à 7 (concordância total) para cada uma das 23 questões avaliadas. Ao final temse um percentual de adequação da diretriz para cada um dos seis domínios avaliados (AGREE NEXT STEPS CONSORTIUM, 2009).

Apesar de não previsto pelas orientações do instrumento, optou-se por realizar uma análise de concordância entre os juízes, utilizando-se o teste kappa com intuito de evitar aleatoriedade da análise ou mesmo um baixo grau de concordância. Seguindo outros estudos (MOLINO et al., 2016), considerou-se um kappa de concordância moderada (kappa $>0,4)$ como meta para esse tipo de estudo. A Tabela 13 descreve padrão de concordância a partir da análise de kappa usando critérios de Landis e Koch's (LANDIS; KOCH, 1977). 
Tabela 13 - Coeficiente de Kappa segundo Landis \& Koch

\begin{tabular}{cc}
\hline Classificação & Kappa \\
\hline Quase perfeita & 0,8 a 1 \\
\hline Substancial & 0,6 a 0,8 \\
\hline Moderada & 0,4 a 0,6 \\
\hline Regular & 0,2 a 0,4 \\
\hline Discreta & 0 a 0,2 \\
\hline Pobre & 0 a -1
\end{tabular}

Para análise de concordância da avaliação, foi definido entre os juízes que notas 1 e 2, seriam ambas consideradas "baixas", notas 3, 4, 5 consideradas "intermediárias" e notas 6 e 7 consideradas "altas". Avaliando-se a concordância entre essas categorias obteve-se um kappa inicial de 0.263 (regular). Na sequência foi realizada uma reunião entre os juízes, a fim de discutir os principais pontos de dissenso nos critérios de avaliação, e após nova avaliação independente obteve-se um kappa final de 0.598 (moderado).

Na comparação entre os resultados das diretrizes para doenças relacionadas à pobreza (DRP) e das doenças globais de alto custo (GAC) foi realizado teste de significância de $t$ student entre as médias dos diferentes domínios do AGREE II.

O instrumento não define um padrão para indicar se a diretriz como um todo deve ou não ser recomendada e a fim de tornar a avaliação menos subjetiva quanto a este quesito, neste estudo, se consensuou que o domínio (iii) "rigor do desenvolvimento" seria o padrão principal para avaliação global da diretriz, seguindo definição de outros autores (MOLINO et al., 2016).

\section{Resultados e Discussão:}

A variabilidade das publicações se refletiu no dissenso de suas denominações: “cadernos de atenção básica”, "guias”, “protocolos”, “consensos”, “manuais”, “diretrizes técnicas". Apesar de algumas diferenças conceituais entre os termos, não parece haver 
consenso na literatura sobre a denominação padrão desse tipo de documento que aqui se optou por chamar genericamente de "diretriz clínica". Porém, a falta de padrão nas publicações do ente federal da saúde contribui para um acesso confuso a essas informações, tanto por pesquisadores como para profissionais de saúde alvo.

A diversidade de recomendações para o manejo de uma mesma doença parece perigosa na medida que pode gerar conflitos entre as condutas sugeridas, dada as diferenças dos métodos de elaboração das diretrizes.

O instrumento utilizado AGREE II, no entanto, é sensível a diferentes tipos de diretrizes, pois avalia questões globais e necessárias a qualquer tipo de documento guia para os cuidados terapêuticos. O resultado das avaliações, estão expressos em percentuais de adequação (0 a 100) para domínio e cada uma das 32 diretrizes validadas (Tabela 14).

Tabela 14 - Percentuais de adequação das diretrizes avaliadas segundo AGREE II

\begin{tabular}{lcccccc}
\hline Diretriz & $\begin{array}{c}\text { Escopo e } \\
\text { finalidade }\end{array}$ & $\begin{array}{c}\text { Envolvimento } \\
\text { das partes }\end{array}$ & $\begin{array}{c}\text { Rigor no } \\
\text { desenvolv. }\end{array}$ & $\begin{array}{c}\text { Clareza da } \\
\text { apresentação }\end{array}$ & Aplicabilidade & $\begin{array}{c}\text { Independência } \\
\text { editorial }\end{array}$ \\
\hline DRP 01 & $65 \%$ & $10 \%$ & $5 \%$ & $51 \%$ & $24 \%$ & $4 \%$ \\
\hline DRP 02 & $46 \%$ & $24 \%$ & $1 \%$ & $43 \%$ & $10 \%$ & $4 \%$ \\
\hline DRP 03 & $68 \%$ & $26 \%$ & $8 \%$ & $54 \%$ & $40 \%$ & $4 \%$ \\
\hline DRP 04 & $57 \%$ & $24 \%$ & $11 \%$ & $51 \%$ & $25 \%$ & $2 \%$ \\
\hline DRP 05 & $86 \%$ & $31 \%$ & $7 \%$ & $53 \%$ & $43 \%$ & $0 \%$ \\
\hline DRP 06 & $74 \%$ & $18 \%$ & $5 \%$ & $60 \%$ & $39 \%$ & $0 \%$ \\
\hline DRP 07 & $82 \%$ & $7 \%$ & $4 \%$ & $58 \%$ & $22 \%$ & $0 \%$ \\
\hline DRP 08 & $75 \%$ & $7 \%$ & $6 \%$ & $65 \%$ & $20 \%$ & $0 \%$ \\
\hline DRP 09 & $81 \%$ & $40 \%$ & $8 \%$ & $71 \%$ & $44 \%$ & $0 \%$ \\
\hline DRP 10 & $88 \%$ & $35 \%$ & $4 \%$ & $65 \%$ & $35 \%$ & $0 \%$ \\
\hline DRP 11 & $63 \%$ & $26 \%$ & $6 \%$ & $54 \%$ & $31 \%$ & $0 \%$ \\
\hline DRP 12 & $74 \%$ & $31 \%$ & $6 \%$ & $67 \%$ & $33 \%$ & $0 \%$ \\
\hline DRP 13 & $76 \%$ & $35 \%$ & $3 \%$ & $75 \%$ & $32 \%$ & $0 \%$ \\
\hline DRP 14 & $88 \%$ & $58 \%$ & $19 \%$ & $79 \%$ & $45 \%$ & $0 \%$ \\
\hline DRP 15 & $79 \%$ & $21 \%$ & $4 \%$ & $57 \%$ & $35 \%$ & $0 \%$ \\
\hline DRP 16 & $78 \%$ & $24 \%$ & $8 \%$ & $68 \%$ & $42 \%$ & $0 \%$ \\
\hline GAC 17 & $94 \%$ & $40 \%$ & $57 \%$ & $93 \%$ & $30 \%$ & $46 \%$ \\
\hline GAC 18 & $97 \%$ & $40 \%$ & $53 \%$ & $90 \%$ & $25 \%$ & $40 \%$ \\
\hline GAC 19 & $89 \%$ & $39 \%$ & $53 \%$ & $75 \%$ & $33 \%$ & $27 \%$ \\
\hline
\end{tabular}




\begin{tabular}{lllllll}
\hline GAC 20 & $83 \%$ & $42 \%$ & $52 \%$ & $65 \%$ & $22 \%$ & $46 \%$ \\
\hline GAC 21 & $81 \%$ & $43 \%$ & $43 \%$ & $61 \%$ & $33 \%$ & $27 \%$ \\
\hline GAC 22 & $86 \%$ & $44 \%$ & $47 \%$ & $58 \%$ & $26 \%$ & $46 \%$ \\
\hline GAC 23 & $86 \%$ & $44 \%$ & $46 \%$ & $75 \%$ & $23 \%$ & $46 \%$ \\
\hline GAC 24 & $88 \%$ & $44 \%$ & $45 \%$ & $76 \%$ & $26 \%$ & $46 \%$ \\
\hline GAC 25 & $85 \%$ & $44 \%$ & $49 \%$ & $74 \%$ & $22 \%$ & $46 \%$ \\
\hline GAC 26 & $85 \%$ & $44 \%$ & $44 \%$ & $63 \%$ & $19 \%$ & $46 \%$ \\
\hline GAC 27 & $85 \%$ & $44 \%$ & $49 \%$ & $63 \%$ & $24 \%$ & $46 \%$ \\
\hline GAC 28 & $83 \%$ & $42 \%$ & $46 \%$ & $64 \%$ & $23 \%$ & $46 \%$ \\
\hline GAC 30 & $85 \%$ & $44 \%$ & $46 \%$ & $72 \%$ & $27 \%$ & $46 \%$ \\
\hline GAC 31 & $85 \%$ & $44 \%$ & $42 \%$ & $61 \%$ & $30 \%$ & $46 \%$ \\
\hline GAC 32 & $83 \%$ & $44 \%$ & $45 \%$ & $61 \%$ & $21 \%$ & $46 \%$ \\
\hline
\end{tabular}

Os resultados das avaliações dos juízes também são apresentados na Tabela 15, de acordo com a média das notas ( 1 a 7) dadas em cada domínio, numa comparação direta entre os dois grupos de diretrizes avaliadas. O teste $t$-student demonstrou diferença estatística entre todas as médias apresentadas.

Tabela 15 - Média das Pontuações de Diretrizes de Doenças da Pobreza versus Doenças Globais de Alto Custo segundo AGREE II

\begin{tabular}{lccc}
\hline \multicolumn{1}{c}{ Domínio de Avaliação } & DRP & GAC & $\boldsymbol{P}$ \\
\hline Escopo e Finalidade & 5,4 & 6,2 & $<0,01$ \\
\hline Envolvimento das Partes Interessadas & 2,6 & 3,6 & $<0,01$ \\
\hline Rigor e Desenvolvimento & 1,4 & 3,9 & $<0,01$ \\
\hline Clareza da apresentação & 4,6 & 5,2 & $<0,01$ \\
\hline Aplicabilidade & 2,9 & 2,5 & $<0,05$ \\
\hline Independência Editorial & 1,1 & 3,6 & $<0,01$ \\
\hline
\end{tabular}

\section{Escopo e Finalidade}

Esse domínio visa basicamente analisar se os objetivos da diretriz, as doenças cobertas e a população a quem se destina estão bem definidos. As diretrizes de doenças globais de alto culto apresentaram maiores pontuações $(86 \%$ ou 6,2$)$ quando comparadas às diretrizes das doenças da pobreza $(74 \%$ ou 5,4$)$ apesar dessas últimas também apresentarem 
em média pontuação alta. Destaca-se que o formato padrão das GAC definem com exatidão as condições cobertas pela diretriz, inclusive usando o recurso da Código Internacional de Doenças (CID), além de possuir claramente descritos os critérios de "inclusão" e "exclusão". Molino et al., (2016); Ronsoni et al., (2015) também verificaram maiores pontuações nesses itens, apesar dos dois estudos terem centrado as análises apenas em protocolos de doenças crônicas não-transmissíveis.

\section{Envolvimento das Partes Interessadas}

Nesse domínio, já podemos verificar uma redução nas pontuações e percentuais de adequação de ambos os grupos de diretrizes avaliados, apesar da manutenção da superioridade entre as médias GAC $(43 \%$ ou 3,6$)$ que as DRP $(26 \%$ ou 2,6). Destaca-se dois pontos fracos: a falta de envolvimento de todos os grupos profissionais interessados e o não estabelecimento da participação da população-alvo. A diretriz de cuidado da doença falciforme (DRP 08), que possui o menor percentual de adequação no domínio (7\%), por exemplo, foi elaborado apenas por dois médicos especialistas, sem participação relatada de outros profissionais de saúde ou de metodologistas para busca e análise de evidências.

Uma diferença importante entre os grupos avaliados é que todas as diretrizes GAC são previamente aprovadas pela Conitec e passam por consulta pública de no mínimo 20 dias, aberta a toda sociedade. Apenas uma diretriz (DRP 14) do grupo de DRP foi previamente avaliada pela Conitec e passou por consulta pública. Nenhuma das 32 diretrizes avaliadas relatou ter algum tipo de participação ativa de usuários na sua elaboração.

A participação de pacientes na elaboração de diretrizes clínicas tem se mostrado como uma dificuldade, por questões relacionadas tanto a estrutura fechada da área de ATS, quanto pela desconfiança de que seus representantes possam ser influenciados por empresas farmacêuticas (VAN DE BOVENKAMP; TRAPPENBURG, 2009; VAN DE 
BOVENKAMP; ZUIDERENT-JERAK, 2015). Porém, diferentes estudos demonstram que essa estratégia é crucial para melhorar a qualidade das recomendações de cuidado, pois permite identificar pontos discordantes entre profissionais e pacientes, verificar quais as queixas prioritárias na perceptiva do usuários, pontos pouco observados pelos cuidadores e melhorar as estratégias de adesão (SERRANO-AGUILAR et al., 2016; UTENS et al., 2016).

\section{Rigor do Desenvolvimento}

Esse domínio apresentou uma das maiores disparidades entre os grupos avaliados, com as diretrizes GAC possuindo um percentual de adequação aos critérios do instrumento quase sete vezes maior (48\%) que as que as diretrizes DRP (7\%) e uma média de pontuação dos juízes $(3,9)$ quase três vezes maior $(1,4)$.

Questões fundamentais para determinar a qualidade das diretrizes foram totalmente negligenciadas nas DRP como descrição dos métodos de busca, seleção das evidências e formulação das recomendações, descrição de pontos fortes, limitações, benefícios e riscos à saúde, além de procedimentos de revisão por experts e atualização permanente da diretriz.

Dentre as diretrizes avaliadas, o Guia de Doenças Infeciosas e Parasitárias (DRP 02), recebeu o menor percentual de adequação (1\%), a publicação que tem uma proposta de ser um guia rápido para a atenção básica não possui seção que esclareça ao leitor os métodos de elaboração das recomendações e sequer possui referências bibliográficas. Apesar disto esse documento possui a maior tiragem dentre as publicações avaliadas, com 90 mil exemplares.

Molino et al., (2016) e Ronsoni (2013) chegaram a avaliar algumas diretrizes GAC do Ministério da Saúde e encontraram valores de percentual de adequação parecidos, com médias de $41 \%$ e $36 \%$ respectivamente.

Os decretos $n^{\circ} 7508 / 11$ e 7646/11 estabeleceram que os PCDT do Ministério da Saúde devem ser atualizados a cada dois anos, atribuindo a Conitec a constituição ou 
alteração dessas diretrizes. Todos os documentos GAC avaliados atenderam a essas normativas. Das 16 diretrizes para DPR, uma foi publicada antes dos decretos e das demais apenas uma foi publicada em conformidade com as normativas legais (BRASIL. PRESIDÊNCIA DA REPÚBLICA, 2011a, 2011b; MEGA et al., 2015).

\section{Clareza da apresentação}

Segundo domínio com as maiores pontuações, mesmo mantendo a tendência de médias maiores das diretrizes GAC (70\% e 5,2) quando comparadas as diretrizes DRP (61\% e 4,6). De uma maneira geral, ambos os grupos apresentam linguagem clara, geralmente abordando vários aspectos da questão de saúde.

As diretrizes GAC se mostram mais sintéticas que os documentos de DRP. Estes últimos possuíam uma grande variedade de formatos e tamanhos dos documentos, contrastando com o primeiro grupo, que possuía um formato padrão estabelecido anteriormente meio da portaria especifica, com roteiro para elaboração de PCDT e consequentemente apresentando maior coerência na sua apresentação (BRASIL. MS. SAS, 2009).

\section{Aplicabilidade}

Outro campo com resultado baixo para ambos os grupos é o domínio “aplicabilidade". Nesse campo são avaliadas questões que descrevam fatores facilitadores e barreiras para implantação das diretrizes, recursos que devem ser utilizados e critérios para o seu monitoramento por exemplo (AGREE NEXT STEPS CONSORTIUM, 2009).

Apesar da pequena margem de diferença observa-se que as diretrizes DRP apresentaram pontuações superiores $(33 \%$ e 2,9$)$ as diretrizes GAC $(25 \%$ e 2,5$)$. O que 
demonstra uma certa preocupação da área elaboradora com a aplicação das orientações em contextos de maior dificuldade operacional.

O caráter normativo e com pouca abordagem nas ações para implementação das diretrizes já foram descritos por outros autores que avaliaram alguns PCDT do Ministério da Saúde e encontraram resultados semelhantes a este estudo, como Ronsoni (2013;2015) (37,5\% e 3,3) e Molino et al., (2016) (34\%).

\section{Independência Editorial}

Assim como o domínio "rigor do desenvolvimento", essa foi uma das categorias que mais apresentou discrepância entre as pontuações das diretrizes GAC $(43 \%$ e 3,6) e das diretrizes DRP (1\% e 1,1). Trata-se de item que avalia o grau de credibilidade e isenção na produção das diretrizes.

Observa-se que as diretrizes GAC não alcançaram pontuações maiores por não especificarem claramente no texto das diretrizes os procedimentos para evitar influência dos órgãos financiadores do documento e os encaminhamentos para potenciais conflitos de interesse. Apesar de que em documentos e normativas acessórios são definidos procedimentos e atribuições de cada grupo de participantes, além de especificar que todos assinaram declaração de conflitos de interesse (BRASIL. MS. SCTIE, 2015b; MOLINO et al., 2016).

Já as diretrizes DRP não possuíram nenhum procedimento ou norma semelhante, não havendo registro de assinatura de declaração de conflito de interesses, nem tampouco ações para evitar a influência negativa do órgão financiador na definição das recomendações. 


\section{Comparação Internacional}

Com intuito de analisar os resultados alcançados dentro de uma perspectiva internacional, realizou-se uma comparação dos percentuais de adequação por domínio com os resultados do trabalho de Alonso-Coelho et al.(2010), uma revisão sistemática de estudos de todo o mundo que reuniu 625 diretrizes diferentes. Para compor a Figura 12 foram utilizados os dados mais atuais do estudo em questão, com diretrizes publicadas a partir de 2003.

Figura 12 - Percentuais de adequação dos domínios do AGREE II comparados as diretrizes internacionais de Alonso-Colho et al. (2010)

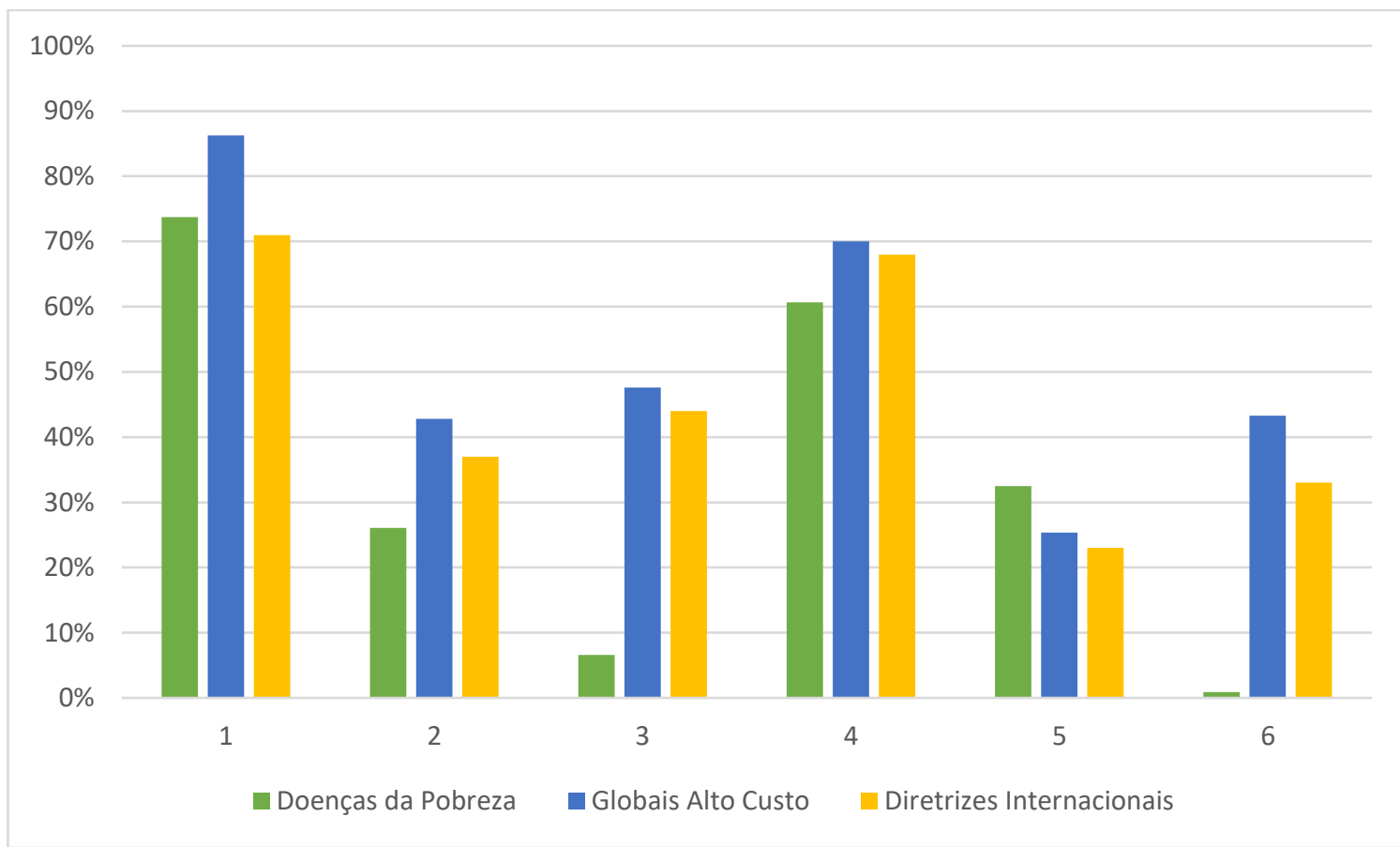

Fonte: O Autor

É possível verificar que de uma maneira geral, as diretrizes GAC estão em consonância aos padrões internacionais, com resultados semelhantes e levemente superiores em todos os domínios avaliados.

Já as diretrizes DRP apresentam resultados inferiores na maioria dos domínios. Os principais contrastes podem ser observados no domínio "rigor do desenvolvimento" e no domínio "independência editorial", reforçando os achados que verificam que esses 
documentos apresentam falhas nos critérios metodológicos sob a ótica da saúde baseada em evidências e nos procedimentos para garantia da isenção no processo de elaboração.

\section{Avaliação Global da Diretriz Clínica}

A comparabilidade dos resultados desse estudo com achados internacionais, demonstram a eficácia do método escolhido, no entanto, os juízes participantes não consideram adequado avaliar individualmente se uma determinada diretriz seria recomenda ou não para uso, conforme descrito no AGREE II. Por isso, optou-se por adotar critérios baseados nas análises dos domínios anteriores.

Pelo maior destaque em trabalhos semelhantes (ALONSO-COELLO et al., 2010; MOLINO et al., 2016; SMITH et al., 2015; ZHANG et al., 2014), adotou-se a concepção de que o domínio "rigor do desenvolvimento" deveria ser o item central de análise por sua relevância e maior número de parâmetros de análise. Considerou-se como uma diretriz "recomendada" as que possuíam percentual superior a 50\% em rigor do desenvolvimento e em mais dois outros domínios; foi considerada "recomendada com ressalvas" a diretriz que possuía percentual entre " $30 \%$ a $50 \%$ em rigor do desenvolvimento, mas superior a $50 \%$ em outros dois domínios; e por último foi considerada "não recomenda" aquelas com percentual inferior a $30 \%$ em rigor do desenvolvimento.

Por esses critérios, os PCDT para artrite reumatoide (GAC 17), hepatite viral C (GAC 18) e de câncer de mama (GAC 19) foram considerados "recomendados", já as demais diretrizes GAC (20 a 32) foram consideradas "recomendadas com ressalvas". Esse resultado está em consonância com outros três estudos semelhantes que verificaram que os PCDT do Ministério da Saúde (GAC), precisam de continuas adequações, mas apresentam padrão metodológico superior a outras diretrizes nacionais e comparável a outras diretrizes internacionais (MOLINO et al., 2016; RONSONI, 2013; RONSONI et al., 2015). 
Todas as diretrizes DRP (01 a 16) foram consideradas "não recomendadas", pois basicamente não atingiram critérios mínimos de método científico, não trazendo informações que demonstrassem ao leitor se o documento foi ou não elaborado pela ótica da saúde baseada em evidências.

Doenças com maior percentual de pontuação no AGREE II são justamente as que demandam um maior gasto do Ministério da Saúde com medicamentos (artrite, hepatite C e câncer de mama), com impacto orçamentário bilionário no sistema de saúde brasileiro e na maioria dos sistemas de saúde dos países desenvolvidos. (ANDRIEUX-MEYER et al., 2015; BRASIL. MS. SCTIE, 2014). Os menores percentuais foram para documentos que definiam o tratamento de doenças da pobreza de pouca visibilidade como parasitoses intestinais, brucelose, oncocercose, tracoma, entre outras.

Esse contraste incita sobre a influência que a pressão orçamentária exerce nas prioridades de ação e de investimentos na qualificação da saúde. O que não parece ser uma decisão acertada, uma vez que são as doenças da pobreza que possuem um menor potencial de geração de evidencias, decorrentes do menor investimento em pesquisa clínica (SANTANA; LEITE, 2016). Soma-se a isso a tendência de menor abordagem desses temas nos currículos de formação da aérea da saúde, que consequentemente gera maior necessidade por diretrizes clínicas consistentes (CRUMP et al., 2010).

\section{Considerações Finais:}

Pelos achados desse trabalho é possível verificar um duplo padrão de qualidade na elaboração de diretrizes clínicas do Ministério da Saúde, em que as doenças que demandam tecnologias de alto custo apresentaram melhores pontuações na avaliação pelo AGREE II quando comparadas as diretrizes de doenças da pobreza que normalmente demandam tecnologias antigas e de baixo custo. 
Discrepâncias encontradas na qualidade e nos métodos se seleção e uso das evidências científicas, bem como nos critérios de transparência editorial são preocupantes e devem ser revistos para as diretrizes de doenças da pobreza.

Infere-se que o poder orçamentário e a pressão dos recursos também influenciam a priorização dos trabalhos e a qualidade da assistência no setor público, fazendo com que doenças que são negligenciadas pelo mercado farmacêutico também sejam negligenciadas em determinados níveis pelo sistema de saúde. 


\section{CONSIDERAÇÕES FINAIS}




\section{CONSIDERAÇÕES FINAIS DA TESE}

Os diferentes achados dessa tese nos permitem observar que o país traçou um caminho de avanços em diversos pontos nas políticas farmacêuticas para doenças da pobreza, porém diferentes barreiras ainda se configuram como desafios para a superação dessas doenças no Brasil.

Talvez a própria saúde pública tenha dado seus primeiros passos em torno do combate a essas doenças, como ilustra episódios históricos como a "revolta da vacina" ou as diferentes ações de combate as "epidemias" brasileiras. Essas ações contribuíram inclusive para a drástica redução da mortalidade por doenças infeciosas no último século.

Quando verificamos os resultados das pesquisas clínicas com medicamentos no país, observamos que, por mais que durante décadas tenha-se discutido sobre a falta de investimento na pesquisa com medicamentos para "doenças negligenciadas", não se observou mudanças práticas no panorama de ensaios clínicos e o prognóstico não parece bom quando verificamos que apenas $4 \%$ das pesquisas tem alguma relação com doenças da pobreza. Esse resultado faz ainda mais sentido quando outros autores apontam entre 1,3\% a 4,6\% de registro de novos medicamentos para essas doenças. Mesmo caracterizadas por tratamentos antigos e em alguns casos associados a falhas terapêuticas e eventos adversos.

Apesar disso, um achado do estudo leva a refutar a tese do desequilíbrio 90/10 no Brasil, uma vez que o percentual de ensaios clínicos tem sido proporcional aos percentuais de carga de doença, não avaliando, porém, se são doenças com maior ou menor grau de alternativas terapêuticas.

Mesmo num contexto de escassez de oferta pelo mercado, se evidencia o esforço do SUS de incorporação de tecnologias para doenças da pobreza, como verificado na continua disponibilização de vacinas pelo PNI ou no crescimento de itens incluídos na Rename ao longo das suas edições. 
No entanto, a modernização do arcabouço regulatório criando estratégias de incentivo para o registro de medicamentos com pouco interesse pelo mercado se mostrou uma necessidade para ação governamental. Legislações específicas para "medicamentos órfãos" e outras formas de fomento à pesquisa e registro comuns a outras agências exemplificam o quanto o Brasil precisa avançar.

Regras diferenciadas para análises de incorporação de tecnologias no SUS se mostram necessárias após a criação da Conitec e consequente estabelecimento de um novo padrão na avaliação de evidências. Um padrão que nem sempre pode ser alcançado quando se fala em doenças pouco pesquisadas.

Para os medicamentos já incorporados pode-se verificar à difícil ação de manter seu acesso uma vez que metade dos itens possuem apenas um produtor nacional ou não possuem registro, caracterizando então um quadro potencial de insustentabilidade na oferta. Três estratégias importantes foram observadas e discutidas nessa tese.

A centralização do financiamento e da aquisição, permitindo que a maioria dos medicamentos dessas doenças não sofressem com oscilações de orçamento regionais e fosse criado uma cadeia única logística com os laboratórios oficiais (principais fornecedores).

O investimento na rede de laboratórios oficiais para atendimento dessa demanda se mostrou fundamental para garantia da oferta desses itens. Na última década, os laboratórios públicos foram responsáveis por quase $2 / 3$ dos contratos.

A aquisição via organismos internacionais também representou uma estratégia importante, principalmente quando se tratavam de novas tecnologias e medicamentos que ainda não podiam ser produzidos por laboratórios oficiais.

Em contextos de crise fiscal e disputas por orçamento fica o receio com o grande crescimento dos gastos com medicamentos de alto custo e demandas judiciais, estes últimos já superiores aos investimentos em doenças da pobreza. Percebe-se que há um abismo de 
investimentos quando se compara algumas doenças da pobreza e outras que envolvem medicamentos de alto custo.

Essa disparidade de investimentos se reflete inclusive nas ações de qualificação para essas doenças, como se pode verificar na comparação realizada entre as diretrizes clínicas de Doenças Relacionadas à Pobreza e Doenças Globais de Alto Custo. Essas últimas apresentavam parâmetros de qualidade metodológica na elaboração muito superiores e comparáveis as diretrizes produzidas internacionalmente. A diretrizes para doenças da pobreza apresentam falhas graves em questões de rigor do desenvolvimento e independência editorial, por exemplo, o que coloca em questionamento sua adoção para organizar a assistência terapêutica aos pacientes dessas doenças no SUS.

Com a universidade e os serviços de saúde cada vez mais voltados a pauta da alta tecnologia, retornar à atenção para essas doenças foi uma das contribuições pretendidas dessa tese. Discutir e ampliar o entendimento do que as doenças da pobreza não se restringem apenas as um grupo restrito de doenças infeciosas é outro ponto relevante apontado.

Limitações importantes do estudo estão relacionadas a divergências na literatura sobre quais doenças e agravos se enquadrariam no conceito de "relacionadas à pobreza" o que levou o autor a definir um rol para execução de suas análises, mas que pode em maior ou menor grau dificultar a comparabilidade com outros autores.

A dificuldade de acesso ou não confiabilidade de algumas bases de dados também impediu a realização de determinadas análises pretendidas inicialmente, como os dados relativos a casos notificados ou pessoas atendidas para determinadas doenças, que poderiam gerar informações importantes de valores per capita ou outras análises econômicas e que demonstrassem diferentes graus de iniquidades.

Novos estudos que abordem comparações internacionais são necessários, para análise comparada de estratégias e resultados de outros sistemas de saúde. Estudos que 
demonstrem impacto de algumas ações e políticas levantadas em contextos regionais, nos estados ou municípios também podem ampliar o debate e trazer luz a lacunas do trabalho. O monitoramento do acesso aos medicamentos distribuídos pelo Ministério da Saúde, e questões relacionadas a efetividade do seu uso assim como aspectos de farmacovigilância são pouco abordados na literatura científica e precisam de novos estudos para análise das políticas farmacêuticas do SUS.

Os diferentes dados e análises desse trabalho permitiram identificar um componente claro de iniquidade na execução do direito de acesso a medicamentos no país. As comparações realizadas entre doenças da pobreza e outras doenças demonstram que influências mercadológicas, pressões orçamentárias e políticas, ou grau de empoderamento dos interessados impactam decisivamente na efetivação do acesso. Intervenções equitativas são necessárias para garantir que tenhamos um real SUS para todos. 


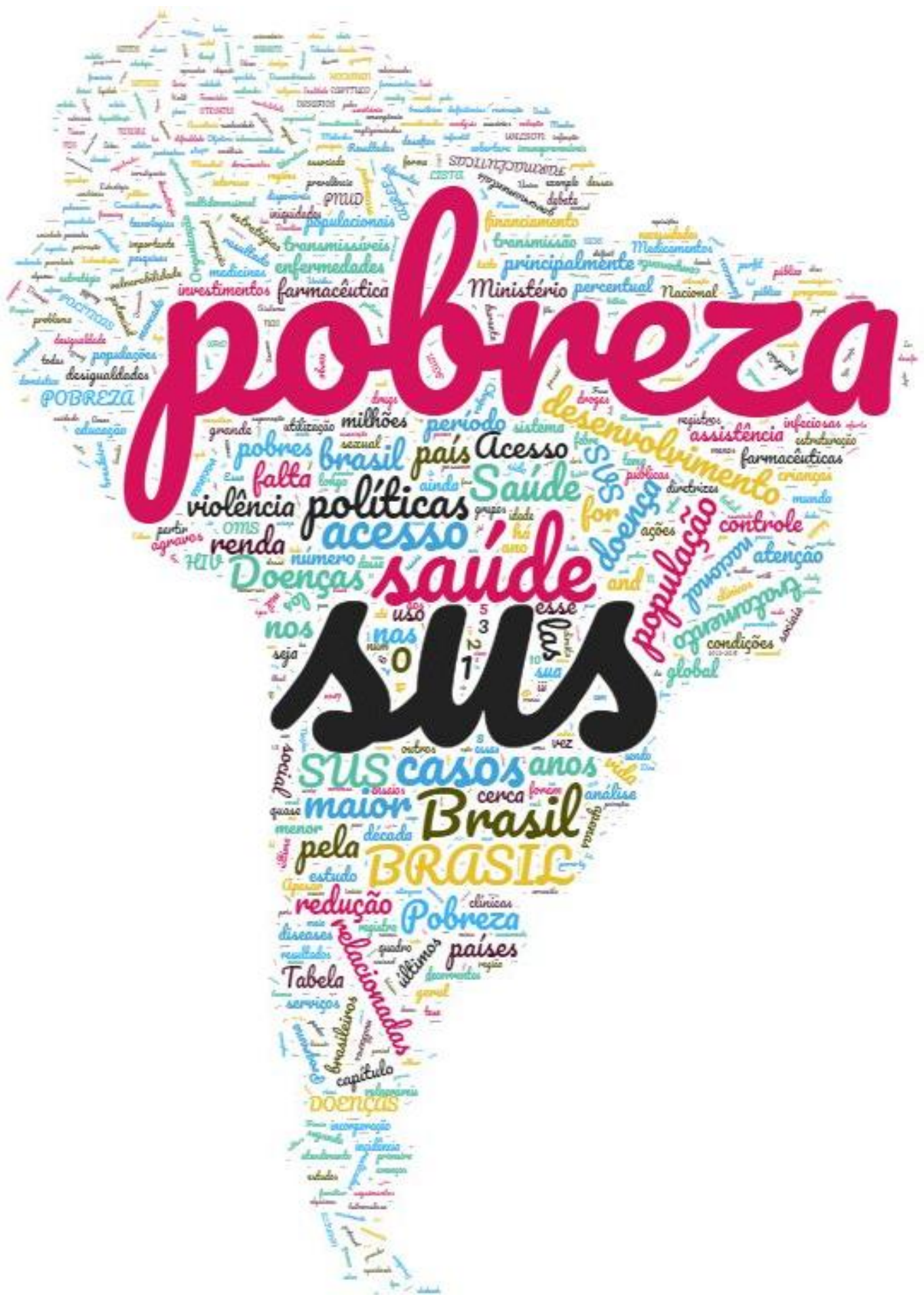




$$
5
$$




\section{REFERÊNCIAS BIBLIOGRÁFICAS}

ACADEMIA BRASILEIRA DE CIÊNCIAS. Doenças neglicenciadas. Rio de Janeiro: Academia Brasileira de Ciências, 2010. 56 p.

AGREE NEXT STEPS CONSORTIUM. The AGREE II Instrument [versão em português]. Consórcio AGREE, 2009.

AITH, F. M. A.; DALLARI, S. G. Regulação de medicamentos no mundo globalizado. São Paulo: CEPEDISA, 2014. 633 p.

ALONSO-COELLO, P. et al. The quality of clinical practice guidelines over the last two decades: a systematic review of guideline appraisal studies. Quality \& safety in health care, v. 19, n. 6, p. e58, 2010.

ALVES, H.; ESCOREL, S. Massa marginal na América Latina: mudanças na conceituação e enfrentamento da pobreza 40 anos após uma teoria. Physis: Revista de Saúde Coletiva, v. 22, n. 1, p. 99-117, 2012.

ANDREWS, C. Ethical and scientific implications of the globalization of clinical research. The New England Journal of Medicine, v. 360, n. 26, p. 2793, 2009.

ANDRIEUX-MEYER, I. et al. Disparity in market prices for hepatitis C virus direct-acting drugs. The Lancet: Global Health, v. 3, n. 11, p. e676-e677, 2015.

ASSIS, A. M. O. et al. Desigualdade, pobreza e condições de saúde e nutrição na infância no Nordeste brasileiro. Cadernos de Saúde Pública, v. 23, n. 10, p. 2337-2350, 2007.

CUETO, M. et al. Pensar o Sistema Único de Saúde do século XXI: entrevista com Lígia Bahia. História, Ciências, Saúde - Manguinhos, v. 21, n. 1, p. 93-107, 2014.

BARRETO, M. L. et al. Successes and failures in the control of infectious diseases in Brazil: Social and environmental context, policies, interventions, and research needs. The Lancet, v. 377, n. 9780, p. 1877-1889, 2011.

BASTOS, V. D. Laboratórios farmacêuticos oficiais e doenças negligenciadas: perspectivas de política pública. Revista do BNDES, v. 13, n. 25, p. 269-298, 2006.

BERTOLDI, A. D. et al. Sociodemographic profile of medicines users in Brazil: results from the 2014 PNAUM survey. Revista de Saúde Pública, v. 50, suplemento 2, p. 1s-5s, 2016.

BOCHNER, R.; STRUCHINER, C. J. Acidentes por animais peçonhentos e sistemas nacionais de informação. Cadernos de Saúde Pública, v. 18, n. 3, p. 735-746, 2002.

BOCHNER, R.; STRUCHINER, C. J. Epidemiologia dos acidentes ofídicos nos últimos 100 anos no Brasil: uma revisão. Cadernos de Saúde Pública, v. 19, n. 1, p. 7-16, 2003.

BOING, A. C. et al. The influence of health expenditures on household impoverishment in Brazil. Revista de Saúde Pública, v. 48, n. 5, p. 797-807, 2014. 
BOTELHO, S. F.; MARTINS, M. A. P.; REIS, A. M. M. Análise de medicamentos novos registrados no Brasil na perspectiva do Sistema Único de Saúde e da carga de doença.

Ciência \& Saúde Coletiva, 2017. No prelo.

BRANDÃO, C. M. R. et al. Gastos do Ministério da Saúde do Brasil com medicamentos de alto custo: uma análise centrada no paciente. Value in Health, v. 14, n. 5, p. S71-S77, 2011.

BRASIL. Agência Nacional de Vigilância Sanitária. Central de Atendimento da Anvisa. Resposta Anvisa sobre questionamento do Hidrato de Cloral. 2015. Disponível em: < http://sbnc.org.br/wpcontent/uploads/2015/11/1446567352_RESPOSTA_RECENTE_AN VISA_-_HIDRATO_DE_CLORAL.pdf >. Acesso em: outubro de 2016.

BRASIL. AGÊNCIA NACIONAL DE VIGILÂNCIA SANITÁRIA. Resolução n. 11, de 22 de março de 2011. Dispõe sobre o controle da substância Talidomida e do medicamento que a contenha. Diário Oficial da União, Brasília, 24 mar. 2011.

BRASIL. AGÊNCIA NACIONAL DE VIGILÂNCIA SANITÁRIA. Resolução RDC n. 204, de 14 de novembro de 2006. Estabelece as Boas Práticas de distribuição e

fracionamento de insumos farmacêuticos. Diário Oficial da União, Brasília, 16 nov. 2006.

BRASIL. MINISTÉRIO DA SAÚDE. Situação Epidemiologica da Hanseníase.

Disponível em <http://portalsaude.saude.gov.br/index.php/o-

ministerio/principal/secretarias/svs/hanseniase >. Acesso em agosto de 2016a.

BRASIL. MINISTÉRIO DA SAÚDE. Situação Epidemiologica do Tracoma no Brasil.

Disponível em < http://portalsaude.saude.gov.br/index.php/o-

ministerio/principal/secretarias/svs/tracoma> Acesso em agosto de 2016 b.

BRASIL. MINISTÉRIO DA SAÚDE. Situação Epidemiológica da Cólera. Disponível em <http://portalsaude.saude.gov.br/index.php/o-

ministerio/principal/secretarias/svs/colera> Acessado em agosto de 2016c.

BRASIL. MINISTÉRIO DA SAÚDE. Situação Epidemiologica da Dengue. Disponível em <http://portalsaude.saude.gov.br/index.php/o-

ministerio/principal/secretarias/svs/dengue> Acessado em agosto de 2016d.

BRASIL. MINISTÉRIO DA SAÚDE. Doença de Chagas. Aspectos Epidemiológicos.

Disponível em <http://portalsaude.saude.gov.br/index.php/o-

ministerio/principal/secretarias/svs/doenca-de-chagas> Acessado em agosto de 2016e.

BRASIL. MINISTÉRIO DA SAÚDE. Registro Brasileiro de Ensaios Clínicos (ReBEC). Disponível em:< http://www.ensaiosclinicos.gov.br/ >. Acesso em: jul. $2016 f$.

BRASIL. MINISTÉRIO DA SAÚDE. FUNDAÇÃO OSWALDO CRUZ. Instituto de Comunicação e Informação Científica e Tecnológica em Saúde. Pesquisa Nacional sobre o uso de crack. Rio de Janeiro: Editora ICICT/FIOCRUZ, 2014. 224 p.

BRASIL. MINISTÉRIO DA SAÚDE. Secretaria de Vigilância em Saúde. Secretaria de Ciência, Tecnologias e Insumos Estratégicos. Nota Informativa Conjunta 109/2015: Orienta a respeito da priorização da penicilina $\mathrm{G}$ benzatina para sífilis em gestantes e 
penicilina cristalina para sífilis congênita no país e alternativas para o tratamento da sífilis. Brasília: Ministério da Saúde, 2015.

BRASIL. MINISTÉRIO DA SAÚDE. Portaria n. 2.556, de 28 de outubro de 2011. Estabelece mecanismo de repasse financeiro do Fundo Nacional de Saúde aos Fundos de Saúde Estaduais, do Distrito Federal e Municipais, por meio do Piso Variável de Vigilância e Promoção da Saúde, para implantação, implementação e fortalecimento da Vigilância Epidemiológica de Hanseníase, Tracoma, Esquistossomose e Geohelmintíases. Diário Oficial da União, Brasília, 31 out. 2011.

BRASIL. MINISTÉRIO DA SAÚDE. Portaria n. 204, de 29 de janeiro de 2007. Regulamenta o financiamento e a transferência dos recursos federais para as ações e os serviços de saúde, na forma de blocos de financiamento, com o respectivo monitoramento e controle. Diário Oficial da União, Brasília, 31 jan. 2007.

BRASIL. MINISTÉRIO DA SAÚDE. SECRETARIA DE ATENÇÃO À SAÚDE. Prevenção e Controle de Agravos Nutricionais. Disponível em < http://dab.saude.gov.br/portaldab/ape_pcan.php> Acesso em março de 2016.

BRASIL. MINISTÉRIO DA SAÚDE. SECRETARIA DE ATENÇÃO À SAÚDE. NutriSUS: guia de evidências: estratégia de fortificação da alimentação infantil com micronutrientes (vitaminas e minerais) em pó. Brasília: Ministério da Saúde, 2015. 50 p.

BRASIL. MINISTÉRIO DA SAÚDE. SECRETARIA DE ATENÇÃO À SAÚDE. Anticoncepção de emergência: perguntas e respostas para profissionais de saúde. Departamento de Ações Programáticas Estratégicas. Brasília: Editora do Ministério da Saúde, 2011. 44 p.

BRASIL. MINISTÉRIO DA SAÚDE. SECRETARIA DE ATENÇÃO À SAÚDE. Portaria n. 375, de 10 de novembro de 2009. Aprova o roteiro a ser utilizado na elaboração de Protocolos Clínicos e Diretrizes Terapêuticas (PCDT). Diário Oficial da União, Brasília, 11 nov. 2009.

BRASIL. MINISTÉRIO DA SAÚDE. SECRETARIA DE CIÊNCIA, TECNOLOGIA E INSUMOS ESTRATÉGICOS. Componente Especializado da Assistência

Farmacêutica: inovação para a garantia do acesso a medicamentos no SUS. Brasília: Ministério da Saúde, 2014. 164 p.

BRASIL. MINISTÉRIO DA SAÚDE. SECRETARIA DE CIÊNCIA, TECNOLOGIA E INSUMOS ESTRATÉGICOS. Departamento de Assistência Farmacêutica e Insumos Estratégicos. Relação Nacional de Medicamentos Essenciais: Rename 2014. Brasília: Ministério da Saúde, 2015a. 230 p.

BRASIL. MINISTÉRIO DA SAÚDE. SECRETARIA DE CIÊNCIA, TECNOLOGIA E INSUMOS ESTRATÉGICOS. Portaria n. 27, de 12 de junho de 2015. Aprova o fluxo de trabalho para elaboração e atualização dos PCDT no âmbito da Conitec. Diário Oficial da União, Brasília, 16 jun. 2015b.

BRASIL. MINISTÉRIO DA SAÚDE. SECRETARIA DE GESTÃO ESTRATÉGICA E 
PARTICIPATIVA. Política Nacional de Saúde Integral da População Negra: uma política para o SUS. Brasília: Editora do Ministério da Saúde, 2013. 36 p.

BRASIL. MINISTÉRIO DA SAÚDE. SECRETARIA DE VIGILÂNCIA EM SAÚDE. Detectar, tratar e curar: desafios e estratégias brasileiras frente à tuberculose. Boletim Epidemiológico, v. 46, n. 9, p. 1-19, 2015a.

BRASIL. MINISTÉRIO DA SAÚDE. SECRETARIA DE VIGILÂNCIA EM SAÚDE. Doença de Chagas aguda no Brasil: série histórica de 2000 a 2013. Boletim Epidemiológico, v. 46, n. 21, p. 1-9, 2015b.

BRASIL. MINISTÉRIO DA SAÚDE. SECRETARIA DE VIGILÂNCIA EM SAÚDE. Departamento de Vigilância das Doenças Transmissíveis. Febre de Chikungunya: manejo clínico. Brasília: Ministério da Saúde, 2015c. 28 p.

BRASIL. MINISTÉRIO DA SAÚDE. SECRETARIA DE VIGILÂNCIA EM SAÚDE. Departamento de DST, Aids e Hepatites Virais. Protocolo Clínico e Diretrizes

Terapêuticas para Profilaxia Antirretroviral Pós-Exposição de Risco à Infecção pelo HIV. Brasília: Ministério da Saúde, 2015d. 54 p.

BRASIL. MINISTÉRIO DA SAÚDE. SECRETARIA DE VIGILÂNCIA EM SAÚDE. Malária: monitoramento dos casos no Brasil em 2014. Boletim Epidemiológico, v. 46, n. 25, p. 1-5, 2015e.

BRASIL. MINISTÉRIO DA SAÚDE. SECRETARIA DE VIGILÂNCIA EM SAÚDE. Departamento de Análise de Situação em Saúde. Saúde Brasil 2013: uma análise da situação de saúde e das doenças transmissíveis relacionadas à pobreza. Brasília: Ministério da Saúde, 2014a. 384 p.

BRASIL. MINISTÉRIO DA SAÚDE. SECRETARIA DE VIGILÂNCIA EM SAÚDE. Guia de vigilância em saúde. Brasília: Ministério da Saúde, 2014b. 812 p.

BRASIL. MINISTÉRIO DA SAÚDE. SECRETARIA DE VIGILÂNCIA EM SAÚDE. Departamento de Vigilância Epidemiológica. Programa Nacional de Imunizações (PNI): 40 anos. Brasília-DF: Ministério da Saúde, 2013a. 236 p.

BRASIL. MINISTÉRIO DA SAÚDE. SECRETARIA DE VIGILÂNCIA EM SAÚDE. Tuberculose: alinhada com o social, afinada com a tecnologia. Boletim Epidemiológico, v. 44, n. 2, p. 1-6, 2013b.

BRASIL. MINISTÉRIO DA SAÚDE. SECRETARIA DE VIGILÂNCIA EM SAÚDE. Departamento de Vigilância de Doenças e Agravos não Transmissíveis e Promoção da Saúde. Sistema de Vigilância de Violências e Acidentes (Viva): 2009, 2010 e 2011. Brasília: Ministério da Saúde, 2013c. 164 p.

BRASIL. MINISTÉRIO DA SAÚDE. SECRETARIA DE VIGILÂNCIA EM SAÚDE. Departamento de Vigilância em Doenças Transmissíveis. Plano integrado de ações estratégicas de eliminação da hanseníase, filariose, esquistossomose e oncocercose como problema de saúde pública, tracoma como causa de cegueira e controle das geohelmintíases : plano de ação 2011-2015. Brasília: Ministério da Saúde, 2012. 100 p. 
BRASIL. MINISTÉRIO DA SAÚDE. SECRETARIA DE VIGILÂNCIA EM SAÚDE. Departamento de DST, Ainda e Hepatites Virais. Protocolo de assistência farmacêutica em DST/HIV/Aids: recomendações do Grupo de Trabalho de Assistência Farmacêutica. Brasília: Ministério da Saúde, 2010. 224 p.

BRASIL. MINISTÉRIO DA SAÚDE. SECRETARIA DE VIGILÂNCIA EM SAÚDE. Departamento de Vigilância Epidemiológica. Guia de vigilância epidemiológica e eliminação da filariose linfática. Brasília: Ministério da Saúde, 2009. 80 p.

BRASIL. MINISTÉRIO DA SAÚDE. SECRETARIA DE VIGILÂNCIA EM SAÚDE. Programa Nacional de Imunizações - 30 anos. Brasília: Ministério da Saúde, 2003. 208 p.

BRASIL. MINISTÉRIO DO DESENVOLVIMENTO SOCIAL E COMBATE À FOME. O Brasil sem miséria. Brasília: MDS, 2014. 848 p.

BRASIL. PRESIDÊNCIA DA REPÚBLICA. Decreto n ${ }^{\circ} 7.508$ de 28 de Junho de 2011 o planejamento da saúde, a assistência à saúde e a articulação interfederativa, e dá outras providências. Diário Oficial da União, Brasília, 29 jun. 2011.

BRASIL. PRESIDÊNCIA DA REPÚBLICA. Decreto $n^{0} 7.646$, de 21 de dezembro de 2011. Dispõe sobre a Comissão Nacional de Incorporação de Tecnologias no SUS e sobre o processo administrativo para incorporação, exclusão e alteração de tecnologias em saúde pelo SUS, e dá outras providências. Diário Oficial da União, Brasília, 22 dez. 2011.

BRASIL. PRESIDÊNCIA DA REPÚBLICA. Lei n. 8.080, de 19 de setembro de 1990. Dispõe sobre as condições para a promoção, proteção e recuperação da saúde, a organização e o funcionamento dos serviços correspondentes e dá outras providências. Diário Oficial da União, Brasília, 20 set. 1990.

BRASIL. PRESIDÊNCIA DA REPÚBLICA. Lei n. 9.782, de 26 de janeiro de 1999. Define o Sistema Nacional de Vigilância Sanitária, cria a Agência Nacional de Vigilância Sanitária, e dá outras providências. Diário Oficial da União, Brasília, 27 jan. 1999.

BRASIL. PRESIDÊNCIA DA REPÚBLICA. Lei n ${ }^{\circ}$ 10.191, de 14 de fevereiro de 2001. Dispõe sobre a aquisição de produtos para a implementação de ações de saúde no âmbito do Ministério da Saúde. Diário Oficial da União, Brasília, 16 fev. 2001.

BROUWERS, M. C. et al. AGREE II: advancing guideline development, reporting and evaluation in health care. Canadian Medical Association Journal, v. 182, n. 18, p. E839E842, 2010.

BUSS, P. M.; PELLEGRINI FILHO, A. Iniqüidades em saúde no Brasil, nossa mais grave doença: comentários sobre o documento de referência e os trabalhos da Comissão Nacional sobre Determinantes Sociais da Saúde. Cadernos de Saúde Pública, v. 22, n. 9, p. 20052008, set. 2006.

CABRAL, M. M. L.; SCHINDLER, H. C.; ABATH, F. G. C. Regulamentações, conflitos e ética da pesquisa médica em países em desenvolvimento. Revista de Saúde Pública, v. 40, n. 3, p. 521-527, 2006. 
CAMPOS, A. L. V. Combatendo nazistas e mosquitos: militares norte-americanos no Nordeste brasileiro (1941-45). História, Ciências, Saúde-Manguinhos, v. 5, n. 3, p. 603620, 1999.

CANARY, L. A.; KLEVENS, R. M.; HOLMBERG, S. D. Limited access to new hepatitis $\mathrm{C}$ virus treatment under state Medicaid programs. Annals of Internal Medicine, v. 163, n. 3, p. 226-228, 2015.

CARMO, L. F. et al. Concentração de sódio e glicose em soro de reidratação oral preparado por Agentes Comunitários de Saúde. Ciência \& Saúde Coletiva, v. 17, n. 2, p. 445-452, 2012.

CERDA L., J.; VALDIVIA C., G. John Snow, la epidemia de cólera y el nacimiento de la epidemiología moderna. Revista Chilena de Infectología, v. 24, n. 4, p. 331-334, 2007.

CHIEFFI, A. L.; BARATA, R. B. Judicialização da política pública de assistência farmacêutica e eqüidade. Cadernos de Saúde Pública, v. 25, n. 8, p. 1839-1849, 2009.

CHIEFFI, A. L.; BARATA, R. C. B. Ações judiciais: estratégia da indústria farmacêutica para introdução de novos medicamentos. Revista de Saúde Pública, v. 44, n. 3, p. 421429, 2010.

CHIRAC, P.; TORREELE, E. Proportion of new drugs developed over the period from 1975 to 2004 that were for neglected tropical diseases and tuberculosis. The Lancet, v. 12, p. 1560-1561, 2006.

COHEN, J. Ebola vaccine: little and late. Science, v. 345, n. 6203, p. 1441-1442, 2014.

COHEN, J.; DIBNER, M. S.; WILSON, A. Development of and access to products for neglected diseases. PloS one, v. 5, n. 5, p. e10610, 2010.

COMISSÃO NACIONAL DE INCORPORAÇÃO DE TECNOLOGIAS NO SUS. Miltefosina para o tratamento da Leishmaniose Tegumentar. Brasília: Ministério da Saúde, 2016. 23 p.

COMISSÃO NACIONAL DE INCORPORAÇÃO DE TECNOLOGIAS NO SUS.

Relatório 130 - Suplemento alimentar com múltiplos micronutrientes em pó para implantação do NutriSUS. Brasília: Ministério da Saúde, 2014. 14 p.

COMISSÃO NACIONAL DE INCORPORAÇÃO DE TECNOLOGIAS NO SUS.

Relatório 21 - Vacina Tetraviral (Sarampo, Caxumba, Rubéola e Varicela). Brasília: Ministério da Saúde, 2013. 129 p.

CONTANDRIOPOULOS, A. P. A avaliação na área da saúde: conceitos e métodos. In: HARTZ, Z. M. A. (Org.). Avaliação em saúde: dos modelos conceituais a prática na análise da implantação de programas. Rio de Janeiro: Editora Fiocruz, 1997. p. 29-47

COOPER, J. M. et al. Em tempo: a persistência da sífilis congênita no Brasil - Mais avanços são necessários! Revista Paulista de Pediatria, v. 34, n. 3, p. 251-253, 2016.

CRUMP, J. A.; SUGARMAN, J.; WORKING GROUP ON ETHICS GUIDELINES FOR GLOBAL HEALTH TRAINING (WEIGHT). Ethics and best practice guidelines for 
training experiences in global health. American Journal of Tropical Medicine and Hygiene, v. 83, n. 6, p. 1178-1182, 2010.

DEPARTAMENTO DE CIÊNCIA E TECNOLOGIA DO MINISTÉRIO DA SAÚDE. Doenças negligenciadas: estratégias do Ministério da Saúde. Revista de Saúde Pública, v. 44, n. 1, p. 200-202, 2010.

DIAS, J. C. P. Globalização, iniqüidade e doença de Chagas. Cadernos de Saúde Pública, v. 23, n. suppl.1, p. S13-S22, 2007.

DINIZ, D. et al. (Org.). Ética em pesquisa: temas globais. Brasília: Letras Livres/ Editora UnB, 2008. 404 p.

DOMINGUES, C. M. A. S.; TEIXEIRA, A. M. D. S. Coberturas vacinais e doenças imunopreveníveis no Brasil no período 1982-2012: avanços e desafios do Programa Nacional de Imunizações. Epidemiologia e Serviços de Saúde, v. 22, n.1, p. 9-27, 2013.

DOMINGUES, C. M. A. S.; TEIXEIRA, A. M. D. S.; CARVALHO, S. M. D. National immunization program: Vaccination, compliance and pharmacovigilance. Revista do Instituto de Medicina Tropical de Sao Paulo, v. 54, n. suppl.18, p. 22-27, 2012.

DUARTE, P. S.; RAMOS, D. G.; PEREIRA, J. C. R. Padrão de incorporação de fármacos antiretrovirais pelo sistema público de saúde no Brasil. Revista Brasileira de Epidemiologia, v. 14, n. 4, p. 541-547, 2011.

DUPONT, A. G.; WILDER, P. B. V. Access to orphan drugs despite poor quality of clinical evidence. British Journal of Clinical Pharmacology, v. 71, n. 4, p. 488-496, 2011.

EUROPEAN MEDICINES AGENCY. Committee for Orphan Medicinal Products. Positive opinion for orphan designation of hydroxyurea for the treatment of sickle cell syndrome. London: EMEA, 2008.

EUROPEAN MEDICINES AGENCY. Orphan designation. Disponível em < http://www.ema.europa.eu/ema/index.jsp?curl=pages/regulation/general/general_content_0 00029.jsp> Acesso em agosto de 2016.

FARIA, N. R. et al. Zika virus in the Americas: early epidemiological and genetic findings. Science, v. 352, n. 6283, p. 345-349, 2016.

FAÚNDES, A. et al. Violência sexual: procedimentos indicados e seus resultados no atendimento de urgência de mulheres vítimas de estupro. Revista Brasileira de Ginecologia e Obstetrícia, v. 28, n. 2, p. 126-135, 2006.

FEIJÓ, R. B.; SÁFADI, M. A. P. Immunizations: three centuries of success and ongoing challenges. Jornal de Pediatria, v. 82, n. 3, suppl, p. S1-S3, 2006.

FIGUEIREDO, T. A.; SCHRAMM, J. M. A.; PEPE, V. L. E. Seleção de medicamentos essenciais e a carga de doença no Brasil. Cadernos de Saúde Pública, v. 30, n. 11, p. 2344-2356, 2014.

FOOD AND DRUG ADMINISTRATION. Orphan Drug Act. Disponível em < 
http://www.fda.gov/RegulatoryInformation/Legislation/SignificantAmendmentstotheFDC Act/OrphanDrugAct/> Acesso em agosto de 2016.

FREITAS, F. et al. Uncomplicated Plasmodium vivax and P. falciparum malaria in Brazil: evidence on single and combined drug treatments recommended by offi cial guidelines.

Cadernos de Saúde Pública, v. 23, n. 10, p. 2285-2294, 2007.

GADELHA, A.; LEITE, I.; VALENTE, J. Relatório final do Projeto Estimativa da carga de doença do Brasil - 1998. Rio de Janeiro: ENSP/Fiocruz/FENSPTEC, 2002.

GARCIA, L. P. et al. Epidemiologia das doenças negligenciadas no Brasil e gastos federais com medicamentos. Texto para discussão - IPEA, n. 1607, p. 7-62, 2011.

GARRAFA, V.; LORENZO, C. Helsinque 2008: redução de proteção e maximização de interesses privados. Revista da Associação Médica Brasileira, v. 55, n. 5, p. 514-518, 2009.

GAVA, C. M.; BERMUDEZ, J. A. Z.; PEPE, V. L. E. Novos medicamentos registrados no Brasil: podem ser considerados como avanço terapêutico? Ciência \& Saúde Coletiva, v. 15, p. 3403-3412, 2010.

GÓES, M. A. O.; JERALDO, V. L. S.; OLIVEIRA, A. S. Urbanização da leishmaniose visceral: aspectos clínicos e epidemiológicos em Aracaju, Sergipe, Brasil. Revista Brasileira de Medicina de Família e Comunidade, v. 9, n. 31, p. 119, 2013.

GOMES, R. et al. O novo cenário de concorrência na indústria farmacêutica brasileira. BNDES Setorial, v. 39, p. 97-134, 2014.

GOMES, R. D. P. et al. Ensaios clínicos no Brasil: competitividade internacional e desafios. BNDES Setorial, v. 36, p. 45-84, 2012.

GUIMARÃES, R. Technological incorporation in the Unified Health System (SUS): the problem and ensuing challenges. Ciência \& Saúde Coletiva, v. 19, n. 12, p. 4899-4908, 2014.

HADINEGORO, S. R. et al. Efficacy and long-term safety of a dengue vaccine in regions of endemic disease. The New England Journal of Medicine, v. 373, n. 13, p. 1195-1206, 2015.

HAMEL, R. et al. Zika virus: epidemiology, clinical features and host-virus interaction. Microbes and Infection, v. 18, n. 7-8, p. 441-449, 2016.

HEALTH POVERTY ACTION. Poverty and health. Disponível em < https://www.healthpovertyaction.org/> Acesso em fevereiro de 2016.

HOCHMAN, G. Priority, invisibility and eradication: the history of smallpox and the Brazilian public health agenda. Medical History, v. 53, n. 2, p. 229-252, 2009a.

HOCHMAN, G. "O Brasil não é só doença": o programa de saúde pública de Juscelino Kubitschek. História, Ciências, Saúde-Manguinhos, v. 16, p. 313-331, 2009b.

HOCHMAN, G. O sal como solução? políticas de saúde e endemias rurais no Brasil (19401960). Sociologias, v. 12, n. 24, p. 158-193, 2010. 
HOCHMAN, G. Vacinação, varíola e uma cultura da imunização no Brasil. Ciência \& Saúde Coletiva, v. 16, n. 2, p. 375-386, 2011.

HORST, M. M. L. L.; SOLER, O. Fundo Estratégico da Organização Pan-Americana da Saúde: mecanismo facilitador para melhorar o acesso aos medicamentos. Revista

Panamericana de Salud Pública, v. 27, n. 1, p. 43-48, 2010.

HUNT, P.; KHOSLA, R. The human right to medicines. Sur - International Journal of Human Rights, n. 8, p. 99-115, 2008.

INICIATIVA MEDICAMENTOS PARA DOENÇAS NEGLIGENCIADAS. Porque é necessária uma convenção sobre P\&D essencial em saúde? Genebra: DnDI, 2012.

INSTITUTO BRASILEIRO DE GEOGRAFIA E ESTATÍSTICA. Pesquisa de

Orçamentos Familiares - POF 2008-2009. Rio de Janeiro: IBGE, 2011.

INSTITUTO BRASILEIRO DE GEOGRAFIA E ESTATÍSTICA. Pesquisa Nacional por Amostra de Domicílios - 2015. Rio de Janeiro: IBGE, 2016.

INSTITUTO DO BRASILEIRO DE GEOGRAFIA E ESTATÍSTICA. Índice Nacional de Preços ao Consumidor Amplo. Disponível em:<

http://www.ibge.gov.br/home/estatistica/ indicadores/precos/inpc_ipca/defaultinpc.shtm> Acesso em janeiro de 2017.

INSTITUTO OSWALDO CRUZ. Nota Tecnica nº1 de 2011: Embasamento técnico e sugestões para ações de controle das doenças da pobreza no programa de erradicação da pobreza extrema no Brasil. Rio de Janeiro: Fiocruz/Diretoria, 2011.

JAMAL, L. F.; MOHERDAUI, F. Tuberculose e infecção pelo HIV no Brasil: magnitude do problema e estratégias para o controle. Revista de Saúde Pública, v. 41, p. 104-110, 2007.

KORNIS, G. E. M.; BRAGA, M. H.; PAULA, P. A. B. Transformações recentes da indústria farmacêutica: um exame da experiência mundial e brasileira no século XXI. Physis: Revista de Saúde Coletiva, v. 24, n. 3, p. 885-908, 2014.

KREDO, T. et al. Guide to clinical practice guidelines: the current state of play. International Journal for Quality in Health Care, v. 28, n. 1, p. 122-128, 2016.

LANDIS, J. R.; KOCH, G. G. The measurement of observer agreement for categorical data. Biometrics, v. 33, n. 1, p. 159-174, 1977.

LEITÃO, L. C. A. et al. Judicialização da saúde na garantia do acesso ao medicamento. Revista de Salud Pública, v. 16, n. 3, p. 360-370, 2014.

LEITE, I. D. C. et al. Projeção da carga de doença no Brasil (1998-2013). In: BUSS, P. M.; TEMPORÃO, J. G.; CARVALHEIRO, J. R. Vacinas, Soros e Imunizações no Brasil. Rio de Janeiro: Fiocruz, 2015. p. 51-65.

LESSA, S. D. C.; DÓREA, J. G. Bioética e vacinação infantil em massa. Revista Bioetica, v. 21, n. 2, p. 226-236, 2013.

LEVAC, D.; COLQUHOUN, H.; O’BRIEN, K. K. Scoping studies: advancing the 
methodology. Implementation Science, v. 5, p. 69, 2010.

LEVER, R. A.; WHITTY, C. J. M. Ebola virus disease: emergence, outbreak and future directions. British Medical Bulletin, v. 117, n. 1, p. 95-106, 2016.

LOBATO, M. Problema vital, Jeca Tatu e outros textos. São Paulo: Biblioteca Azul, 2010. 144 p.

LOPES, L. C. et al. Uso racional de medicamentos antineoplásicos e ações judiciais no Estado de São Paulo. Revista de Saúde Pública, v. 44, n. 4, p. 620-628, 2010.

LUCHETTI, M. Global Health and the 10/90 gap. British Journal of Medical Practitioners, v. 7, n. 4, p. 731, 2014.

MACINKO, J.; HARRIS, M. J. Brazil's Family Health Strategy — delivering communitybased primary care in a universal health system. The New England Journal of Medicine, v. 372, n. 23, p. 2177-2181, 2015.

MAGALHÃES, J. L. Estratégia governamental para internalização de fármacos \& medicamentos em doenças negligenciadas. Rio de Janeiro: Universidade Federal do Rio de Janeiro, 2010.

MAGALHÃES, J. L.; ANTUNES, A. M. D. S.; BOECHAT, N. Laboratórios

farmacêuticos oficiais e sua relevância para saúde pública do Brasil. Reciis, v. 5, n. 1, p. 85-99, 2011.

MANDERSON, L. et al. Social research on neglected diseases of poverty: continuing and emerging themes. PLoS Neglected Tropical Diseases, v. 3, n. 2, p. e332, 2009.

MARINHO E.; LINHARES, F.; CAMPELO, G. Os programas de transferência de renda do governo impactam a pobreza no Brasil? Revista Brasileira de Economia, v. 65, n. 3, p. 267-288, 2011.

MARQUES, R. M.; PIOLA, S. F.; ROA, A. C. Sistema de Saúde no Brasil: organização e financiamento. Rio de Janeiro: ABrES; Brasília: Ministério da Saúde, Departamento de Economia da Saúde, Investimentos e Desenvolvimento; OPAS/OMS no Brasil, 2016. 260 p.

MCINTYRE, D.; MOONEY, G. Aspectos econômicos da equidade em saúde. Rio de Janeiro: Fiocruz, 2014. 348p.

MÉDICOS SEM FRONTEIRAS. Desequilibrio fatal: a crise em pesquisa e desenvolvimento de drogas para doenças negligenciadas. Geneva: Grupo de Trabalho de Drogas para Doenças Negligenciadas, Médicos Sem Fronteiras, 2001.

MEGA, T. P. et al. Protocolos clínicos e diretrizes terapêuticas no SUS: histórico, desafios e perspectivas. Revista Eletrônica Gestão e Saúde, v. 6, supl. 4, 2015. Disponível em: <http://gestaoesaude.unb.br/index.php/gestaoesaude/article/view/1440>. Acesso em: 20 mai 2015.

MENDES, E. V. As redes de atenção à saúde. Ciências \& Saúde Coletiva, v. 15, n. 5, p. 2297, 2010. 
MIHIGO, R. et al. African vaccination week as a vehicle for integrated health service delivery. BMC Health Services Research, v. 15, n. 1, p. 358, 2015.

MINAYO, M. C. S.; SANCHES, O. Qualitativo-quantitativo: oposição ou complementaridade? Cadernos de Saúde Pública, v. 9, n. 3, p. 239-248, 1993.

MOLINO, C. G. R. C. et al. Non-communicable disease clinical practice guidelines in Brazil: a systematic assessment of methodological quality and transparency. PLOS ONE, v. 11, n. 11, p. e0166367, 2016.

MOREIRA, A. Panorama sobre a hanseníase: quadro atual e perspectivas. História, Ciências, Saúde-Manguinhos, v. 10, n. suppl. 1, p. 291-307, 2003.

MUJICA: "Los que comen bien, piensan que se gasta demasiado en política social".

LARED21, 15 mar. 2013. Disponível em: < http://www.lr21.com.uy/politica/1092902mujica-los-que-comen-bien-piensan-que-se-gasta-demasiado-en-politica-social $>$. Acesso em: 1 fev. 2016.

MUNIZ, É. S. “Basta aplicar uma injeção?”: concepções de saúde, higiene e nutrição no Programa de Erradicação da Bouba no Brasil, 1956-1961. História, Ciências, SaúdeManguinhos, v. 19, n. 1, p. 197-216, 2012.

MURRAY, C. J. L. et al. Disability-adjusted life years (DALYs) for 291 diseases and injuries in 21 regions, 1990-2010: a systematic analysis for the Global Burden of Disease Study 2010. The Lancet, v. 380, n. 9859, p. 2197-2223, 2012.

NASCIMENTO, D. R. As campanhas de vacinação contra a poliomielite no Brasil (19601990). Ciência \& Saúde Coletiva, v. 16, n. 2, p. 501-511, 2011.

NOBREGA, C. R.; LIMA, A. F. C. Custo de procedimentos relacionados ao tratamento quimioterápico ambulatorial de mulheres portadoras de câncer de mama. Revista da Escola de Enfermagem da USP, v. 48, n. 4, p. 699-705, 2014.

NUNN, P. et al. Tuberculosis control in the era of HIV. Nature reviews. Immunology, v. 5, n. 10, p. 819-826, 2005.

OLIVEIRA, E. A.; LABRA, M. E.; BERMUDEZ, J. A produção pública de medicamentos no Brasil: uma visão geral. Cadernos de Saúde Pública, v. 22, n. 11, p. 2379-2389, nov. 2006.

ORGANIZACIÓN MUNDIAL DE LA SALUD. Acceso equitativo a los medicamentos esenciales: un marco para la acción colectiva. Perspectivas políticas de la OMS sobre medicamentos, v. 8, p. 1-6, 2004.

ORGANIZACIÓN PANAMERICANA DE LA SALUD. Leishmaniasis en las Américas: recomendaciones para el tratamiento. Washington: OPAS, 2013.

ORTIZ, R. C.; ANVERSA, L. Epidemiologia da leishmaniose visceral em Bauru, São Paulo, no período de 2004 a 2012: um estudo descritivo. Epidemiologia e Serviços de Saúde, v. 24, n. 1, p. 97-104, 2015.

OSORIO-DE-CASTRO, C. G. S. et al. A proposal for an evaluation model of 
pharmaceutical services for malaria. v. 25, n. 9, p. 2075-2082, 2009.

PAIM, J. et al. The Brazilian health system: history, advances, and challenges. The Lancet, v. 377, n. 9779, p. 1778-1797, maio 2011.

PAIM, J. S. A Constituição Cidadã e os 25 anos do Sistema Único de Saúde (SUS). Cadernos de Saúde Pública, v. 29, n. 10, p. 1927-1936, 2013.

PAIVA, S. P.; BRANDÃO, E. R. Contracepção de emergência no contexto das farmácias: revisão crítica de literatura. Physis: Revista de Saúde Coletiva, v. 22, n. 1, p. 17-34, 2012.

PAULA, P. A. B. et al. Política de medicamentos: da universalidade de direitos aos limites da operacionalidade. Physis, v. 19, n. 4, p. 1111-1125, 2009.

PARKER, M.; WILSON, G. Diseases of poverty. In: Poverty and development into the 21 st century. Oxford ; New York: Open University in association with Oxford University Press, 2000.

PARRA, J. G. Medicamentos huérfanos: regulación y controversias. Boletín de Informacíon Farmacoterapéutica de Navarra, v. 23, n. 1, p. 1-13, 2015.

PEDRAZA, D. F. Disponibilidad de alimentos como factor determinante de la Seguridad Alimentaria y Nutricional y sus representaciones en Brasil. Revista de Nutrição, v. 18, n. 1, p. 129-143, 2005.

PEDRIQUE, B. et al. The drug and vaccine landscape for neglected diseases (2000-11): a systematic assessment. The Lancet Global Health, v. 1, n. 6, p. 371-379, 2013.

PEN, M.; GROSSI, M.; PENNA, G. Country profile: leprosy in Brazil. Leprosy Review, v. 84, n. 3, p. 308-315, 2013.

PENIDO, A. “Ações judiciais impactam em até R\$ 7 bilhões no SUS”, diz ministro. Portal da Saúde - SUS, 24 ago. 2016. Disponível em:

$<$ http://portalsaude.saude.gov.br/index.php/cidadao/principal/agencia-saude/25275ministro-da-saude-fala-sobre-impacto-de-acoes-judiciais-no-sus>. Acesso em: 30 nov. 2016.

PEREIRA, L. R. L.; FREITAS, O. A evolução da Atenção Farmacêutica e a perspectiva para o Brasil. Revista Brasileira de Ciências Farmacêuticas, v. 44, n. 4, p. 601-612, 2008.

PEREIRA, V.; SALOMON, F.; SOUZA, A. Critérios para decisões sobre incorporação de tecnologias em saúde no Brasil e no mundo. Revista Eletrônica Gestão \& Saúde, v. 6, n. supl 4, p. 3066-93, 2015.

PETRYNA, A. Experimentalidade: ciência, capital e poder no mundo dos ensaios clínicos. Horizontes Antropológicos, v. 17, n. 35, p. 127-160, 2011.

PIOVESAN, F. Ações afirmativas no Brasil: desafios e perspectivas. Revista Estudos Feministas, v. 16, n. 3, p. 887-896, 2008.

PLATT, O. S. Hydroxyurea for the Treatment of Sickle Cell Anemia. The New England 
Journal of Medicine, v. 358, p. 1362-1369, 2008.

PONTES, F. Doenças negligenciadas ainda matam 1 milhão por ano no mundo. Inovação em pauta, v. 6, p. 69-73, 2009.

PONTES, V. M. O. et al. Reações adversas em pacientes com doença de Chagas tratados com benzonidazol, no Estado do Ceará. Revista da Sociedade Brasileira de Medicina Tropical, v. 43, n. 2, p. 182-187, 2010.

PROGRAMA DAS NAÇÕES UNIDAS PARA O DESENVOLVIMENTO. Índice de Pobreza Multidimensional. Disponível em < http://www.pnud.org.br/arquivos/FAQ IPM.pdf> Acesso em dezembro de 2014.

RABELO, R. B. et al. A Comissão Nacional de Incorporação de Tecnologias no SUS: um balanço de seus primeiros anos de atuação. Revista Eletrônica Gestão \& Saúde, v. 6, n. supl. 4, p. 3225-40, 2015.

RAW, I.; HIGASHI, H. G. Auto-suficiência e inovação na produção de vacinas e saúde pública. Estudos Avançados, v. 22, n. 64, p. 155-170, 2008.

RAZZOLINI, M. T. P.; GÜNTHER, W. M. R. Impactos na saúde das deficiências de acesso a água. Saúde e Sociedade, v. 17, n. 1, p. 21-32, 2008.

RESEARCH AND TRAINING IN TROPICAL DISEASES (TDR). Diseases of poverty. Disponível em: <http://www.who.int/tdr/en/> Acesso em fevereiro de 2016.

RESENDE, K. S. As parcerias para o desenvolvimento produtivo (PDPS) e o estímulo à inovação em instituições farmacêuticas públicas e privadas brasileiras. Rio de Janeiro: Escola Nacional de Saúde Publica Sergio Arouca, 2013. 176 p.

REYES, P. A; VALLEJO, M. Trypanocidal drugs for late stage, symptomatic Chagas disease (Trypanosoma cruzi infection). Cochrane database of systematic reviews (Online), n. 4, p. CD004102, 2011.

RIBEIRO, R. C. Diretrizes clínicas : como avaliar a qualidade? Revista da Sociedade Brasileira de Clínica Médica, v. 8, n. 4, p. 350-355, 2010.

ROCHA, A. C. R. P. et al. O discurso coletivo de ex-hanseniano morador de um antigo leprosário no nordeste do Brasil. Interface: Communication, Health, Education, v. 15, n. 36, p. 213-223, 2011.

RONSONI, R. D. M. Avaliação dos protocolos clínicos e diretrizes terapêuticas do Ministério da Saúde segundo método AGREE II. Rio de Janeiro: Escola Nacional de Saúde Publica Sérgio Arouca, 2013.

RONSONI, R. D. M. et al. Avaliação de oito Protocolos Clínicos e Diretrizes Terapêuticas (PCDT) do Ministério da Saúde por meio do instrumento AGREE II: um estudo piloto.

Cadernos de Saúde Pública, v. 31, n. 6, p. 1157-1162, 2015.

ROSENFELD, R. M.; SHIFFMAN, R. N. Clinical practice guideline development manual: A quality-driven approach for translating evidence into action. Otolaryngology: Head and Neck Surgery, v. 140, n. 6 suppl., p. 1-43, 2009. 
ROZENFELD, S. Farmacêutico: profissional de saúde e cidadão. Ciência \& Saúde Coletiva, v. 13, n. suppl, p. 561-568, 2008.

SACHS, J. D. O fim da Pobreza. São Paulo: Companhia das letras, 2005. 472 p.

SANT'ANA, J. M. B. et al. Racionalidade terapêutica: elementos médico-sanitários nas demandas judiciais de medicamentos. Revista de Saúde Pública, v. 45, n. 4, p. 714-721, 2011.

SANTANA, R. S.; CATANHEIDE, I. D. Relação Nacional de Medicamentos: uma construção permanente. Cadernos de Saúde Pública, v. 31, n. 3, p. 647-650, 2015.

SANTANA, R. S.; LEITE, S. N. Prioridades da pesquisa clínica com medicamentos no Brasil e as doenças da pobreza. Revista Panamericana de Salud Publica, v. 40, n. 5, p. 355-361, 2016.

SANTANA, R. S.; LUPATINI, E. O.; LEITE, S. N. Registro e incorporação no SUS: Barreiras de acesso a medicamentos para doenças da pobreza? Ciencia \& Saude Coletiva, 2017. No prelo.

SANTOS, A. O.; DELDUQUE, M. C.; ALVES, S. M. C. Os três poderes do Estado e o financiamento do SUS: o ano de 2015. Cadernos de Saúde Pública, v. 32, n. 1, 2016.

SANTOS, B. N.; QUEIROZ, L. B.; SACCHETIM, S. C. Percepção da equipe de saúde responsável pela assistência aos portadores de Hanseníase acerca do abandono do tratamento pelos pacientes. Revista Educação em Saúde, v. 1, n. 2, p. 96-107, 2015.

SANTOS, J. Resposta brasileira ao controle da tuberculose. Revista de Saúde Pública, v. 41, p. 89-93, 2007.

SANTOS, F. L. A. DOS et al. Pesquisa , desenvolvimento e inovação para o controle das doenças negligenciadas. Revista de ciências farmacêuticas básica e aplicada, v. 33, n. 1, p. 37-47, 2012.

SCHATZMAYR, H. G. Novas perspectivas em vacinas virais. História, Ciências, SaúdeManguinhos, v. 10, n. suppl. 2, p. 655-669, 2003.

SCHRAIBER, L. B.; GOMES, R.; COUTO, M. T. Homens e saúde na pauta da Saúde Coletiva. Ciência \& Saúde Coletiva, v. 10, n. 1, p. 7-17, 2005.

SCHRAMM, J. M. D. A. et al. Transição epidemiológica e o estudo de carga de doença no Brasil. Ciência \& Saúde Coletiva, v. 9, n. 4, p. 897-908, 2004.

SEN, A. Desenvolvimento como Liberdade. São Paulo: Companhia das letras, 2010. 416 p.

SEOANE-VAZQUEZ, E. et al. Incentives for orphan drug research and development in the United States. Orphanet Journal of Rare Diseases, v. 3, p. 33, 2008.

SERRANO-AGUILAR, P. et al. Patient participation in the development of a clinical guideline for inherited retinal dystrophies. Expert Opinion on Orphan Drugs, v. 4, n. 7 , p. 691-697, 2016. 
SILVA, E.; NICOLETTI, M. Controle e tratamento das doenças negligenciadas: visão da situação atual. Revista Saúde, v. 4742, n. 11, p. 65-81, 2013.

SILVA, J. S.; MARIANO, Z. D. F.; SCOPEL, I. A dengue no Brasil e as políticas de combate ao Aedes aegypti: da tentativa da erradicação ás políticas de controle. Revista Brasileira de Geografia Médica e da Saúde, v. 3, n. 6, p. 163-175, 2008.

SILVA, L. J. DA. O controle das endemias no Brasil e sua história. Ciência e Cultura, v. 55, n. 1, p. 44-47, 2003.

SILVEIRA, A. C.; PIMENTA JUNIOR, F. A inserção institucional do controle da doença de Chagas. Revista da Sociedade Brasileira de Medicina Tropical, v. 44, n. suppl. II, p. 19-24, 2011.

SINGH, A.; SINGH, S. Diseases of poverty and lifestyle, well-being and human development. Mens Sana Monographs, v. 6, n. 1, p. 187, 2008.

SMITH, C. A. M. et al. A systematic critical appraisal of clinical practice guidelines in juvenile idiopathic arthritis using the Appraisal of Guidelines for Research and Evaluation II (AGREE II) Instrument. PLOS ONE, v. 10, n. 9, p. e0137180, 2015.

SOUZA, C. M.; ADESSE, L. Violência sexual no Brasil: perspectivas e desafios. Brasília: Secretaria Especial de Políticas para as Mulheres, 2005. 188 p.

SOUZA, A. L. P.et al. A Rede Brasileira de Produção Pública de Medicamentos na perspectiva da gestão de cadeias de suprimentos: o papel das TIC. Revista de Administração Pública, v. 49, n. 3, p. 615-641, 2015.

SOUZA, C. M. C. A gripe espanhola em Salvador, 1918: cidade de becos e cortiços. História, Ciências, Saúde-Manguinhos, v. 12, n. 1, p. 71-99, 2005.

STEVENS, P. Diseases of poverty and the 90/10 gap. 2004. In: Fighting the Diseases of Poverty. New Brunswick: NJ, 2008. 298 p.

STEVENS, P. O combate às Doenças da Pobreza. Porto Alegre: Sul Editores, 2008. 303 p.

TANOWITZ, H. B. et al. Perspectives on trypanosoma cruzi-induced heart disease (chagas disease). Progress in Cardiovascular Diseases, v. 51, n. 6, p. 524-539, 2009.

TAVARES, N. U. L. et al. Factors associated with low adherence to medicine treatment for chronic diseases in Brazil. Revista de Saúde Pública, v. 50, 2016.

TEMPORÃO, J. G. O Programa Nacional de Imunizações (PNI): origens e desenvolvimento. História, Ciências, Saúde-Manguinhos, v. 10, n. supl. 2, p. 601-617, 2003.

TORRES, I. D. C. Judicialização do acesso a medicamentos no Brasil: uma revisão sistemática. 2013.88 f. Dissertação (Mestrado Profissional em Saúde Coletiva) - Instituto de Saúde Coletiva. Universidade Federal da Bahia, Salvador, 2013.

TROUILLER, P. et al. Drugs for neglected diseases: a failure of the market and a public health failure? Tropical Medicine and International Health, v. 6, n. 11, p. 945-951, 
2001.

TUNIS, S. R.; STRYER, D. B.; CLANCY, C. M. Practical clinical trials: increasing the value of clinical research for decision making in clinical and health policy. Journal of the American Medical Association, v. 290, n. 12, p. 1624-1632, 2003.

U.S. NATIONAL INSTITUTES OF HEALTH. Locations of Recruiting Studies.

Disponível em: <https://clinicaltrials.gov/> Acesso em setembro de 2016a.

U.S. NATIONAL INSTITUTES OF HEALTH. ClinicalTrials.gov. Disponível em: $<$ https://clinicaltrials.gov/> Acesso em setembro de 2016b.

UNITED NATIONS DEVELOPMENT PROGRAMME. Human Development Report 2014: Sustaining human progress: reducing vulnerabilities and building resilience. New York: UNDP, 2014. 239 p.

UNITED NATIONS OFFICE ON DRUGS AND CRIME. World Drug Report 2015. Vienna: UN, 2015. 162p.

UTENS, C. M. A. et al. How to integrate research evidence on patient preferences in pharmaceutical coverage decisions and clinical practice guidelines: A qualitative study among Dutch stakeholders. Health Policy, v. 120, n. 1, p. 120-128, 2016.

VALLE, D.; NACIF PIMENTA, D.; AGUIAR, R. Zika, dengue e chikungunya: desafios e questões. Epidemiologia e Serviços de Saúde, v. 25, n. 2, p. 1-2, 2016.

VALLE, D; AGUIAR, R.; PIMENTA, D. Lançando luz sobre a dengue. Ciência e Cultura, v. 67, n. 3, p. 4-5. 2015.

VAN DE BOVENKAMP, H. M.; TRAPPENBURG, M. J. Reconsidering patient participation in guideline development. Health Care Analysis, v. 17, n. 3, p. 198-216, 2009.

VAN DE BOVENKAMP, H. M.; ZUIDERENT-JERAK, T. An empirical study of patient participation in guideline development: exploring the potential for articulating patient knowledge in evidence-based epistemic settings. Health Expectations : an international journal of public participation in health care and health policy, v. 18, n. 5, p. 942-955, 2015.

VARGAS-PELÁEZ, C. M. et al. Right to health, essential medicines, and lawsuits for access to medicines - a scoping study. Social Science \& Medicine, v. 121, p. 48-55, 2014.

VARGAS, M. et al. Inovação na indústria química e biotecnológica em saúde: Em busca de uma agenda virtuosa. Revista de Saúde Pública, v. 46, n. suppl.1, p. 37-40, 2012.

VASCONCELOS, P. F. D. C. Doença pelo vírus Zika: um novo problema emergente nas Américas? Revista Pan-Amazônica de Saúde, v. 6, n. 2, p. 9-10, 2015.

VASEN, F. Regulación tecnológica y valores sociales: un análisis del caso farmacéutico. Scientia Agricola, v. 6, n. 3, 2008.

VIANA, A. L. D.; FAUSTO, M. C. R.; LIMA, L. D. DE. Política de saúde e eqüidade. São Paulo em Perspectiva, v. 17, n. 1, p. 58-68, 2003. 
VIDAL, Á. T. et al. O desenvolvimento do Monitoramento do Horizonte Tecnológico no mundo e a proposta brasileira. Boletim do Instituto de Saúde, v. 14, n. 2, p. 171-177, 2013.

VIEIRA-DA-SILVA, L. M.; ALMEIDA FILHO, N. Eqüidade em saúde: uma análise crítica de conceitos Health equity: a critical analysis of concepts. Cadernos de Saúde Pública, v. 25, p. S217-S226, 2009.

VIEIRA, F. S. Assistência farmacêutica no sistema público de saúde no Brasil. Revista Panamericana de Salud Pública, v. 27, n. 2, p. 149-156, 2010.

VIEIRA, F.S. Crise econômica, austeridade fiscal e saúde: que lições podem ser aprendidas? In: BRASIL. Instituto de Pesquisa Econômica e Aplicada. Nota Tecnica no 26. Brasília: IPEA, 2016.

VIEIRA, F. S.; BENEVIDES, R. P. DE S. E. O Direito à Saúde no Brasil em Tempos de Crise Econômica, Ajuste Fiscal e Reforma Implícita do Estado. Revista de Estudos e Pesquisas sobre as Américas, v. 10, n. 3, p. 1-28, 2016.

VILLARINHO, M. V. et al. Políticas públicas de saúde face à epidemia da AIDS e a assistência às pessoas com a doença. Revista Brasileira de Enfermagem, v. 66, n. 2, p. 271-277, 2013.

VILLELA, W. V.; LAGO, T. Conquistas e desafios no atendimento das mulheres que sofreram violência sexual. Cadernos de Saúde Pública, v. 23, n. 2, p. 471-475, 2007.

WALDMAN, E. A. et al. Vigilância de eventos adversos pós-vacinação e segurança de programas de imunização. Revista de Saúde Pública, v. 45, n. 1, p. 173-184, 2011.

WELLINGS, K. et al. Sexual behaviour in context: a global perspective. The Lancet, v. 368, n. 9548, p. 1706-1728, 2006.

WERNECK, G. L. Forum: geographic spread and urbanization of visceral leishmaniasis in Brazil. Introduction. Cadernos de Saúde Pública, v. 24, n. 12, p. 2937-2940, 2008.

WHITTEMORE, R.; KNAFL, K. The integrative review: updated methodology. Journal of Advanced Nursing, v. 52, n. 5, p. 546-553, 2005.

WITZEL, M. D. R. F. Produção científica brasileira na área de atenção farmacêutica entre 1990 e 2007. 2009. 94 f. Dissertação (Mestrado em Saúde Pública) - Universidade de São Paulo, São Paulo, 2009.

WORLD BANK GROUP. Shared prosperity and poverty eradication in Latin America and the Caribbean. Washington: World Bank Group, 2015. 47 p.

WORLD HEALTH ORGANIZATION. The rational use of drugs: report of the Conference of Experts Nairobi, 1985. Geneva: WHO,1987. 331 p. .

WORLD HEALTH ORGANIZATION. Preventive chemotherapy in human helminthiasis. Geneva: WHO, 2006. 62 p.

WORLD HEALTH ORGANIZATION. Global leprosy situation, 2010. Weekly epidemiological record, v. 85, n. 35, p. 337-348, 2010. 
WORLD HEALTH ORGANIZATION. Global report for research on infectious diseases of poverty. Geneva: WHO, 2012. 184 p.

WORLD HEALTH ORGANIZATION. Fulfilling a promise: to ensure immunization for all in Africa. Geneva: 2016. 24 p.

XAVIER, L. G. Ministério atua para garantir penicilina no SUS, afirma diretor. Portal da Câmara dos Deputados, 29 set. 2015. Disponível em:

<http://www2.camara.leg.br/camaranoticias/noticias/SAUDE/497088-MINISTERIOATUA-PARA-GARANTIR-PENICILINA-NO-SUS,-AFIRMA-DIRETOR.html>. Acesso em: 20 jan. 2016.

YAZBEK, M. C. Pobreza no Brasil contemporâneo e formas de seu enfrentamento. Serviço Social \& Sociedade, n. 110, p. 288-322, 2012.

ZHANG, Z. et al. Evaluation of the quality of guidelines for myasthenia gravis with the AGREE II Instrument. PLoS ONE, v. 9, n. 11, p. e111796, 2014. 


\section{APENDICES}

\section{APÊNDICE I - MEDICAMENTOS UTILIZADOS EM DOENÇAS E AGRAVOS RELACIONADOS À POBREZA}

\begin{tabular}{|c|c|c|c|c|c|c|c|c|c|}
\hline Medicamento & $\begin{array}{c}\text { Doença ou } \\
\text { Agravo }\end{array}$ & Tipo DRP & $\begin{array}{l}\text { № de } \\
\text { registros }\end{array}$ & $\begin{array}{l}\text { Tipo de } \\
\text { Fabricante }\end{array}$ & \begin{tabular}{|c|} 
Componente \\
da Rename \\
2014 \\
\end{tabular} & $\begin{array}{c}\text { Rename } \\
2012\end{array}$ & $\begin{array}{c}\text { Rename } \\
2010\end{array}$ & $\begin{array}{l}\text { Rename } \\
2008\end{array}$ & $\begin{array}{c}\text { Rename } \\
2006\end{array}$ \\
\hline aciclovir 200 mg comprimido & $\begin{array}{l}\text { Varicela e Herpes } \\
\text { Zoster }\end{array}$ & $\begin{array}{l}\text { Infectocontagiosas } \\
\text { Imunopreveníveis }\end{array}$ & 21 & PP & BÁSICO & SIM & SIM & SIM & SIM \\
\hline $\begin{array}{l}\text { aciclovir sódico } 250 \text { mg pó para } \\
\text { solução injetável }\end{array}$ & $\begin{array}{l}\text { Varicela e Herpes } \\
\text { Zoster }\end{array}$ & $\begin{array}{l}\text { Infectocontagiosas } \\
\text { Imunopreveníveis }\end{array}$ & 4 & PRIVADO & BÁSICO & SIM & SIM & SIM & SIM \\
\hline $\begin{array}{l}\text { albendazol } 40 \mathrm{mg} / \mathrm{mL} \text { suspensão } \\
\text { oral }\end{array}$ & Geo-helmitíases & $\begin{array}{c}\text { Infectocontagiosas NÃO } \\
\text { Imunopreveníveis }\end{array}$ & 18 & PRIVADO & BÁSICO & SIM & SIM & SIM & SIM \\
\hline $\begin{array}{l}\text { albendazol } 400 \text { mg comprimido } \\
\text { mastigável }\end{array}$ & Geo-helmitíases & $\begin{array}{l}\text { Infectocontagiosas NÃO } \\
\text { Imunopreveníveis }\end{array}$ & 12 & PRIVADO & $\begin{array}{c}\text { BÁSICO E } \\
\text { ESTRATÉGICO }\end{array}$ & SIM & SIM & SIM & SIM \\
\hline $\begin{array}{l}\text { Amoxicilina } 50 \text { mg/mL pó para } \\
\text { suspensão oral (Básico) }\end{array}$ & $\begin{array}{l}\text { Leptospirose e } \\
\text { outras infecções }\end{array}$ & $\begin{array}{c}\text { Infectocontagiosas NÃO } \\
\text { Imunopreveníveis }\end{array}$ & 6 & PRIVADO & BÁSICO & SIM & SIM & SIM & SIM \\
\hline $\begin{array}{l}\text { anfotericina B (desoxicolato) } 50 \mathrm{mg} \\
\text { solução injetável }\end{array}$ & Leishmanioses & $\begin{array}{l}\text { Infectocontagiosas NÃO } \\
\text { Imunopreveníveis }\end{array}$ & 4 & PRIVADO & Estratégico & SIM & $\operatorname{SIM}$ & SIM & $\mathrm{SIM}$ \\
\hline $\begin{array}{l}\text { anfotericina B complexo lipídico } \\
100 \text { mg solução injetável }\end{array}$ & $\begin{array}{l}\text { Paracocidiodimicose } \\
\text { e outras micoses } \\
\text { profundas } \\
\end{array}$ & $\begin{array}{l}\text { Infectocontagiosas NÃO } \\
\text { Imunopreveníveis }\end{array}$ & 1 & PRIVADO & Estratégico & SIM & NÃO & NÃO & NÃO \\
\hline $\begin{array}{l}\text { anfotericina B lipossomal } 50 \text { mg } \\
\text { solução injetável }\end{array}$ & Leishmanioses & $\begin{array}{l}\text { Infectocontagiosas NÃO } \\
\text { Imunopreveníveis }\end{array}$ & 1 & PRIVADO & Estratégico & SIM & NÃO & NÃO & NÃO \\
\hline $\begin{array}{l}\text { antimoniato de Meglumina } \\
300 \mathrm{mg} / \mathrm{mL} \text { solução injetável }\end{array}$ & Leishmanioses & $\begin{array}{c}\text { Infectocontagiosas NÃO } \\
\text { Imunopreveníveis }\end{array}$ & 1 & PRIVADO & Estratégico & SIM & SIM & SIM & SIM \\
\hline $\begin{array}{l}\text { artemeter } 80 \mathrm{mg} / \mathrm{mL} \text { solução } \\
\text { injetável }\end{array}$ & Malária & $\begin{array}{l}\text { Infectocontagiosas NÃO } \\
\text { Imunopreveníveis }\end{array}$ & 0 & IMPORTAÇÃO & Estratégico & SIM & SIM & SIM & SIM \\
\hline
\end{tabular}




\begin{tabular}{|c|c|c|c|c|c|c|c|c|c|}
\hline Medicamento & $\begin{array}{c}\text { Doença ou } \\
\text { Agravo }\end{array}$ & Tipo DRP & $\begin{array}{l}\text { № de } \\
\text { registros }\end{array}$ & $\begin{array}{l}\text { Tipo de } \\
\text { Fabricante }\end{array}$ & $\begin{array}{c}\text { Componente } \\
\text { da Rename } \\
2014 \\
\end{array}$ & $\begin{array}{c}\text { Rename } \\
2012\end{array}$ & $\begin{array}{c}\text { Rename } \\
2010\end{array}$ & $\begin{array}{l}\text { Rename } \\
2008\end{array}$ & $\begin{array}{l}\text { Rename } \\
2006\end{array}$ \\
\hline $\begin{array}{l}\text { artemeter+ lumefantrina } 20 \mathrm{mg}+ \\
120 \mathrm{mg} \text { comprimido }\end{array}$ & Malária & $\begin{array}{c}\text { Infectocontagiosas NÃO } \\
\text { Imunopreveníveis }\end{array}$ & 0 & IMPORTAÇÃO & Estratégico & SIM & NÃO & NÃO & NÃO \\
\hline $\begin{array}{l}\text { artesunato + mefloquina } 100 \mathrm{mg}+ \\
220 \mathrm{mg} \text { comprimido revestido }\end{array}$ & Malária & $\begin{array}{c}\text { Infectocontagiosas NÃO } \\
\text { Imunopreveníveis }\end{array}$ & 1 & PUBLICO & Estratégico & SIM & SIM & NÃO & NÃO \\
\hline $\begin{array}{l}\text { artesunato + mefloquina } 25 \mathrm{mg}+ \\
55 \mathrm{mg} \text { comprimido revestido }\end{array}$ & Malária & $\begin{array}{c}\text { Infectocontagiosas NÃO } \\
\text { Imunopreveníveis }\end{array}$ & 1 & PUBLICO & Estratégico & SIM & SIM & NÃO & NÃO \\
\hline $\begin{array}{l}\text { artesunato } 60 \mathrm{mg} / \mathrm{mL} \text { pó liófilo para } \\
\text { injeção endovenosa }\end{array}$ & Malária & $\begin{array}{c}\text { Infectocontagiosas NÃO } \\
\text { Imunopreveníveis }\end{array}$ & 0 & IMPORTAÇÃO & Estratégico & SIM & SIM & SIM & SIM \\
\hline atazanavir 300 mg cápsula dura & $\begin{array}{l}\text { Violência doméstica } \\
\text { e sexual }\end{array}$ & $\begin{array}{c}\text { Infectocontagiosas NÃO } \\
\text { Imunopreveníveis }\end{array}$ & 2 & PP & Estratégico & SIM & NÃO & NÃO & NÃO \\
\hline $\begin{array}{l}\text { azitromicina } 250 \mathrm{mg} \text { comprimido } \\
\text { revestido }\end{array}$ & $\begin{array}{l}\text { Tracoma e Infecção } \\
\text { Genital }\end{array}$ & $\begin{array}{c}\text { Infectocontagiosas NÃO } \\
\text { Imunopreveníveis }\end{array}$ & 0 & $\begin{array}{c}\text { NÃO } \\
\text { DISPONIVEL }\end{array}$ & Estratégico & NÃO & NÃO & NÃO & NÃO \\
\hline $\begin{array}{l}\text { azitromicina } 500 \text { mg comprimido } \\
\text { revestido }\end{array}$ & $\begin{array}{l}\text { Tracoma e Infecção } \\
\text { Genital }\end{array}$ & $\begin{array}{l}\text { Infectocontagiosas NÃO } \\
\text { Imunopreveníveis }\end{array}$ & 27 & PRIVADO & $\begin{array}{c}\text { BÁSICO E } \\
\text { ESTRATÉGICO }\end{array}$ & SIM & SIM & SIM & SIM \\
\hline $\begin{array}{l}\text { azitromicina } 600 \text { mg pó para } \\
\text { suspensão oral }\end{array}$ & $\begin{array}{l}\text { Tracoma e Infecção } \\
\text { Genital }\end{array}$ & $\begin{array}{c}\text { Infectocontagiosas NÃO } \\
\text { Imunopreveníveis }\end{array}$ & 7 & PRIVADO & $\begin{array}{c}\text { BÁSICO E } \\
\text { ESTRATÉGICO }\end{array}$ & SIM & NÃO & NÃO & NÃO \\
\hline $\begin{array}{l}\text { benzilpenicilina benzatina } 1.200 .00 \\
\text { UI pó para suspensão injetável }\end{array}$ & $\begin{array}{l}\text { Febre reumática e } \\
\text { outras infecções }\end{array}$ & $\begin{array}{c}\text { Infectocontagiosas NÃO } \\
\text { Imunopreveníveis }\end{array}$ & 4 & PP & BÁSICO & SIM & SIM & SIM & SIM \\
\hline $\begin{array}{l}\text { benzilpenicilina benzatina } 600.00 \mathrm{UI} \\
\text { pó para suspensão injetável }\end{array}$ & $\begin{array}{l}\text { Febre reumática e } \\
\text { outras infecções }\end{array}$ & $\begin{array}{l}\text { Infectocontagiosas NÃO } \\
\text { Imunopreveníveis }\end{array}$ & 4 & PP & BÁSICO & SIM & SIM & SIM & SIM \\
\hline $\begin{array}{l}\text { benzilpenicilina potássica } 5.000 .000 \\
\text { UI pó para solução injetável (Básico) }\end{array}$ & $\begin{array}{l}\text { Leptospirose, } \\
\text { Meningites e outras } \\
\text { infecções }\end{array}$ & $\begin{array}{l}\text { Infectocontagiosas NÃO } \\
\text { Imunopreveníveis }\end{array}$ & 3 & PRIVADO & BÁSICO & SIM & SIM & SIM & SIM \\
\hline $\begin{array}{l}\text { benzilpenicilina procaina + } \\
\text { benzilpenicilina potássica } \\
\text { suspensão injetável de } 300.000 \mathrm{UI}+ \\
100.000 \mathrm{UI}\end{array}$ & $\begin{array}{l}\text { Sífilis e outras } \\
\text { infecções sexuais }\end{array}$ & $\begin{array}{l}\text { Infectocontagiosas NÃO } \\
\text { Imunopreveníveis }\end{array}$ & 3 & PP & BÁSICO & SIM & SIM & SIM & SIM \\
\hline
\end{tabular}




\begin{tabular}{|c|c|c|c|c|c|c|c|c|c|}
\hline Medicamento & $\begin{array}{c}\text { Doença ou } \\
\text { Agravo }\end{array}$ & Tipo DRP & $\begin{array}{l}\text { № de } \\
\text { registros }\end{array}$ & $\begin{array}{c}\text { Tipo de } \\
\text { Fabricante }\end{array}$ & \begin{tabular}{|c|}
$\begin{array}{c}\text { Componente } \\
\text { da Rename } \\
2014\end{array}$ \\
\end{tabular} & $\begin{array}{c}\text { Rename } \\
2012\end{array}$ & $\begin{array}{c}\text { Rename } \\
2010\end{array}$ & $\begin{array}{l}\text { Rename } \\
2008\end{array}$ & $\begin{array}{c}\text { Rename } \\
2006\end{array}$ \\
\hline benznidazol 100 mg comprimido & Doença de Chagas & $\begin{array}{l}\text { Infectocontagiosas NÃO } \\
\text { Imunopreveníveis }\end{array}$ & 1 & PUBLICO & Estratégico & SIM & SIM & SIM & SIM \\
\hline benznidazol $12,5 \mathrm{mg}$ comprimido & Doença de Chagas & \begin{tabular}{|c|} 
Infectocontagiosas NÃO \\
Imunopreveníveis
\end{tabular} & 1 & PUBLICO & Estratégico & SIM & NÃO & NÃO & NÃO \\
\hline $\begin{array}{l}\text { benzoilmetronidazol } 40 \mathrm{mg} / \mathrm{mL} \\
\text { suspensão oral (Básico) }\end{array}$ & Geo-helmitíases & $\begin{array}{l}\text { Infectocontagiosas NÃO } \\
\text { Imunopreveníveis }\end{array}$ & 6 & PRIVADO & BÁSICO & SIM & SIM & SIM & NÃO \\
\hline $\begin{array}{l}\text { ceftriaxona } 1 \text { g pó para solução } \\
\text { injetável (Básico) }\end{array}$ & \begin{tabular}{|l|} 
Leptospirose, \\
Meningites e outras \\
infecções
\end{tabular} & $\begin{array}{l}\text { Infectocontagiosas NÃO } \\
\text { Imunopreveníveis }\end{array}$ & 12 & PRIVADO & BÁSICO & SIM & SIM & SIM & SIM \\
\hline $\begin{array}{l}\text { ceftriaxona } 250 \mathrm{mg} \text { pó para solução } \\
\text { injetável }\end{array}$ & $\begin{array}{l}\text { Sífilis, Meningites e } \\
\text { outras infecções } \\
\text { sexuais }\end{array}$ & $\begin{array}{l}\text { Infectocontagiosas NÃO } \\
\text { Imunopreveníveis }\end{array}$ & 4 & PRIVADO & BÁSICO & SIM & NÃO & NÃO & NÃO \\
\hline ciprofloxacino 500 mg comprimido & $\begin{array}{l}\text { Sífilis e outras } \\
\text { infecções sexuais }\end{array}$ & $\begin{array}{l}\text { Infectocontagiosas NÃO } \\
\text { Imunopreveníveis }\end{array}$ & 26 & PRIVADO & BÁSICO & SIM & SIM & SIM & SIM \\
\hline $\begin{array}{l}\text { clindamicina } 150 \mathrm{mg} / \mathrm{mL} \text { solução } \\
\text { injetável }\end{array}$ & $\begin{array}{l}\text { Malária e outras } \\
\text { infecções }\end{array}$ & $\begin{array}{l}\text { Infectocontagiosas NÃO } \\
\text { Imunopreveníveis }\end{array}$ & 7 & PRIVADO & Estratégico & SIM & SIM & SIM & SIM \\
\hline clindamicina 300 mg cápsula & $\begin{array}{l}\text { Malária e outras } \\
\text { infecções }\end{array}$ & $\begin{array}{l}\text { Infectocontagiosas NÃO } \\
\text { Imunopreveníveis }\end{array}$ & 5 & PRIVADO & $\begin{array}{c}\text { BÁSICO E } \\
\text { ESTRATÉGICO }\end{array}$ & SIM & SIM & SIM & SIM \\
\hline clofazimina $100 \mathrm{mg}$ cápsula & Hanseníase & $\begin{array}{c}\text { Infectocontagiosas NÃO } \\
\text { Imunopreveníveis }\end{array}$ & 0 & IMPORTAÇÃO & Estratégico & SIM & SIM & SIM & SIM \\
\hline clofazimina $50 \mathrm{mg}$ cápsula & Hanseníase & $\begin{array}{l}\text { Infectocontagiosas NÃO } \\
\text { Imunopreveníveis }\end{array}$ & 0 & IMPORTAÇÃO & Estratégico & SIM & SIM & SIM & SIM \\
\hline $\begin{array}{l}\text { cloranfenicol } 250 \text { mg cápsula ou } \\
\text { comprimido }\end{array}$ & $\begin{array}{l}\text { Febre Maculosa e } \\
\text { outras rickettsioses }\end{array}$ & $\begin{array}{l}\text { Infectocontagiosas NÃO } \\
\text { Imunopreveníveis }\end{array}$ & 0 & $\begin{array}{c}\text { NÃO } \\
\text { DISPONIVEL }\end{array}$ & BÁSICO & SIM & SIM & SIM & SIM \\
\hline
\end{tabular}




\begin{tabular}{|c|c|c|c|c|c|c|c|c|c|}
\hline Medicamento & $\begin{array}{l}\text { Doença ou } \\
\text { Agravo }\end{array}$ & Tipo DRP & $\begin{array}{l}\text { № de } \\
\text { registros }\end{array}$ & $\begin{array}{l}\text { Tipo de } \\
\text { Fabricante }\end{array}$ & \begin{tabular}{|c|}
$\begin{array}{c}\text { Componente } \\
\text { da Rename } \\
2014 \\
\end{array}$ \\
\end{tabular} & $\begin{array}{l}\text { Rename } \\
2012\end{array}$ & $\begin{array}{c}\text { Rename } \\
2010\end{array}$ & $\begin{array}{l}\text { Rename } \\
2008\end{array}$ & $\begin{array}{l}\text { Rename } \\
2006\end{array}$ \\
\hline $\begin{array}{l}\text { cloranfenicol, palmitato de } \\
54,4 \mathrm{mg} / \mathrm{mL} \text { xarope ou cloranfenicol } \\
25 \mathrm{mg} / \mathrm{mL} \text { suspensão oral }\end{array}$ & $\begin{array}{l}\text { Febre Maculosa e } \\
\text { outras rickettsioses }\end{array}$ & $\begin{array}{l}\text { Infectocontagiosas NÃO } \\
\text { Imunopreveníveis }\end{array}$ & 0 & IMPORTAÇÃO & $\begin{array}{c}\text { BÁSICO E } \\
\text { ESTRATÉGICO }\end{array}$ & SIM & SIM & SIM & SIM \\
\hline cloroquina 150 mg comprimido & Malária & $\begin{array}{l}\text { Infectocontagiosas NÃO } \\
\text { Imunopreveníveis }\end{array}$ & 2 & PUBLICO & Estratégico & SIM & SIM & SIM & SIM \\
\hline dapsona $100 \mathrm{mg}$ comprimido & Hanseníase & $\begin{array}{l}\text { Infectocontagiosas NÃO } \\
\text { Imunopreveníveis }\end{array}$ & 0 & IMPORTAÇÃO & Estratégico & SIM & SIM & SIM & SIM \\
\hline dapsona 50mg comprimido & Hanseníase & $\begin{array}{l}\text { Infectocontagiosas NÃO } \\
\text { Imunopreveníveis }\end{array}$ & 0 & IMPORTAÇÃO & Estratégico & SIM & SIM & SIM & SIM \\
\hline $\begin{array}{l}\text { Dietilcarbamazina } 50 \mathrm{mg} \\
\text { comprimido }\end{array}$ & Filariose & $\begin{array}{l}\text { Infectocontagiosas NÃO } \\
\text { Imunopreveníveis }\end{array}$ & 1 & PÚBLICO & Estratégico & SIM & SIM & SIM & SIM \\
\hline Doxiciclina 100 mg comprimido & $\begin{array}{l}\text { Febre Maculosa, } \\
\text { Leptospirose, } \\
\text { Malária e outras } \\
\text { rickettsioses }\end{array}$ & $\begin{array}{l}\text { Infectocontagiosas NÃO } \\
\text { Imunopreveníveis }\end{array}$ & 8 & PRIVADO & Estratégico & SIM & SIM & SIM & SIM \\
\hline $\begin{array}{l}\text { Doxiciclina } 100 \text { mg pó para solução } \\
\text { injetável }\end{array}$ & $\begin{array}{l}\text { Febre Maculosa e } \\
\text { outras rickettsioses }\end{array}$ & $\begin{array}{l}\text { Infectocontagiosas NÃO } \\
\text { Imunopreveníveis }\end{array}$ & 0 & $\begin{array}{c}\text { NÃO } \\
\text { DISPONIVEL }\end{array}$ & Estratégico & NÃO & NÃO & NÃO & NÃO \\
\hline fluconazol 100 mg cápsula & $\begin{array}{l}\text { Paracocidiodimicose } \\
\text { e outras micoses } \\
\text { profundas }\end{array}$ & $\begin{array}{l}\text { Infectocontagiosas NÃO } \\
\text { Imunopreveníveis }\end{array}$ & 6 & PRIVADO & $\begin{array}{c}\text { BÁSICO E } \\
\text { ESTRATÉGICO }\end{array}$ & SIM & SIM & SIM & SIM \\
\hline $\begin{array}{l}\text { fluconazol } 2 \mathrm{mg} / \mathrm{mL} \text { solução } \\
\text { injetável }\end{array}$ & $\begin{array}{l}\text { Paracocidiodimicose } \\
\text { e outras micoses } \\
\text { profundas }\end{array}$ & $\begin{array}{l}\text { Infectocontagiosas NÃO } \\
\text { Imunopreveníveis }\end{array}$ & 8 & PRIVADO & BÁSICO & SIM & SIM & SIM & SIM \\
\hline $\begin{array}{l}\text { imunoglobulina antirrábica } 150 \\
\text { UI/mL solução injetável }\end{array}$ & Raiva & $\begin{array}{l}\text { Infectocontagiosas } \\
\text { Imunopreveníveis }\end{array}$ & 1 & PRIVADO & Estratégico & SIM & SIM & SIM & SIM \\
\hline $\begin{array}{l}\text { imunoglobulina antitetânica } 250 \\
\mathrm{UI} / \mathrm{mL} \text { solução injetável }\end{array}$ & Tétano & $\begin{array}{l}\text { Infectocontagiosas } \\
\text { Imunopreveníveis }\end{array}$ & 2 & PRIVADO & Estratégico & SIM & SIM & SIM & SIM \\
\hline
\end{tabular}




\begin{tabular}{|c|c|c|c|c|c|c|c|c|c|}
\hline Medicamento & $\begin{array}{c}\text { Doença ou } \\
\text { Agravo }\end{array}$ & Tipo DRP & $\begin{array}{l}\text { № de } \\
\text { registros }\end{array}$ & $\begin{array}{c}\text { Tipo de } \\
\text { Fabricante }\end{array}$ & \begin{tabular}{|c|}
$\begin{array}{c}\text { Componente } \\
\text { da Rename } \\
2014\end{array}$ \\
\end{tabular} & $\begin{array}{c}\text { Rename } \\
2012\end{array}$ & $\begin{array}{c}\text { Rename } \\
2010\end{array}$ & $\begin{array}{l}\text { Rename } \\
2008\end{array}$ & $\begin{array}{c}\text { Rename } \\
2006\end{array}$ \\
\hline imunoglobulina antivaricela zoster & $\begin{array}{l}\text { Varicela e Herpes } \\
\text { Zoster }\end{array}$ & $\begin{array}{l}\text { Infectocontagiosas } \\
\text { Imunopreveníveis }\end{array}$ & 1 & PRIVADO & Estratégico & SIM & NÃO & NÃO & NÃO \\
\hline $\begin{array}{l}\text { isoniazida + rifampicina } 75 \mathrm{mg}+ \\
150 \mathrm{mg} \text { comprimido }\end{array}$ & Tuberculose & $\begin{array}{l}\text { Infectocontagiosas NÃO } \\
\text { Imunopreveníveis }\end{array}$ & 1 & PUBLICO & Estratégico & SIM & SIM & NÃO & NÃO \\
\hline Isoniazida 100 mg Comprimido & Tuberculose & $\begin{array}{l}\text { Infectocontagiosas NÃO } \\
\text { Imunopreveníveis }\end{array}$ & 1 & PUBLICO & Estratégico & SIM & SIM & SIM & SIM \\
\hline $\begin{array}{l}\text { isotionato pentamidina } 300 \mathrm{mg} / \mathrm{sal} \\
\text { solução injetável }\end{array}$ & Leishmanioses & $\begin{array}{l}\text { Infectocontagiosas NÃO } \\
\text { Imunopreveníveis }\end{array}$ & 0 & IMPORTAÇÃO & Estratégico & SIM & SIM & SIM & SIM \\
\hline itraconazol 10 mg/mL solução oral & $\begin{array}{l}\text { Paracocidiodimicose } \\
\text { e outras micoses } \\
\text { profundas }\end{array}$ & $\begin{array}{l}\text { Infectocontagiosas NÃO } \\
\text { Imunopreveníveis }\end{array}$ & 0 & $\begin{array}{c}\text { NÃO } \\
\text { DISPONIVEL }\end{array}$ & BÁSICO & SIM & SIM & SIM & SIM \\
\hline itraconazol 100 mg cápsula & $\begin{array}{l}\text { Paracocidiodimicose } \\
\text { e outras micoses } \\
\text { profundas }\end{array}$ & $\begin{array}{l}\text { Infectocontagiosas NÃO } \\
\text { Imunopreveníveis }\end{array}$ & 13 & PRIVADO & $\begin{array}{c}\text { BÁSICO E } \\
\text { ESTRATÉGICO }\end{array}$ & SIM & SIM & SIM & SIM \\
\hline ivermectina $6 \mathrm{mg}$ comprimido & $\begin{array}{l}\text { Ectoparasitoses, } \\
\text { Geo-helmitíases, } \\
\text { Oncocercose }\end{array}$ & $\begin{array}{l}\text { Infectocontagiosas NÃO } \\
\text { Imunopreveníveis }\end{array}$ & 6 & PRIVADO & BÁSICO & SIM & SIM & SIM & SIM \\
\hline
\end{tabular}




\begin{tabular}{|c|c|c|c|c|c|c|c|c|c|}
\hline Medicamento & $\begin{array}{c}\text { Doença ou } \\
\text { Agravo }\end{array}$ & Tipo DRP & $\begin{array}{l}\text { № de } \\
\text { registros }\end{array}$ & $\begin{array}{c}\text { Tipo de } \\
\text { Fabricante }\end{array}$ & $\begin{array}{c}\text { Componente } \\
\text { da Rename } \\
2014 \\
\end{array}$ & $\begin{array}{c}\text { Rename } \\
2012\end{array}$ & $\begin{array}{l}\text { Rename } \\
2010\end{array}$ & $\begin{array}{c}\text { Rename } \\
2008\end{array}$ & $\begin{array}{c}\text { Rename } \\
2006\end{array}$ \\
\hline levonorgestrel $0,75 \mathrm{mg}$ comprimido & $\begin{array}{l}\text { Violência doméstica } \\
\text { e sexual }\end{array}$ & $\begin{array}{l}\text { Outras Doenças da } \\
\text { Pobreza }\end{array}$ & 7 & PRIVADO & $\begin{array}{c}\text { BÁSICO } \\
\text { (centralizado) }\end{array}$ & SIM & NÃO & NÃO & NÃO \\
\hline levonorgestrel $1,5 \mathrm{mg}$ comprimido & $\begin{array}{l}\text { Violência doméstica } \\
\text { e sexual }\end{array}$ & $\begin{array}{l}\text { Outras Doenças da } \\
\text { Pobreza }\end{array}$ & 3 & PRIVADO & $\begin{array}{c}\text { BÁSICO } \\
\text { (centralizado) }\end{array}$ & SIM & SIM & SIM & SIM \\
\hline $\begin{array}{l}\text { micronutrientes (cada sachê de } 1 \mathrm{~g} \\
\text { contém: vitamina A } 400 \mathrm{mcg} \text {, } \\
\text { vitamina D } 5 \mathrm{mcg} \text {, vitamina E } 5 \mathrm{mg} \text {, } \\
\text { vitamina C } 30 \mathrm{mg} \text {, vitamina B1 0,5 } \\
\mathrm{mg} \text {, vitamina B2 0,5 mg, vitamina B6 } \\
0,5 \mathrm{mg} \text {, vitamina PP } 6 \mathrm{mg} \text {, vitamina } \\
\text { B9 } 150 \mathrm{mcg} \text {, vitamina B12 0,9 mcg, } \\
\text { ferro } 10 \mathrm{mg} \text {, zinco } 4,1 \mathrm{mg} \text {, cobre } 560 \\
\mathrm{mcg} \text {, selênio } 17 \mathrm{mcg} \text {, iodo } 90 \mathrm{mcg} \text { ) }\end{array}$ & Anemias carenciais & $\begin{array}{l}\text { Outras Doenças da } \\
\text { Pobreza }\end{array}$ & 0 & IMPORTAÇÃO & Estratégico & NÃO & NÃO & NÃO & NÃO \\
\hline $\begin{array}{l}\text { minociclina } 100 \mathrm{mg} \text { comprimido } \\
\text { revestido }\end{array}$ & Hanseníase & \begin{tabular}{|c|} 
Infectocontagiosas NÃO \\
Imunopreveníveis
\end{tabular} & 2 & PP & Estratégico & SIM & SIM & SIM & SIM \\
\hline ofloxacino $400 \mathrm{mg}$ comprimido & $\begin{array}{l}\text { Hanseníase e } \\
\text { Tuberculose }\end{array}$ & $\begin{array}{l}\text { Infectocontagiosas NÃO } \\
\text { Imunopreveníveis }\end{array}$ & 7 & PP & Estratégico & SIM & SIM & SIM & SIM \\
\hline oxamniquina $50 \mathrm{mg} / \mathrm{mL}$ solução oral & Esquistossomose & $\begin{array}{l}\text { Infectocontagiosas NÃO } \\
\text { Imunopreveníveis }\end{array}$ & 1 & PRIVADO & Estratégico & SIM & SIM & SIM & SIM \\
\hline
\end{tabular}




\begin{tabular}{|c|c|c|c|c|c|c|c|c|c|}
\hline Medicamento & $\begin{array}{l}\text { Doença ou } \\
\text { Agravo }\end{array}$ & Tipo DRP & $\begin{array}{l}\text { № de } \\
\text { registros }\end{array}$ & $\begin{array}{c}\text { Tipo de } \\
\text { Fabricante }\end{array}$ & $\begin{array}{c}\text { Componente } \\
\text { da Rename } \\
2014 \\
\end{array}$ & $\begin{array}{c}\text { Rename } \\
2012\end{array}$ & $\begin{array}{c}\text { Rename } \\
2010\end{array}$ & $\begin{array}{l}\text { Rename } \\
2008\end{array}$ & $\begin{array}{l}\text { Rename } \\
2006\end{array}$ \\
\hline $\begin{array}{l}\text { palmitato de retinol (vitamina A) } \\
100.000 \text { Ul cápsula }\end{array}$ & Anemias carenciais & $\begin{array}{l}\text { Outras Doenças da } \\
\text { Pobreza }\end{array}$ & 1 & PÚBLICO & Estratégico & SIM & NÃO & NÃO & NÃO \\
\hline $\begin{array}{l}\text { palmitato de retinol (vitamina A) } \\
150.000 \mathrm{UI} / \mathrm{mL} \text { solução oleosa }\end{array}$ & Anemias carenciais & $\begin{array}{c}\text { Outras Doenças da } \\
\text { Pobreza }\end{array}$ & 1 & PRIVADO & Estratégico & SIM & SIM & SIM & SIM \\
\hline $\begin{array}{l}\text { palmitato de retinol (vitamina A) } \\
200.000 \text { Ul cápsula }\end{array}$ & Anemias carenciais & $\begin{array}{l}\text { Outras Doenças da } \\
\text { Pobreza }\end{array}$ & 1 & PÚBLICO & Estratégico & SIM & SIM & SIM & SIM \\
\hline pentoxifilina $400 \mathrm{mg}$ comprimido & hanseniase & $\begin{array}{l}\text { Infectocontagiosas NÃO } \\
\text { Imunopreveníveis }\end{array}$ & 3 & PP & Estratégico & SIM & NÃO & NÃO & NÃO \\
\hline permetrina 10 mg/g (1\%) loção & Ectoparasitoses & $\begin{array}{l}\text { Infectocontagiosas NÃO } \\
\text { Imunopreveníveis }\end{array}$ & 10 & PRIVADO & BÁSICO & SIM & SIM & SIM & SIM \\
\hline permetrina 50 mg/g (5\%) loção & Ectoparasitoses & $\begin{array}{l}\text { Infectocontagiosas NÃO } \\
\text { Imunopreveníveis }\end{array}$ & 5 & PRIVADO & BÁSICO & SIM & SIM & SIM & SIM \\
\hline pirazinamida $3 \%$ solução oral & Tuberculose & $\begin{array}{l}\text { Infectocontagiosas NÃO } \\
\text { Imunopreveníveis }\end{array}$ & 1 & PUBLICO & Estratégico & SIM & SIM & SIM & SIM \\
\hline piridoxina 100 mg comprimido & Tuberculose & $\begin{array}{l}\text { Infectocontagiosas NÃO } \\
\text { Imunopreveníveis }\end{array}$ & 1 & PRIVADO & Estratégico & SIM & NÃO & NÃO & NÃO \\
\hline praziquantel $600 \mathrm{mg}$ comprimido & Esquistossomose & $\begin{array}{l}\text { Infectocontagiosas NÃO } \\
\text { Imunopreveníveis }\end{array}$ & 1 & PUBLICO & Estratégico & SIM & SIM & SIM & SIM \\
\hline primaquina 15 mg comprimido & Malária & $\begin{array}{c}\text { Infectocontagiosas NÃO } \\
\text { Imunopreveníveis }\end{array}$ & 1 & PUBLICO & Estratégico & SIM & SIM & SIM & SIM \\
\hline primaquina $5 \mathrm{mg}$ comprimido & Malária & $\begin{array}{l}\text { Infectocontagiosas NÃO } \\
\text { Imunopreveníveis }\end{array}$ & 1 & PUBLICO & Estratégico & SIM & SIM & SIM & SIM \\
\hline $\begin{array}{l}\text { quinina } 300 \mathrm{mg} / \mathrm{mL} \text { solução } \\
\text { injetável }\end{array}$ & Malária & $\begin{array}{l}\text { Infectocontagiosas NÃO } \\
\text { Imunopreveníveis }\end{array}$ & 1 & PUBLICO & Estratégico & SIM & SIM & SIM & SIM \\
\hline quinina 500 mg comprimido & Malária & $\begin{array}{l}\text { Infectocontagiosas NÃO } \\
\text { Imunopreveníveis }\end{array}$ & 1 & PUBLICO & Estratégico & SIM & SIM & SIM & SIM \\
\hline
\end{tabular}




\begin{tabular}{|c|c|c|c|c|c|c|c|c|c|}
\hline Medicamento & $\begin{array}{c}\text { Doença ou } \\
\text { Agravo }\end{array}$ & Tipo DRP & $\begin{array}{l}\text { № de } \\
\text { registros }\end{array}$ & $\begin{array}{l}\text { Tipo de } \\
\text { Fabricante }\end{array}$ & \begin{tabular}{|c|}
$\begin{array}{c}\text { Componente } \\
\text { da Rename } \\
2014\end{array}$ \\
\end{tabular} & $\begin{array}{c}\text { Rename } \\
2012\end{array}$ & $\begin{array}{c}\text { Rename } \\
2010\end{array}$ & $\begin{array}{l}\text { Rename } \\
2008\end{array}$ & $\begin{array}{c}\text { Rename } \\
2006\end{array}$ \\
\hline Rifabutina $150 \mathrm{mg}$ & Tuberculose & $\begin{array}{c}\text { Infectocontagiosas NÃO } \\
\text { Imunopreveníveis }\end{array}$ & 0 & IMPORTAÇÃO & Estratégico & SIM & NÃO & NÃO & NÃO \\
\hline $\begin{array}{l}\text { rifampicina }+ \text { isoniazida }+ \\
\text { pirazinamida }+ \text { etambutol } 150 \mathrm{mg}+ \\
75 \mathrm{mg}+400 \mathrm{mg}+275 \mathrm{mg} \\
\text { comprimido revestido }\end{array}$ & Tuberculose & $\begin{array}{l}\text { Infectocontagiosas NÃO } \\
\text { Imunopreveníveis }\end{array}$ & 1 & PÚBLICO & Estratégico & SIM & SIM & NÃO & NÃO \\
\hline rifampicina 150 mg cápsula & Hanseniase & $\begin{array}{c}\text { Infectocontagiosas NÃO } \\
\text { Imunopreveníveis }\end{array}$ & 0 & IMPORTAÇÃO & Estratégico & SIM & NÃO & NÃO & NÃO \\
\hline $\begin{array}{l}\text { rifampicina } 20 \mathrm{mg} / \mathrm{mL}(2 \%) \\
\text { suspensão oral }\end{array}$ & $\begin{array}{l}\text { Tuberculose e } \\
\text { Meningites }\end{array}$ & $\begin{array}{l}\text { Infectocontagiosas NÃO } \\
\text { Imunopreveníveis }\end{array}$ & 1 & PÚBLICO & Estratégico & SIM & SIM & SIM & SIM \\
\hline Rifampicina 300 mg cápsula & $\begin{array}{l}\text { Quimioprofilaxia } \\
\text { Meningites, } \\
\text { Hanseniase } \\
\end{array}$ & $\begin{array}{l}\text { Infectocontagiosas NÃO } \\
\text { Imunopreveníveis }\end{array}$ & 2 & - & Estratégico & SIM & SIM & SIM & SIM \\
\hline $\begin{array}{l}\text { sais para reidratação oral 27,9 g } \\
\text { envelope (pó) }\end{array}$ & $\begin{array}{l}\text { Cólera e outras } \\
\text { doenças diarreicas } \\
\text { agudas }\end{array}$ & $\begin{array}{l}\text { Infectocontagiosas NÃO } \\
\text { Imunopreveníveis }\end{array}$ & 2 & PP & $\begin{array}{c}\text { BÁSICO E } \\
\text { ESTRATÉGICO }\end{array}$ & SIM & SIM & SIM & SIM \\
\hline $\begin{array}{l}\text { soro antiaracnídico (Loxosceles e } \\
\text { Phoneutria) e escorpiônico (Tityus) }\end{array}$ & $\begin{array}{l}\text { Envenenamento por } \\
\text { animais } \\
\text { peçonhentos }\end{array}$ & $\begin{array}{l}\text { Infectocontagiosas NÃO } \\
\text { Imunopreveníveis }\end{array}$ & 1 & PÚBLICO & Estratégico & SIM & SIM & NÃO & NÃO \\
\hline $\begin{array}{l}\text { soro antibotrópico (pentavalente) - } \\
\text { serpentes do gênero Bothrops }\end{array}$ & $\begin{array}{l}\text { Envenenamento por } \\
\text { animais } \\
\text { peçonhentos }\end{array}$ & $\begin{array}{l}\text { Infectocontagiosas NÃO } \\
\text { Imunopreveníveis }\end{array}$ & 3 & PÚBLICO & Estratégico & SIM & SIM & NÃO & SIM \\
\hline $\begin{array}{l}\text { soro antibotrópico (pentavalente) e } \\
\text { anticrotálico }\end{array}$ & $\begin{array}{l}\text { Envenenamento por } \\
\text { animais } \\
\text { peçonhentos }\end{array}$ & $\begin{array}{l}\text { Infectocontagiosas NÃO } \\
\text { Imunopreveníveis }\end{array}$ & 3 & PÚBLICO & Estratégico & SIM & SIM & SIM & SIM \\
\hline $\begin{array}{l}\text { soro antibotrópico (pentavalente) e } \\
\text { antilaquético (cobra gênero } \\
\text { lachesis) }\end{array}$ & $\begin{array}{l}\text { Envenenamento por } \\
\text { animais } \\
\text { peçonhentos }\end{array}$ & $\begin{array}{l}\text { Infectocontagiosas NÃO } \\
\text { Imunopreveníveis }\end{array}$ & 3 & PÚBLICO & Estratégico & SIM & SIM & SIM & SIM \\
\hline
\end{tabular}




\begin{tabular}{|c|c|c|c|c|c|c|c|c|c|}
\hline Medicamento & $\begin{array}{l}\text { Doença ou } \\
\text { Agravo }\end{array}$ & Tipo DRP & $\begin{array}{l}\text { № de } \\
\text { registros }\end{array}$ & $\begin{array}{l}\text { Tipo de } \\
\text { Fabricante }\end{array}$ & $\begin{array}{l}\text { Componente } \\
\text { da Rename } \\
2014\end{array}$ & $\begin{array}{c}\text { Rename } \\
2012\end{array}$ & $\begin{array}{l}\text { Rename } \\
2010\end{array}$ & $\begin{array}{c}\text { Rename } \\
2008\end{array}$ & $\begin{array}{l}\text { Rename } \\
2006\end{array}$ \\
\hline soro antibotulínico $A B$ (bivalente) & $\begin{array}{l}\text { Envenenamento por } \\
\text { animais } \\
\text { peçonhentos }\end{array}$ & $\begin{array}{l}\text { Infectocontagiosas NÃO } \\
\text { Imunopreveníveis }\end{array}$ & 1 & PÚBLICO & Estratégico & SIM & SIM & SIM & SIM \\
\hline $\begin{array}{l}\text { soro anticrotálico - serpentes do } \\
\text { gênero Crotalus (cascavel) }\end{array}$ & $\begin{array}{l}\text { Envenenamento por } \\
\text { animais } \\
\text { peçonhentos }\end{array}$ & $\begin{array}{l}\text { Infectocontagiosas NÃO } \\
\text { Imunopreveníveis }\end{array}$ & 3 & PÚBLICO & Estratégico & SIM & SIM & SIM & SIM \\
\hline soro antidiftérico & Difteria & $\begin{array}{l}\text { Infectocontagiosas } \\
\text { Imunopreveníveis }\end{array}$ & 1 & PÚBLICO & Estratégico & SIM & SIM & SIM & SIM \\
\hline $\begin{array}{l}\text { soro antielapídico (bivalente) - } \\
\text { serpentes do gênero Micrurus } \\
\text { (corais verdadeiras) }\end{array}$ & $\begin{array}{l}\text { Envenenamento por } \\
\text { animais } \\
\text { peçonhentos }\end{array}$ & $\begin{array}{l}\text { Infectocontagiosas NÃO } \\
\text { Imunopreveníveis }\end{array}$ & 2 & PÚBLICO & Estratégico & SIM & SIM & SIM & SIM \\
\hline soro antiescorpiônico & $\begin{array}{l}\text { Envenenamento por } \\
\text { animais } \\
\text { peçonhentos }\end{array}$ & $\begin{array}{l}\text { Infectocontagiosas NÃO } \\
\text { Imunopreveníveis }\end{array}$ & 3 & PÚBLICO & Estratégico & SIM & SIM & SIM & SIM \\
\hline $\begin{array}{l}\text { soro antilonômico - taturana } \\
\text { (Lonomia obliqua) }\end{array}$ & $\begin{array}{l}\text { Envenenamento por } \\
\text { animais } \\
\text { peçonhentos }\end{array}$ & $\begin{array}{l}\text { Infectocontagiosas NÃO } \\
\text { Imunopreveníveis }\end{array}$ & 1 & PÚBLICO & Estratégico & SIM & SIM & SIM & SIM \\
\hline $\begin{array}{l}\text { soro antiloxoscélico (trivalente) ou } \\
\text { soro antiaracnídico (Loxosceles, } \\
\text { Phoneutria e Tityus) }\end{array}$ & $\begin{array}{l}\text { Envenenamento por } \\
\text { animais } \\
\text { peçonhentos }\end{array}$ & $\begin{array}{l}\text { Infectocontagiosas NÃO } \\
\text { Imunopreveníveis }\end{array}$ & 1 & PÚBLICO & Estratégico & SIM & SIM & SIM & SIM \\
\hline soro antirrábico & Raiva & $\begin{array}{l}\text { Infectocontagiosas } \\
\text { Imunopreveníveis }\end{array}$ & 3 & PÚBLICO & Estratégico & SIM & SIM & SIM & SIM \\
\hline soro antitetânico & Tétano & $\begin{array}{l}\text { Infectocontagiosas } \\
\text { Imunopreveníveis }\end{array}$ & 2 & PÚBLICO & Estratégico & SIM & SIM & SIM & SIM \\
\hline $\begin{array}{l}\text { sulfato de zinco } 10 \text { mg comprimido } \\
\text { mastigável (Básico) }\end{array}$ & Anemias carenciais & $\begin{array}{l}\text { Outras Doenças da } \\
\text { Pobreza }\end{array}$ & 0 & $\begin{array}{c}\text { NÃO } \\
\text { DISPONIVEL }\end{array}$ & BÁSICO & SIM & SIM & SIM & NÃO \\
\hline $\begin{array}{l}\text { sulfato de zinco } 200 \mathrm{mcg} / \mathrm{mL} \text { solução } \\
\text { injetável (Básico) }\end{array}$ & Anemias carenciais & $\begin{array}{l}\text { Outras Doenças da } \\
\text { Pobreza }\end{array}$ & 1 & PRIVADO & BÁSICO & SIM & SIM & SIM & NÃO \\
\hline
\end{tabular}




\begin{tabular}{|c|c|c|c|c|c|c|c|c|c|}
\hline Medicamento & $\begin{array}{l}\text { Doença ou } \\
\text { Agravo }\end{array}$ & Tipo DRP & $\begin{array}{l}\text { № de } \\
\text { registros }\end{array}$ & $\begin{array}{l}\text { Tipo de } \\
\text { Fabricante }\end{array}$ & $\begin{array}{c}\text { Componente } \\
\text { da Rename } \\
2014 \\
\end{array}$ & $\begin{array}{c}\text { Rename } \\
2012\end{array}$ & $\begin{array}{l}\text { Rename } \\
2010\end{array}$ & $\begin{array}{l}\text { Rename } \\
2008\end{array}$ & $\begin{array}{l}\text { Rename } \\
2006\end{array}$ \\
\hline sulfato de zinco $4 \mathrm{mg} / \mathrm{mL}$ xarope & Anemias carenciais & $\begin{array}{l}\text { Outras Doenças da } \\
\text { Pobreza }\end{array}$ & 0 & - & BÁSICO & SIM & SIM & SIM & NÃO \\
\hline $\begin{array}{l}\text { sulfato ferroso } 25 \mathrm{mg} / \mathrm{mL} \text { solução } \\
\text { oral }\end{array}$ & Anemias carenciais & $\begin{array}{l}\text { Outras Doenças da } \\
\text { Pobreza }\end{array}$ & 5 & PRIVADO & BÁSICO & SIM & SIM & SIM & SIM \\
\hline $\begin{array}{l}\text { sulfato ferroso } 40 \mathrm{mg} \text { comprimido } \\
\text { (Básico) }\end{array}$ & Anemias carenciais & $\begin{array}{c}\text { Outras Doenças da } \\
\text { Pobreza } \\
\end{array}$ & 6 & PRIVADO & BÁSICO & SIM & SIM & SIM & SIM \\
\hline talidomida 100mg comprimido & Hanseníase & $\begin{array}{c}\text { Infectocontagiosas NÃO } \\
\text { Imunopreveníveis }\end{array}$ & 1 & PÚBLICO & Estratégico & SIM & SIM & NÃO & NÃO \\
\hline teclozana $10 \mathrm{mg} / \mathrm{mL}$ suspensão oral & Geo-helmitíases & $\begin{array}{l}\text { Infectocontagiosas NÃO } \\
\text { Imunopreveníveis }\end{array}$ & 1 & PRIVADO & BÁSICO & SIM & SIM & NÃO & NÃO \\
\hline $\begin{array}{l}\text { teclozana } 500 \text { mg comprimido } \\
\text { (Básico) }\end{array}$ & Geo-helmitíases & \begin{tabular}{|c|}
$\begin{array}{c}\text { Infectocontagiosas NÃO } \\
\text { Imunopreveníveis }\end{array}$ \\
\end{tabular} & 1 & PRIVADO & BÁSICO & SIM & SIM & NÃO & NÃO \\
\hline $\begin{array}{l}\text { tenofovir + lamivudina } 300 \mathrm{mg}+ \\
300 \text { mgcomprimido revestido }\end{array}$ & $\begin{array}{l}\text { Violência doméstica } \\
\text { e sexual }\end{array}$ & $\begin{array}{c}\text { Outras Doenças da } \\
\text { Pobreza }\end{array}$ & 1 & PRIVADO & Estratégico & NÃO & NÃO & NÃO & NÃO \\
\hline $\begin{array}{l}\text { tetrahydrobiopterin - } \mathrm{BH} 4 \\
\text { (Sapropterina) } 100 \mathrm{mg} \text { Comprimido }\end{array}$ & Raiva & $\begin{array}{l}\text { Infectocontagiosas } \\
\text { Imunopreveníveis }\end{array}$ & 1 & PRIVADO & Estratégico & SIM & NÃO & NÃO & NÃO \\
\hline tiamina $300 \mathrm{mg}$ comprimido & Anemias carenciais & $\begin{array}{l}\text { Outras Doenças da } \\
\text { Pobreza }\end{array}$ & & PRIVADO & BÁSICO & SIM & SIM & SIM & SIM \\
\hline $\begin{array}{l}\text { vacina adsorvida difteria e tétano } \\
\text { adulto suspensão injetável }\end{array}$ & Difteria e tetano & $\begin{array}{l}\text { Infectocontagiosas } \\
\text { Imunopreveníveis }\end{array}$ & 0 & - & Estratégico & SIM & SIM & SIM & NÃO \\
\hline $\begin{array}{l}\text { vacina adsorvida difteria e tétano } \\
\text { infantil suspensão injetável }\end{array}$ & Difteria e tetano & $\begin{array}{l}\text { Infectocontagiosas } \\
\text { Imunopreveníveis }\end{array}$ & 0 & - & Estratégico & SIM & NÃO & NÃO & NÃO \\
\hline $\begin{array}{l}\text { vacina adsorvida difteria, tétano e } \\
\text { pertússis (acelular) adulto } \\
\text { suspensão injetável }\end{array}$ & $\begin{array}{l}\text { Difteria, Tetano, } \\
\text { Coqueluche }\end{array}$ & $\begin{array}{l}\text { Infectocontagiosas } \\
\text { Imunopreveníveis }\end{array}$ & 2 & PRIVADO & Estratégico & SIM & SIM & NÃO & NÃO \\
\hline
\end{tabular}




\begin{tabular}{|c|c|c|c|c|c|c|c|c|c|}
\hline Medicamento & $\begin{array}{l}\text { Doença ou } \\
\text { Agravo }\end{array}$ & Tipo DRP & $\begin{array}{l}\text { № de } \\
\text { registros }\end{array}$ & $\begin{array}{c}\text { Tipo de } \\
\text { Fabricante }\end{array}$ & $\begin{array}{c}\text { Componente } \\
\text { da Rename } \\
2014 \\
\end{array}$ & $\begin{array}{c}\text { Rename } \\
2012\end{array}$ & $\begin{array}{l}\text { Rename } \\
2010\end{array}$ & $\begin{array}{l}\text { Rename } \\
2008\end{array}$ & $\begin{array}{l}\text { Rename } \\
2006\end{array}$ \\
\hline $\begin{array}{l}\text { vacina adsorvida difteria, tétano e } \\
\text { pertússis (acelular) infantil } \\
\text { suspensão injetável }\end{array}$ & $\begin{array}{l}\text { Difteria, Tetano, } \\
\text { Coqueluche }\end{array}$ & $\begin{array}{l}\text { Infectocontagiosas } \\
\text { Imunopreveníveis }\end{array}$ & 1 & PRIVADO & Estratégico & NÃO & NÃO & NÃO & NÃO \\
\hline $\begin{array}{l}\text { vacina adsorvida difteria, tétano e } \\
\text { pertússis suspensão injetável }\end{array}$ & $\begin{array}{l}\text { Difteria, Tetano, } \\
\text { Coqueluche }\end{array}$ & $\begin{array}{l}\text { Infectocontagiosas } \\
\text { Imunopreveníveis }\end{array}$ & 0 & - & Estratégico & SIM & NÃO & SIM & SIM \\
\hline $\begin{array}{l}\text { vacina adsorvida difteria, tétano, } \\
\text { pertússis, hepatite B } \\
\text { (recombinante) e Haemophilus } \\
\text { influenza e B (conjugada) } \\
\text { suspensão injetável }\end{array}$ & $\begin{array}{l}\text { Difteria, Tetano, } \\
\text { Coqueluche, } \\
\text { Hepatite, Influenza }\end{array}$ & $\begin{array}{l}\text { Infectocontagiosas } \\
\text { Imunopreveníveis }\end{array}$ & 0 & - & Estratégico & SIM & NÃO & NÃO & NÃO \\
\hline $\begin{array}{l}\text { vacina BCG pó liofilizado para } \\
\text { suspensão injetável }\end{array}$ & Tuberculose & $\begin{array}{c}\text { Infectocontagiosas NÃO } \\
\text { Imunopreveníveis }\end{array}$ & 2 & PRIVADO & Estratégico & SIM & SIM & SIM & SIM \\
\hline vacina cólera (inativada) & $\begin{array}{l}\text { Cólera e outras } \\
\text { doenças diarreicas } \\
\text { agudas }\end{array}$ & $\begin{array}{l}\text { Infectocontagiosas } \\
\text { Imunopreveníveis }\end{array}$ & 0 & - & Estratégico & NÃO & NÃO & NÃO & NÃO \\
\hline $\begin{array}{l}\text { vacina febre amarela (atenuada) pó } \\
\text { liofilizado para solução injetável }\end{array}$ & $\begin{array}{l}\text { Febre Amarela e } \\
\text { Outras Arboviroses }\end{array}$ & $\begin{array}{l}\text { Infectocontagiosas } \\
\text { Imunopreveníveis }\end{array}$ & 2 & PP & Estratégico & SIM & SIM & SIM & SIM \\
\hline $\begin{array}{l}\text { vacina febre tifoide (polissacarídica) } \\
\text { solução injetável }\end{array}$ & Febre Tifoide & $\begin{array}{l}\text { Infectocontagiosas } \\
\text { Imunopreveníveis }\end{array}$ & 1 & PRIVADO & Estratégico & SIM & SIM & SIM & SIM \\
\hline $\begin{array}{l}\text { vacina meningocócica C (conjugada) } \\
\text { pó liofilizado para suspensão } \\
\text { injetável }\end{array}$ & Meningites & $\begin{array}{l}\text { Infectocontagiosas } \\
\text { Imunopreveníveis }\end{array}$ & 2 & PRIVADO & Estratégico & SIM & SIM & SIM & SIM \\
\hline $\begin{array}{l}\text { vacina pneumocócica } 10 \text {-valente } \\
\text { (conjugada) suspensão injetável }\end{array}$ & Meningites & $\begin{array}{l}\text { Infectocontagiosas } \\
\text { Imunopreveníveis }\end{array}$ & 2 & $\mathrm{PP}$ & Estratégico & SIM & NÃO & NÃO & NÃO \\
\hline $\begin{array}{l}\text { vacina pneumocócica } 23 \text {-valente } \\
\text { (polissacarídica) solução injetável }\end{array}$ & Meningites & $\begin{array}{l}\text { Infectocontagiosas } \\
\text { Imunopreveníveis }\end{array}$ & 2 & PRIVADO & Estratégico & SIM & NÃO & NÃO & NÃO \\
\hline
\end{tabular}




\begin{tabular}{|c|c|c|c|c|c|c|c|c|c|}
\hline Medicamento & $\begin{array}{c}\text { Doença ou } \\
\text { Agravo }\end{array}$ & Tipo DRP & $\begin{array}{l}\text { № de } \\
\text { registros }\end{array}$ & $\begin{array}{l}\text { Tipo de } \\
\text { Fabricante }\end{array}$ & $\begin{array}{c}\text { Componente } \\
\text { da Rename } \\
2014 \\
\end{array}$ & $\begin{array}{c}\text { Rename } \\
2012\end{array}$ & $\begin{array}{c}\text { Rename } \\
2010\end{array}$ & $\begin{array}{l}\text { Rename } \\
2008\end{array}$ & $\begin{array}{c}\text { Rename } \\
2006\end{array}$ \\
\hline $\begin{array}{l}\text { vacina poliomielite } 1 \text {, } 2 \text { e } 3 \\
\text { (atenuada) solução oral }\end{array}$ & Poliomielite & $\begin{array}{l}\text { Infectocontagiosas } \\
\text { Imunopreveníveis }\end{array}$ & 1 & PÚBLICO & Estratégico & SIM & SIM & SIM & SIM \\
\hline \begin{tabular}{|l|} 
vacina poliomielite 1,2 e 3 \\
(inativada) solução injetável
\end{tabular} & Poliomielite & $\begin{array}{l}\text { Infectocontagiosas } \\
\text { Imunopreveníveis }\end{array}$ & 1 & PRIVADO & Estratégico & SIM & NÃO & NÃO & NÃO \\
\hline $\begin{array}{l}\text { vacina raiva (inativada) pó } \\
\text { liofilizado para solução injetável e } \\
\text { pó liofilizado para suspensão } \\
\text { injetável }\end{array}$ & Raiva & $\begin{array}{l}\text { Infectocontagiosas } \\
\text { Imunopreveníveis }\end{array}$ & 2 & PP & Estratégico & SIM & SIM & SIM & SIM \\
\hline $\begin{array}{l}\text { vacina rotavirus humano G1P1 [8] } \\
\text { (atenuada) suspensão oral }\end{array}$ & \begin{tabular}{|l|} 
Cólera e outras \\
doenças diarreicas \\
agudas \\
\end{tabular} & $\begin{array}{l}\text { Infectocontagiosas } \\
\text { Imunopreveníveis }\end{array}$ & 3 & PP & Estratégico & SIM & SIM & SIM & SIM \\
\hline vacina sarampo, caxumba, rubéola & Caxumba & $\begin{array}{l}\text { Infectocontagiosas } \\
\text { Imunopreveníveis }\end{array}$ & 4 & PP & Estratégico & SIM & SIM & SIM & SIM \\
\hline $\begin{array}{l}\text { vacina sarampo, caxumba, rubéola } \\
\text { e varicela (atenuada) pó liofilizado } \\
\text { para solução injetável }\end{array}$ & Caxumba & $\begin{array}{l}\text { Infectocontagiosas } \\
\text { Imunopreveníveis }\end{array}$ & 1 & PRIVADO & Estratégico & NÃO & NÃO & NÃO & NÃO \\
\hline $\begin{array}{l}\text { vacina varicela (atenuada) pó } \\
\text { liofilizado para solução injetável }\end{array}$ & $\begin{array}{l}\text { Varicela e Herpes } \\
\text { Zoster }\end{array}$ & $\begin{array}{l}\text { Infectocontagiosas } \\
\text { Imunopreveníveis }\end{array}$ & 4 & PRIVADO & Estratégico & SIM & NÃO & NÃO & NÃO \\
\hline
\end{tabular}




\section{APÊNDICE II - RESULTADOS DAS DIRETRIZES AVALIADAS SEGUNDO A FERRAMENTA AGREE II}

\begin{tabular}{|c|c|c|c|c|c|c|c|c|c|c|c|c|c|c|c|c|c|c|c|c|c|c|c|c|}
\hline \multirow[t]{2}{*}{ Diretriz Avaliada --> } & \multicolumn{6}{|c|}{$\frac{\text { 1) Guia de vigilância em }}{\text { saúde (2014) }}$} & \multicolumn{6}{|c|}{$\frac{\begin{array}{c}\text { 2) Guia de doenças } \\
\text { infecciosas e parasitárias }\end{array}}{(2010)}$} & \multicolumn{6}{|c|}{$\frac{\text { 3) Guia dos Casos de }}{\text { Beribéri (2012) }}$} & \multicolumn{6}{|c|}{$\frac{\text { 4) NutriSUS: guia de }}{\underline{\text { evidências (2015) }}}$} \\
\hline & $\begin{array}{l}\mathrm{J}- \\
1\end{array}$ & $\left|\begin{array}{l}J- \\
2\end{array}\right|$ & $\left|\begin{array}{l}\text { J- } \\
\mathbf{3}\end{array}\right|$ & $\begin{array}{l}J- \\
4\end{array}$ & MED & Total & $\begin{array}{c}\mathrm{J}- \\
1\end{array}$ & $\begin{array}{l}\mathrm{J}- \\
2\end{array}$ & J- & $\mid \begin{array}{l}J- \\
4\end{array}$ & MED & Total & J- & $\left|\begin{array}{l}\mathrm{J}- \\
\mathbf{2}\end{array}\right|$ & $\mid \begin{array}{l}J- \\
3\end{array}$ & $\begin{array}{l}J- \\
4\end{array}$ & MED & Total & J- & $\left|\begin{array}{l}\text { J- } \\
2\end{array}\right|$ & $\left|\begin{array}{c}J- \\
3\end{array}\right|$ & $\begin{array}{l}J- \\
4\end{array}$ & MED & Total \\
\hline DOMÍNIO 1. ESCOPO E FINALIDADE & 13 & 12 & 17 & 17 & 4,9 & $65 \%$ & 12 & 8 & 10 & 15 & 3,8 & $46 \%$ & 17 & 15 & 11 & 18 & 5,1 & $68 \%$ & 15 & 13 & 13 & 12 & 4,4 & $57 \%$ \\
\hline $\begin{array}{l}\text { O(s) objetivo(s) geral(is) da(s) diretriz(es) } \\
\text { encontra(m)-se especificamente descrito(s)? }\end{array}$ & 3 & 3 & 5 & 5 & 4,0 & & 2 & 2 & 3 & 5 & 3,0 & & 4 & 6 & 2 & 5 & 4,3 & & 4 & 2 & 3 & 5 & 3,5 & \\
\hline $\begin{array}{l}\text { A(s) questão(ões) de saúde coberta(s) pela diretriz } \\
\text { encontra }(\mathrm{m}) \text {-se especificamente descrita(s)? }\end{array}$ & 4 & 4 & 6 & 7 & 5,3 & & 4 & 3 & 4 & 4 & 3,8 & & 7 & 4 & 4 & 7 & 5,5 & & 5 & 5 & 5 & 3 & 4,5 & \\
\hline $\begin{array}{l}\text { A população (pacientes, público, etc.) a quem a } \\
\text { diretriz se destina encontra-se especificamente } \\
\text { descrita? }\end{array}$ & 6 & 5 & 6 & 5 & 5,5 & & 6 & 3 & 3 & 6 & 4,5 & & 6 & 5 & 5 & 6 & 5,5 & & 6 & 6 & 5 & 4 & 5,3 & \\
\hline $\begin{array}{l}\text { DOMÍNIO 2. ENVOLVIMENTO DAS PARTES } \\
\text { INTERESSADAS }\end{array}$ & 5 & 5 & 5 & 4 & 1,6 & $10 \%$ & 7 & 7 & 8 & 7 & 2,4 & $24 \%$ & 7 & 8 & 8 & 8 & 2,6 & $26 \%$ & 8 & 7 & 7 & 7 & 2,4 & $24 \%$ \\
\hline $\begin{array}{l}\text { A equipe de desenvolvimento da diretriz inclui } \\
\text { indivíduos de todos os grupos profissionais } \\
\text { relevantes? }\end{array}$ & 2 & 2 & 2 & 1 & 1,8 & & 2 & 2 & 2 & 1 & 1,8 & & 2 & 2 & 2 & 2 & 2,0 & & 3 & 1 & 1 & 1 & 1,5 & \\
\hline $\begin{array}{l}\text { Procurou-se conhecer as opiniões e preferências da } \\
\text { população-alvo (pacientes, público, etc.)? }\end{array}$ & 1 & 1 & 1 & 1 & 1,0 & & 1 & 1 & 1 & 1 & 1,0 & & 1 & 1 & 1 & 1 & 1,0 & & 1 & 1 & 1 & 1 & 1,0 & \\
\hline $\begin{array}{l}\text { Os usuários-alvo da diretriz estão claramente } \\
\text { definidos? }\end{array}$ & 2 & 2 & 2 & 2 & 2,0 & & 4 & 4 & 5 & 5 & 4,5 & & 4 & 5 & 5 & 5 & 4,8 & & 4 & 5 & 5 & 5 & 4,8 & \\
\hline DOMÍNIO 3. RIGOR DO DESENVOLVIMENTO & 9 & 14 & 9 & 10 & 1,3 & $5 \%$ & 8 & 10 & 8 & 8 & 1,1 & $1 \%$ & 10 & 14 & 11 & 12 & 1,5 & $8 \%$ & 13 & 15 & 13 & 13 & 1,7 & $11 \%$ \\
\hline $\begin{array}{l}\text { Foram utilizados métodos sistemáticos para a } \\
\text { busca de evidências? }\end{array}$ & 1 & 1 & 1 & 1 & 1,0 & & 1 & 1 & 1 & 1 & 1,0 & & 1 & 2 & 1 & 1 & 1,3 & & 1 & 2 & 1 & 1 & 1,3 & \\
\hline $\begin{array}{l}\text { Os critérios para a seleção de evidências estão } \\
\text { claramente descritos? }\end{array}$ & 1 & 1 & 1 & 1 & 1,0 & & 1 & 1 & 1 & 1 & 1,0 & & 1 & 1 & 1 & 1 & 1,0 & & 1 & 1 & 1 & 1 & 1,0 & \\
\hline
\end{tabular}




\begin{tabular}{|c|c|c|c|c|c|c|c|c|c|c|c|c|c|c|c|c|c|c|c|c|c|c|c|c|}
\hline $\begin{array}{l}\text { Os pontos fortes e limitações do corpo de } \\
\text { evidências estão claramente descritos? }\end{array}$ & 1 & 2 & 1 & 1 & 1,3 & & 1 & 1 & 1 & 1 & 1,0 & & 1 & 1 & 1 & 1 & 1,0 & & 1 & 1 & 1 & 1 & 1,0 & \\
\hline $\begin{array}{l}\text { Os métodos para a formulação das recomendações } \\
\text { estão claramente descritos? }\end{array}$ & 1 & 1 & 1 & 2 & 1,3 & & 1 & 1 & 1 & 1 & 1,0 & & 1 & 2 & 1 & 1 & 1,3 & & 1 & 2 & 1 & 1 & 1,3 & \\
\hline $\begin{array}{l}\text { Os benefícios, efeitos colaterais e riscos à saúde } \\
\text { foram considerados na formulação das } \\
\text { recomendações? }\end{array}$ & 2 & 3 & 2 & 2 & 2,3 & & 1 & 2 & 1 & 1 & 1,3 & & 3 & 4 & 4 & 5 & 4,0 & & 3 & 3 & 3 & 3 & 3,0 & \\
\hline $\begin{array}{l}\text { Existe uma relação explícita entre as } \\
\text { recomendações e as evidências que Ihe dão } \\
\text { suporte? }\end{array}$ & 1 & 2 & 1 & 1 & 1,3 & & 1 & 1 & 1 & 1 & 1,0 & & 1 & 2 & 1 & 1 & 1,3 & & 4 & 4 & 4 & 4 & 4,0 & \\
\hline $\begin{array}{l}\text { A diretriz foi revisada externamente por experts } \\
\text { antes da sua publicação? }\end{array}$ & 1 & 2 & 1 & 1 & 1,3 & & 1 & 2 & 1 & 1 & 1,3 & & 1 & 1 & 1 & 1 & 1,0 & & 1 & 1 & 1 & 1 & 1,0 & \\
\hline $\begin{array}{l}\text { Um procedimento para atualização da diretriz está } \\
\text { disponível? }\end{array}$ & 1 & 2 & 1 & 1 & 1,3 & & 1 & 1 & 1 & 1 & 1,0 & & 1 & 1 & 1 & 1 & 1,0 & & 1 & 1 & 1 & 1 & 1,0 & \\
\hline DOMÍNIO 4. CLAREZA DA APRESENTAÇÃO & 12 & 11 & 13 & 13 & 4,1 & $51 \%$ & 10 & 9 & 11 & 13 & 3,6 & $43 \%$ & 12 & 15 & 13 & 11 & 4,3 & $54 \%$ & 12 & 12 & 11 & 14 & 4,1 & $51 \%$ \\
\hline $\begin{array}{l}\text { As recomendações são específicas e sem } \\
\text { ambiguidade? }\end{array}$ & 3 & 4 & 5 & 3 & 3,8 & & 3 & 3 & 4 & 4 & 3,5 & & 4 & 5 & 4 & 5 & 4,5 & & 4 & 4 & 3 & 5 & 4,0 & \\
\hline $\begin{array}{l}\text { As diferentes opções de abordagem da condição ou } \\
\text { problema de saúde estão claramente } \\
\text { apresentadas? }\end{array}$ & 4 & 5 & 4 & 5 & 4,5 & & 3 & 4 & 3 & 4 & 3,5 & & 4 & 5 & 4 & 1 & 3,5 & & 4 & 5 & 3 & 5 & 4,3 & \\
\hline $\begin{array}{l}\text { As recomendações-chave são facilmente } \\
\text { identificadas? }\end{array}$ & 5 & 2 & 4 & 5 & 4,0 & & 4 & 2 & 4 & 5 & 3,8 & & 4 & 5 & 5 & 5 & 4,8 & & 4 & 3 & 5 & 4 & 4,0 & \\
\hline DOMÍNIO 5. APLICABILIDADE & 12 & 11 & 8 & 8 & 2,4 & $24 \%$ & 8 & 9 & 4 & 5 & 1,6 & $10 \%$ & 13 & 17 & 9 & 15 & 3,4 & $40 \%$ & 13 & 18 & 4 & 5 & 2,5 & $25 \%$ \\
\hline $\begin{array}{l}\text { A diretriz descreve os fatores facilitadores e as } \\
\text { barreiras para sua aplicação? }\end{array}$ & 4 & 3 & 5 & 5 & 4,3 & & 2 & 2 & 1 & 2 & 1,8 & & 4 & 5 & 1 & 5 & 3,8 & & 4 & 5 & 1 & 2 & 3,0 & \\
\hline $\begin{array}{l}\text { A diretriz traz aconselhamento e/ou ferramentas } \\
\text { sobre como as recomendações podem ser } \\
\text { colocadas em prática? }\end{array}$ & 4 & 3 & 1 & 1 & 2,3 & & 2 & 2 & 1 & 1 & 1,5 & & 5 & 6 & 6 & 7 & 6,0 & & 5 & 5 & 1 & 1 & 3,0 & \\
\hline
\end{tabular}




\begin{tabular}{|c|c|c|c|c|c|c|c|c|c|c|c|c|c|c|c|c|c|c|c|c|c|c|c|c|}
\hline $\begin{array}{l}\text { Foram consideradas as potenciais implicações } \\
\text { quanto aos recursos decorrentes da aplicação das } \\
\text { recomendações? }\end{array}$ & 2 & 2 & 1 & 1 & 1,5 & & 2 & 2 & 1 & 1 & 1,5 & & 2 & 3 & 1 & 1 & 1,8 & & 2 & 4 & 1 & 1 & 2,0 & \\
\hline $\begin{array}{l}\text { A diretriz apresenta critérios para o seu } \\
\text { monitoramento e/ou auditoria? }\end{array}$ & 2 & 3 & 1 & 1 & 1,8 & & 2 & 3 & 1 & 1 & 1,8 & & 2 & 3 & 1 & 2 & 2,0 & & 2 & 4 & 1 & 1 & 2,0 & \\
\hline DOMÍNIO 6. INDEPENDÊNCIA EDITORIAL & 3 & 3 & 2 & 2 & 1,3 & $4 \%$ & 3 & 3 & 2 & 2 & 1,3 & $4 \%$ & 3 & 3 & 2 & 2 & 1,3 & $4 \%$ & 3 & 2 & 2 & 2 & 1,1 & $2 \%$ \\
\hline $\begin{array}{l}\text { O parecer do órgão financiador não exerceu } \\
\text { influência sobre o conteúdo da diretriz? }\end{array}$ & 2 & 2 & 1 & 1 & 1,5 & & 2 & 2 & 1 & 1 & 1,5 & & 2 & 2 & 1 & 1 & 1,5 & & 2 & 1 & 1 & 1 & 1,3 & \\
\hline $\begin{array}{l}\text { Foram registrados e abordados os conflitos de } \\
\text { interesse dos membros da equipe que } \\
\text { desenvolveram a diretriz? }\end{array}$ & 1 & 1 & 1 & 1 & 1,0 & & 1 & 1 & 1 & 1 & 1,0 & & 1 & 1 & 1 & 1 & 1,0 & & 1 & 1 & 1 & 1 & 1,0 & \\
\hline
\end{tabular}

\begin{tabular}{|c|c|c|c|c|c|c|c|c|c|c|c|c|c|c|c|c|c|c|c|c|c|c|c|}
\hline \multirow[t]{2}{*}{ Diretriz Avaliada --> } & \multicolumn{6}{|c|}{$\frac{\text { 5) Manual de }}{\text { Suplementação de Vitamina }}$} & \multicolumn{6}{|c|}{$\begin{array}{l}\text { 6) Suplementação de Ferro: } \\
\underline{\text { manual de condutas (2013) }}\end{array}$} & \multicolumn{6}{|c|}{$\frac{\frac{7) \text { Dengue: diagnóstico e }}{\text { manejo clínico - adulto e }}}{\text { criança, 5ed. (2016). }}$} & \multicolumn{5}{|c|}{$\begin{array}{l}\frac{\text { 8) Doença falciforme: }}{\text { condutas básicas para }} \\
\text { tratamento (2012) }\end{array}$} \\
\hline & $\begin{array}{c}\text { J- } \\
1\end{array} \mid$ & $\left|\begin{array}{l}\mathrm{J}- \\
2\end{array}\right|$ & $\left|\begin{array}{l}\mathrm{J} \\
3\end{array}\right|$ & $\begin{array}{l}\mathrm{J}- \\
4\end{array}$ & MED & Total & $\begin{array}{c}\mathrm{J}- \\
1\end{array}$ & $\begin{array}{l}\text { J- } \\
2\end{array}$ & \begin{tabular}{l|l}
$\mathrm{J}-$ & $\mathbf{5}$ \\
$\mathbf{3}$ & $\mathbf{2}$
\end{tabular} & $\begin{array}{l}\mathrm{J}- \\
4\end{array}$ & MED & Total & $\begin{array}{c}J- \\
1\end{array}$ & \begin{tabular}{|l|}
$J-$ \\
2
\end{tabular} & J- & $\begin{array}{l}\mathrm{J}- \\
4\end{array}$ & MED & Total & $\begin{array}{c}\mathrm{J}- \\
1\end{array}$ & $\begin{array}{l}\mathrm{J}- \\
2\end{array}$ & \begin{tabular}{l|l} 
J- & J. \\
3 & 4
\end{tabular} & 4 MED & Total \\
\hline DOMÍNIO 1. ESCOPO E FINALIDADE & 18 & 16 & 19 & 21 & 6,2 & $86 \%$ & 15 & 13 & 19 & 18 & 5,4 & $74 \%$ & 19 & 14 & 182 & 20 & 5,9 & $82 \%$ & 19 & 101 & 162 & 215,5 & $75 \%$ \\
\hline $\begin{array}{l}\text { O(s) objetivo(s) geral(is) da(s) diretriz(es) } \\
\text { encontra(m)-se especificamente descrito(s)? }\end{array}$ & 5 & 6 & 7 & 7 & 6,3 & & 4 & 3 & 7 & 7 & 5,3 & & 7 & 5 & 6 & 7 & 6,3 & & 5 & 2 & 77 & $7 \quad 5,3$ & \\
\hline $\begin{array}{l}\text { A(s) questão(ões) de saúde coberta(s) pela diretriz } \\
\text { encontra }(m) \text {-se especificamente descrita(s)? }\end{array}$ & 7 & 5 & 5 & 7 & 6,0 & & 6 & 4 & 6 & 4 & 5,0 & & 7 & 5 & 5 & 7 & 6,0 & & 7 & 3 & 57 & $7 \quad 5,5$ & \\
\hline $\begin{array}{l}\text { A população (pacientes, público, etc.) a quem a } \\
\text { diretriz se destina encontra-se especificamente } \\
\text { descrita? }\end{array}$ & 6 & 5 & 7 & 7 & 6,3 & & 5 & 6 & 6 & 7 & 6,0 & & 5 & 4 & 7 & 6 & 5,5 & & 7 & 5 & 47 & $\begin{array}{ll}7 & 5,8\end{array}$ & \\
\hline $\begin{array}{l}\text { DOMÍNIO 2. ENVOLVIMENTO DAS PARTES } \\
\text { INTERESSADAS }\end{array}$ & 8 & 8 & 9 & 9 & 2,8 & $31 \%$ & 5 & 6 & 7 & 7 & 2,1 & $18 \%$ & 5 & 4 & 3 & 5 & 1,4 & 7\% & 5 & 3 & 45 & $\begin{array}{ll}5 & 1,4\end{array}$ & 7\% \\
\hline
\end{tabular}


A equipe de desenvolvimento da diretriz inclui indivíduos de todos os grupos profissionais relevantes?

Procurou-se conhecer as opiniões e preferências da população-alvo (pacientes, público, etc.)?

Os usuários-alvo da diretriz estão claramente definidos?

DOMÍNIO 3. RIGOR DO DESENVOLVIMENTO

Foram utilizados métodos sistemáticos para a busca de evidências?

Os critérios para a seleção de evidências estão claramente descritos?

Os pontos fortes e limitações do corpo de evidências estão claramente descritos?

Os métodos para a formulação das

recomendações estão claramente descritos?

Os benefícios, efeitos colaterais e riscos à saúde

foram considerados na formulação das

recomendações?

Existe uma relação explícita entre as

recomendações e as evidências que lhe dão

suporte?

A diretriz foi revisada externamente por experts antes da sua publicação?

Um procedimento para atualização da diretriz está disponível?

DOMíNIO 4. CLAREZA DA APRESENTAÇÃO

As recomendações são específicas e sem ambiguidade?

\begin{tabular}{|c|c|c|c|c|c|c|c|c|c|c|c|c|c|c|c|c|c|c|c|c|c|c|c|}
\hline 1 & 1 & 1 & 1 & 1,0 & & 1 & 1 & 1 & 1 & 1,0 & & 2 & 1 & 1 & 2 & 1,5 & & 2 & & 2 & 2 & 1,8 & \\
\hline 1 & 1 & 1 & 1 & 1,0 & & 1 & 1 & 1 & 1 & 1,0 & & 1 & 1 & 1 & 1 & 1,0 & & 1 & 1 & 1 & 1 & 1,0 & \\
\hline 6 & 6 & 7 & 7 & 6,5 & & 3 & 4 & 5 & 5 & 4,3 & & 2 & 2 & 1 & 2 & 1,8 & & 2 & 1 & 1 & 2 & 1,5 & \\
\hline 11 & 13 & 10 & 12 & 1,4 & 7\% & 10 & 10 & 9 & 12 & 1,3 & $5 \%$ & 9 & 11 & 9 & 10 & 1,2 & $4 \%$ & 10 & 12 & 10 & 11 & 1,3 & $6 \%$ \\
\hline 1 & 1 & 1 & 1 & 1,0 & & 1 & 1 & 1 & 1 & 1,0 & & 1 & 1 & 1 & 1 & 1,0 & & 1 & 1 & 1 & 1 & 1,0 & \\
\hline 1 & 1 & 1 & 1 & 1,0 & & 1 & 1 & 1 & 1 & 1,0 & & 1 & 1 & 1 & 1 & 1,0 & & 1 & 1 & 1 & 1 & 1,0 & \\
\hline 1 & 1 & 1 & 1 & 1,0 & & 1 & 1 & 1 & 1 & 1,0 & & 1 & 1 & 1 & 1 & 1,0 & & 1 & 1 & 1 & 1 & 1,0 & \\
\hline 1 & 1 & 1 & 1 & 1,0 & & 1 & 1 & 1 & 1 & 1,0 & & 1 & 1 & 1 & 1 & 1,0 & & 1 & 1 & 1 & 1 & 1,0 & \\
\hline 3 & 4 & 3 & 5 & 3,8 & & 2 & 2 & 2 & 2 & 2,0 & & 2 & 2 & 2 & 3 & 2,3 & & 3 & 4 & 3 & 4 & 3,5 & \\
\hline 2 & 3 & 1 & 1 & 1,8 & & 2 & 2 & 1 & 4 & 2,3 & & 1 & 2 & 1 & 1 & 1,3 & & 1 & 2 & 1 & 1 & 1,3 & \\
\hline 1 & 1 & 1 & 1 & 1,0 & & 1 & 1 & 1 & 1 & 1,0 & & 1 & 2 & 1 & 1 & 1,3 & & 1 & 1 & 1 & 1 & 1,0 & \\
\hline 1 & 1 & 1 & 1 & 1,0 & & 1 & 1 & 1 & 1 & 1,0 & & 1 & 1 & 1 & 1 & 1,0 & & 1 & 1 & 1 & 1 & 1,0 & \\
\hline 13 & 10 & 13 & 14 & 4,2 & $53 \%$ & 14 & 13 & 12 & 16 & 4,6 & $60 \%$ & 16 & 10 & 14 & 14 & 4,5 & $58 \%$ & 16 & 14 & 12 & 17 & 4,9 & $65 \%$ \\
\hline 4 & 3 & 4 & 5 & 4,0 & & 4 & 4 & 3 & 5 & 4,0 & & 5 & 3 & 5 & 4 & 4,3 & & 5 & 4 & 3 & 5 & 4,3 & \\
\hline
\end{tabular}


As diferentes opções de abordagem da condição ou problema de saúde estão claramente apresentadas?

As recomendações-chave são facilmente identificadas?

DOMÍNIO 5. APLICABILIDADE

A diretriz descreve os fatores facilitadores e as barreiras para sua aplicação?

A diretriz traz aconselhamento e/ou ferramentas sobre como as recomendações podem ser colocadas em prática?

Foram consideradas as potenciais implicações quanto aos recursos decorrentes da aplicação das recomendações?

A diretriz apresenta critérios para o seu monitoramento e/ou auditoria?

\section{DOMÍNIO 6. INDEPENDÊNCIA EDITORIAL}

O parecer do órgão financiador não exerceu influência sobre o conteúdo da diretriz?

Foram registrados e abordados os conflitos de interesse dos membros da equipe que desenvolveram a diretriz?

\begin{tabular}{|c|c|c|c|c|c|c|c|c|c|c|c|c|c|c|c|c|c|c|c|c|c|c|c|}
\hline 4 & 4 & 4 & 4 & 4,0 & & 4 & 4 & 3 & 5 & 4,0 & & 5 & 5 & 4 & 5 & 4,8 & & 5 & 4 & 3 & 5 & 4,3 & \\
\hline 5 & 3 & 5 & 5 & 4,5 & & 6 & 5 & 6 & 6 & 5,8 & & 6 & 2 & 5 & 5 & 4,5 & & 6 & 6 & 6 & 7 & 6,3 & \\
\hline 17 & 15 & 9 & 16 & 3,6 & $43 \%$ & 14 & 17 & 9 & 13 & 3,3 & $39 \%$ & 14 & 8 & 7 & 8 & 2,3 & $22 \%$ & 14 & 10 & 4 & 7 & 2,2 & $20 \%$ \\
\hline 5 & 2 & 1 & 5 & 3,3 & & 5 & 4 & 1 & 5 & 3,8 & & 5 & 2 & 1 & 2 & 2,5 & & 5 & 3 & 1 & 3 & 3,0 & \\
\hline 6 & 6 & 6 & 7 & 6,3 & & 5 & 6 & 6 & 6 & 5,8 & & 5 & 2 & 4 & 4 & 3,8 & & 5 & 4 & 1 & 2 & 3,0 & \\
\hline 2 & 3 & 1 & 1 & 1,8 & & 2 & 4 & 1 & 1 & 2,0 & & 2 & 2 & 1 & 1 & 1,5 & & 2 & 2 & 1 & 1 & 1,5 & \\
\hline 4 & 4 & 1 & 3 & 3,0 & & 2 & 3 & 1 & 1 & 1,8 & & 2 & 2 & 1 & 1 & 1,5 & & 2 & 1 & 1 & 1 & 1,3 & \\
\hline 2 & 2 & 2 & 2 & 1,0 & $0 \%$ & 2 & 2 & 2 & 2 & 1,0 & $0 \%$ & 2 & 2 & 2 & 2 & 1,0 & $0 \%$ & 2 & 2 & 2 & 2 & 1,0 & $0 \%$ \\
\hline 1 & 1 & 1 & 1 & 1,0 & & 1 & 1 & 1 & 1 & 1,0 & & 1 & 1 & 1 & 1 & 1,0 & & 1 & 1 & 1 & 1 & 1,0 & \\
\hline 1 & 1 & 1 & 1 & 1,0 & & 1 & 1 & 1 & 1 & 1,0 & & 1 & 1 & 1 & 1 & 1,0 & & 1 & 1 & 1 & 1 & 1,0 & \\
\hline
\end{tabular}

\section{Diretriz Avaliada -->}

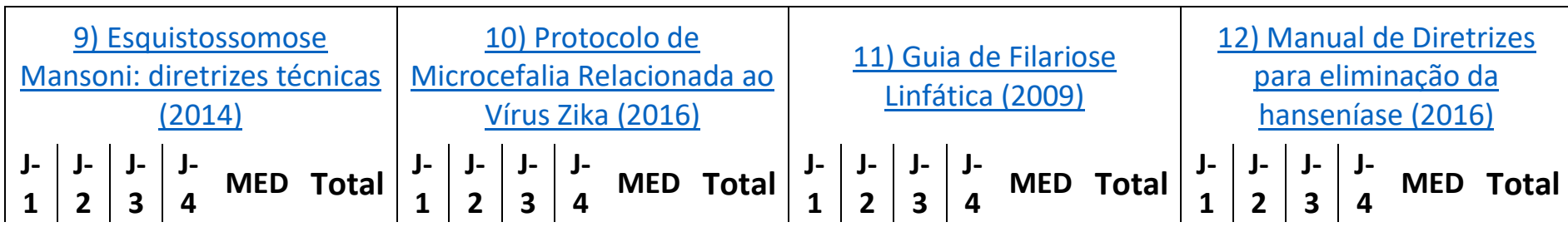




\begin{tabular}{|c|c|c|c|c|c|c|c|c|c|c|c|c|c|c|c|c|c|c|c|c|c|c|c|c|}
\hline DOMÍNIO 1. ESCOPO E FINALIDADE & 20 & 13 & 162 & 21 & 5,8 & $81 \%$ & 21 & 14 & 20 & 20 & 6,3 & $88 \%$ & 13 & 12 & 13 & 19 & 4,8 & $63 \%$ & 15 & 15 & 17 & 18 & 5,4 & $74 \%$ \\
\hline $\begin{array}{l}\text { O(s) objetivo(s) geral(is) da(s) diretriz(es) } \\
\text { encontra(m)-se especificamente descrito(s)? }\end{array}$ & 6 & 5 & 6 & 7 & 6,0 & & 7 & 4 & 7 & 7 & 6,3 & & 3 & 5 & 6 & 7 & 5,3 & & 4 & 6 & 7 & 7 & 6,0 & \\
\hline $\begin{array}{l}\text { A(s) questão(ões) de saúde coberta(s) pela diretriz } \\
\text { encontra(m)-se especificamente descrita(s)? }\end{array}$ & 7 & 4 & 4 & 7 & 5,5 & & 7 & 5 & 6 & 6 & 6,0 & & 5 & 3 & 3 & 5 & 4,0 & & 5 & 4 & 6 & 5 & 5,0 & \\
\hline $\begin{array}{l}\text { A população (pacientes, público, etc.) a quem a } \\
\text { diretriz se destina encontra-se especificamente } \\
\text { descrita? }\end{array}$ & 7 & 4 & 6 & 7 & 6,0 & & 7 & 5 & 7 & 7 & 6,5 & & 5 & 4 & 4 & 7 & 5,0 & & 6 & 5 & 4 & 6 & 5,3 & \\
\hline $\begin{array}{l}\text { DOMÍNIO 2. ENVOLVIMENTO DAS PARTES } \\
\text { INTERESSADAS }\end{array}$ & 11 & 12 & 9 & 9 & 3,4 & $40 \%$ & 10 & 10 & 8 & 9 & 3,1 & $35 \%$ & 9 & 9 & 8 & 5 & 2,6 & $26 \%$ & 9 & 10 & 8 & 7 & 2,8 & $31 \%$ \\
\hline $\begin{array}{l}\text { A equipe de desenvolvimento da diretriz inclui } \\
\text { indivíduos de todos os grupos profissionais } \\
\text { relevantes? }\end{array}$ & 4 & 4 & 2 & 1 & 2,8 & & 3 & 3 & 1 & 1 & 2,0 & & 4 & 3 & 4 & 1 & 3,0 & & 4 & 4 & 2 & 1 & 2,8 & \\
\hline $\begin{array}{l}\text { Procurou-se conhecer as opiniões e preferências } \\
\text { da população-alvo (pacientes, público, etc.)? }\end{array}$ & 1 & 2 & 1 & 1 & 1,3 & & 1 & 2 & 1 & 1 & 1,3 & & 1 & 1 & 1 & 1 & 1,0 & & 1 & 1 & 1 & 1 & 1,0 & \\
\hline $\begin{array}{l}\text { Os usuários-alvo da diretriz estão claramente } \\
\text { definidos? }\end{array}$ & 6 & 6 & 6 & 7 & 6,3 & & 6 & 5 & 6 & 7 & 6,0 & & 4 & 5 & 3 & 3 & 3,8 & & 4 & 5 & 5 & 5 & 4,8 & \\
\hline DOMÍNIO 3. RIGOR DO DESENVOLVIMENTO & 10 & 17 & 10 & 10 & 1,5 & $8 \%$ & 8 & 12 & 8 & 11 & 1,2 & $4 \%$ & 8 & 14 & 9 & 12 & 1,3 & $6 \%$ & 9 & 13 & 9 & 13 & 1,4 & $6 \%$ \\
\hline $\begin{array}{l}\text { Foram utilizados métodos sistemáticos para a } \\
\text { busca de evidências? }\end{array}$ & 1 & 1 & 1 & 1 & 1,0 & & 1 & 1 & 1 & 1 & 1,0 & & 1 & 1 & 1 & 1 & 1,0 & & 1 & 1 & 1 & 1 & 1,0 & \\
\hline $\begin{array}{l}\text { Os critérios para a seleção de evidências estão } \\
\text { claramente descritos? }\end{array}$ & 1 & 1 & 1 & 1 & 1,0 & & 1 & 1 & 1 & 1 & 1,0 & & 1 & 1 & 1 & 1 & 1,0 & & 1 & 1 & 1 & 1 & 1,0 & \\
\hline $\begin{array}{l}\text { Os pontos fortes e limitações do corpo de } \\
\text { evidências estão claramente descritos? }\end{array}$ & 1 & 3 & 1 & 1 & 1,5 & & 1 & 1 & 1 & 1 & 1,0 & & 1 & 2 & 1 & 1 & 1,3 & & 1 & 1 & 1 & 1 & 1,0 & \\
\hline $\begin{array}{l}\text { Os métodos para a formulação das } \\
\text { recomendações estão claramente descritos? }\end{array}$ & 1 & 2 & 1 & 1 & 1,3 & & 1 & 1 & 1 & 2 & 1,3 & & 1 & 1 & 1 & 1 & 1,0 & & 1 & 1 & 1 & 2 & 1,3 & \\
\hline $\begin{array}{l}\text { Os benefícios, efeitos colaterais e riscos à saúde } \\
\text { foram considerados na formulação das } \\
\text { recomendações? }\end{array}$ & 3 & 5 & 3 & 3 & 3,5 & & 1 & 2 & 1 & 2 & 1,5 & & 1 & 4 & 2 & 5 & 3,0 & & 2 & 4 & 2 & 5 & 3,3 & \\
\hline
\end{tabular}


Existe uma relação explícita entre as recomendações e as evidências que lhe dão suporte?

A diretriz foi revisada externamente por experts antes da sua publicação?

Um procedimento para atualização da diretriz está disponível?

DOMÍNIO 4. CLAREZA DA APRESENTAÇÃO

As recomendações são específicas e sem

ambiguidade?

As diferentes opções de abordagem da condição ou problema de saúde estão claramente apresentadas?

As recomendações-chave são facilmente identificadas?

DOMÍNIO 5. APLICABILIDADE

A diretriz descreve os fatores facilitadores e as barreiras para sua aplicação?

\begin{tabular}{|c|c|c|c|c|c|c|c|c|c|c|c|c|c|c|c|c|c|c|c|c|c|c|c|}
\hline 1 & 2 & 1 & 1 & 1,3 & & 1 & 2 & 1 & 1 & 1,3 & & 1 & 2 & 1 & 1 & 1,3 & & 1 & 2 & 1 & 1 & 1,3 & \\
\hline 1 & 2 & 1 & 1 & 1,3 & & 1 & 2 & 1 & 1 & 1,3 & & 1 & 2 & 1 & 1 & 1,3 & & 1 & 2 & 1 & 1 & 1,3 & \\
\hline 1 & 1 & 1 & 1 & 1,0 & & 1 & 2 & 1 & 2 & 1,5 & & 1 & 1 & 1 & 1 & 1,0 & & 1 & 1 & 1 & 1 & 1,0 & \\
\hline 16 & 12 & 16 & 19 & 5,3 & $71 \%$ & 15 & 13 & 17 & 14 & 4,9 & $65 \%$ & 13 & 13 & 9 & 16 & 4,3 & $54 \%$ & 14 & 13 & 15 & 18 & 5,0 & $67 \%$ \\
\hline 5 & 3 & 4 & 5 & 4,3 & & 4 & 4 & 6 & 5 & 4,8 & & 4 & 4 & 3 & 6 & 4,3 & & 4 & 4 & 5 & 6 & 4,8 & \\
\hline 7 & 6 & 6 & 7 & 6,5 & & 5 & 5 & 4 & 5 & 4,8 & & 5 & 5 & 2 & 5 & 4,3 & & 6 & 4 & 5 & 7 & 5,5 & \\
\hline 4 & 3 & 6 & 7 & 5,0 & & 6 & 4 & 7 & 4 & 5,3 & & 4 & 4 & 4 & 5 & 4,3 & & 4 & 5 & 5 & 5 & 4,8 & \\
\hline 15 & 17 & 9 & 17 & 3,6 & $44 \%$ & 12 & 16 & 8 & 14 & 3,1 & $35 \%$ & 13 & 12 & 8 & 13 & 2,9 & $31 \%$ & 11 & 15 & 8 & 14 & 3,0 & $33 \%$ \\
\hline 5 & 6 & 1 & 7 & 4,8 & & 4 & 5 & 1 & 5 & 3,8 & & 5 & 3 & 1 & 5 & 3,5 & & 3 & 4 & 1 & 6 & 3,5 & \\
\hline 6 & 6 & 6 & 7 & 6,3 & & 4 & 6 & 5 & 7 & 5,5 & & 4 & 5 & 5 & 6 & 5,0 & & 4 & 6 & 5 & 6 & 5,3 & \\
\hline 2 & 3 & 1 & 2 & 2,0 & & 2 & 2 & 1 & 1 & 1,5 & & 2 & 2 & 1 & 1 & 1,5 & & 2 & 2 & 1 & 1 & 1,5 & \\
\hline 2 & 2 & 1 & 1 & 1,5 & & 2 & 3 & 1 & 1 & 1,8 & & 2 & 2 & 1 & 1 & 1,5 & & 2 & 3 & 1 & 1 & 1,8 & \\
\hline 2 & 2 & 2 & 2 & 1,0 & $0 \%$ & 2 & 2 & 2 & 2 & 1,0 & $0 \%$ & 2 & 2 & 2 & 2 & 1,0 & $0 \%$ & 2 & 2 & 2 & 2 & 1,0 & $0 \%$ \\
\hline 1 & 1 & 1 & 1 & 1,0 & & 1 & 1 & 1 & 1 & 1,0 & & 1 & 1 & 1 & 1 & 1,0 & & 1 & 1 & 1 & 1 & 1,0 & \\
\hline
\end{tabular}

A diretriz traz aconselhamento e/ou ferramentas sobre como as recomendações podem ser colocadas em prática?

Foram consideradas as potenciais implicações quanto aos recursos decorrentes da aplicação das recomendações?

A diretriz apresenta critérios para o seu monitoramento e/ou auditoria?

DOMÍNIO 6. INDEPENDÊNCIA EDITORIA

O parecer do órgão financiador não exerceu influência sobre o conteúdo da diretriz? 
Foram registrados e abordados os conflitos de interesse dos membros da equipe que desenvolveram a diretriz? $\begin{array}{lllll}1 & 1 & 1 & 1 & 1,0\end{array} \mid \begin{array}{lllll}1 & 1 & 1 & 1 & 1,0\end{array}$

$\begin{array}{lllll}1 & 1 & 1 & 1 & \mathbf{1}, 0\end{array}$

$\begin{array}{lllll}1 & 1 & 1 & 1 & 1,0\end{array}$

\begin{tabular}{|c|c|c|c|c|c|c|c|c|c|c|c|c|c|c|c|c|c|c|c|c|c|c|c|c|}
\hline \multirow[t]{2}{*}{ Diretriz Avaliada --> } & \multicolumn{6}{|c|}{$\begin{array}{l}\frac{\text { 13) Leptospirose: }}{\text { Diagnóstico e Manejo }} \\
\underline{\text { Clínico (2014) }}\end{array}$} & \multicolumn{6}{|c|}{$\frac{\begin{array}{l}\text { 14) PCDT Infecções } \\
\text { Sexualmente Transmissíveis }\end{array}}{\underline{(2016)}}$} & \multicolumn{6}{|c|}{$\frac{\text { 15) Manual do tracoma }}{\underline{(2014)}}$} & \multicolumn{6}{|c|}{$\frac{\text { 16) Prevenção e tratamento }}{\frac{\text { dos agravos da violência }}{\underline{\text { sexual (2012) }}}}$} \\
\hline & $\begin{array}{c}\mathrm{J} \\
1\end{array}$ & $\left|\begin{array}{l}J- \\
2\end{array}\right|$ & $\begin{array}{l}\mathrm{J}- \\
\mathbf{3}\end{array}$ & $\begin{array}{l}J- \\
4\end{array}$ & MED & Total & $\begin{array}{c}J- \\
1\end{array}$ & $\left|\begin{array}{l}J- \\
2\end{array}\right|$ & $\left|\begin{array}{l}J- \\
3\end{array}\right|$ & $\begin{array}{l}J- \\
4\end{array}$ & MED & Total & J- & $\left|\begin{array}{l}\text { J- } \\
2\end{array}\right|$ & $\begin{array}{l}\text { J- } \\
3\end{array}$ & $\begin{array}{l}J- \\
4\end{array}$ & MED & Total & J- & $\begin{array}{l}\mathrm{J}- \\
2\end{array} \mid$ & $\begin{array}{c}\mathrm{J}- \\
3\end{array} \mid$ & $\begin{array}{l}J- \\
4\end{array}$ & MED & Total \\
\hline DOMÍNIO 1. ESCOPO E FINALIDADE & 17 & 12 & 17 & 21 & 5,6 & $76 \%$ & 19 & 15 & 20 & 21 & 6,3 & $88 \%$ & 18 & 15 & 15 & 21 & 5,8 & $79 \%$ & 18 & 15 & 15 & 20 & 5,7 & $78 \%$ \\
\hline $\begin{array}{l}\text { O(s) objetivo(s) geral(is) da(s) } \\
\text { encontra(m)-se especificame }\end{array}$ & 4 & 4 & 5 & 7 & 5,0 & & 5 & 6 & 7 & 7 & 6,3 & & 6 & 6 & 7 & 7 & 6,5 & & 6 & 5 & 5 & 7 & 5,8 & \\
\hline $\begin{array}{l}\mathrm{A}(\mathrm{s}) \text { questão(ões) de saúde coberta } \\
\text { encontra(m)-se especificamente de }\end{array}$ & 7 & 5 & 7 & 7 & 6,5 & & 7 & 4 & 7 & 7 & 6,3 & & 7 & 4 & 4 & 7 & 5,5 & & 6 & 4 & 5 & 6 & 5,3 & \\
\hline $\begin{array}{l}\text { A população (pacientes, público, etc.) a quem a } \\
\text { diretriz se destina encontra-se especificamente } \\
\text { descrita? }\end{array}$ & 6 & 3 & 5 & 7 & 5,3 & & 7 & 5 & 6 & 7 & 6,3 & & 5 & 5 & 4 & 7 & 5,3 & & 6 & 6 & 5 & 7 & 6,0 & \\
\hline $\begin{array}{l}\text { DOMÍNIO 2. ENVOLVIMENTO DAS PARTES } \\
\text { INTERESSADAS }\end{array}$ & 9 & 11 & 8 & 9 & 3,1 & $35 \%$ & 15 & 17 & 11 & 11 & 4,5 & $58 \%$ & 7 & 8 & 6 & 6 & 2,3 & $21 \%$ & 8 & 9 & 6 & 6 & 2,4 & $24 \%$ \\
\hline $\begin{array}{l}\text { A equipe de desenvolvimento da diretriz inclui } \\
\text { indivíduos de todos os grupos profissionais } \\
\text { relevantes? }\end{array}$ & 4 & 4 & 2 & 1 & 2,8 & & 4 & 5 & 2 & 1 & 3,0 & & 2 & 2 & 1 & 1 & 1,5 & & 2 & 3 & 1 & 1 & 1,8 & \\
\hline $\begin{array}{l}\text { Procurou-se conhecer as opiniões e preferências } \\
\text { da população-alvo (pacientes, público, etc.)? }\end{array}$ & 1 & 1 & 1 & 1 & 1,0 & & 5 & 5 & 3 & 3 & $4,($ & & 1 & 1 & 1 & 1 & 1,0 & & 1 & 1 & 1 & 1 & 1,0 & \\
\hline $\begin{array}{l}\text { Os usuários-alvo da diretriz estão claramente } \\
\text { definidos? }\end{array}$ & 4 & 6 & 5 & 7 & 5,5 & & 6 & 7 & 6 & 7 & 6,5 & & 4 & 5 & 4 & 4 & 4,3 & & 5 & 5 & 4 & 4 & 4,5 & \\
\hline DOMÍNIO 3. RIGOR DO DESENVOLVIMENTO & 9 & 11 & 8 & 9 & 1,2 & $3 \%$ & 17 & 24 & 12 & 16 & 2,2 & $19 \%$ & 9 & 12 & 8 & 10 & 1,2 & $4 \%$ & 11 & 14 & 11 & 12 & 1,5 & $8 \%$ \\
\hline
\end{tabular}


Foram utilizados métodos sistemáticos para a busca de evidências?

Os critérios para a seleção de evidências estão claramente descritos?

Os pontos fortes e limitações do corpo de evidências estão claramente descritos?

Os métodos para a formulação das

recomendações estão claramente descritos?

Os benefícios, efeitos colaterais e riscos à saúde

foram considerados na formulação das

recomendações?

Existe uma relação explícita entre as

recomendações e as evidências que lhe dão

suporte?

A diretriz foi revisada externamente por experts antes da sua publicação?

Um procedimento para atualização da diretriz está disponível?

\section{DOMÍNIO 4. CLAREZA DA APRESENTAÇÃO}

As recomendações são específicas e sem ambiguidade?

As diferentes opções de abordagem da condição ou problema de saúde estão claramente apresentadas?

As recomendações-chave são facilmente identificadas?

DOMÍNIO 5. APLICABILIDADE

A diretriz descreve os fatores facilitadores e as barreiras para sua aplicação?

\begin{tabular}{|c|c|c|c|c|c|c|c|c|c|c|c|c|c|c|c|c|c|c|c|c|c|c|c|}
\hline 1 & 1 & 1 & 1 & 1,0 & & 2 & 3 & 1 & 1 & 1,8 & & 1 & 1 & 1 & 1 & 1,0 & & 1 & 1 & 1 & 1 & 1,0 & \\
\hline 1 & 1 & 1 & 1 & 1,0 & & 1 & 2 & 1 & 1 & 1,3 & & 1 & 1 & 1 & 1 & 1,0 & & 1 & 1 & 1 & 1 & 1,0 & \\
\hline 1 & 1 & 1 & 1 & 1,0 & & 2 & 3 & 1 & 2 & 2,0 & & 2 & 1 & 1 & 1 & 1,3 & & 2 & 1 & 1 & 1 & 1,3 & \\
\hline 1 & 1 & 1 & 1 & 1,0 & & 1 & 2 & 1 & 1 & 1,3 & & 1 & 1 & 1 & 1 & 1,0 & & 1 & 1 & 1 & 1 & 1,0 & \\
\hline 2 & 2 & 1 & 2 & 1,8 & & 3 & 4 & 2 & 4 & 3,3 & & 1 & 3 & 1 & 3 & 2,0 & & 3 & 5 & 4 & 5 & 4,3 & \\
\hline 1 & 2 & 1 & 1 & 1,3 & & 2 & 3 & 1 & 1 & 1,8 & & 1 & 2 & 1 & 1 & 1,3 & & 1 & 2 & 1 & 1 & 1,3 & \\
\hline 1 & 2 & 1 & 1 & 1,3 & & 2 & 2 & 1 & 3 & 2,0 & & 1 & 2 & 1 & 1 & 1,3 & & 1 & 2 & 1 & 1 & 1,3 & \\
\hline 1 & 1 & 1 & 1 & 1,0 & & 4 & 5 & 4 & 3 & 4,0 & & 1 & 1 & 1 & 1 & 1,0 & & 1 & 1 & 1 & 1 & 1,0 & \\
\hline 16 & 14 & 17 & 19 & 5,5 & $75 \%$ & 16 & 19 & 14 & 20 & 5,8 & $79 \%$ & 15 & 8 & 12 & 18 & 4,4 & $57 \%$ & 16 & 17 & 13 & 15 & 5,1 & $68 \%$ \\
\hline 5 & 5 & 5 & 6 & 5,3 & & 5 & 6 & 4 & 6 & 5,3 & & 4 & 2 & 4 & 6 & 4,0 & & 4 & 5 & 3 & 4 & 4,0 & \\
\hline 6 & 5 & 7 & 7 & 6,3 & & 6 & 7 & 4 & 7 & 6,0 & & 6 & 4 & 3 & 7 & 5,0 & & 6 & 6 & 4 & 5 & 5,3 & \\
\hline 5 & 4 & 5 & 6 & 5,0 & & 5 & 6 & 6 & 7 & 6,0 & & 5 & 2 & 5 & 5 & 4,3 & & 6 & 6 & 6 & 6 & 6,0 & \\
\hline 15 & 11 & 8 & 13 & 2,9 & $32 \%$ & 16 & 18 & 9 & 16 & 3,7 & $45 \%$ & 15 & 14 & 9 & 12 & 3,1 & $35 \%$ & 16 & 15 & 9 & 16 & 3,5 & $42 \%$ \\
\hline 4 & 2 & 1 & 5 & 3,0 & & 6 & 6 & 1 & 5 & 4,5 & & 5 & 3 & 1 & 3 & 3,0 & & 6 & 5 & 1 & 7 & 4,8 & \\
\hline
\end{tabular}


A diretriz traz aconselhamento e/ou ferramentas sobre como as recomendações podem ser colocadas em prática?

Foram consideradas as potenciais implicações quanto aos recursos decorrentes da aplicação das recomendações?

A diretriz apresenta critérios para o seu monitoramento e/ou auditoria?

DOMÍNIO 6. INDEPENDÊNCIA EDITORIAL

O parecer do órgão financiador não exerceu

influência sobre o conteúdo da diretriz?

Foram registrados e abordados os conflitos de

interesse dos membros da equipe que

desenvolveram a diretriz?

\begin{tabular}{|c|c|c|c|c|c|c|c|c|c|c|}
\hline 6 & 5 & 5 & 6 & 5,5 & & 6 & 6 & 6 & 7 & 6,3 \\
\hline 2 & 2 & 1 & 1 & 1,5 & & 2 & 3 & 1 & 3 & 2,3 \\
\hline 3 & 2 & 1 & 1 & 1,8 & & 2 & 3 & 1 & 1 & 1,8 \\
\hline 2 & 2 & 2 & 2 & 1,0 & $0 \%$ & 2 & 2 & 2 & 2 & 1,0 \\
\hline 1 & 1 & 1 & 1 & 1,0 & & 1 & 1 & 1 & 1 & 1,0 \\
\hline 1 & 1 & 1 & 1 & 1,0 & & 1 & 1 & 1 & 1 & 1,0 \\
\hline
\end{tabular}

6

$\begin{array}{lllll}6 & 6 & 6 & 7 & 6,3\end{array}$

$\begin{array}{lllll}2 & 3 & 1 & 1 & 1,8\end{array}$

$\begin{array}{lllll}2 & 3 & 1 & 1 & 1,8\end{array}$

$\begin{array}{lllll}2 & 2 & 1 & 1 & \mathbf{1}, 5\end{array}$

$\begin{array}{lllll}2 & 1 & 1 & 1 & 1,3\end{array}$

$\begin{array}{llllll}2 & 2 & 2 & 2 & 1,0 & 0 \%\end{array}$

$\begin{array}{lllll}1 & 1 & 1 & 1 & \mathbf{1}, 0\end{array}$

$\begin{array}{lllll}1 & 1 & 1 & 1 & 1,0\end{array}$

$\begin{array}{lllll}1 & 1 & 1 & 1 & 1,0\end{array}$ $\begin{array}{llllll}2 & 2 & 2 & 2 & 1,0 & 0 \%\end{array}$

$\begin{array}{lllll}1 & 1 & 1 & 1 & \mathbf{1}, 0\end{array}$

\begin{tabular}{|c|c|c|c|c|c|c|c|c|c|c|c|c|c|c|c|c|c|c|c|c|c|c|c|c|}
\hline \multirow[t]{2}{*}{ Diretriz Avaliada --> } & \multicolumn{6}{|c|}{$\frac{\text { 17) Artrite Reumatóide }}{\underline{(2015)}}$} & \multicolumn{6}{|c|}{$\frac{\text { 18) Hepatite Viral C e }}{\underline{\text { Coinfecções (2015) }}}$} & \multicolumn{6}{|c|}{ 19) Câncer de Mama (2015) } & \multicolumn{6}{|c|}{ 20) Artrite Reativa (2015) } \\
\hline & $\left|\begin{array}{c}\mathrm{J} \\
1\end{array}\right|$ & $\left|\begin{array}{c}\mathrm{J}- \\
2\end{array}\right|$ & $\left|\begin{array}{l}\mathrm{J}- \\
\mathbf{3}\end{array}\right|$ & $\begin{array}{l}J- \\
4\end{array}$ & MED & Total & \begin{tabular}{|c|}
$J-$ \\
1
\end{tabular} & $\begin{array}{l}J- \\
2\end{array}$ & $\left|\begin{array}{l}J- \\
3\end{array}\right|$ & $\begin{array}{l}J- \\
4\end{array}$ & MED & Total & $\left|\begin{array}{c}J- \\
1\end{array}\right|$ & J- & $\begin{array}{l}\mathrm{J}- \\
3\end{array}$ & $\begin{array}{l}J- \\
4\end{array}$ & MED & Total & \begin{tabular}{|c|}
$J-$ \\
1
\end{tabular} & $\begin{array}{l}\mathrm{J}- \\
2\end{array}$ & J- & $\begin{array}{l}J- \\
4\end{array}$ & MED & Total \\
\hline DOMÍNIO 1. ESCOPO E FINALIDADE & 20 & 20 & 20 & 20 & 6,7 & $94 \%$ & 20 & 20 & 21 & 21 & 6,8 & $97 \%$ & 20 & 18 & 18 & 20 & 6,3 & $89 \%$ & 19 & 18 & 15 & 20 & 6,0 & $83 \%$ \\
\hline $\begin{array}{l}\text { O(s) objetivo(s) geral(is) da(s) diretriz(es) } \\
\text { encontra(m)-se especificamente descrito(s)? }\end{array}$ & 6 & 6 & 6 & 7 & 6,3 & & 6 & 6 & 7 & 7 & 6,5 & & 6 & 5 & 6 & 7 & 6,0 & & 5 & 6 & 6 & 7 & 6,0 & \\
\hline $\begin{array}{l}\text { A(s) questão(ões) de saúde coberta(s) pela diretriz } \\
\text { encontra(m)-se especificamente descrita(s)? }\end{array}$ & 7 & 7 & 7 & 6 & 6,8 & & 7 & 7 & 7 & 7 & 7,0 & & 7 & 7 & 7 & 6 & 6,8 & & 7 & 7 & 5 & 6 & 6,3 & \\
\hline $\begin{array}{l}\text { A população (pacientes, público, etc.) a quem a } \\
\text { diretriz se destina encontra-se especificamente } \\
\text { descrita? }\end{array}$ & 7 & 7 & 7 & 7 & 7,0 & & 7 & 7 & 7 & 7 & 7,0 & & 7 & 6 & 5 & 7 & 6,3 & & 7 & 5 & 4 & 7 & 5,8 & \\
\hline
\end{tabular}




\begin{tabular}{|c|c|c|c|c|c|c|c|c|c|c|c|c|c|c|c|c|c|c|c|c|c|c|c|c|}
\hline $\begin{array}{l}\text { DOMÍNIO 2. ENVOLVIMENTO DAS PARTES } \\
\text { INTERESSADAS }\end{array}$ & 14 & 11 & 8 & 8 & 3,4 & $40 \%$ & 14 & 11 & 8 & 8 & 3,4 & $40 \%$ & 13 & 12 & 7 & 8 & 3,3 & $39 \%$ & 12 & 14 & 8 & 8 & 3,5 & $42 \%$ \\
\hline $\begin{array}{l}\text { A equipe de desenvolvimento da diretriz inclui } \\
\text { indivíduos de todos os grupos profissionais } \\
\text { relevantes? }\end{array}$ & 5 & 3 & 1 & 1 & 2,5 & & 5 & 3 & 1 & 1 & 2,5 & & 4 & 3 & 1 & 1 & 2,3 & & 4 & 4 & 1 & 1 & 2,5 & \\
\hline $\begin{array}{l}\text { Procurou-se conhecer as opiniões e preferências } \\
\text { da população-alvo (pacientes, público, etc.)? }\end{array}$ & 5 & 3 & 3 & 3 & 3,5 & & 5 & 3 & 3 & 3 & 3,5 & & 5 & 4 & 3 & 3 & 3,8 & & 5 & 5 & 3 & 3 & 4,0 & \\
\hline $\begin{array}{l}\text { Os usuários-alvo da diretriz estão claramente } \\
\text { definidos? }\end{array}$ & 4 & 5 & 4 & 4 & 4,3 & & 4 & 5 & 4 & 4 & 4,3 & & 4 & 5 & 3 & 4 & 4,0 & & 3 & 5 & 4 & 4 & 4,0 & \\
\hline DOMÍNIO 3. RIGOR DO DESENVOLVIMENTO & 41 & 38 & 30 & 32 & 4,4 & $57 \%$ & 41 & 26 & 34 & 33 & 4,2 & $53 \%$ & 37 & 38 & 29 & 29 & 4,2 & $53 \%$ & 37 & 36 & 29 & 30 & 4,1 & $52 \%$ \\
\hline $\begin{array}{l}\text { Foram utilizados métodos sistemáticos para a } \\
\text { busca de evidências? }\end{array}$ & 7 & 7 & 7 & 6 & 6,8 & & 7 & 4 & 7 & 4 & 5,5 & & 7 & 7 & 7 & 6 & 6,8 & & 7 & 7 & 7 & 6 & 6,8 & \\
\hline $\begin{array}{l}\text { Os critérios para a seleção de evidências estão } \\
\text { claramente descritos? }\end{array}$ & 7 & 6 & 5 & 6 & 6,0 & & 7 & 3 & 4 & 5 & 4,8 & & 4 & 5 & 5 & 5 & 4,8 & & 5 & 5 & 4 & 5 & 4,8 & \\
\hline $\begin{array}{l}\text { Os pontos fortes e limitações do corpo de } \\
\text { evidências estão claramente descritos? }\end{array}$ & 5 & 3 & 1 & 2 & 2,8 & & 5 & 2 & 3 & 3 & 3,3 & & 4 & 3 & 3 & 4 & 3,5 & & 4 & 3 & 3 & 3 & 3,3 & \\
\hline $\begin{array}{l}\text { Os métodos para a formulação das } \\
\text { recomendações estão claramente descritos? }\end{array}$ & 2 & 2 & 1 & 1 & 1,5 & & 2 & 2 & 1 & 1 & 1,5 & & 2 & 3 & 1 & 1 & 1,8 & & 2 & 3 & 1 & 1 & 1,8 & \\
\hline $\begin{array}{l}\text { Os benefícios, efeitos colaterais e riscos à saúde } \\
\text { foram considerados na formulação das } \\
\text { recomendações? }\end{array}$ & 6 & 6 & 6 & 7 & 6,3 & & 6 & 5 & 6 & 7 & 6,0 & & 6 & 5 & 4 & 4 & 4,8 & & 5 & 5 & 4 & 5 & 4,8 & \\
\hline $\begin{array}{l}\text { Existe uma relação explícita entre as } \\
\text { recomendações e as evidências que lhe dão } \\
\text { suporte? }\end{array}$ & 6 & 5 & 4 & 4 & 4,8 & & 6 & 4 & 7 & 7 & 6,0 & & 6 & 5 & 3 & 3 & 4,3 & & 6 & 4 & 4 & 4 & 4,5 & \\
\hline $\begin{array}{l}\text { A diretriz foi revisada externamente por experts } \\
\text { antes da sua publicação? }\end{array}$ & 3 & 6 & 3 & 3 & 3,8 & & 3 & 3 & 3 & 3 & 3,0 & & 3 & 5 & 3 & 3 & 3,5 & & 3 & 4 & 3 & 3 & 3,3 & \\
\hline $\begin{array}{l}\text { Um procedimento para atualização da diretriz está } \\
\text { disponível? }\end{array}$ & 5 & 3 & 3 & 3 & 3,5 & & 5 & 3 & 3 & 3 & 3,5 & & 5 & 5 & 3 & 3 & 4,0 & & 5 & 5 & 3 & 3 & 4,0 & \\
\hline DOMÍNIO 4. CLAREZA DA APRESENTAÇÃO & 18 & 19 & 21 & 21 & 6,6 & $93 \%$ & 18 & 17 & 21 & 21 & 6,4 & $90 \%$ & 16 & 17 & 16 & 17 & 5,5 & $75 \%$ & 15 & 16 & 11 & 17 & 4,9 & $65 \%$ \\
\hline
\end{tabular}




\begin{tabular}{|c|c|c|c|c|c|c|c|c|c|c|c|c|c|c|c|c|c|c|c|c|c|c|c|c|}
\hline $\begin{array}{l}\text { As recomendações são específicas e sem } \\
\text { ambiguidade? }\end{array}$ & 6 & 6 & 7 & 7 & 6,5 & & 6 & 5 & 7 & 7 & 6,3 & & 6 & 6 & 6 & 7 & 6,3 & & 6 & 6 & 5 & 6 & 5,8 & \\
\hline $\begin{array}{l}\text { As diferentes opções de abordagem da condição } \\
\text { ou problema de saúde estão claramente } \\
\text { apresentadas? }\end{array}$ & 6 & 7 & 7 & 7 & 6,8 & & 6 & 6 & 7 & 7 & 6,5 & & 7 & 6 & 6 & 6 & 6,3 & & 4 & 5 & 3 & 6 & 4,5 & \\
\hline $\begin{array}{l}\text { As recomendações-chave são facilmente } \\
\text { identificadas? }\end{array}$ & 6 & 6 & 7 & 7 & 6,5 & & 6 & 6 & 7 & 7 & 6,5 & & 3 & 5 & 4 & 4 & 4,0 & & 5 & 5 & 3 & 5 & 4,5 & \\
\hline DOMÍNIO 5. APLICABILIDADE & 12 & 15 & 6 & 12 & 2,8 & $30 \%$ & 13 & 13 & 6 & 8 & 2,5 & $25 \%$ & 13 & 15 & 6 & 14 & 3,0 & $33 \%$ & 12 & 13 & 6 & 6 & 2,3 & $22 \%$ \\
\hline $\begin{array}{l}\text { A diretriz descreve os fatores facilitadores e as } \\
\text { barreiras para sua aplicação? }\end{array}$ & 4 & 4 & 3 & 4 & 3,8 & & 4 & 4 & 3 & 4 & 3,8 & & 4 & 5 & 3 & 4 & 4,0 & & 4 & 4 & 3 & 3 & 3,5 & \\
\hline $\begin{array}{l}\text { A diretriz traz aconselhamento e/ou ferramentas } \\
\text { sobre como as recomendações podem ser } \\
\text { colocadas em prática? }\end{array}$ & 3 & 4 & 1 & 4 & 3,0 & & 4 & 4 & 1 & 2 & 2,8 & & 3 & 3 & 1 & 2 & 2,3 & & 3 & 3 & 1 & 1 & 2,0 & \\
\hline $\begin{array}{l}\text { Foram consideradas as potenciais implicações } \\
\text { quanto aos recursos decorrentes da aplicação das } \\
\text { recomendações? }\end{array}$ & 2 & 3 & 1 & 3 & 2,3 & & 2 & 2 & 1 & 1 & 1,5 & & 2 & 3 & 1 & 3 & 2,3 & & 2 & 3 & 1 & 1 & 1,8 & \\
\hline $\begin{array}{l}\text { A diretriz apresenta critérios para o seu } \\
\text { monitoramento e/ou auditoria? }\end{array}$ & 3 & 4 & 1 & 1 & 2,3 & & 3 & 3 & 1 & 1 & 2,0 & & 4 & 4 & 1 & 5 & 3,5 & & 3 & 3 & 1 & 1 & 2,0 & \\
\hline DOMÍNIO 6. INDEPENDÊNCIA EDITORIAL & 9 & 6 & 7 & 8 & 3,8 & $46 \%$ & 6 & 6 & 7 & 8 & 3,4 & $40 \%$ & 9 & 5 & 5 & 2 & 2,6 & $27 \%$ & 9 & 6 & 7 & 8 & 3,8 & $46 \%$ \\
\hline $\begin{array}{l}\text { O parecer do órgão financiador não exerceu } \\
\text { influência sobre o conteúdo da diretriz? }\end{array}$ & 4 & 2 & 3 & 3 & 3,0 & & 1 & 2 & 3 & 3 & 2,3 & & 4 & 2 & 1 & 1 & 2,0 & & 4 & 2 & 3 & 3 & 3,0 & \\
\hline $\begin{array}{l}\text { Foram registrados e abordados os conflitos de } \\
\text { interesse dos membros da equipe que } \\
\text { desenvolveram a diretriz? }\end{array}$ & 5 & 4 & 4 & 5 & 4,5 & & 5 & 4 & 4 & 5 & 4,5 & & 5 & 3 & 4 & 1 & 3,3 & & 5 & 4 & 4 & 5 & 4,5 & \\
\hline
\end{tabular}




\begin{tabular}{|c|c|c|c|c|c|c|c|c|c|c|c|c|c|c|c|c|c|c|c|c|c|c|c|c|}
\hline \multirow[t]{2}{*}{ Diretriz Avaliada --> } & \multicolumn{6}{|c|}{$\frac{\text { 21) Câncer de Cabeça e }}{\text { Pescoço (2015) }}$} & \multicolumn{6}{|c|}{ 22) Doença Celíaca (2015) } & \multicolumn{6}{|c|}{$\frac{\text { 23) Esclerose Lateral }}{\text { Amiotrófica (2015) }}$} & \multicolumn{6}{|c|}{$\frac{\text { 24) Esclerose Múltipla }}{\underline{(2015)}}$} \\
\hline & $\left|\begin{array}{c}\mathrm{J} \\
1\end{array}\right|$ & $\left|\begin{array}{l}\mathbf{J}- \\
2\end{array}\right|$ & $\left|\begin{array}{c}\mathrm{J}- \\
\mathbf{3}\end{array}\right|$ & $\begin{array}{l}J- \\
4\end{array}$ & MED & Total & $\begin{array}{l} \\
1\end{array}$ & $\mid \begin{array}{l}J- \\
2\end{array}$ & $\begin{array}{l}\mathbf{J}- \\
3\end{array}$ & \begin{tabular}{|l|}
$J-$ \\
4
\end{tabular} & MED & Total & $\begin{array}{c}\mathrm{J}- \\
1\end{array}$ & $\begin{array}{l}\mathrm{J}- \\
2\end{array}$ & $\begin{array}{l}\mathrm{J}- \\
3\end{array} \mid$ & $\begin{array}{l}J- \\
4\end{array}$ & MED & Total & $\begin{array}{l}J- \\
1\end{array}$ & $\begin{array}{l}J- \\
2\end{array}$ & $\begin{array}{l}\mathrm{J}- \\
3\end{array}$ & $\begin{array}{l}J- \\
4\end{array}$ & MED & Total \\
\hline DOMÍNIO 1. ESCOPO E FINALIDADE & 20 & 15 & 15 & 20 & 5,8 & $81 \%$ & 20 & 20 & 14 & 20 & 6,2 & $86 \%$ & 20 & 20 & 14 & 20 & 6,2 & $86 \%$ & 20 & 20 & 15 & 20 & 6,3 & $88 \%$ \\
\hline $\begin{array}{l}\text { O(s) objetivo(s) geral(is) da(s) diretriz(es) } \\
\text { encontra(m)-se especificamente descrito(s)? }\end{array}$ & 6 & 5 & 6 & 7 & 6,0 & & 6 & 6 & 6 & 7 & 6,3 & & 6 & 6 & 6 & 7 & 6,3 & & 6 & 6 & 6 & 7 & 6,3 & \\
\hline $\begin{array}{l}\text { A(s) questão(ões) de saúde coberta(s) pela diretriz } \\
\text { encontra }(m) \text {-se especificamente descrita(s)? }\end{array}$ & 7 & 6 & 5 & 6 & 6,0 & & 7 & 7 & 5 & 6 & 6,3 & & 7 & 7 & 5 & 6 & 6,3 & & 7 & 7 & 5 & 6 & 6,3 & \\
\hline $\begin{array}{l}\text { A população (pacientes, público, etc.) a quem a } \\
\text { diretriz se destina encontra-se especificamente } \\
\text { descrita? }\end{array}$ & 7 & 4 & 4 & 7 & 5,5 & & 7 & 7 & 3 & 7 & 6,0 & & 7 & 7 & 3 & 7 & 6,0 & & 7 & 7 & 4 & 7 & 6,3 & \\
\hline $\begin{array}{l}\text { DOMÍNIO 2. ENVOLVIMENTO DAS PARTES } \\
\text { INTERESSADAS }\end{array}$ & 14 & 13 & 8 & 8 & 3,6 & $43 \%$ & 14 & 14 & 8 & 8 & 3,7 & $44 \%$ & 14 & 14 & 8 & 8 & 3,7 & $44 \%$ & 14 & 14 & 8 & 8 & 3,7 & $44 \%$ \\
\hline $\begin{array}{l}\text { A equipe de desenvolvimento da diretriz inclui } \\
\text { indivíduos de todos os grupos profissionais } \\
\text { relevantes? }\end{array}$ & 5 & 4 & 1 & 1 & 2,8 & & 5 & 4 & 1 & 1 & 2,8 & & 5 & 4 & 1 & 1 & 2,8 & & 5 & 4 & 1 & 1 & 2,8 & \\
\hline $\begin{array}{l}\text { Procurou-se conhecer as opiniões e preferências } \\
\text { da população-alvo (pacientes, público, etc.)? }\end{array}$ & 5 & 5 & 3 & 3 & 4,0 & & 5 & 5 & 3 & 3 & 4,0 & & 5 & 5 & 3 & 3 & 4,0 & & 5 & 5 & 3 & 3 & 4,0 & \\
\hline $\begin{array}{l}\text { Os usuários-alvo da diretriz estão claramente } \\
\text { definidos? }\end{array}$ & 4 & 4 & 4 & 4 & 4,0 & & 4 & 5 & 4 & 4 & 4,3 & & 4 & 5 & 4 & 4 & 4,3 & & 4 & 5 & 4 & 4 & 4,3 & \\
\hline DOMÍNIO 3. RIGOR DO DESENVOLVIMENTO & 36 & 33 & 23 & 22 & 3,6 & $43 \%$ & 38 & 34 & 25 & 26 & 3,8 & $47 \%$ & 38 & 34 & 23 & 25 & 3,8 & $46 \%$ & 38 & 34 & 20 & 26 & 3,7 & $45 \%$ \\
\hline $\begin{array}{l}\text { Foram utilizados métodos sistemáticos para a } \\
\text { busca de evidências? }\end{array}$ & 7 & 6 & 7 & 6 & 6,5 & & 7 & 7 & 7 & 6 & 6,8 & & 7 & 7 & 7 & 6 & 6,8 & & 7 & 7 & 5 & 5 & 6,0 & \\
\hline $\begin{array}{l}\text { Os critérios para a seleção de evidências estão } \\
\text { claramente descritos? }\end{array}$ & 4 & 5 & 1 & 2 & 3,0 & & 5 & 5 & 3 & 5 & 4,5 & & 5 & 5 & 3 & 4 & 4,3 & & 5 & 5 & 2 & 5 & 4,3 & \\
\hline $\begin{array}{l}\text { Os pontos fortes e limitações do corpo de } \\
\text { evidências estão claramente descritos? }\end{array}$ & 4 & 3 & 1 & 2 & 2,5 & & 5 & 3 & 1 & 1 & 2,5 & & 5 & 3 & 1 & 1 & 2,5 & & 5 & 3 & 1 & 1 & 2,5 & \\
\hline
\end{tabular}


Os métodos para a formulação das

recomendações estão claramente descritos?

Os benefícios, efeitos colaterais e riscos à saúde

foram considerados na formulação das

recomendações?

Existe uma relação explícita entre as

recomendações e as evidências que lhe dão

suporte?

A diretriz foi revisada externamente por experts

antes da sua publicação?

Um procedimento para atualização da diretriz está disponível?

$\begin{array}{lllll}5 & 3 & 3 & 1 & 3,0\end{array}$

DOMÍNIO 4. CLAREZA DA APRESENTAÇÃO

$\begin{array}{llllll}14 & 14 & 12 & 16 & \mathbf{4}, 7 & \mathbf{6 1}\end{array}$

As recomendações são específicas e sem

ambiguidade?

$\begin{array}{lllll}6 & 5 & 6 & 6 & 5,8\end{array}$

As diferentes opções de abordagem da condição

ou problema de saúde estão claramente

$\begin{array}{lllll}5 & 5 & 3 & 6 & 4,8\end{array}$

apresentadas?

As recomendações-chave são facilmente identificadas?

$\begin{array}{lllll}3 & 4 & 3 & 4 & 3,5\end{array}$

DOMÍNIO 5. APLICABILIDADE

$\begin{array}{llllll}13 & 17 & 6 & 12 & 3,0 & 33 \%\end{array}$

A diretriz descreve os fatores facilitadores e as barreiras para sua aplicação?

$\begin{array}{lllll}4 & 5 & 3 & 4 & 4,0\end{array}$

A diretriz traz aconselhamento e/ou ferramentas

sobre como as recomendações podem ser

$\begin{array}{lllll}3 & 3 & 1 & 2 & 2,3\end{array}$

colocadas em prática?

Foram consideradas as potenciais implicações

quanto aos recursos decorrentes da aplicação das recomendações?

\begin{tabular}{|c|c|c|c|c|c|c|c|c|c|c|c|c|c|c|c|c|c|}
\hline 2 & 3 & 2 & 1 & 2,0 & & 2 & 3 & 1 & 1 & 1,8 & & 2 & 3 & 1 & 1 & 1,8 & \\
\hline 5 & 5 & 3 & 3 & 4,0 & & 5 & 5 & 4 & 4 & 4,5 & & 5 & 5 & 4 & 5 & 4,8 & \\
\hline 6 & 4 & 3 & 4 & 4,3 & & 6 & 4 & 3 & 3 & 4,0 & & 6 & 4 & 3 & 3 & 4,0 & \\
\hline 3 & 4 & 3 & 3 & 3,3 & & 3 & 4 & 1 & 3 & 2,8 & & 3 & 4 & 1 & 3 & 2,8 & \\
\hline 5 & 3 & 3 & 3 & 3,5 & & 5 & 3 & 3 & 3 & 3,5 & & 5 & 3 & 3 & 3 & 3,5 & \\
\hline 6 & 13 & 11 & 14 & 4,5 & $58 \%$ & 17 & 17 & 15 & 17 & 5,5 & $75 \%$ & 17 & 17 & 15 & 18 & 5,6 & $76 \%$ \\
\hline 6 & 5 & 5 & 6 & 5,5 & & 6 & 6 & 6 & 6 & 6,0 & & 6 & 6 & 6 & 6 & 6,0 & \\
\hline 5 & 4 & 3 & 3 & 3,8 & & 6 & 6 & 6 & 6 & 6,0 & & 6 & 6 & 6 & 7 & 6,3 & \\
\hline 5 & 4 & 3 & 5 & 4,3 & & 5 & 5 & 3 & 5 & 4,5 & & 5 & 5 & 3 & 5 & 4,5 & \\
\hline 3 & 14 & 5 & 9 & 2,6 & $26 \%$ & 12 & 14 & 6 & 6 & 2,4 & $23 \%$ & 12 & 14 & 6 & 9 & 2,6 & $26 \%$ \\
\hline 4 & 5 & 2 & 2 & 3,3 & & 4 & 5 & 3 & 3 & 3,8 & & 4 & 4 & 3 & 4 & 3,8 & \\
\hline 3 & 3 & 1 & 1 & 2,0 & & 3 & 3 & 1 & 1 & 2,0 & & 3 & 4 & 1 & 3 & 2,8 & \\
\hline & 3 & 1 & 1 & 1,8 & & 2 & 3 & 1 & 1 & 1,8 & & 2 & 3 & 1 & 1 & 1,8 & \\
\hline
\end{tabular}


A diretriz apresenta critérios para o seu monitoramento e/ou auditoria?

\begin{tabular}{|c|c|c|c|c|c|c|c|c|c|c|c|c|c|c|c|c|c|c|c|c|c|c|c|}
\hline 4 & 3 & 1 & 5 & 3,3 & & 4 & 3 & 1 & 5 & 3,3 & & 3 & 3 & 1 & 1 & 2,0 & & 3 & 3 & 1 & 1 & 2,0 & \\
\hline 9 & 5 & 5 & 2 & 2,6 & $27 \%$ & 9 & 6 & 7 & 8 & 3,8 & $46 \%$ & 9 & 6 & 7 & 8 & 3,8 & $46 \%$ & 9 & 6 & 7 & 8 & 3,8 & $46 \%$ \\
\hline 4 & 2 & 1 & 1 & 2,0 & & 4 & 2 & 3 & 3 & 3,0 & & 4 & 2 & 3 & 3 & 3,0 & & 4 & 2 & 3 & 3 & 3,0 & \\
\hline 5 & 3 & 4 & 1 & 3,3 & & 5 & 4 & 4 & 5 & 4,5 & & 5 & 4 & 4 & 5 & 4,5 & & 5 & 4 & 4 & 5 & 4,5 & \\
\hline
\end{tabular}

\begin{tabular}{|c|c|c|c|c|c|c|c|c|c|c|c|c|c|c|c|c|c|c|c|c|c|c|c|c|}
\hline \multirow[t]{2}{*}{ Diretriz Avaliada --> } & \multicolumn{6}{|c|}{$\frac{25)}{\text { actine }}$} & \multicolumn{6}{|c|}{$\frac{\text { 26) Hipotireoidismo }}{\underline{\text { Congênito (2015) }}}$} & \multicolumn{6}{|c|}{$\frac{\text { 27) Ictioses Hereditárias }}{\underline{(2015)}}$} & \multicolumn{6}{|c|}{$\frac{\text { 28) Insuficiência Adrenal }}{\underline{\text { Primária (2015) }}}$} \\
\hline & $\begin{array}{l}J- \\
1\end{array}$ & \begin{tabular}{|l|}
$\mathrm{J}-$ \\
2
\end{tabular} & J- & $\begin{array}{l}J- \\
4\end{array}$ & MED & Total & $\left|\begin{array}{c}J- \\
1\end{array}\right|$ & $\begin{array}{l}J- \\
2\end{array}$ & \begin{tabular}{|l|} 
\\
3
\end{tabular} & \begin{tabular}{|l|}
$J$ \\
4
\end{tabular} & MED & Total & $\begin{array}{l}\mathrm{J}- \\
1\end{array}$ & $\left|\begin{array}{l}J \\
2\end{array}\right|$ & \begin{tabular}{|l|}
$J-$ \\
3
\end{tabular} & $\begin{array}{l}J- \\
4\end{array}$ & MED & Total & $\begin{array}{l}\mathrm{J}- \\
1\end{array}$ & $\begin{array}{l}J- \\
2\end{array}$ & $\begin{array}{l}\text { J- } \\
3\end{array}$ & \begin{tabular}{|l|}
$J-$ \\
4
\end{tabular} & MED & Total \\
\hline DOMÍNIO 1. ESCOPO E FINALIDADE & 20 & 20 & 13 & 20 & 6,1 & $85 \%$ & 20 & 20 & 13 & 20 & 6,1 & $85 \%$ & 20 & 20 & 13 & 20 & 6,1 & $85 \%$ & 20 & 19 & 13 & 20 & 6,0 & $83 \%$ \\
\hline $\begin{array}{l}\text { O(s) objetivo(s) geral(is) da(s) diretriz(es) } \\
\text { encontra(m)-se especificamente descrito(s)? }\end{array}$ & 6 & 6 & 6 & 7 & 6,3 & & 6 & 6 & 6 & 7 & 6,3 & & 6 & 6 & 6 & 7 & 6,3 & & 6 & 6 & 6 & 7 & 6,3 & \\
\hline $\begin{array}{l}\mathrm{A}(\mathrm{s}) \text { questão(ões) de saúde coberta(s) pela diretriz } \\
\text { encontra(m)-se especificamente descrita(s)? }\end{array}$ & 7 & 7 & 4 & 6 & 6,0 & & 7 & 7 & 4 & 6 & 6,0 & & 7 & 7 & 4 & 6 & 6,0 & & 7 & 6 & 4 & 6 & 5,8 & \\
\hline $\begin{array}{l}\text { A população (pacientes, público, etc.) a quem a } \\
\text { diretriz se destina encontra-se especificamente } \\
\text { descrita? }\end{array}$ & 7 & 7 & 3 & 7 & 6,0 & & 7 & 7 & 3 & 7 & 6,0 & & 7 & 7 & 3 & 7 & 6,0 & & 7 & 7 & 3 & 7 & 6,0 & \\
\hline $\begin{array}{l}\text { DOMÍNIO 2. ENVOLVIMENTO DAS PARTES } \\
\text { INTERESSADAS }\end{array}$ & 14 & 14 & 8 & 8 & 3,7 & $44 \%$ & 14 & 14 & 8 & 8 & 3,7 & $44 \%$ & 14 & 14 & 8 & 8 & 3,7 & $44 \%$ & 14 & 14 & 6 & 8 & 3,5 & $42 \%$ \\
\hline $\begin{array}{l}\text { A equipe de desenvolvimento da diretriz inclui } \\
\text { indivíduos de todos os grupos profissionais } \\
\text { relevantes? }\end{array}$ & 5 & 4 & 1 & 1 & 2,8 & & 5 & 4 & 1 & 1 & 2,8 & & 5 & 4 & 1 & 1 & 2,8 & & 5 & 4 & 1 & 1 & 2,8 & \\
\hline
\end{tabular}


Procurou-se conhecer as opiniões e preferências da população-alvo (pacientes, público, etc.)?

Os usuários-alvo da diretriz estão claramente definidos?

DOMÍNIO 3. RIGOR DO DESENVOLVIMENTO

Foram utilizados métodos sistemáticos para a busca de evidências?

Os critérios para a seleção de evidências estão claramente descritos?

Os pontos fortes e limitações do corpo de evidências estão claramente descritos?

Os métodos para a formulação das recomendações estão claramente descritos?

Os benefícios, efeitos colaterais e riscos à saúde foram considerados na formulação das

recomendações?

Existe uma relação explícita entre as

recomendações e as evidências que lhe dão suporte?

A diretriz foi revisada externamente por experts antes da sua publicação?

$\begin{array}{lllll}5 & 5 & 3 & 3 & 4,0\end{array}$ $49 \%$ $\begin{array}{lllll}7 & 7 & 7 & 6 & 6,8\end{array}$ $\begin{array}{lllll}5 & 5 & 3 & 5 & 4,5\end{array}$ $\begin{array}{lllll}5 & 3 & 1 & 1 & \mathbf{2}, 5\end{array}$

$\begin{array}{lllll}2 & 3 & 1 & 1 & 1,8\end{array}$ $\begin{array}{lllll}6 & 6 & 6 & 6 & 6,0\end{array}$

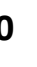
$\begin{array}{lllll}6 & 4 & 3 & 3 & 4,0\end{array}$ Um procedimento para atualização da diretriz está disponível?

DOMÍNIO 4. CLAREZA DA APRESENTAÇÃO As recomendações são específicas e sem ambiguidade?

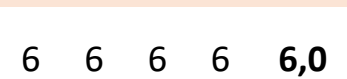
$74 \%$

As diferentes opções de abordagem da condição ou problema de saúde estão claramente

$\begin{array}{lllll}6 & 6 & 5 & 6 & 5,8\end{array}$ apresentadas?

\begin{tabular}{|c|c|c|c|c|c|c|c|c|c|c|c|c|c|c|c|c|c|}
\hline 5 & 5 & 3 & 3 & 4,0 & & 5 & 5 & 3 & 3 & 4,0 & & 5 & 5 & 3 & 3 & 4,0 & \\
\hline 4 & 5 & 4 & 4 & 4,3 & & 4 & 5 & 4 & 4 & 4,3 & & 4 & 5 & 2 & 4 & 3,8 & \\
\hline 37 & 34 & 22 & 24 & 3,7 & $44 \%$ & 38 & 35 & 23 & 30 & 3,9 & $49 \%$ & 37 & 34 & 22 & 27 & 3,8 & $46 \%$ \\
\hline 7 & 7 & 7 & 6 & 6,8 & & 7 & 7 & 7 & 6 & 6,8 & & 7 & 7 & 7 & 6 & 6,8 & \\
\hline 5 & 5 & 3 & 5 & 4,5 & & 5 & 5 & 3 & 3 & 4,0 & & 5 & 5 & 2 & 3 & 3,8 & \\
\hline 4 & 3 & 1 & 1 & 2,3 & & 4 & 3 & 1 & 5 & 3,3 & & 4 & 3 & 1 & 4 & 3,0 & \\
\hline 2 & 3 & 1 & 1 & 1,8 & & 2 & 3 & 1 & 1 & 1,8 & & 2 & 3 & 1 & 1 & 1,8 & \\
\hline 5 & 5 & 3 & 2 & 3,8 & & 6 & 6 & 4 & 6 & 5,5 & & 5 & 5 & 4 & 4 & 4,5 & \\
\hline 5 & 4 & 3 & 3 & 4,0 & & 6 & 4 & 3 & 3 & 4,0 & & 6 & 4 & 3 & 3 & 4,0 & \\
\hline 3 & 4 & 1 & 3 & 2,8 & & 3 & 4 & 1 & 3 & 2,8 & & 3 & 4 & 1 & 3 & 2,8 & \\
\hline & 3 & 3 & 3 & 3,5 & & 5 & 3 & 3 & 3 & 3,5 & & 5 & 3 & 3 & 3 & 3,5 & \\
\hline 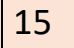 & 15 & 13 & 14 & 4,8 & $63 \%$ & 15 & 16 & 12 & 14 & 4,8 & $63 \%$ & 15 & 15 & 13 & 15 & 4,8 & $64 \%$ \\
\hline 5 & 5 & 5 & 6 & 5,3 & & 5 & 5 & 5 & 5 & 5,0 & & 5 & 5 & 5 & 5 & 5,0 & \\
\hline & 5 & 5 & 3 & 4,5 & & 5 & 6 & 4 & 5 & 5,0 & & 5 & 5 & 4 & 5 & 4,8 & \\
\hline
\end{tabular}




\begin{tabular}{|c|c|c|c|c|c|c|c|c|c|c|c|c|c|c|c|c|c|c|c|c|c|c|c|c|}
\hline $\begin{array}{l}\text { As recomendações-chave são facilmente } \\
\text { identificadas? }\end{array}$ & 5 & 5 & 3 & 5 & 4,5 & & 5 & 5 & 3 & 5 & 4,5 & & 5 & 5 & 3 & 4 & 4,3 & & 5 & 5 & 4 & 5 & 4,8 & \\
\hline DOMÍNIO 5. APLICABILIDADE & 12 & 13 & 6 & 6 & 2,3 & $22 \%$ & 12 & 13 & 4 & 5 & 2,1 & $19 \%$ & 12 & 15 & 6 & 6 & 2,4 & $24 \%$ & 12 & 14 & 6 & 6 & 2,4 & $23 \%$ \\
\hline $\begin{array}{l}\text { A diretriz descreve os fatores facilitadores e as } \\
\text { barreiras para sua aplicação? }\end{array}$ & 4 & 4 & 3 & 3 & 3,5 & & 4 & 4 & 1 & 2 & 2,8 & & 4 & 5 & 3 & 3 & 3,8 & & 4 & 5 & 3 & 3 & 3,8 & \\
\hline $\begin{array}{l}\text { A diretriz traz aconselhamento e/ou ferramentas } \\
\text { sobre como as recomendações podem ser } \\
\text { colocadas em prática? }\end{array}$ & 3 & 3 & 1 & 1 & 2,0 & & 3 & 3 & 1 & 1 & 2,0 & & 3 & 4 & 1 & 1 & 2,3 & & 3 & 3 & 1 & 1 & 2,0 & \\
\hline $\begin{array}{l}\text { Foram consideradas as potenciais implicações } \\
\text { quanto aos recursos decorrentes da aplicação das } \\
\text { recomendações? }\end{array}$ & 2 & 3 & 1 & 1 & 1,8 & & 2 & 3 & 1 & 1 & 1,8 & & 2 & 3 & 1 & 1 & 1,8 & & 2 & 3 & 1 & 1 & 1,8 & \\
\hline $\begin{array}{l}\text { A diretriz apresenta critérios para o seu } \\
\text { monitoramento e/ou auditoria? }\end{array}$ & 3 & 3 & 1 & 1 & 2,0 & & 3 & 3 & 1 & 1 & 2,0 & & 3 & 3 & 1 & 1 & 2,0 & & 3 & 3 & 1 & 1 & 2,0 & \\
\hline DOMÍNIO 6. INDEPENDÊNCIA EDITORIAL & 9 & 6 & 7 & 8 & 3,8 & $46 \%$ & 9 & 6 & 7 & 8 & 3,8 & $46 \%$ & 9 & 6 & 7 & 8 & 3,8 & $46 \%$ & 9 & 6 & 7 & 8 & 3,8 & $46 \%$ \\
\hline $\begin{array}{l}\text { O parecer do órgão financiador não exerceu } \\
\text { influência sobre o conteúdo da diretriz? }\end{array}$ & 4 & 2 & 3 & 3 & 3,0 & & 4 & 2 & 3 & 3 & 3,0 & & 4 & 2 & 3 & 3 & 3,0 & & 4 & 2 & 3 & 3 & 3,0 & \\
\hline $\begin{array}{l}\text { Foram registrados e abordados os conflitos de } \\
\text { interesse dos membros da equipe que } \\
\text { desenvolveram a diretriz? }\end{array}$ & 5 & 4 & 4 & 5 & 4,5 & & 5 & 4 & 4 & 5 & 4,5 & & 5 & 4 & 4 & 5 & 4,5 & & 5 & 4 & 4 & 5 & 4,5 & \\
\hline
\end{tabular}

\begin{tabular}{|c|c|c|c|c|c|c|c|c|c|c|c|c|c|c|c|c|c|c|c|c|c|}
\hline \multirow[t]{2}{*}{ Diretriz Avaliada --> } & \multicolumn{6}{|c|}{ 29) Miastenia Gravis (2015) } & \multicolumn{4}{|c|}{$\frac{\text { 30) Mieloma Múltiplo }}{\underline{(2015)}}$} & \multicolumn{5}{|c|}{$\frac{\text { 31) Síndrome de Guillain- }}{\text { Barré (2015) }}$} & \multicolumn{6}{|c|}{$\frac{\text { 32) Uveítes Posteriores Não- }}{\text { Infecciosas (2015) }}$} \\
\hline & $\left|\begin{array}{c|c|}\text { J- } & \text { J- } \\
1 & 2\end{array}\right|$ & $\mid \begin{array}{l}\mathrm{J} \\
\mathbf{3}\end{array}$ & $\begin{array}{l}\mathrm{J}- \\
4\end{array}$ & MED & Total & $\begin{array}{c}\mathrm{J} \\
1\end{array}$ & \begin{tabular}{|l|l} 
J- & J- \\
2 & 3
\end{tabular} & $\mid \begin{array}{l}J \\
4\end{array}$ & MED & Total & \begin{tabular}{|c|c} 
J- & J- \\
1 & 2
\end{tabular} & $\mid \begin{array}{l}\mathrm{J}- \\
\mathbf{3}\end{array}$ & $\begin{array}{l}J- \\
4\end{array}$ & MED & Total & $\left|\begin{array}{c|}\mathrm{J}- \\
1\end{array}\right|$ & $\begin{array}{l}\text { J- } \\
2\end{array}$ & \begin{tabular}{c|c} 
J- & J \\
$\mathbf{3}$ & $\mathbf{C}$
\end{tabular} & $\mathrm{J}^{-} \mathrm{ME}$ & IED TC & Total \\
\hline DOMÍNIO 1. ESCOPO E FINALIDADE & 2020 & 13 & 20 & 6,1 & $85 \%$ & 20 & 2013 & 320 & 6,1 & $85 \%$ & 2020 & 13 & 20 & 6,1 & $85 \%$ & 20 & 19 & 132 & 206 , & 8,08 & $83 \%$ \\
\hline
\end{tabular}




\begin{tabular}{|c|c|c|c|c|c|c|c|c|c|c|c|c|c|c|c|c|c|c|c|c|c|c|c|c|}
\hline $\begin{array}{l}\text { O(s) objetivo(s) geral(is) da(s) diretriz(es) } \\
\text { encontra(m)-se especificamente descrito(s)? }\end{array}$ & 6 & 6 & 6 & 7 & 6,3 & & 6 & 6 & 6 & 7 & 6,3 & & 6 & 6 & 6 & 7 & 6,3 & & 6 & 6 & 6 & 7 & 6,3 & \\
\hline $\begin{array}{l}\text { A(s) questão(ões) de saúde coberta(s) pela diretriz } \\
\text { encontra(m)-se especificamente descrita(s)? }\end{array}$ & 7 & 7 & 4 & 6 & 6,0 & & 7 & 7 & 4 & 6 & 6,0 & & 7 & 7 & 4 & 6 & 6,0 & & 7 & 6 & 4 & 6 & 5,8 & \\
\hline $\begin{array}{l}\text { A população (pacientes, público, etc.) a quem a } \\
\text { diretriz se destina encontra-se especificamente } \\
\text { descrita? }\end{array}$ & 7 & 7 & 3 & 7 & 6,0 & & 7 & 7 & 3 & 7 & 6,0 & & 7 & 7 & 3 & 7 & 6,0 & & 7 & 7 & 3 & 7 & 6,0 & \\
\hline $\begin{array}{l}\text { DOMÍNIO 2. ENVOLVIMENTO DAS PARTES } \\
\text { INTERESSADAS }\end{array}$ & 14 & 14 & 8 & 8 & 3,7 & $44 \%$ & 14 & 14 & 8 & 8 & 3,7 & $44 \%$ & 14 & 14 & 8 & 8 & 3,7 & $44 \%$ & 14 & 13 & 8 & 8 & 3,6 & $43 \%$ \\
\hline $\begin{array}{l}\text { A equipe de desenvolvimento da diretriz inclui } \\
\text { indivíduos de todos os grupos profissionais } \\
\text { relevantes? }\end{array}$ & 5 & 4 & 1 & 1 & 2,8 & & 5 & 4 & 1 & 1 & 2,8 & & 5 & 4 & 1 & 1 & 2,8 & & 5 & 4 & 1 & 1 & 2,8 & \\
\hline $\begin{array}{l}\text { Procurou-se conhecer as opiniões e preferências } \\
\text { da população-alvo (pacientes, público, etc.)? }\end{array}$ & 5 & 5 & 3 & 3 & 4,0 & & 5 & 5 & 3 & 3 & 4,0 & & 5 & 5 & 3 & 3 & 4,0 & & 5 & 5 & 3 & 3 & 4,0 & \\
\hline $\begin{array}{l}\text { Os usuários-alvo da diretriz estão claramente } \\
\text { definidos? }\end{array}$ & 4 & 5 & 4 & 4 & 4,3 & & 4 & 5 & 4 & 4 & 4,3 & & 4 & 5 & 4 & 4 & 4,3 & & 4 & 4 & 4 & 4 & 4,0 & \\
\hline DOMÍNIO 3. RIGOR DO DESENVOLVIMENTO & 37 & 34 & 22 & 27 & 3,8 & $46 \%$ & 37 & 33 & 202 & 22 & 3,5 & $42 \%$ & 37 & 33 & 22 & 26 & 3,7 & $45 \%$ & 37 & 332 & 222 & 26 & 3,7 & $45 \%$ \\
\hline $\begin{array}{l}\text { Foram utilizados métodos sistemáticos para a } \\
\text { busca de evidências? }\end{array}$ & 7 & 7 & 7 & 6 & 6,8 & & 7 & 7 & 7 & 6 & 6,8 & & 7 & 7 & 7 & 5 & 6,5 & & 7 & 7 & 7 & 5 & 6,5 & \\
\hline $\begin{array}{l}\text { Os critérios para a seleção de evidências estão } \\
\text { claramente descritos? }\end{array}$ & 5 & 5 & 2 & 5 & 4,3 & & 5 & 4 & 1 & 1 & 2,8 & & 5 & 4 & 2 & 5 & 4,0 & & 5 & 4 & 2 & 5 & 4,0 & \\
\hline $\begin{array}{l}\text { Os pontos fortes e limitações do corpo de } \\
\text { evidências estão claramente descritos? }\end{array}$ & 4 & 3 & 1 & 1 & 2,3 & & 4 & 3 & 1 & 2 & 2,5 & & 4 & 3 & 1 & 1 & 2,3 & & 4 & 3 & 1 & 1 & 2,3 & \\
\hline $\begin{array}{l}\text { Os métodos para a formulação das } \\
\text { recomendações estão claramente descritos? }\end{array}$ & 2 & 3 & 1 & 1 & 1,8 & & 2 & 3 & 1 & 1 & 1,8 & & 2 & 3 & 1 & 1 & 1,8 & & 2 & 3 & 1 & 1 & 1,8 & \\
\hline $\begin{array}{l}\text { Os benefícios, efeitos colaterais e riscos à saúde } \\
\text { foram considerados na formulação das } \\
\text { recomendações? }\end{array}$ & 5 & 5 & 4 & 4 & 4,5 & & 5 & 5 & 3 & 3 & 4,0 & & 5 & 5 & 4 & 5 & 4,8 & & 5 & 5 & 4 & 5 & 4,8 & \\
\hline
\end{tabular}


Existe uma relação explícita entre as

recomendações e as evidências que lhe dão

$\begin{array}{lllll}6 & 4 & 3 & 4 & 4,3\end{array}$

$\begin{array}{lllll}6 & 4 & 3 & 3 & 4,0\end{array}$

6

$\begin{array}{llll}4 & 3 & 3 & 4\end{array}$

$\begin{array}{lllll}6 & 4 & 3 & 3 & 4,0\end{array}$

A diretriz foi revisada externamente por experts

antes da sua publicação?

$\begin{array}{lllll}3 & 4 & 1 & 3 & \mathbf{2}, 8\end{array}$

$\begin{array}{lllll}3 & 4 & 1 & 3 & 2,8\end{array}$

$\begin{array}{lllll}3 & 4 & 1 & 3 & \mathbf{2}, 8\end{array}$

$\begin{array}{lllll}3 & 4 & 1 & 3 & \mathbf{2}, 8\end{array}$

Um procedimento para atualização da diretriz está disponível?

$\begin{array}{lllll}5 & 3 & 3 & 3 & 3,5\end{array}$

$\begin{array}{lllll}5 & 3 & 3 & 3 & 3,5\end{array}$

DOMÍNIO 4. CLAREZA DA APRESENTAÇÃO

$\begin{array}{lllll}16 & 17 & 14 & 17 & \mathbf{5}, 3\end{array}$

$72 \%$

$\begin{array}{llllll}15 & 16 & 14 & 11 & 4,7 & \mathbf{6 1} \%\end{array}$

As recomendações são específicas e sem

$\begin{array}{lllll}5 & 6 & 5 & 6 & \mathbf{5}, 5\end{array}$

$\begin{array}{lllll}5 & 6 & 5 & 3 & 4,8\end{array}$

$\begin{array}{llllll}15 & 14 & 12 & 15 & \mathbf{4}, 7 & \mathbf{6 1} \%\end{array}$

ambiguidade?

$\begin{array}{lllll}6 & 6 & 6 & 6 & 6,0\end{array}$

$\begin{array}{lllll}5 & 6 & 5 & 5 & 5,3\end{array}$

5

As diferentes opções de abordagem da condição

ou problema de saúde estão claramente

6,0

5,5

As recomendações-chave são facilmente

identificadas?

$\begin{array}{lllll}5 & 5 & 3 & 5 & 4,5\end{array}$

$\begin{array}{lllll}5 & 4 & 4 & 3 & 4,0\end{array}$

DOMÍNIO 5. APLICABILIDADE

\begin{tabular}{llllll|llllll}
12 & 14 & 6 & 10 & $\mathbf{2}, 6$ & $\mathbf{2 7} \%$ & 14 & 13 & 6 & 12 & $\mathbf{2}, \mathbf{8}$ & $\mathbf{3 0} \%$
\end{tabular}

A diretriz descreve os fatores facilitadores e as

barreiras para sua aplicação?

$\begin{array}{lllll}4 & 5 & 3 & 4 & 4,0\end{array}$

$\begin{array}{lllll}14 & 13 & 6 & 12 & \mathbf{2}, 8\end{array}$

$\%$

$\begin{array}{llllll}12 & 12 & 6 & 6 & \mathbf{2 , 3} & \mathbf{2 1 \%}\end{array}$

$\begin{array}{llllll}12 & 13 & 6 & 6 & \mathbf{2}, 3 & \mathbf{2 2} \%\end{array}$

A diretriz traz aconselhamento e/ou ferramentas

sobre como as recomendações podem ser

$\begin{array}{lllll}4 & 4 & 3 & 4 & 3,8\end{array}$

$\begin{array}{lllll}4 & 3 & 3 & 3 & 3,3\end{array}$

$\begin{array}{lllll}4 & 4 & 3 & 3 & 3,5\end{array}$

$\begin{array}{lllll}3 & 3 & 1 & 1 & 2,0\end{array}$

$\begin{array}{lllll}3 & 3 & 1 & 1 & \mathbf{2}, 0\end{array}$

$\begin{array}{lllll}3 & 3 & 1 & 1 & \mathbf{2}, 0\end{array}$

colocadas em prática?

Foram consideradas as potenciais implicações

quanto aos recursos decorrentes da aplicação das $\quad \begin{array}{lllll}2 & 3 & 1 & 4 & \mathbf{2 , 5}\end{array}$

$\begin{array}{lllll}2 & 3 & 1 & 3 & 2,3\end{array}$

$\begin{array}{lllll}2 & 3 & 1 & 1 & 1,8\end{array}$

$\begin{array}{lllll}2 & 3 & 1 & 1 & 1,8\end{array}$

recomendações?

A diretriz apresenta critérios para o seu monitoramento e/ou auditoria?

$\begin{array}{lllll}3 & 3 & 1 & 1 & \mathbf{2}, 0\end{array}$

$\begin{array}{lllll}5 & 3 & 1 & 4 & 3,3\end{array}$

DOMÍNIO 6. INDEPENDÊNCIA EDITORIAL

$\begin{array}{llllll}9 & 6 & 7 & 8 & 3,8 & 46 \%\end{array}$

$\begin{array}{llllll}9 & 6 & 7 & 8 & 3,8 & 46 \%\end{array}$

$\begin{array}{lllll}3 & 3 & 1 & 1 & \mathbf{2}, 0\end{array}$

$\begin{array}{lllll}3 & 3 & 1 & 1 & \mathbf{2}, 0\end{array}$

$\begin{array}{llllll}9 & 6 & 7 & 8 & 3,8 & 46 \%\end{array}$

$\begin{array}{llllll}9 & 6 & 7 & 8 & 3,8 & 46 \%\end{array}$ 
O parecer do órgão financiador não exerceu

influência sobre o conteúdo da diretriz?

Foram registrados e abordados os conflitos de interesse dos membros da equipe que desenvolveram a diretriz? $\begin{array}{lllll}4 & 2 & 3 & 3 & 3,0\end{array}$

$\begin{array}{llll}4 & 4 & 5 & 4,5\end{array}$ $\begin{array}{lllll}4 & 2 & 3 & 3 & 3,0\end{array}$

$\begin{array}{lllll}5 & 4 & 4 & 5 & 4,5\end{array}$ $\begin{array}{lllll}4 & 2 & 3 & 3 & 3,0\end{array}$ $\begin{array}{lllll}5 & 4 & 4 & 5 & 4,5\end{array}$ $\begin{array}{lllll}4 & 2 & 3 & 3 & 3,0\end{array}$

$\begin{array}{lllll}5 & 4 & 4 & 5 & 4,5\end{array}$ 
ANEXO I - ARTIGO ACEITO PARA PUBLICAÇÃO NA REVISTA CIÊNCIA \& SAÚDE COLETIVA (2016)

\author{
ABRASCO \\ Revista Ciência \& Saúde Coletiva
}

Rio de Janeiro, 25 de outubro de 2016.

Prezado(a)s Sr(a)s. Rafael Santos Santana; Evandro de O. Lupatini; Silvana Nair Leite

Informamos que seu artigo "Registro e incorporação no suS: Barreiras de acesso a medicamentos para doenças da pobreza?" foi selecionado para integrar o Número Temático da Revista Ciência \& Saúde Coletiva e o mesmo já foi avaliado. Abaixo seguem os comentários do revisor.

\title{
Comentários:
}

Parecer 1:

Comentários gerais (observações sobre originalidade, relevância e qualidade de manuscrito) 


\section{ANEXO II - ARTIGo ACEITO PARA PUBLICAÇÃO NA REVISTA PAN-AMERICANA DE SAÚDE PÚBLICA (2016)}

Revista Panamericana de Salud Pública/Pan American Journal of Public Health - 2016-00222.R2 -

Decision on your manuscript $\square$ Doutorado UNB $\quad x$

Revista Panamericana de Salud Pública/Pan American Journal of Public Health <onbehalfof+edit

para mim, rafael.santana -

11 de ago

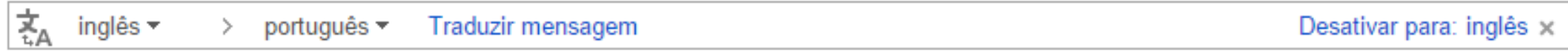

11-Aug-2016

Dear Dr. Santana,

We are pleased to inform you that the revised version of your manuscript 2016-00222.R2, entitled "PRIORIDADES DE PESQUISA

CLINICA COM MEDICAMENTOS NO BRASIL E AS DOENCAS DA POBREZA," has been accepted for publication as Special Report in

the Revista Panamericana de Salud Pública/Pan American Journal of Public Health. As soon as the manuscript has been edited, you will receive from our Associate editor an e-mail with a copy of the edited version along with any queries the editor may have. In advance, thank you for your prompt response to this request.

Sincerely,

for Dr. Damián Vázquez

Managing Editor

... 
Artigo especial

\section{Prioridades da pesquisa clínica com}

\section{medicamentos no Brasil e as}

doenças da pobreza

Rafael Santos Santana ${ }^{1}$ e Silvana Nair Leite ${ }^{2}$

Como citar

Santana RS, Leite SN. Prioridades da pesquisa clínica com medicamentos no Brasil e as doencas da .

RESUMO

Objetivo. Identificar os ensaios clínicos com medicamentos realizados no Brasil entre 2012 2015, com destaque para os que envolvem doenças da pobreza.

Método. Foram pesquisados os repositórios de ensaios clinicos ReBEC e ClinicalTrials.gov. Verificou-se a distribuição dos ensaios clínicos identificados em relação à carga de doenças do país e em relação ao grau de iniquidade (doenças da pobreza vs. doenças não vinculadas à pobreza). Também foram investigadas as fases dos ensaios clínicos, as instituições que conduziram os ensaios e o tipo de financiamento (privado, público ou misto).

Resultados. Foram incluidos 866 ensaios clínicos, 88 identificados no ReBEC e 778 no ClinicolTinls. 73 (8, 8 \% IV. Foram identifiodos 38 emios (4\%) enfocando as deene IV. Foram identicudos 38 ensaios (4\%) enfocando as doenças relacionadas a pobreza. Quanto à carga de doenç̧as, $734(84,8 \%)$ ensaios abordaram as doenças näo transmissiveis, que de fato representam a maior carga de doença no Brasil. A indústria farmacéutica foi a grande responsavel pelo desenvolvimento de ensaios clinicos de medicamentos (55,3\%). O financiamento privado predominou $(57,1 \%)$; entretanto, considerando-se apenas os estudos com doenças da pobreza, $63,1 \%$ foram financiados por recursos públicos.

Conclusões. Os ensaios clínicos com medicamentos realizados no Brasil nos últimos anos possuem relativa conformidade com a proporção de carga de doenças. Porém, as doenças da pobreza não foram prioritárias. São necessárias ações mais efetivas para redirecionar a pesquisa clinica com medicamentos ao atendimento das necessidades nacionais. 


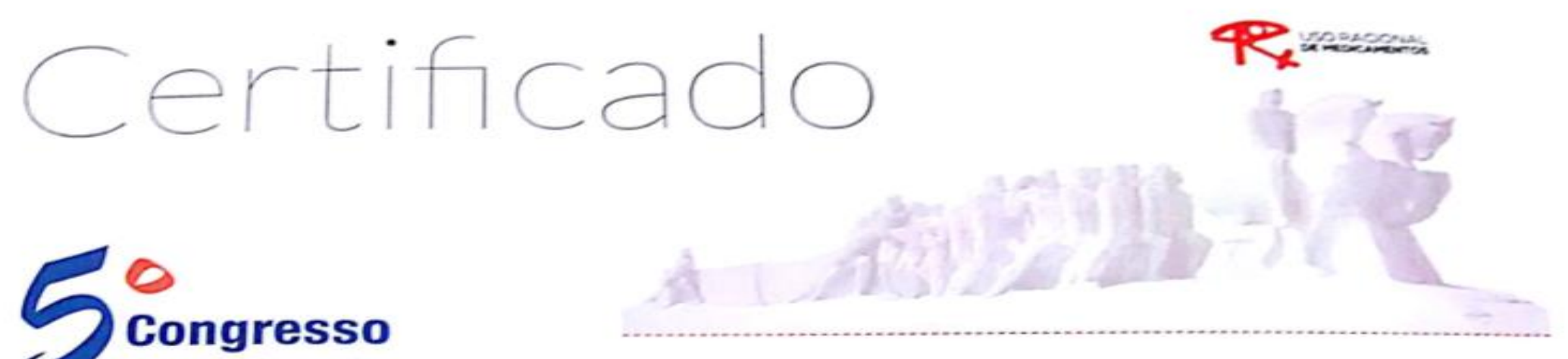

Brasileiro sobre Uso Racional de Medicamentos

Certificarnos que o trabalho "CONTRIBUIÇÕES DA RELAÇÃO NACIONAL dE MEDICAMENuTOS PARA MELHORIA DOS TRATAMENTOS DE DOENÇAS RELACIONADAS A POEREZA", tendo como autores RAFAEL SANTOS SANTANA; Nicole Menezes de Sowza; Evandro de Oiveiro Lupgtin. Diana Graziefe dos Santos; Luiz Henrique Costa; Silvana Nair Leite, foi apresentado na sess Jo "Exposição de Pôster", no $\vee$ Congresso Brasileiro sobre o Uso Racional de Medicamentos, realizado no periodo de 22 a 25 de Setembro de 2014, no Palácio das Convençês Anthembi, em São Paulo/SP.

São Paulo, 25 de Setembro de 2014
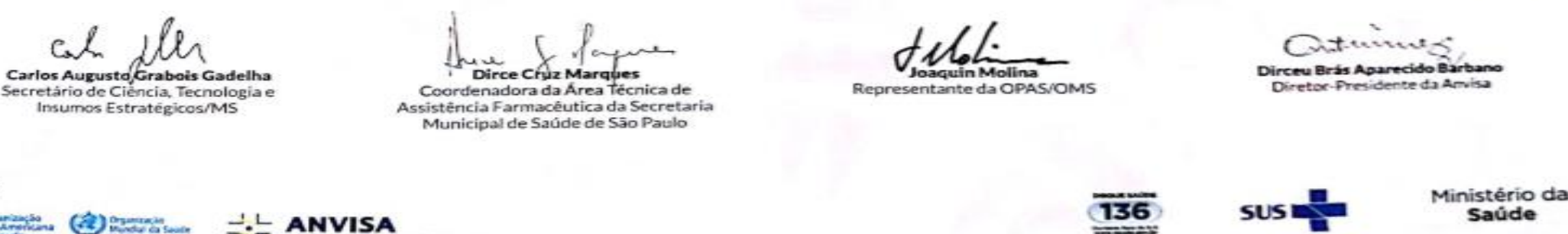

Apoio:

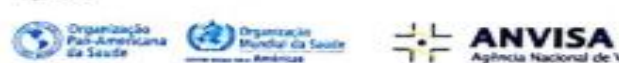

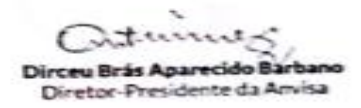




\section{ANEXO IV - TRABALHO APRESENTADO NO 51 ${ }^{\circ}$ CONGRESSO DA SOCIEDADE BRASILEIRA DE MEDICINA TROPICAL}

(FORTALEZA - CE, 2015)

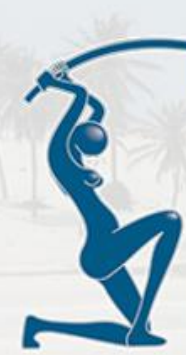

MedTrop 2015

$51^{\circ}$ Congresso da Sociedade

Brasileira de Medicina Tropical
14 a 17 de junho de 2015

Centro de Eventos do Ceará

Fortaleza/CE - Brasil

\section{CERTIFICADO}

Certificamos que o trabalho

DOENÇAS RELACIONADAS À POBREZA E INCORPORAÇÃO DE TECNOLOGIAS NO SUS: UMA PAUTA POSSÍVEL?

Tendo como autores: Rafael Santos Santana, Evandro de Oliveira Lupatini, Gustavo Laine Araújo de Oliveira, Silvana Nair Leite, Luiz Henrique Costa, foi apresentado no $51^{\circ}$ Congresso da Sociedade Brasileira de Medicina Tropical - MEDTROP,

como Pôster na categoria Miscelânea/ Outros.

Fortaleza, 17 de junho de 2015.
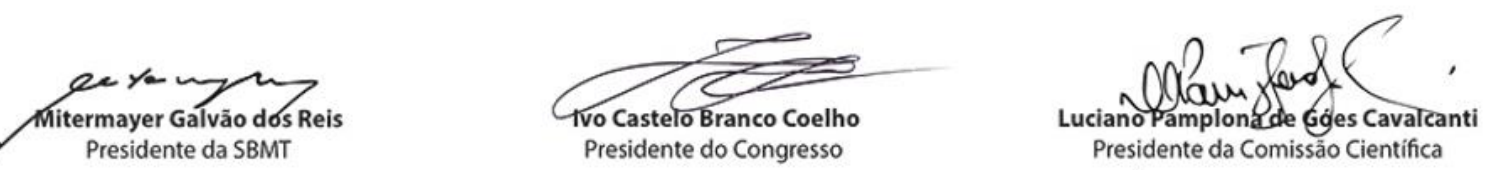
Luciano Pamplona de Góes Cavalcant

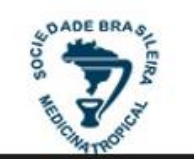

